\title{
ENGINEERING ANALYSES OF LARGE PRECISION CATHODE STRIP CHAMBERS FOR GEM
}

\author{
J. A. Horvath \\ F. C. Belser \\ S. M. Pratuch \\ C. R. Wuest \\ G. Mitselmakher \\ A. Gordeev \\ C. V. Johnson \\ V. A. Polychronakos \\ I. A. Golutvin
}

October 21, 1993 


\section{DISCLAIMER}

This document was prepared as an account of work sponsored by an agency of the United States Government. Neither the United States Government nor the University of California nor any of their employees, makes any warranty, express or implied, or assumes any legal liability or responsibility for the accuracy, completeness, or usefulness of any information, apparatus, product, or process disclosed, or represents that its use would not infringe privately owned rights. Reference herein to any specific commercial products, process, or service by trade name, trademark, manufacturer, or otherwise, does not necessarily constitute or imply its endorsement, recommendation, or favoring by the United States Government or the University of California. The views and opinions of authors expressed herein do not necessarily state or reflect those of the United States Government thereof, and shall not be used for advertising or product endorsement purposes.

Work performed under the auspices of the U.S. Department of Energy by Lawrence Livermore National Laboratory under Contract W-7405-Eng-48. 


\title{
Engineering Analyses of Large
}

\section{Precision Cathode Strip Chambers}

\section{for GEM}

\author{
J.A. Horvath \\ F.C. Belser \\ S.M. Pratuch \\ C.R. Wuest
}

Lawrence Livermore National Laboratory, Livermore CA

G. Mitselmakher

Superconducting Super Collider Laboratory, Dallas TX

\author{
A. Gordeev \\ Institute of Theoretical and Experimental Physics, Moscow, Russia \\ C.V. Johnson \\ Lawrence Livermore National Laboratory - SSC Laboratory \\ V.A. Polychronakos \\ Brookhaven National Laboratory, Upton NY \\ I.A. Golutvin \\ Joint Institute for Nuclear Research, Dubna, Russia
}

October 21,1993

Abstract:

Structural analyses of large precision cathode strip chambers performed up to the date of this publication are documented. Mechanical property data for typical chamber materials are included. This information, originally intended to be an appendix to the "CSC Structural Design Bible," is presented as a guide for future designers of large chambers. 
GEM TN-93-494

\section{Table of Contents}

1. Overview

2. Precision CSC Structural Design Concept

3. Sandwich Skin Materials

4. Sandwich Core Materials

5. Epoxy Filler Materials

6. Radiation Length

7. Comparison of Gap Frame Designs and Materials

8. Gravity Sag as a Function of Sandwich Core Material

9. Parametric Studies

10. Thermal Deformation

11. Support Point Location and Gravity Sag

12. Bulge Due To Internal Pressure

13. Chamber Mode Shapes and Natural Frequencies

14. Chamber Twist

15. Copper-On-Mylar Cathodes

16. Miscellaneous 4-Gap CSC Finite Element Analyses

17. Creep

18. Single Sandwich Panel Gravity Sag

19. Superpanels

20. Finite Element Model Error Analyses

21. References 
GEM TN-93-494

\section{Overview}

The structural design of precision cathode strip chambers is an exercise in producing the lightest, thinnest, and stiffest functioning chamber out of the highest radiation length materials. An understanding of the structural function of each component allows the chamber designer to avoid unnecessary mass.

This paper contains material property data, design formulas, and selected analytical results. Sections are listed in the Table of Contents. Each section is preceded by a short index and summary. Dlustrations of the chamber support structure draw upon the work of Draper Laboratories and Simpson Gumpertz and Heger Inc. GEM Technical Notes relating to chamber mechanical design are listed in the references section. GEM TN-93-350, Gravity Sag of Sandwich Panel Assemblies as Applied to Precision Cathode Strip Chamber Structural Design, provides an explanation the importance of shear coupling between sandwich panels in a chamber. Not cited in the references are numerous unpublished ideas informally proposed by the authors of this paper. Two examples, Gordeev's "discrete posts" and Polychronakos' "cast low density fillers", are analyzed in GEM TN-93-460, Comparison of Gap Frame Designs and Materials for Precision Cathode Strip Chambers.

Originally intended as an Appendix to a comprehensive "CSC Structural Design Bible", this collection of materials is a snapshot-in-time of the state of the structural design of the SSC/GEM precision cathode strip chambers as of October 21, 1993. It is recorded here for the benefit of future chamber designers.

\section{Understanding Chamber Deformation Is Critical}
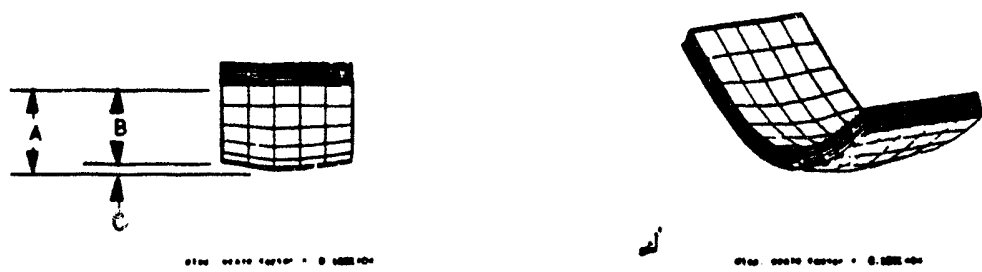

Outer superlayer chamber gravity sag magnified 1,000 times

- Nonlinear orthotropic finite element model is used for 3-dimensional analyses

- Spreadsheet bending model is used for 2-dimensional analyses of sensitivity to geometric parameters and material properties

- Maximum gravity sag ( $A$ ) is sum of long edge bending (B) and sandwich panel sag (C)

- CMM measurements of prototype panels and chambers will provide data on gravity sag, local heat source effects, internal pressure, and creep 
GEM TN-93-494

\section{Precision CSC Structural Design Concept}

Contents:

System views of muon chambers ( 2 pages)

Cross section and plan views of cathode strip chamber conceptual design (2 pages)

Precision cathode etched copper pattern (1 page)

Sandwich panel and gap frame conceptual design (1 page)

CSC panel fabrication specifications (1 page)

Summary:

The conceptual design of the chambers is shown in the drawings by I.A. Golutvin and Y. Kiryushin.

The muon system uses chambers whose size closely matches the maximum size single sheet of copper plated G-10 that can be etched into the precision cathode pattern.

The overall chamber structure is designed to behave as a single beam with shear connections between individual sandwich panels. 

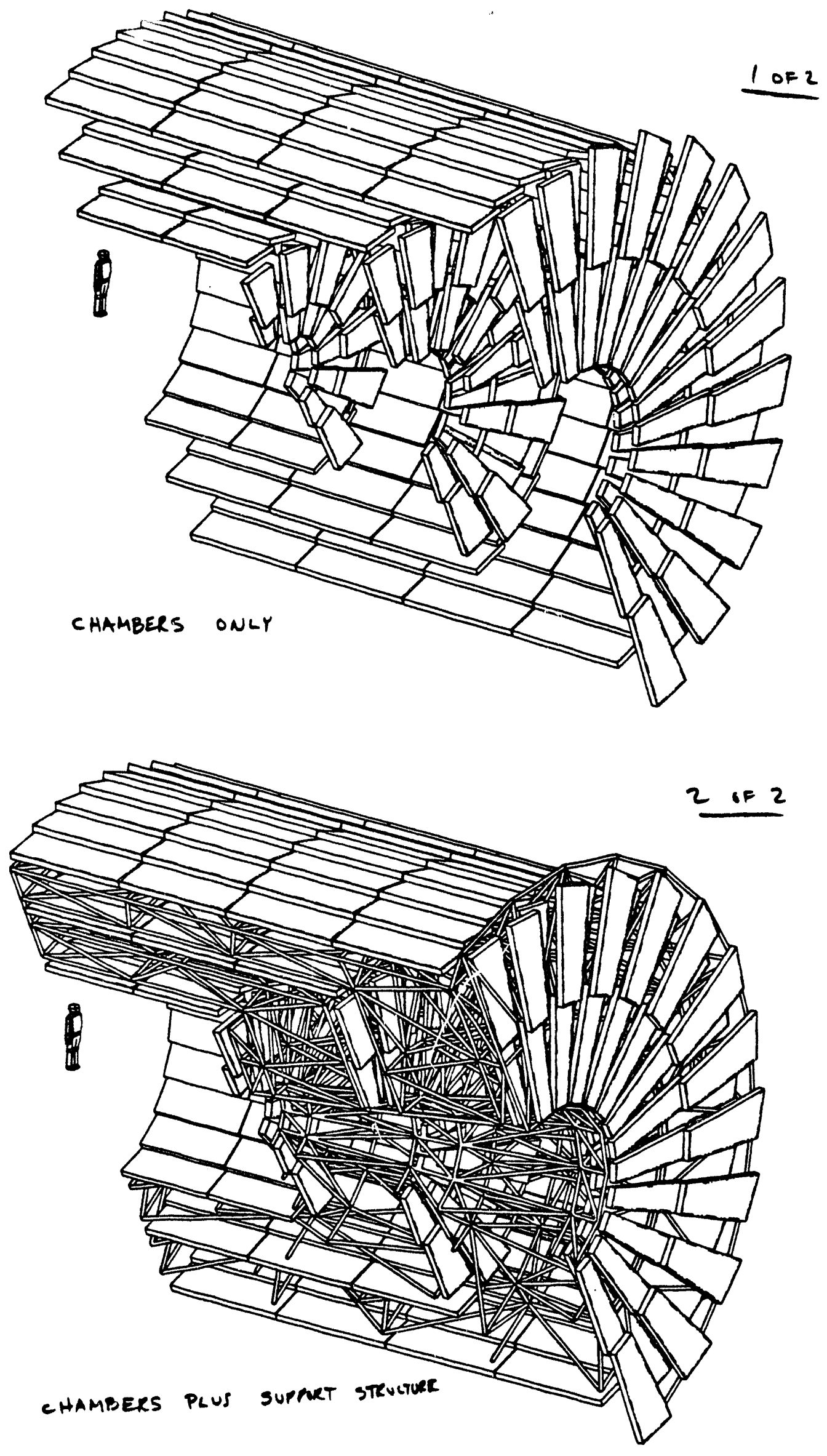


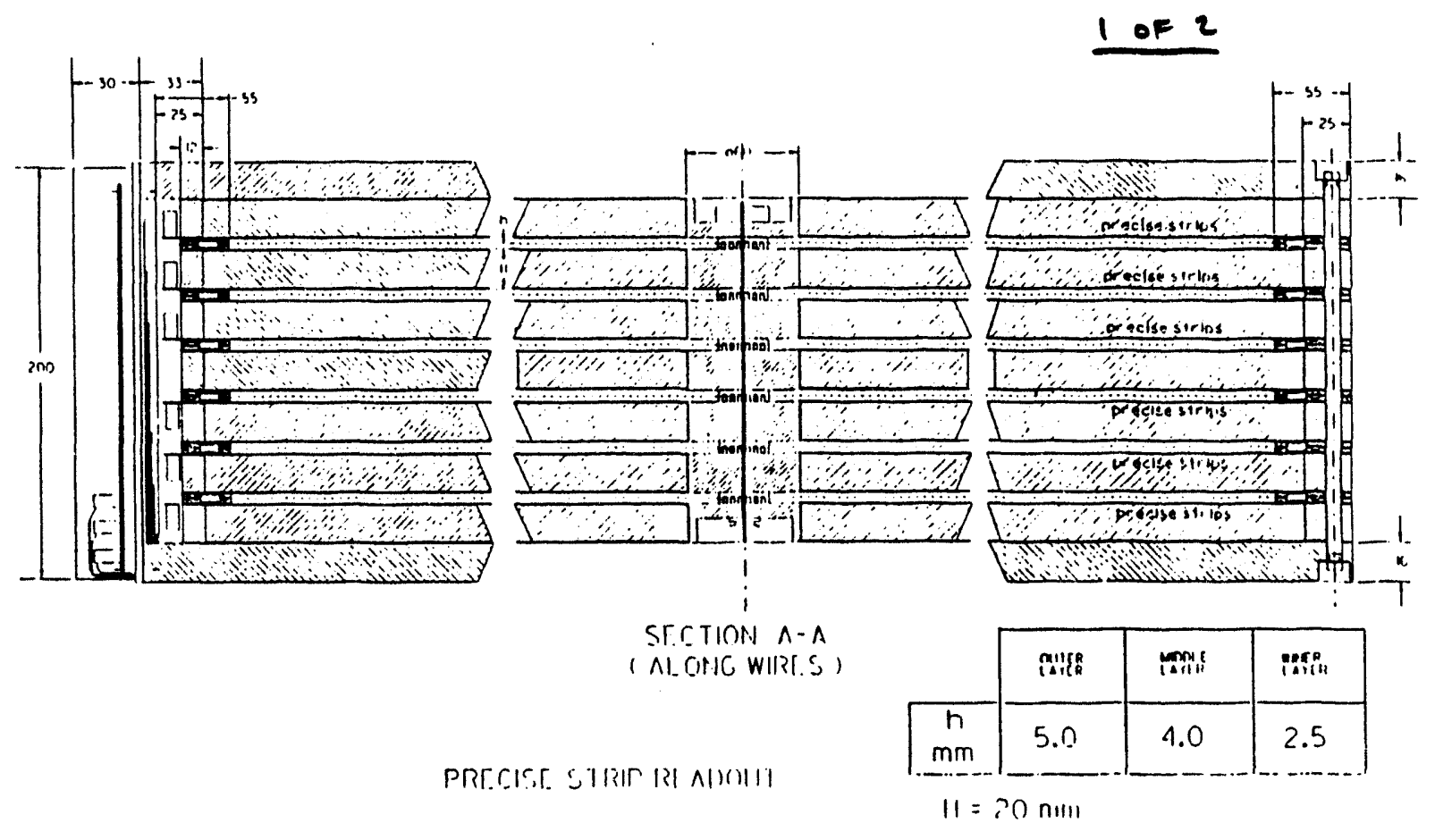

CHAMBER CROSS SECTIONS

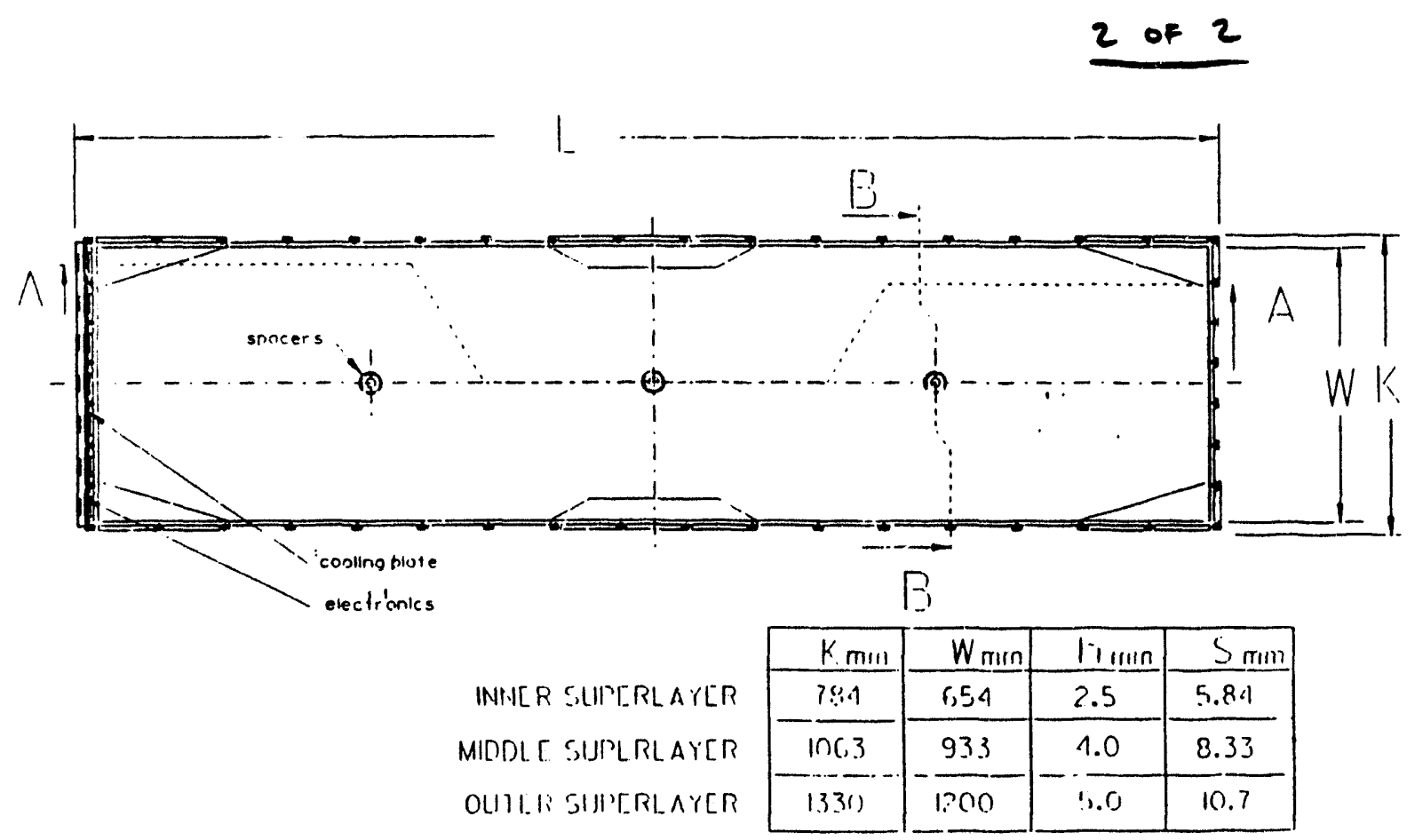

chamber puAN viru

3. SOINTVIN Y. KIRYUSHIN
$03 / 02 / 3993$ 

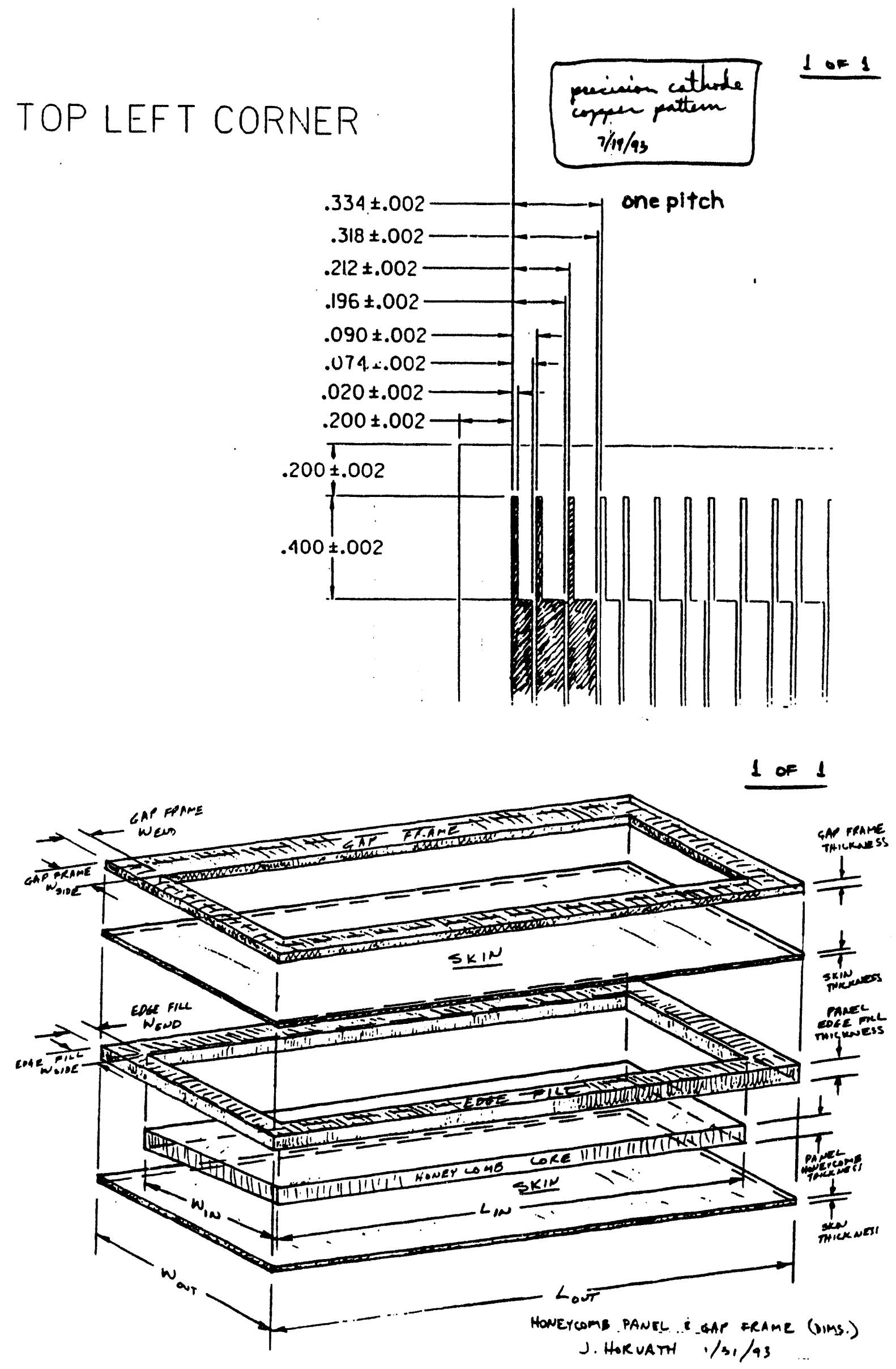

$2-4$ 


\section{CSC Panel Fabrication Specs 1 of 1}

Panel Definition: A $19 \mathrm{~mm}$ (nomina) honeycomb NOMEX sheet sandwiched between two $20 \mathrm{mil}$ (.5 mm) fiberglass (G-10 or FR-4; NEMA specs.) face sheets. The fiberglass face sheets are copper claded on the outward facing sides. The copper on one of the face sheets is etched to provide a precision cathode plane.

\section{Specifications (prioritized)}

1. Flatness

$$
4 \text { mil (100 wn) over } 1.2 \mathrm{~m}
$$

2. Parallel to

$$
4 \text { mil over } 1.2 \mathrm{~m}
$$

3. Net thickness (incl. face sheets) $20 \mathrm{~mm} \pm 10 \mathrm{mi}(.25 \mathrm{~mm})$

4. Squareness

Diagonal measurements \pm 10 mil of each other

5. Length and width dimensions Not set at this time. 
GEM TN-93-494

\section{Sandwich Skin Materials}

\section{Contents:}

Survey of sandwich skin material properties, ref. Hexcel TSB-124 (1 page)

Survey of sandwich skin material properties, ref. M.C. Gill (1 page)

Product data sheet for Gillfab 1045, fiberglass cloth/epoxy NEMA G-10 (2 pages)

Product data sheet for Gillfab 1024, fiberglass reinforced polyester, like G-10 (2 pages)

Product data sheet for GE Grade: 11635H, NEMA FR-4 (1 page)

Micrograph of plated and etched fiberglass cloth/epoxy laminate (1 page)

Analysis of generic G-10 woven fiberglass laminate (5 pages)

Analysis of generic fiherglass $[0 /+\theta /-\theta / 90]$ sym "custorit" (non-cloth) laminate (2 pages)

Analysis of generic fiberglass [0/+45/-45/90]sym "custom" (non-cloth) laminate (4 pages)

\section{Summary:}

The TDR Baseline sandwich panel skin material is Epoxy-Gilltab 1045 (equivalent to 1040 in all mechanical properties except maximum service temperature). It meets the NEMA G10 electrical specifications.

Generic G-10 was selected as the TDR Baseline sandwich skin due to a long history of $\mathrm{Cu}$ plating and etching experience by industry, its electrical properties, the adequacy of its mechanical properties, and its low cost compared to "custom" laminate lay-ups.

Since NEMA G-10 is not a mechanical specification, G-10 from different vendors may have different mechanical properties. Its in-plane modulus varies from 3.0 to $3.3 \mathrm{MSI}$ at 0deg. and 90-deg. (angle measured in-plane) but may drop below 1.8 MSI at 45-deg.

"Custom" non-cloth fiberglass laminates made of unidirectional plies provide mechanical properties optimized for the application but at a premium price. In-plane properties become isotropic by going from a cloth $[0 / 90]$ sym to a $[0 /-45 /+45 / 90]$ sym or a $[-60 / 0 /+60]$ sym custom laminate.

$$
3-1
$$




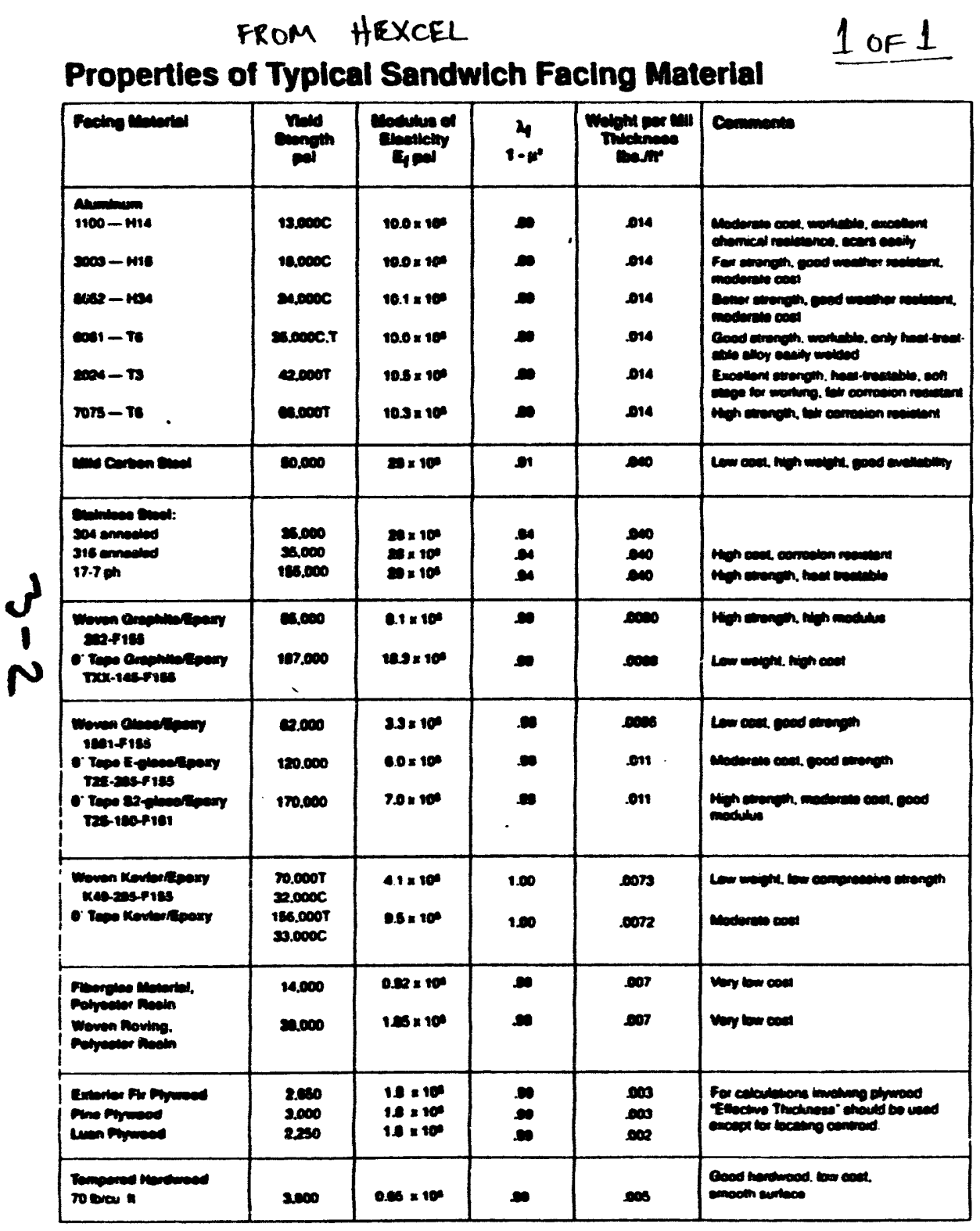

Mancoul Corpordion REF. TSB-124
FRIM M.C.GILL TABLE1 MECHANICAL PROPERTIES 1 of 1 OF TYPICAL SANDWICH FACING MATERIALS

\begin{tabular}{|c|c|c|c|c|}
\hline Facing Material & $\begin{array}{c}\text { Yield } \\
\text { Strength } \\
h(\text { psi } \times \text { 102) }\end{array}$ & $\begin{array}{l}\text { Modulus of } \\
\text { Elasticity } \\
\text { El (pai x ros) }\end{array}$ & 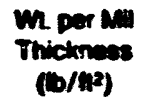 & Comments \\
\hline Aluminum-2024-T3 & 20 & $\begin{array}{l}10 \\
10\end{array}$ & $\begin{array}{l}0.014 \\
0.014\end{array}$ & Cood Arengeth, modorets cood \\
\hline $\begin{array}{l}\text { Aluminum-3003-1716 } \\
\text { Aluminum-6061-T6 }\end{array}$ & 21 & 10 & 0.014 & Workeble. corrotion resiatant \\
\hline Aluminum-7075-T6 & $\infty$ & 10 & 0.014 & High thength and fent rasiatent \\
\hline-- & -- & 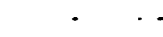 & $\ldots$ & -- \\
\hline Mido carton stoel & 50 & 28 & 0.010 & $\begin{array}{l}\text { Low cont, high whight, hard so cul } \\
\text { whth hand lools }\end{array}$ \\
\hline Stainless steel-316 & $\infty 0$ & 20 & 0.040 & $\begin{array}{l}\text { Heavy, expenaive, hard to bond and } \\
\text { bebricate whin hand tools }\end{array}$ \\
\hline
\end{tabular}

Ttanium: Annealed Ti-75A 70

0.0235 Low corrosion, high con, hard to bond

Fiberglass bininates

$\left\{\begin{array}{l}\text { Epoxy-Gimab 1040 } \\ \text { Epoxy-Giltab 1045 BASELuE }\end{array}\right.$

Phenotic-Gillnb 1002

Polyester-Gittab 1074

Polyimide-Giltab 1028

Polyester-mat-Gillibo 999

Polyester-wowen rovings-

Gllfab 1027

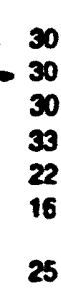

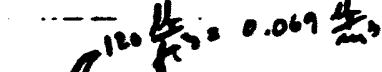

0.014 std epoxy. 100\% senvice verno.

0.01 Migh Etrength. 250\% ervice tomp.

0.01 Cood strength. 3500F service remp.

0.01 Cood strength, most fire-recietent

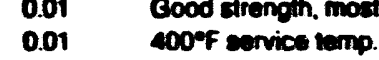

$\begin{array}{ll}0.01 & 100 \% \text { reng } \\ 0.01 & \text { Low cost }\end{array}$

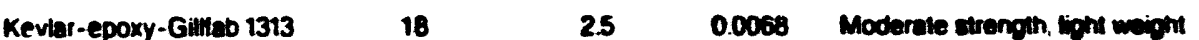

Keviler-phenolic-Giltab $5055 \quad 16 \quad 2.0 \quad 0.0068$ Lioht woight. low emoke

Graphrie-epoxy-Gimeb $1089 \quad 65 \quad 16.0 \quad 0.008$ Which tor palvenic corrocition, nigh

cost, frength, mitiness

Graphite-phenolic $\quad 60 \quad 15.0 \quad 0.000$ Whtch tor oelvenic combaion, high

coet themeth mintom

$\begin{array}{lllll}\text { Douglas fir plywood } & 2.6 & 1.5 & 0.003 \quad \text { Low coet. poor meathering havy }\end{array}$ Tempered hardioand $\quad 2.0 \quad 0.6 \quad 0.0045$ Low cost bow mengin, hivery

REF. THE M.C. GKL "DONRWAY"

VOK. 28 SPRIMG, 1991 - PART 2 


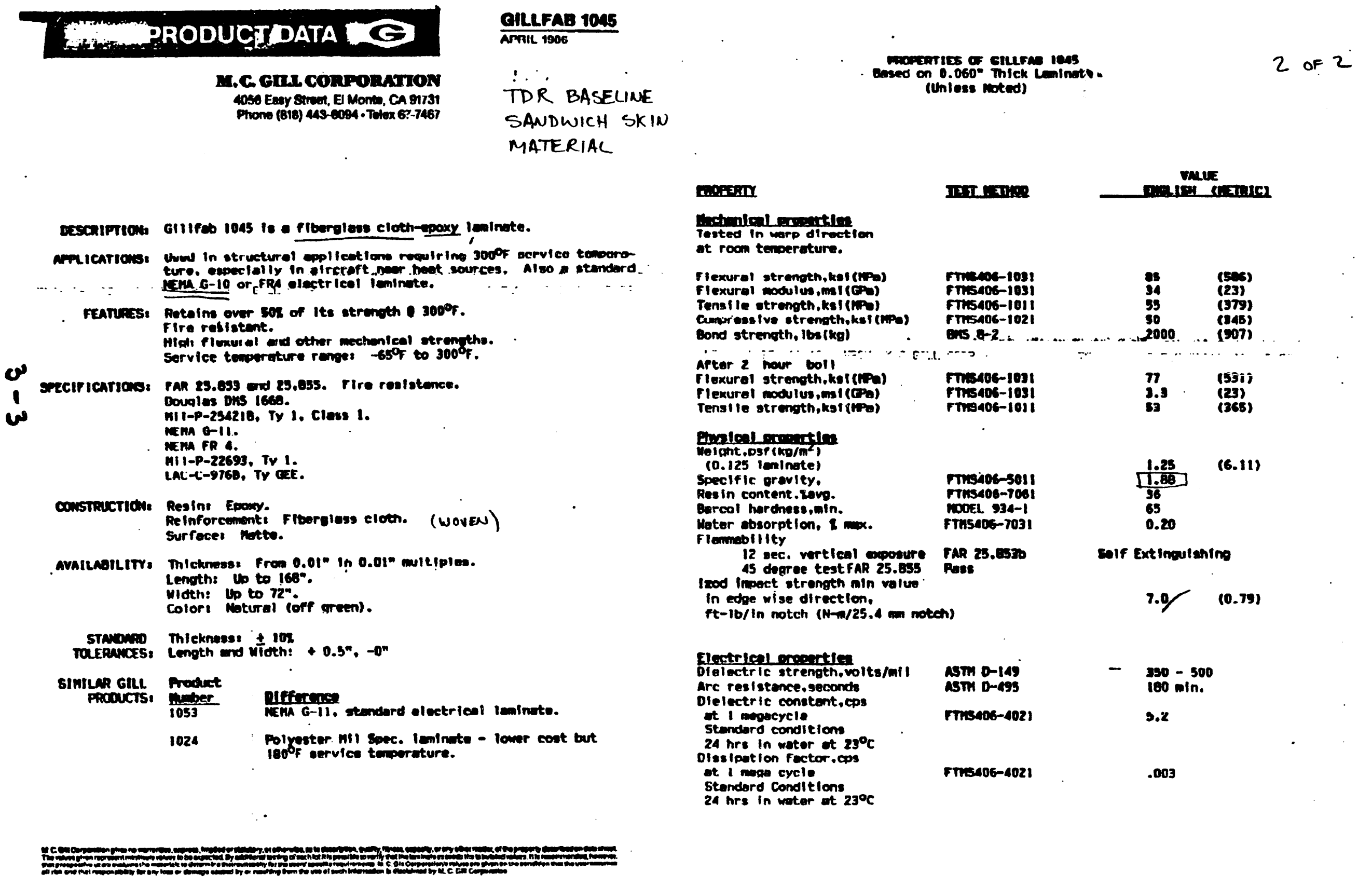


4
4

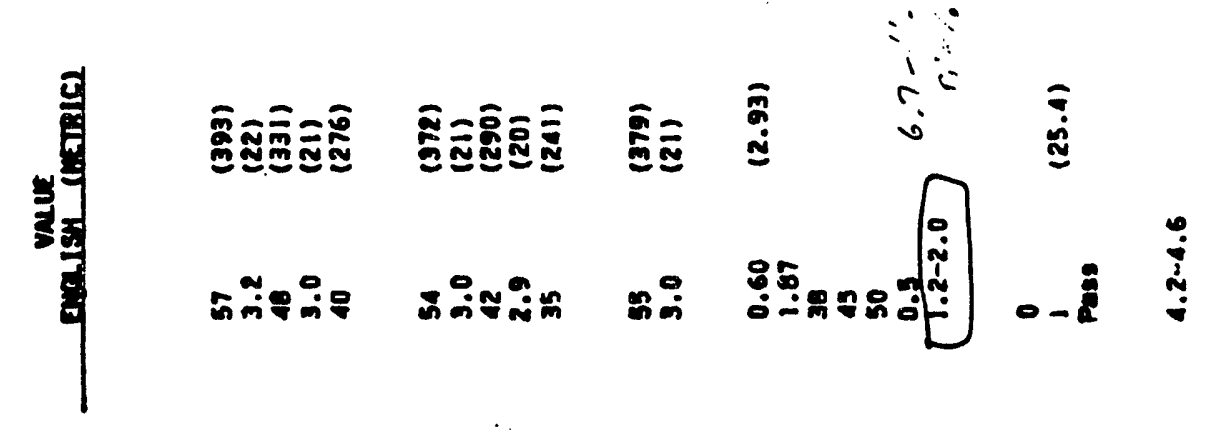
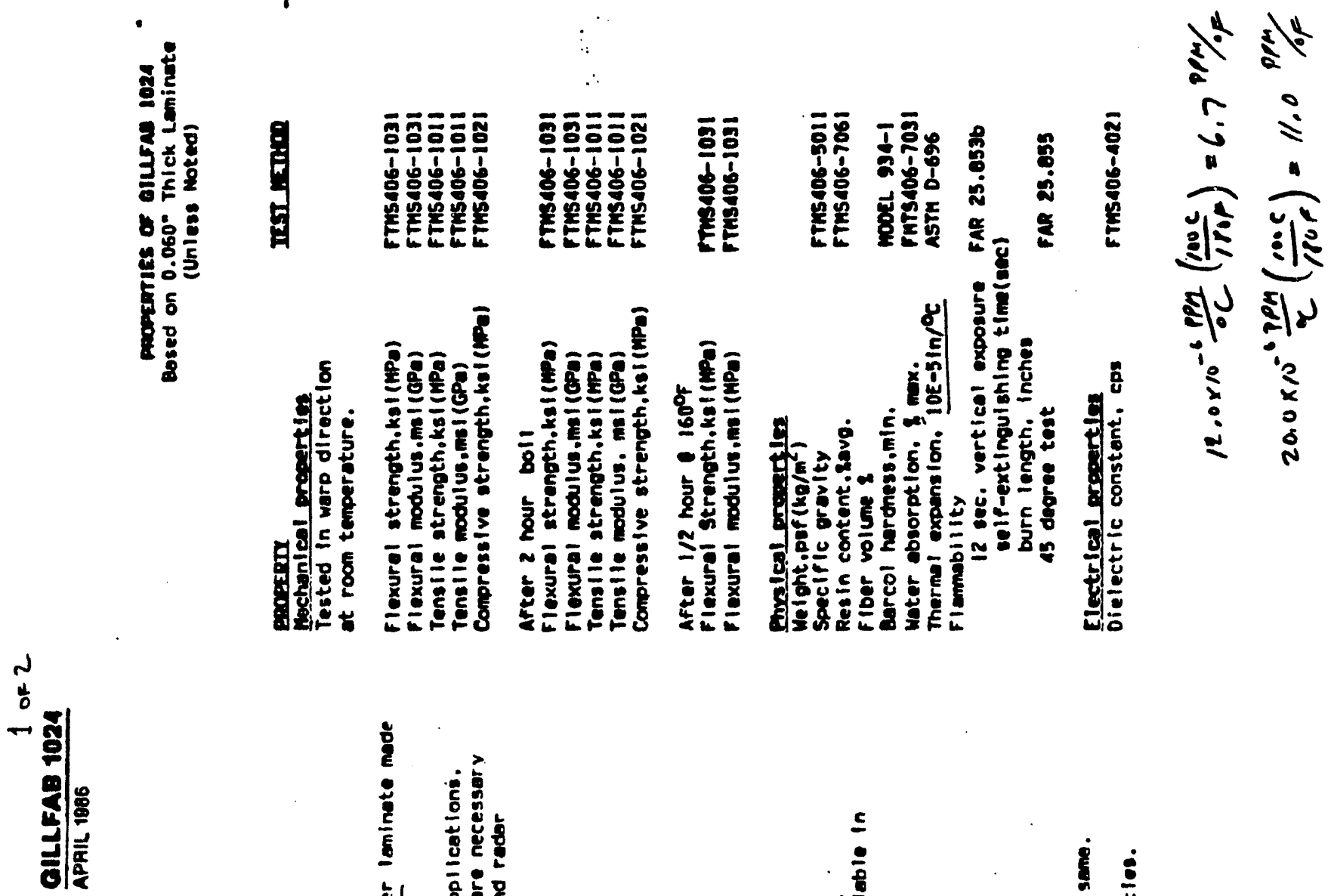

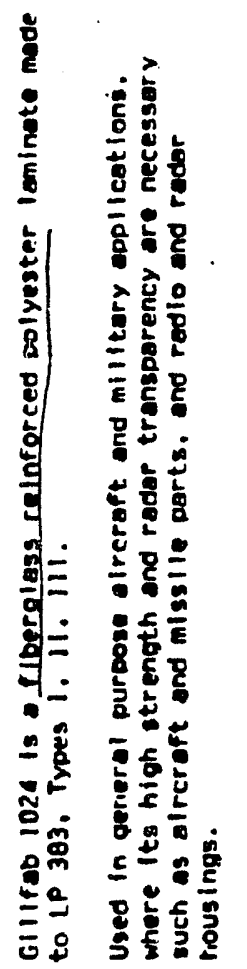

容䓂

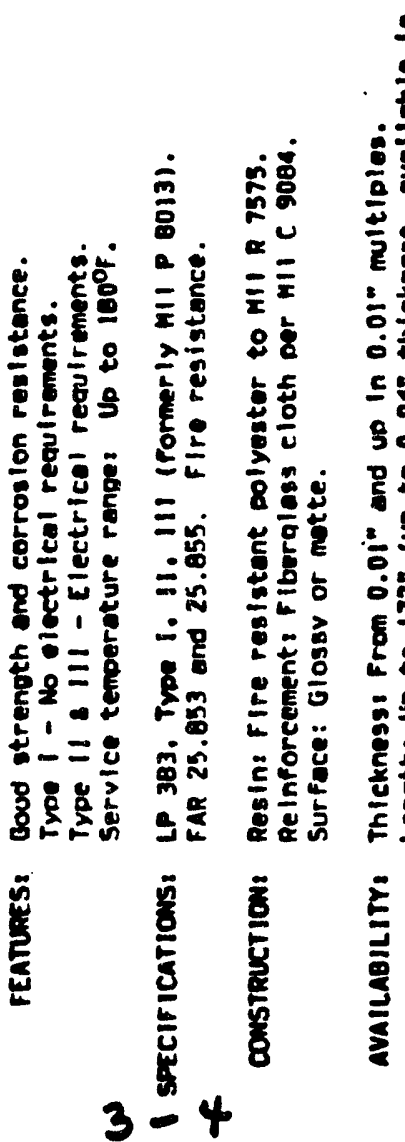

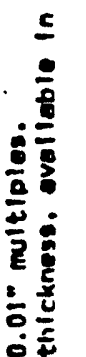

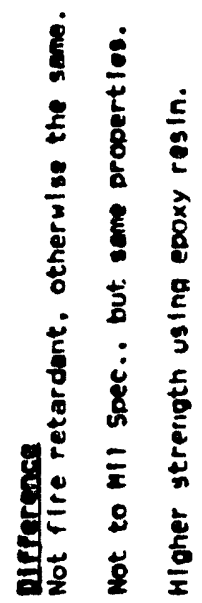

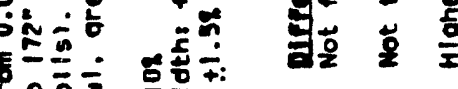

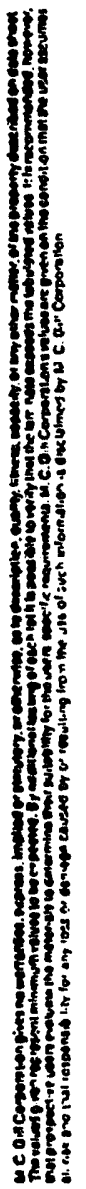




\section{(3)}

GE GRADE: $11635 \mathrm{H}$

TYPE: NEMA FR-4 OR MIL-P-13949G GFN

\begin{tabular}{|c|c|c|c|}
\hline PAOPERTY & $\begin{array}{c}\text { TEST } \\
\text { METHOD } \\
\end{array}$ & $\begin{array}{c}\text { TEST } \\
\text { CONDITION } \\
\end{array}$ & $\begin{array}{c}\text { TYPICAL } \\
\text { VALUE (.059") } \\
\end{array}$ \\
\hline $\begin{array}{l}\text { THERMALL } \\
\text { Glass Transmion Tomporalure ('C) } \\
\text { Z-Axis Expansion (\%) }\end{array}$ & $\begin{array}{l}\text { PPC.TM.650 } 2.4 .25 \text { (DSC) } \\
\text { PPC.TM. } 6502.4 .41(\mathrm{MMA})\end{array}$ & A & $\begin{array}{l}135+1.5 \\
4.5\end{array}$ \\
\hline 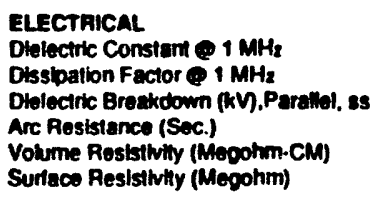 & $\begin{array}{l}\text { IPC.TM-6502.5.5.3 } \\
\text { IPC-TM-6502.5.5.3 } \\
\text { IPC.TM-6502.5.6 } \\
\text { IPC-TM-6502.5.1 } \\
\text { IPC.TM-6502.5.17.1 } \\
\text { IPC.TM.650 2.5.17.1 }\end{array}$ & $\begin{array}{l}\text { C-24/23/50 } \\
C-24 / 23 / 50 \\
0-48 / 50 \\
D-48 / 50 \\
C-96 / 35 / 90 \\
C .96 / 35 / 90\end{array}$ & $\begin{array}{l}4.7 \\
.020 \\
75 \\
120 \\
>10^{\circ} \\
>10^{\circ}\end{array}$ \\
\hline 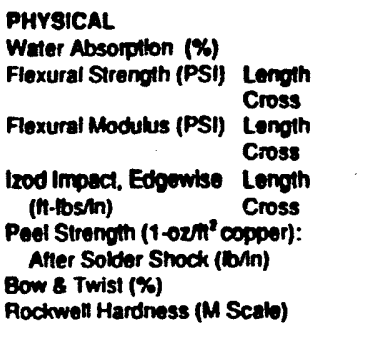 & $\begin{array}{l}\text { IPC-TM-650 2.6.2.1 } \\
\text { IPC-TM-650 2.4.4 } \\
\text { ASTM D } 790 \\
\text { ASTM D } 790 \\
\text { IPC-TM-650 } 2.4 .8 \\
\text { GE } 2 \\
\text { ASTM D } 785\end{array}$ & $\begin{array}{l}\hat{0.24 / 23} \\
\hat{A} \\
\hat{A} \\
\hat{A} \\
\hat{A} \\
\hat{A} \\
10 \text { Sec. } 550^{\circ} \mathrm{F} \\
\text { Simulaled UV } \\
\hat{A}\end{array}$ & $\begin{array}{l}.09 \\
65.000 \\
60.000 \\
3.0 \times 10^{\circ} \\
2.5 \times 10 \\
10.0 \\
5.7 \\
10 \\
10 \\
.5 \\
110\end{array}$ \\
\hline $\begin{array}{l}\text { UNDERWAITERS LABOAATORIES } \\
\text { Flammability } 3 \\
\text { Temperature Index ('C) Eloc Mech. } \\
\text { Maximum Operating i emperature ('C) } \\
\text { Solder Limils (Sec. @ emp.) }\end{array}$ & $\begin{array}{l}\text { Ur } 94 \\
\text { U: } \\
\text { uL } \\
\text { uL }\end{array}$ & $\begin{array}{l}\text { A } \\
500^{\circ}\left(260^{\circ} \mathrm{C}\right) \\
550^{\circ} \mathrm{F}\left(288^{\circ} \mathrm{C}\right)\end{array}$ & $\begin{array}{l}\text { vo } \\
130 / 140 \\
130 \\
40^{\circ} \\
20^{\circ}\end{array}$ \\
\hline
\end{tabular}

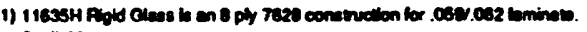

(2) Aveiletbo upon requolet

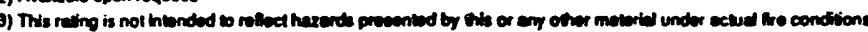

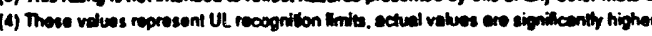

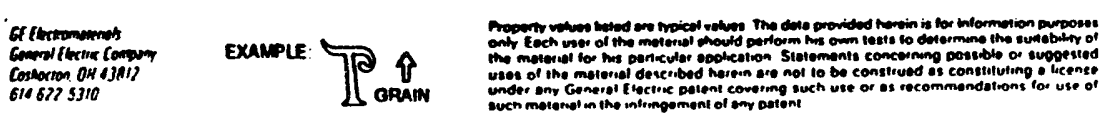

1 of 1

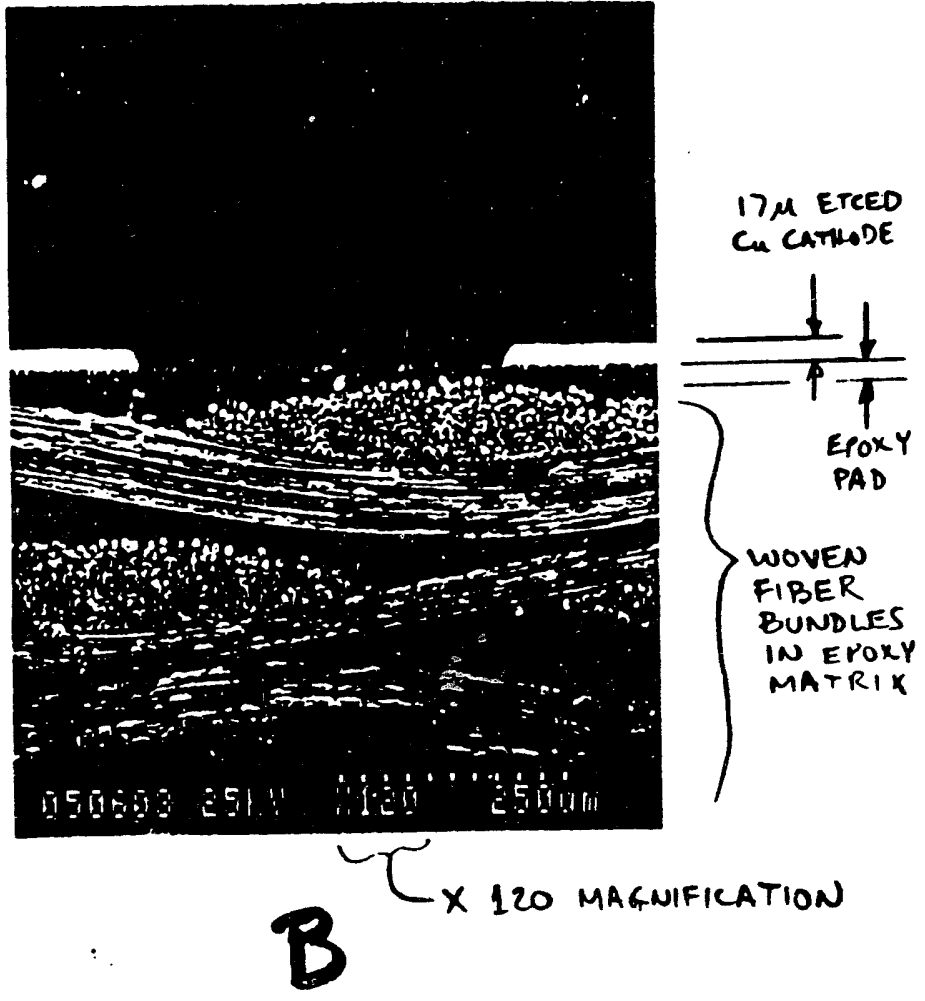

MICROGRAPH SHOWING WOVEN -

FIBER BUNDLES AND

EPOXY PAD UNDER ETCHED -

COPPER CATHODE - 


$$
\text { GENERIC G-10 }
$$

Elastic Modulus of Generic (0/90)sym Fiberglass Laminate (E is NOT quasi-isotropic)

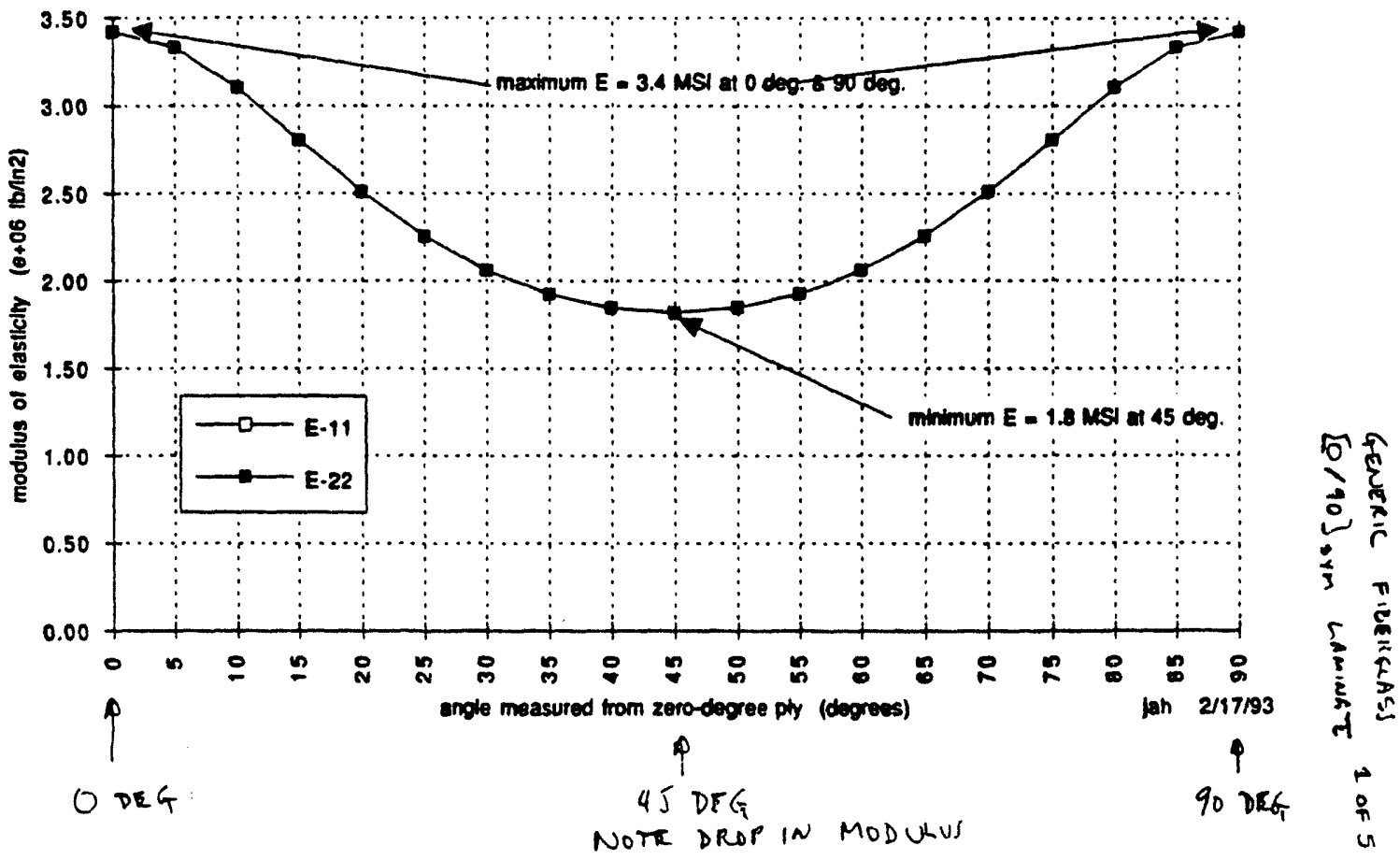

generic CTE $\langle 0 / 90\rangle$

GENERIC G-IU

CTE of Generic (0/90)sym Fiberglass Laminate (CTE is quasi-isotropic)

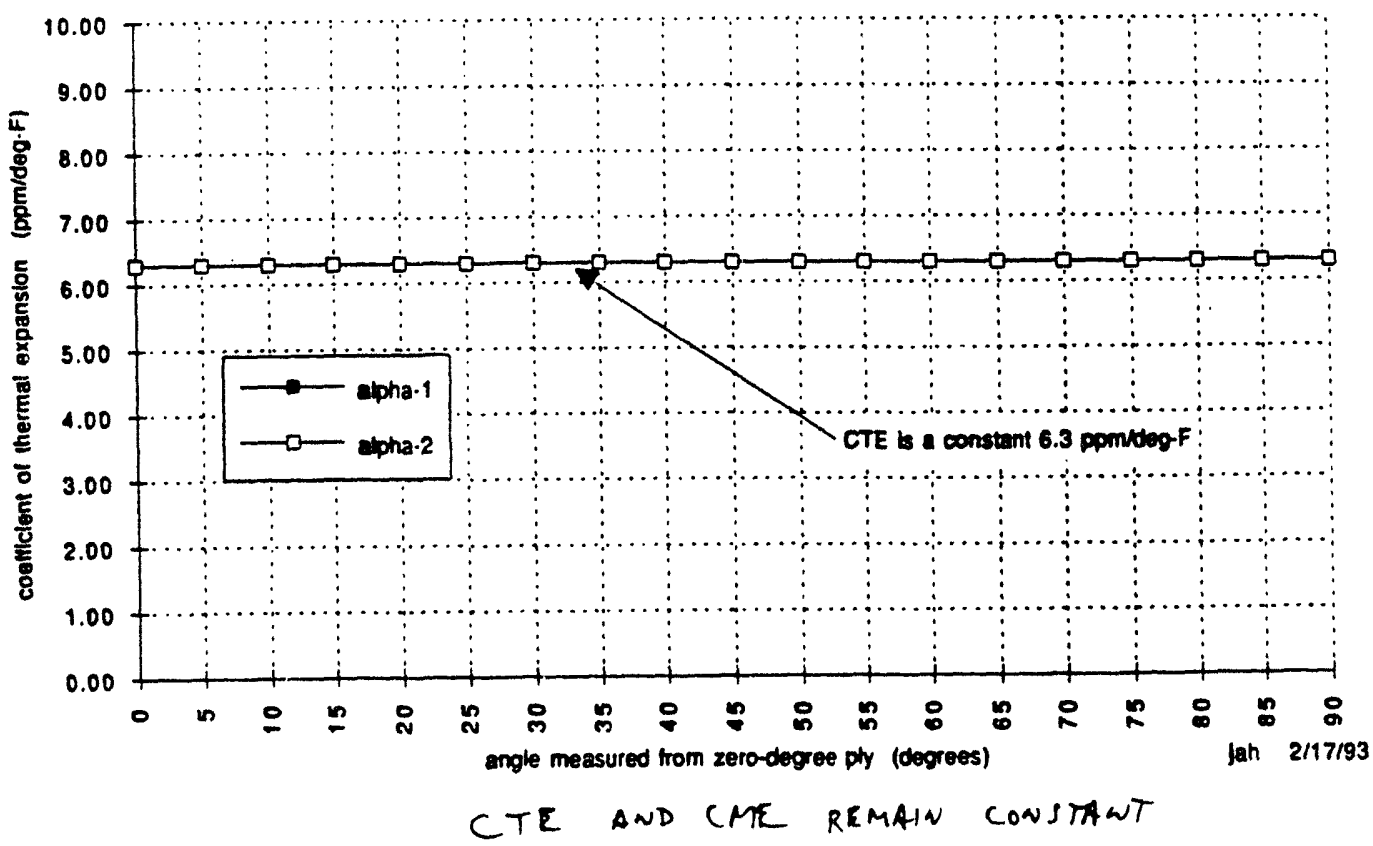




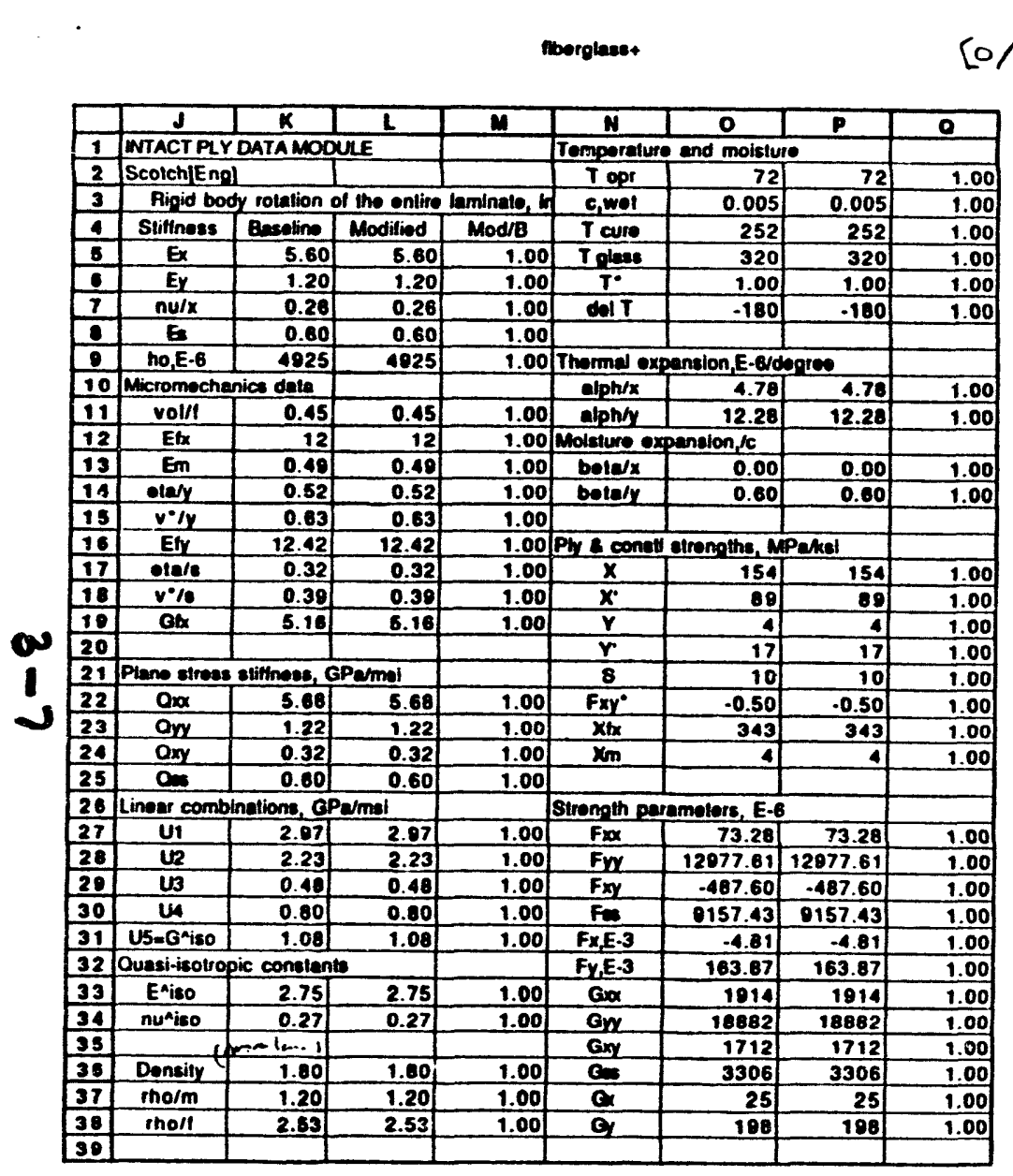

PROPERTIES OF A SINGLE PLY
$[0 / 90]$ sym

$30=5$

-

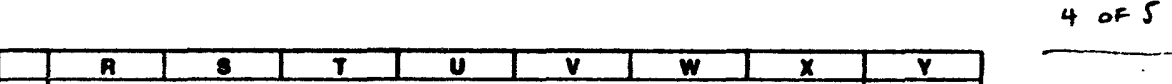

propretiRs OF A $[0 / 90]_{\text {SYM }}$ LAMINATIL

i.e. WOVEN CLOTH 
troorglases.

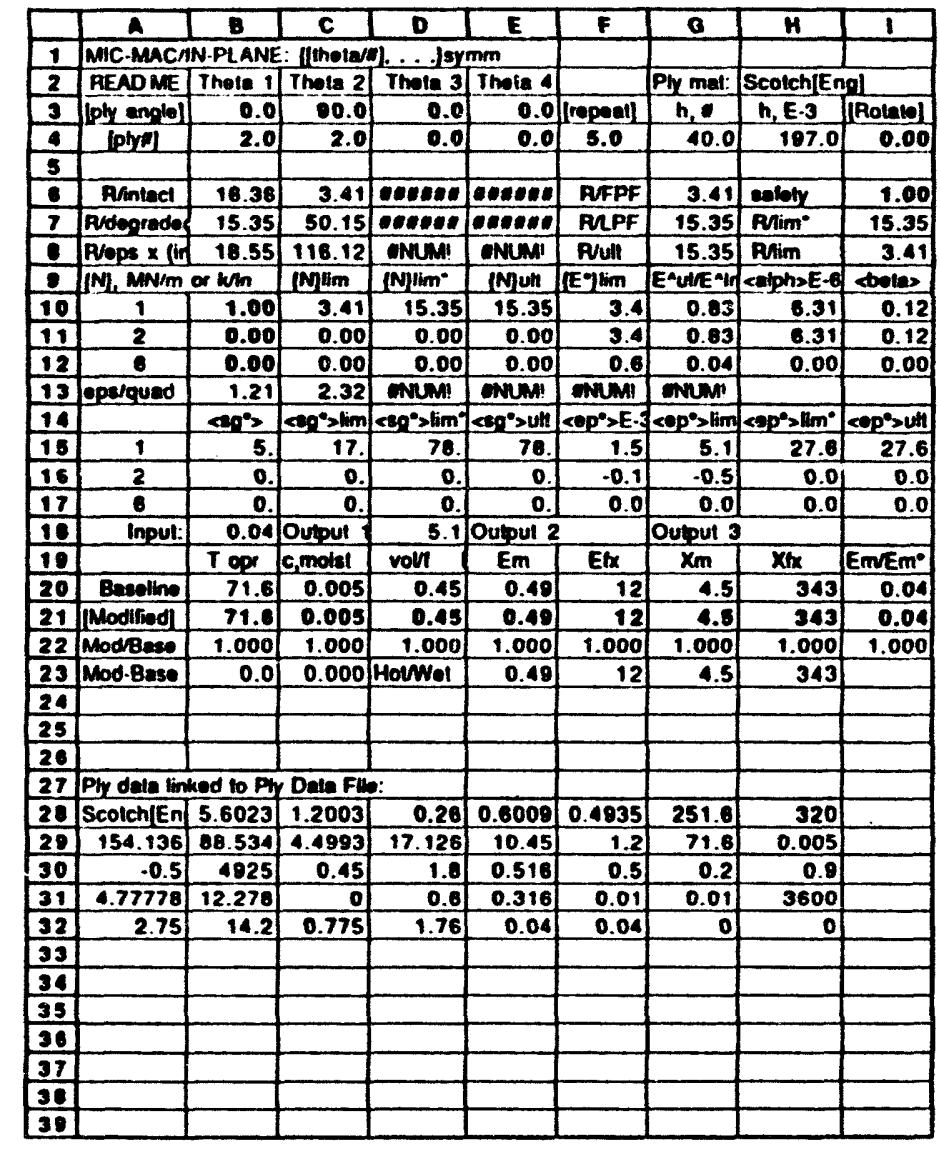

RESULTING PROPRRTY SUMMARY
$[0 / 90]_{\mathrm{sm}}$

5 of 5 
generic Exx

Elastic Modulus of Generic Fiberglass Laminate (0/+theta/-theta/90)sym

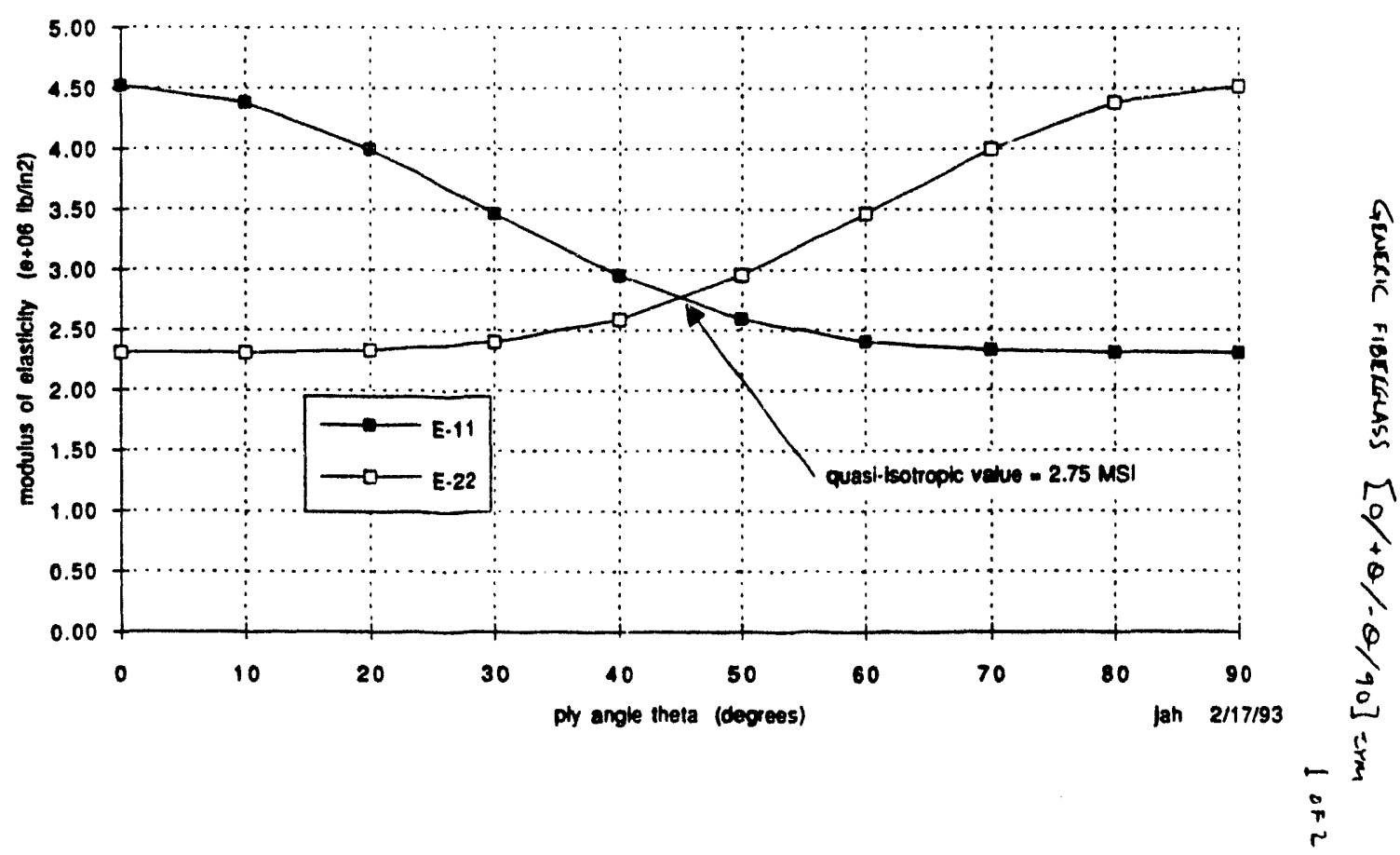

generic CTE

CTE of Generic Fiberglass Laminate (O/+theta/-theta/90)sym

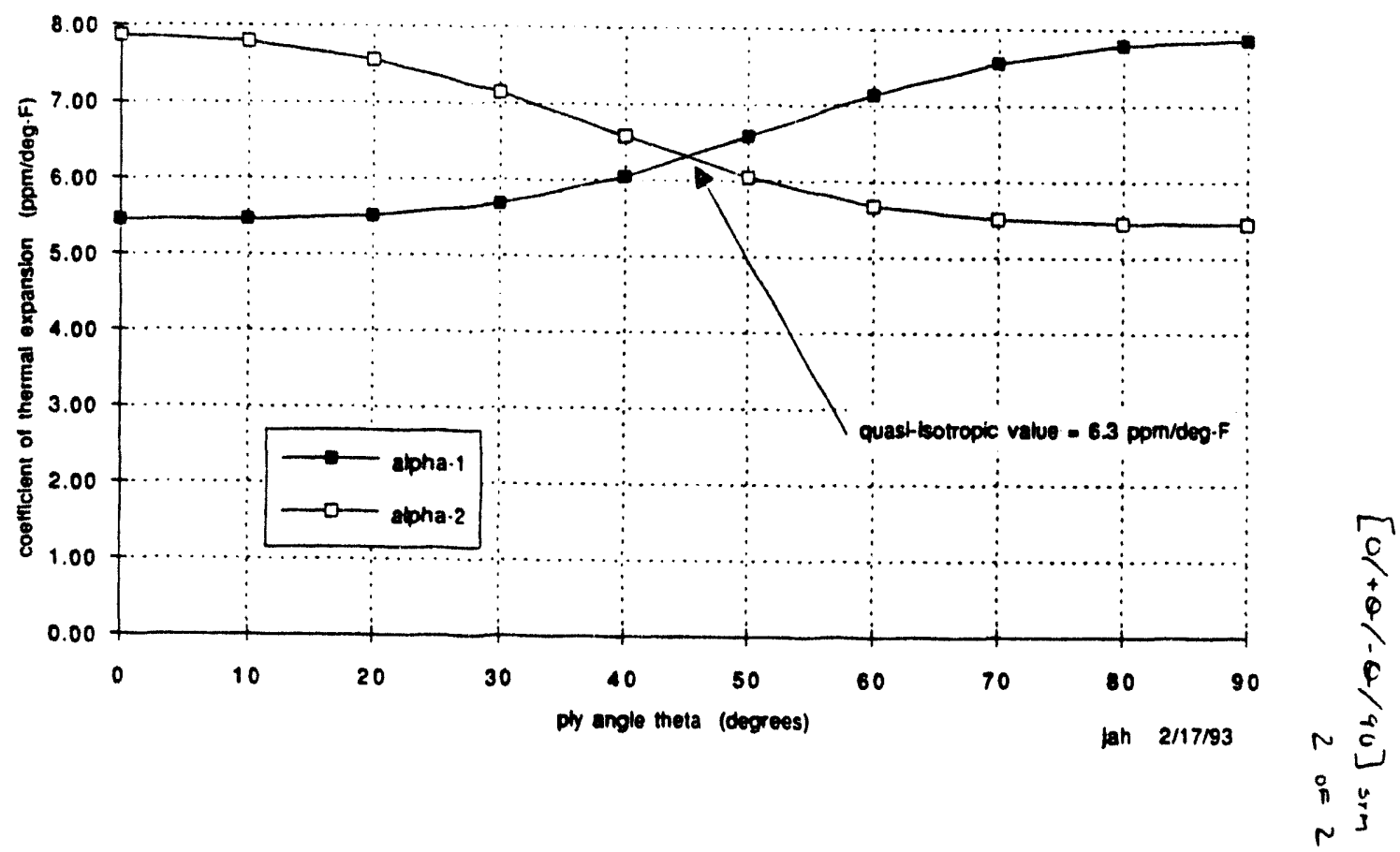


Elastic Modulus of Generic $(0 /+45 /-45 / 90)$ sym Fiberglass Laminate (quasi-isotropic)

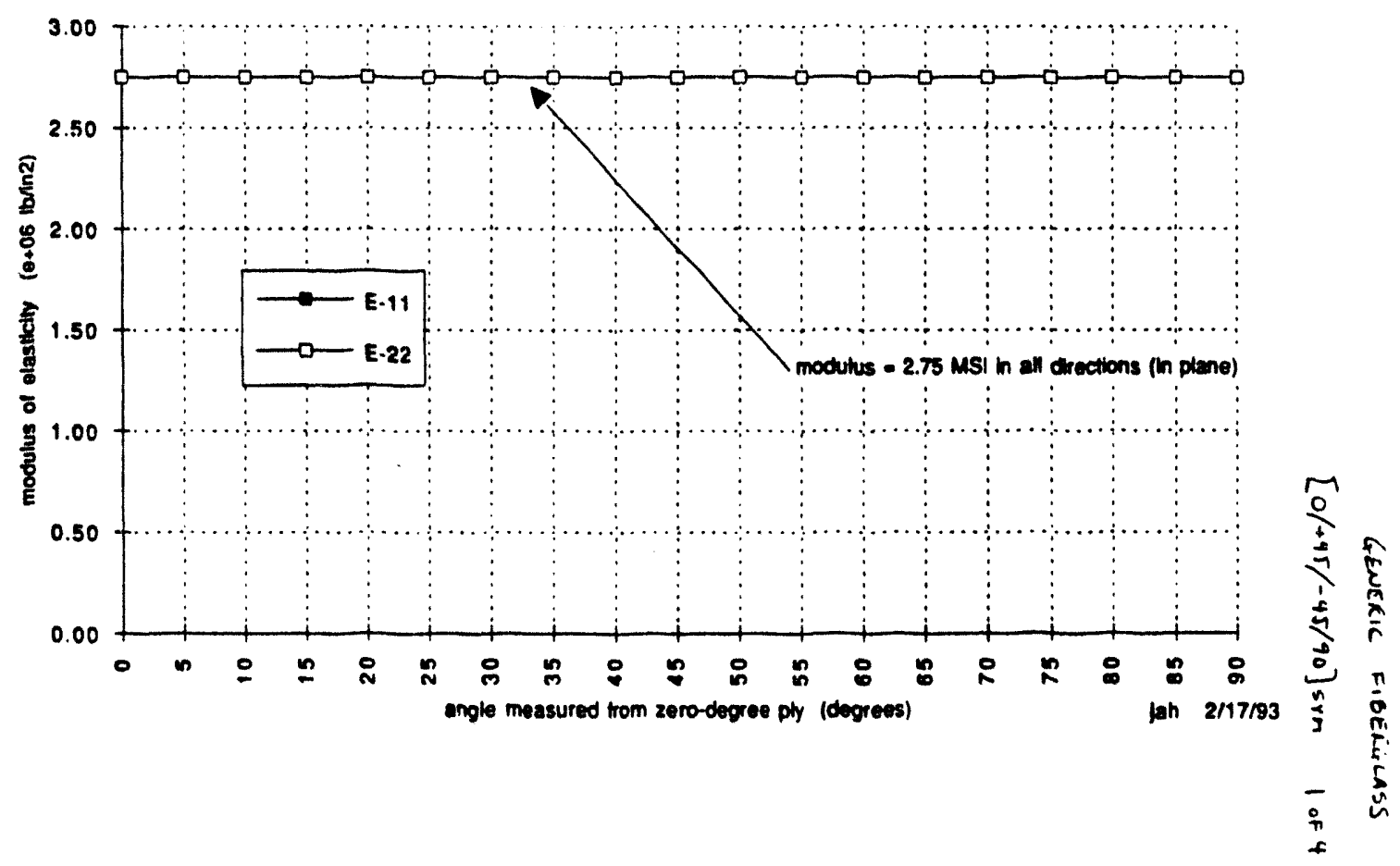


moorolesses $\quad[0 / 405 /-45 / 90] \leq \mathrm{mm}$

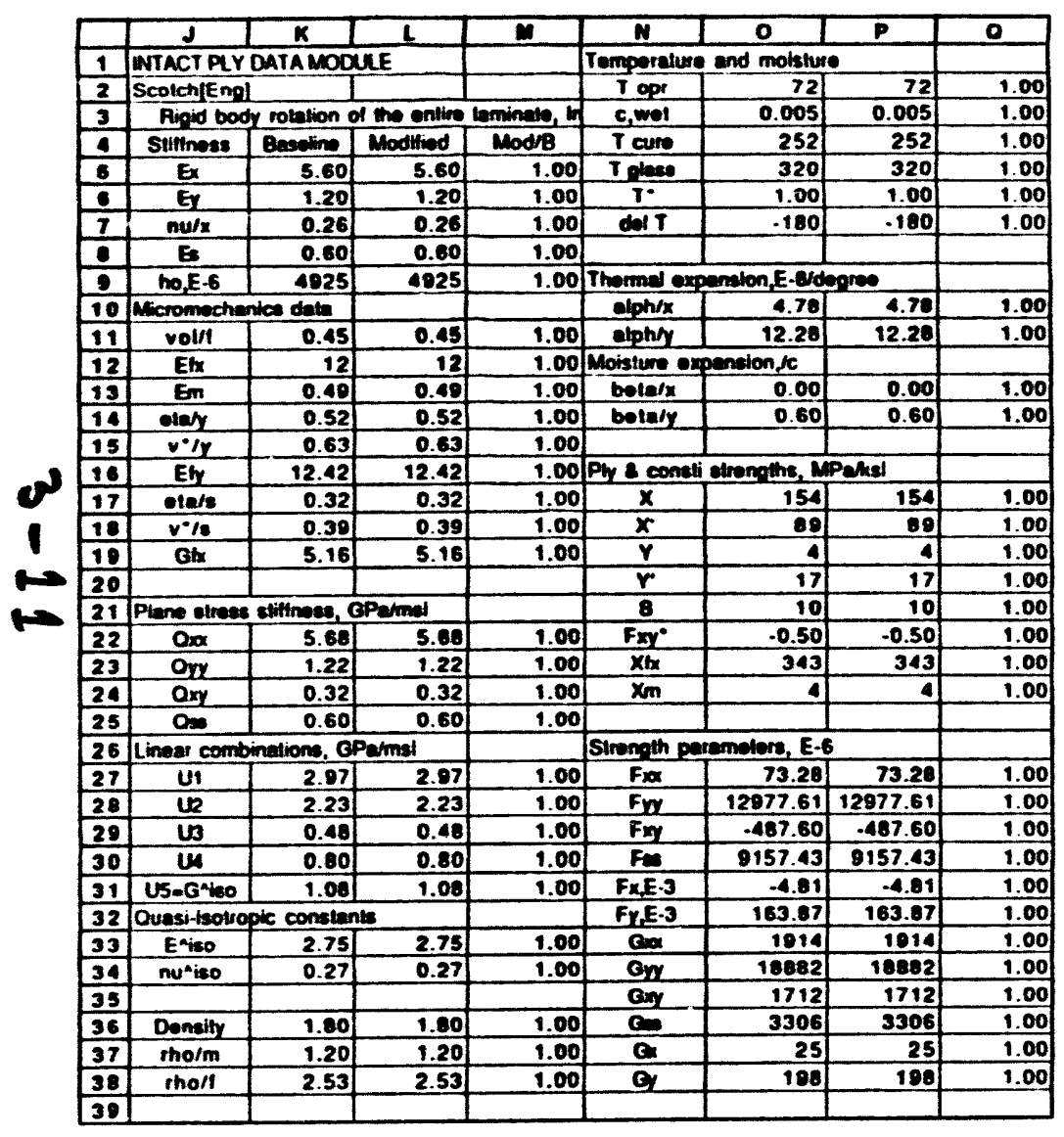

$2=4$

\begin{tabular}{|c|c|c|c|c|c|c|c|c|}
\hline & ค & 8 & $\mathbf{T}$ & U & $\mathbf{v}$ & $\mathbf{w}$ & $\mathbf{x}$ & $\mathbf{y}$ \\
\hline \multicolumn{9}{|c|}{ ACT LAMINATE MOOUL US MODULE - deafle end hyprothermel conatents } \\
\hline 2 & & & & & & & & \\
\hline 3 & |Anglel & theta/1 & tholu/2 & thole/3 & thoter/4 & & & \\
\hline 4 & (thetel & 0.0 & 45.0 & -45.0 & 80.0 & JPEPT] & & \\
\hline 8 & [uspel & 2.0 & 2.0 & 2.0 & 2.0 & 6 & & \\
\hline 8 & $2 x, y=0$ & $0 E+00$ & 2E.00 & $-2 E+\infty 0$ & SE+00 & $n+1 r+\infty$ & & \\
\hline 7 & 4x,ind & $O E+00$ & $3 E+00$ & $-3 E+00$ & OE+00 & 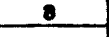 & & \\
\hline \multicolumn{9}{|l|}{ - } \\
\hline - & Top $2^{\circ}$ & 1.00 & 0.75 & 0.50 & 0.25 & & & \\
\hline 10 & Bott $z^{\circ}$ & 0.75 & 0.50 & 0.25 & 0.00 & & & \\
\hline 11 & $\operatorname{del}\left(2^{\circ}\right)$ & 0.25 & 0.25 & 0.25 & 0.25 & $h_{4}$ & & \\
\hline 12 & & & & & & AE-01 & & \\
\hline 13 & & & & & & & 2.000 & \\
\hline 14 & 81111 & $10 / 1$ & $101 / 2$ & $101 / 3$ & $10 / 4$ & [a] & $|A \cdot|$ & \\
\hline 15 & 11 & 5.68 & 2.40 & 2.40 & 1.22 & 1.17 & 2.07 & \\
\hline 16 & 22 & 1.22 & 2.48 & 2.40 & 5.68 & 1.17 & 2.07 & \\
\hline 17 & $21-12$ & 0.32 & 1.28 & 1.28 & 0.32 & 0.32 & 0.80 & \\
\hline 10 & 66 & 0.60 & 1.57 & 1.57 & 0.60 & 0.43 & 1.08 & \\
\hline 10 & $6:-16$ & 0.00 & 1.12 & -1.12 & 0.00 & 0.00 & 0.00 & \\
\hline 20 & $62-26$ & 0.00 & 1.12 & -1.12 & 0.00 & 0.00 & 0.00 & \\
\hline 21 & & & & & $\underline{\mu}$ & SE-01 & & \\
\hline 22 & Compl & $101 . \mathrm{m} / \mathrm{GN}$ & & {$\left[0^{\circ}\right]$} & & E10 & & \\
\hline 23 & 11 & 0.02 & & AE-01 & & 2.75 & & \\
\hline 24 & 22 & 0.02 & & AE-01 & & 2.75 & & \\
\hline 25 & $21-12$ & -0.25 & & $-1 E-01$ & & 0.27 & 0.27 & \\
\hline 26 & 66 & 2.34 & & OE.01 & & 1.08 & & \\
\hline 27 & 61.18 & 0.00 & & $4 E-18$ & & 0.00 & & \\
\hline 20 & $62-26$ & 0.00 & & $-2 E \cdot 17$ & & 0.00 & & $E, C_{P}$ \\
\hline 29 & & & & & & & & $X M P$ \\
\hline 30 & \multicolumn{4}{|c|}{ Nonmechanical etroes $(\mathrm{Pa})$ end etreln } & & Volla & & tho \\
\hline 31 & $V=11 A$ & $\begin{array}{l}0.250 \\
\end{array}$ & 0.000 & 0.000 & -0.250 & 0.000 & & $A=x$ ploipl \\
\hline 32 & $V \cdot / 3 A$ & 0.000 & 0.250 & $\begin{array}{r}-0.250 \\
\end{array}$ & 0.000 & 0.000 & & rol tho \\
\hline 33 & & $p^{n} n \pi$ & $p^{A n} 1 c$ & $\operatorname{sen} \pi$ & $\log ^{a} n / c$ & theo 0 & bole 0 & epefiso \\
\hline 34 & 1 & 2E-05 & 0.460 & 2E-05 & 0.460 & 6.305 & 0.122 & rol ofiff \\
\hline 35 & 2 & TE.-06 & -0.270 & 2E-05 & 0.460 & 6.305 & 0.122 & opec stitt \\
\hline 36 & 6 & $\sin ^{a} n_{0}$ & cpsano & 2E-22 & $\theta E-10$ & 0.000 & 0.000 & $\sec R$ \\
\hline 37 & 1 & $-2 E-03$ & $.5 E-04$ & $0 / x$ & -OE-04 & 0.000 & & nu/iso \\
\hline 38 & 2 & $-2 E-03$ & $-5 E-04$ & $\theta / y$ & BE-0a & -0.001 & & $\ln (\mathbf{n u})$ \\
\hline 39 & 6 & $-8 E-20$ & $-4 E \cdot 20$ & 10 & $O E+00$ & 0.000 & & \\
\hline
\end{tabular}

$30<4$ 


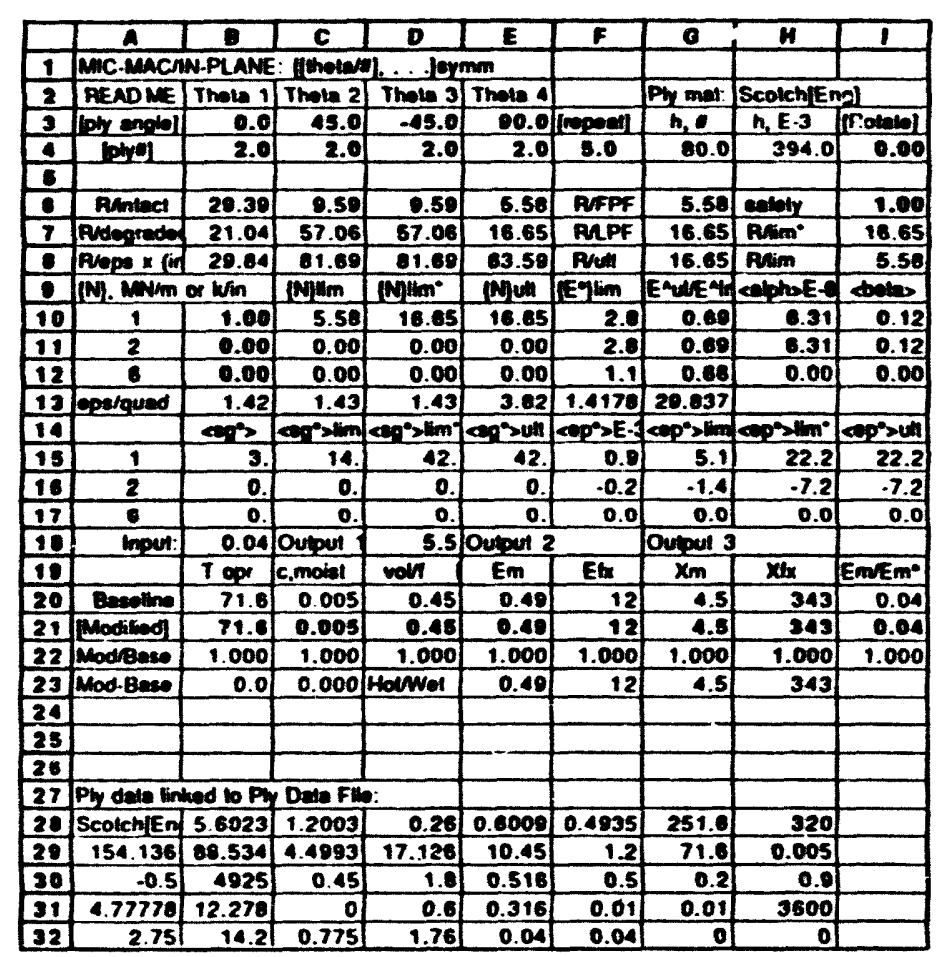




\title{
4. Sandwich Core Materials
}

\begin{abstract}
Contents:
Survey of various core materials and their densities and mechanical properties ( 3 pages)

Data for HRH-10 aramid fiber/phenolic resin (Nomex) TDR Baseline core (4 pages)

Data for polymethacrylimide foam (Rohacell) core materials (4 pages)
\end{abstract}

\section{Summary:}

The TDR Baseline sandwich panel core material was aramid fiber/phenolic resin (Nomex) honeycomb. Hexcel corporation calls this line of Nomex honeycomb material HRH-10. The lowest density/shear modulus ratio HRH-10 material, HRH-10-1/8-1.8, was selected as the baseline. It has $1 / 8$ inch cells and weighs $1.8 \mathrm{lb} / \mathrm{ft} 3(0.029 \mathrm{~g} / \mathrm{cm} 3)$.

Lower cost and better properties per unit mass were available with aluminum honeycomb materials but they were not chosen because an electrically insulating material was required to separate cathodes without introducing capacitance in the core.

Honeycomb materials have two different shear moduli due to their construction. HRH-10$1 / 8-1.8$ has a shear modulus of $1.5 \mathrm{ksi}$ in one direction and 3.8 in the other. For CSC's the highest shear modulus would be aligned to the long span of the chamber to better resist gravity sag.

An alternate core material is polymethacrylimide foam (Rohacell). The lowest density Rohacell available is $31-\mathrm{IG}$ at $1.9 \mathrm{lb} / \mathrm{ft} 3(0.031 \mathrm{~g} / \mathrm{cm} 3)$. Its shear modulus is $1.99 \mathrm{ksi}$ in all directions. Since it would be approximately half as stiff in shear in the long direction for essentially the same mass as HRH-10-1/8-1.8 it was not chosen as the TDR Baseline core material. Its virtue is its isotropic properties which allow it to better resist local loads such as would occur it the sandwich panel were used for a flooring sheet.

$$
4-1
$$


SANDWICH CORE MATERIALS - SURVEY $1 / 3$

SANDWICH CORE MATERIALS (CONTINUED)

SURVEY $2 / 3$

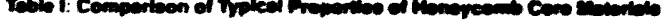

\begin{tabular}{|c|c|c|c|c|c|c|c|c|c|}
\hline 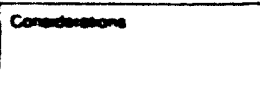 & ${ }_{0}^{\infty}$ & $\begin{array}{l}2029 \\
\mathrm{CA}\end{array}$ & $\begin{array}{l}\text { aco } \\
\text { con }\end{array}$ & $m$ & MTT & mo & $\operatorname{mon}$ & 10 & $\operatorname{TnC}$ \\
\hline 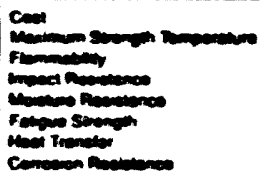 & : & 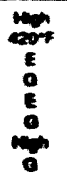 & 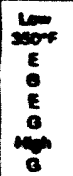 & 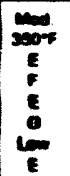 & 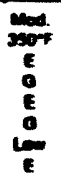 & E) & $\overbrace{0}^{2}$ & 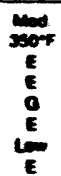 & $\begin{array}{c}200+ \\
E \\
E \\
E \\
E \\
E\end{array}$ \\
\hline
\end{tabular}

e - Exion a a

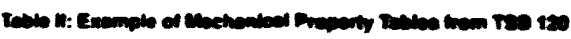

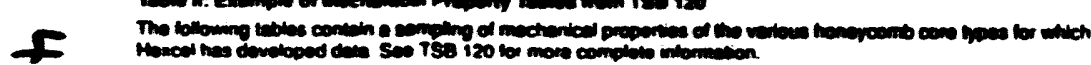

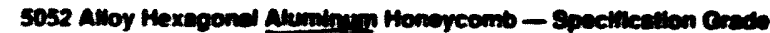

\begin{tabular}{|c|c|c|c|c|c|c|c|c|c|}
\hline \multirow{3}{*}{ 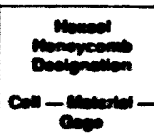 } & \multirow{3}{*}{ 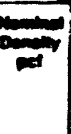 } & \multicolumn{3}{|c|}{ 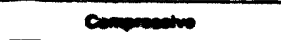 } & \multirow{3}{*}{ in } & \multicolumn{4}{|c|}{ חות משת } \\
\hline & & \multirow{2}{*}{$\infty$} & \multicolumn{2}{|c|}{$\min$} & & \multicolumn{2}{|c|}{20 menen } & \multicolumn{2}{|c|}{ w onstom } \\
\hline & & & 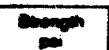 & $\infty$ & & $m$ & $=$ & $=$ & 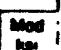 \\
\hline 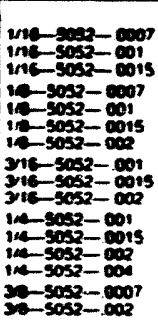 & 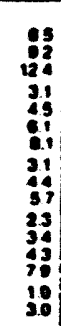 & 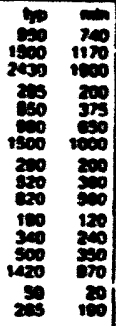 & 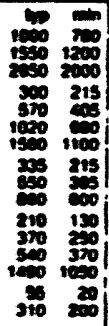 & 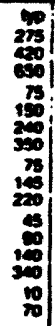 & 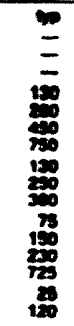 & 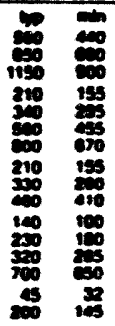 & 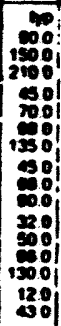 & 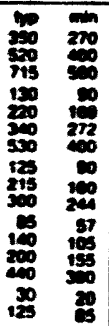 & 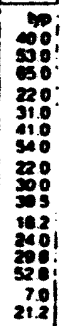 \\
\hline
\end{tabular}

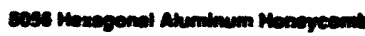

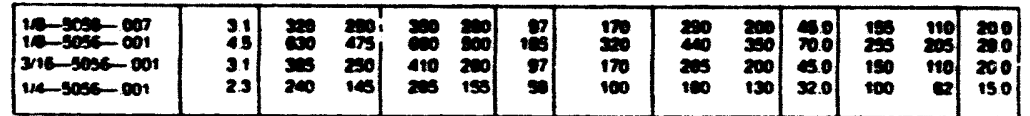

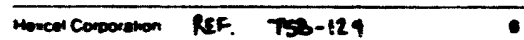

\begin{tabular}{|c|c|c|c|c|c|c|c|c|c|}
\hline \multirow{3}{*}{ |- } & \multirow{3}{*}{ 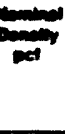 } & \multicolumn{3}{|c|}{ onmonam } & $\infty$ & \multicolumn{4}{|c|}{ man } \\
\hline & & $m$ & $\cos _{0}$ & & & 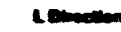 & & wence & \\
\hline & & $\infty$ & $\infty$ & $\infty$ & & $\infty$ & $\infty$ & $\infty$ & $\infty$ \\
\hline 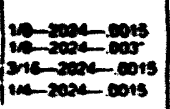 & $\begin{array}{l}80 \\
93 \\
30\end{array}$ & 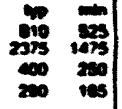 & 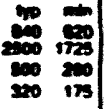 & $\begin{array}{l}\infty \\
\infty \\
\infty \\
\infty\end{array}$ & 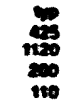 & 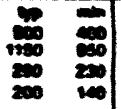 & 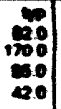 & 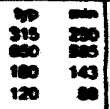 & 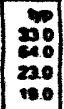 \\
\hline
\end{tabular}

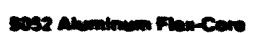

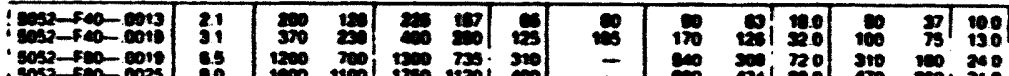

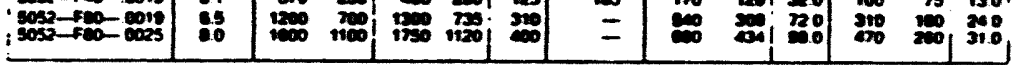

\begin{tabular}{|c|c|c|c|c|c|c|c|c|c|}
\hline 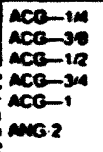 & $\begin{array}{l}49 \\
33 \\
23 \\
13 \\
13 \\
43\end{array}$ & 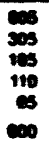 & 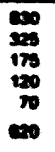 & $\begin{array}{l}10 \\
0 \\
0 \\
00 \\
100\end{array}$ & $\begin{array}{l}806 \\
120 \\
60 \\
25 \\
-\end{array}$ & $\underset{\infty}{\infty}$ & $\begin{array}{l}\infty \\
\infty \\
2 \\
0 \\
0 \\
\infty\end{array}$ & $\begin{array}{c}218 \\
130 \\
00 \\
\infty \\
\infty \\
100 \\
100\end{array}$ & $\begin{array}{l}31 \\
20 \\
15 \\
5 \\
0 \\
20\end{array}$ \\
\hline
\end{tabular}

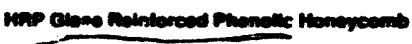

\begin{tabular}{|c|c|c|c|c|c|c|c|}
\hline \multirow{3}{*}{ 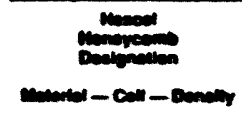 } & \multicolumn{3}{|c|}{ 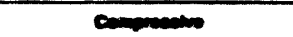 } & \multicolumn{4}{|c|}{ monem } \\
\hline & \multirow{2}{*}{$=$} & \multicolumn{2}{|c|}{ החשרח } & \multicolumn{2}{|c|}{ 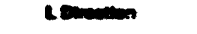 } & \multicolumn{2}{|c|}{ wowem } \\
\hline & & $\infty$ & $\infty$ & $\infty$ & $\infty$ & $m$ & 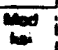 \\
\hline 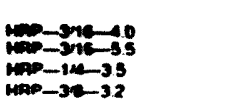 & 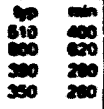 & 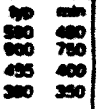 & 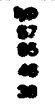 & 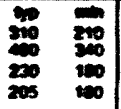 & 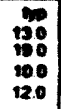 & 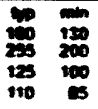 & $\begin{array}{l}70 \\
710 \\
30 \\
80 \\
8.0\end{array}$ \\
\hline
\end{tabular}




$$
\text { SURver } 2 / 3
$$

SANDWICH CORE materials (CONTINUED)

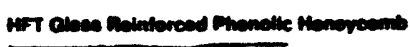

\begin{tabular}{|c|c|c|c|c|c|c|}
\hline \multirow{3}{*}{ תוm - } & \multirow{2}{*}{\multicolumn{2}{|c|}{$\cos _{n=0}$}} & \multicolumn{4}{|c|}{ 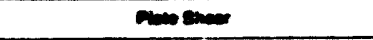 } \\
\hline & & & \multicolumn{2}{|c|}{ Lomeren } & \multicolumn{2}{|c|}{ wonectons } \\
\hline & 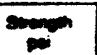 & $\infty$ & mom & $\infty$ & mon & $N^{\infty}$ \\
\hline WT-10-8: & 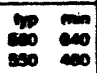 & 8 & $\begin{array}{cc}20 \\
275 \\
2700 \\
210 \\
200\end{array}$ & $\begin{array}{c}300 \\
200 \\
200\end{array}$ & $\begin{array}{ll}200 & 100 \\
230 & 100 \\
140 & 115\end{array}$ & 60 \\
\hline
\end{tabular}

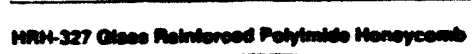

\begin{tabular}{|c|c|c|c|c|c|c|c|}
\hline 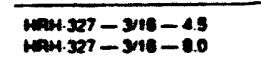 & & 12000 & 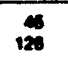 & 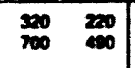 & $\mathbf{z}$ & $\begin{array}{ll}150 & 100 \\
300 & 300\end{array}$ & 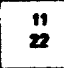 \\
\hline \multicolumn{8}{|l|}{ min andmencon } \\
\hline$=$ & \multicolumn{3}{|c|}{$a \operatorname{angmon}$} & \multicolumn{4}{|c|}{$\operatorname{mos} m$} \\
\hline & \multirow{2}{*}{$\min _{\infty}^{\infty}$} & \multicolumn{2}{|c|}{$\operatorname{mon}$} & \multicolumn{2}{|c|}{ Lomounen } & \multicolumn{2}{|c|}{ wometion } \\
\hline 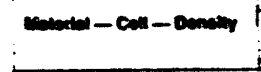 & & \multicolumn{2}{|c|}{ 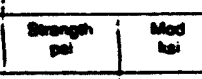 } & $\operatorname{sen} 1$ & $\infty$ & simom i & mos \\
\hline $\operatorname{man}_{111} 11=30=25=$ & 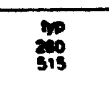 & 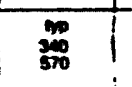 & 偠 & 密 & \multicolumn{2}{|c|}{ 勇 } & $m_{i}^{p}$ \\
\hline \multicolumn{8}{|c|}{ 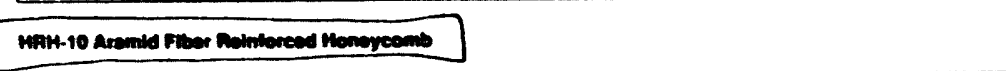 } \\
\hline \multirow{3}{*}{ 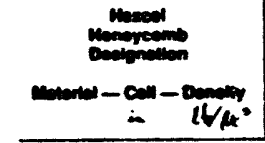 } & \multicolumn{3}{|c|}{ amponsens } & \multicolumn{4}{|c|}{ num smoer } \\
\hline & $\infty$ & $\infty$ & & \multicolumn{2}{|c|}{ Laveren } & \multicolumn{2}{|c|}{ momosion } \\
\hline & $\infty$ & $\infty$ & 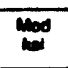 & $\infty$ & 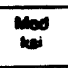 & som & $\infty$ \\
\hline 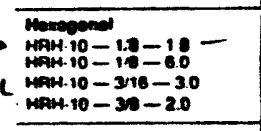 & 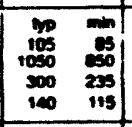 & 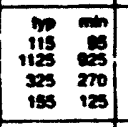 & $\begin{array}{l}70 \\
0.0 \\
20 \\
20 \\
10\end{array}$ & 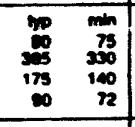 & 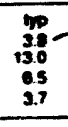 & $\begin{array}{ll}50 \\
380 \\
200 \\
200 \\
100 \\
100 \\
30 & 30 \\
\end{array}$ & $\begin{array}{l}9 \\
19 \\
i s \\
34 \\
34 \\
24\end{array}$ \\
\hline Ox-conox - $216-3.0$ & 200200 & $\begin{array}{|ll|}300 & 200 \\
\end{array}$ & 7 & $119 \quad$ is & 30 & 130 & .0 \\
\hline 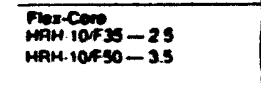 & $\begin{array}{ll}200 & 1900 \\
300 & 300\end{array}$ & $\mid \begin{array}{ll}206 & 173 \\
300 & 0\end{array}$ & 28 & \begin{tabular}{|c|}
100 \\
1700
\end{tabular} & is & 100 & 29 \\
\hline
\end{tabular}


BASELINE CORE MATL. DS-4000 1 of 4

\begin{tabular}{c}
\hline Honeycomb \\
\hline ARH ${ }^{\circ}-10$ \\
Aramid Fiber/Phenolic Resin Honeycomb \\
Data Sheet 4000
\end{tabular}

Funtures

High Strength a L Low Denatures

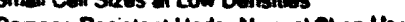

Five-.resistum (sell extingulating)

Walor and Fungus Fesigtent

Excolliond Dielectric Propertices

Good Bonding Surtaces

\section{Apericentions}

7
$=$

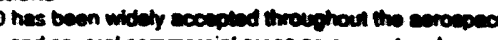

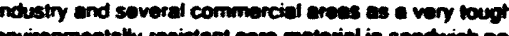

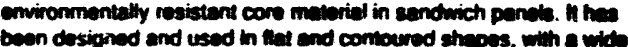

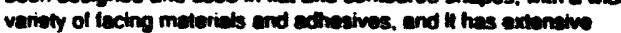

envicos in both structured end non-mtructurel perts. Most of tho mantor

penots of commerciel ipts nuch as the 737, 747, Mo 11. 757, 787.

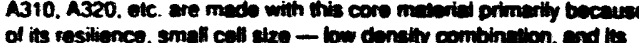

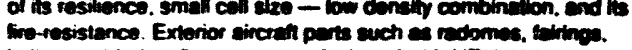

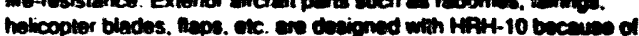

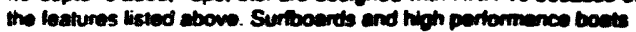

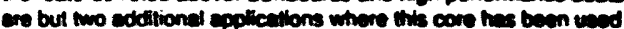

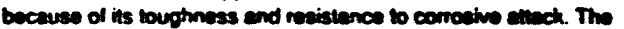

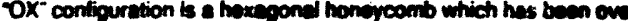

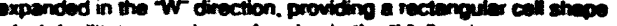

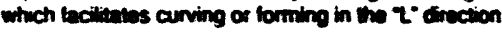

omediplion

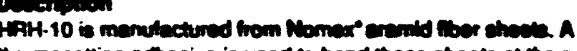

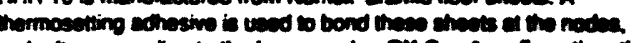

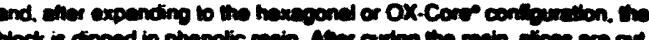

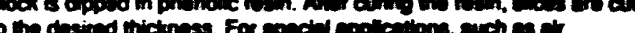

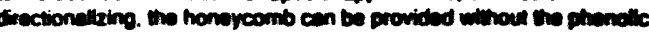

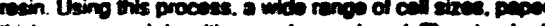

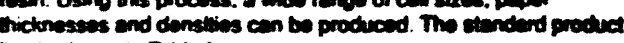

Type Denelonimion

HPH. 10 honeycomb is desioneted es llollows:

unvertat - Coll Stas - Demally

Example: $10-3.0$

whore:

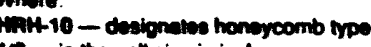

in inches

30. - te the noominal densily in pounds por coticic toon

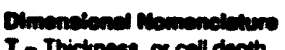

T- Thichness, or coll depth

wi - Lomp dinection, or divection

weong anction, or droction
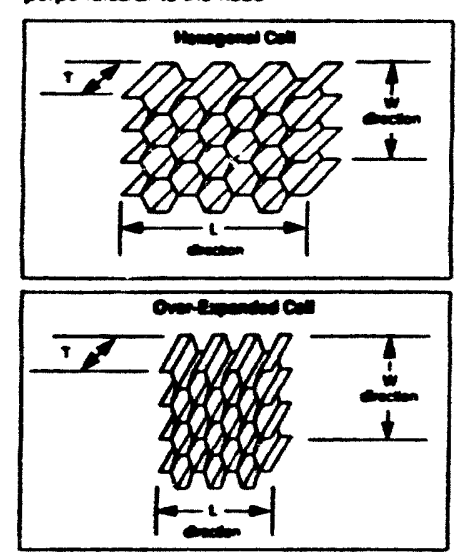

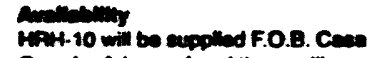

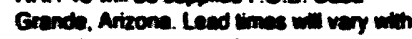
perticuler core ippes molected.

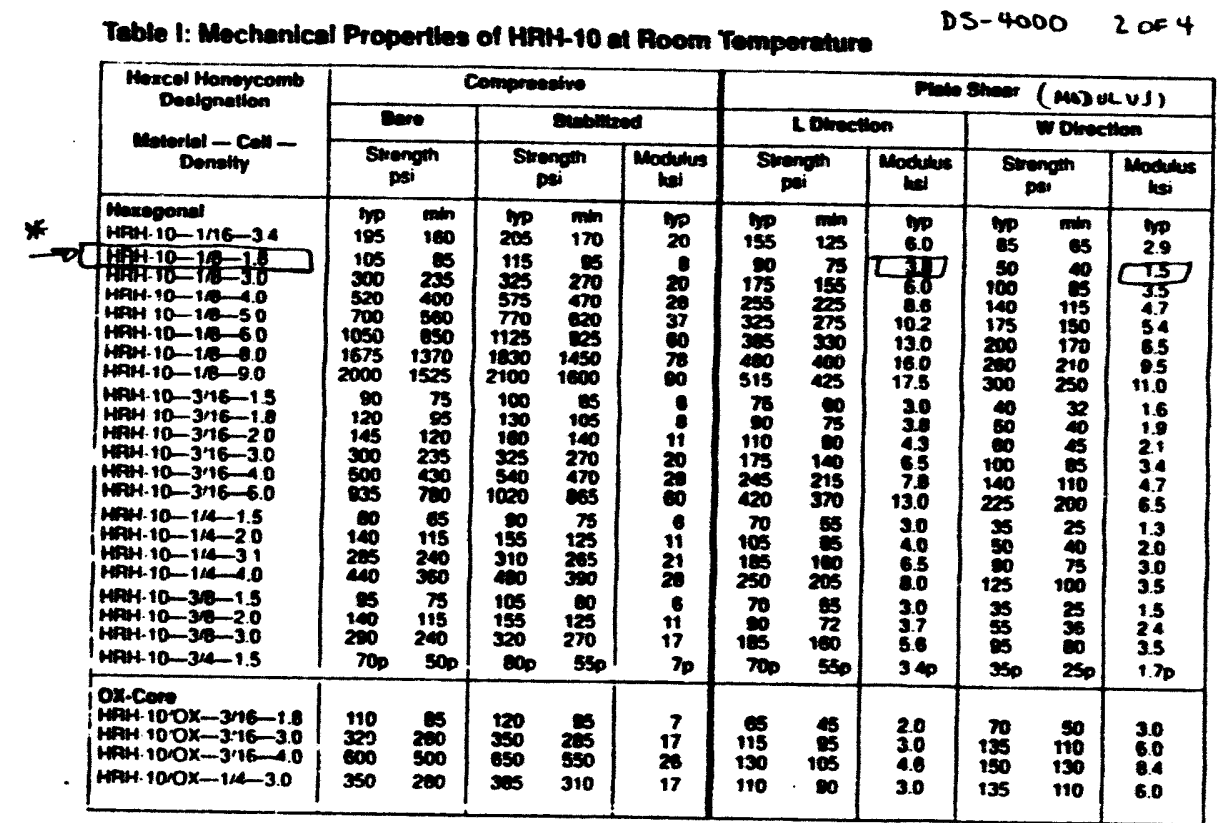

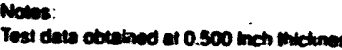

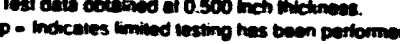

* tor baseune corer materme

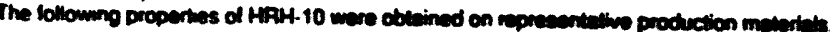

Dindectite Conotant

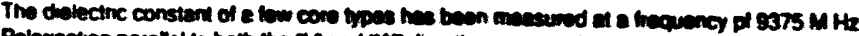

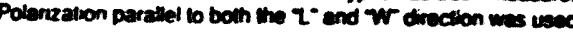

\begin{tabular}{|c|c|c|c|c|}
\hline \multirow{2}{*}{ Cones: } & \multicolumn{2}{|c|}{ 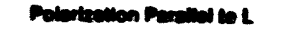 } & \multicolumn{2}{|c|}{ 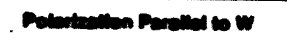 } \\
\hline & 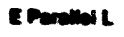 & E Promena w & E ramenall & E Pandum \\
\hline $\begin{array}{l}1.5 \\
20 \\
30 \\
10 \\
50 \\
60\end{array}$ & $\begin{array}{l}1.00 \\
1.0 \\
1.11 \\
113 \\
115 \\
1.10\end{array}$ & $\begin{array}{l}1.00 \\
1.10 \\
111 \\
1.13 \\
1.15 \\
1.0\end{array}$ & $\begin{array}{l}1.04 \\
1.05 \\
1.07 \\
1.10 \\
1.14 \\
1.10\end{array}$ & $\begin{array}{l}1.00 \\
1.00 \\
1.05 \\
1.07 \\
1.00 \\
1.11\end{array}$ \\
\hline
\end{tabular}


8pocial Configuretion and Sthapes

DS-4000 3 of 4

Honeycomb cores cen be cuslom desioned with non-standard mechanical property combinations to meet a varioty of special applications. In addition to the hexegonal and overexpanded (OX) coll shapes HAH.

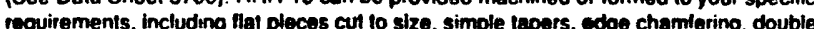
allets, or machining to complax and compound curalures. Hercel has unique capabilities 10 mechine parts to unusual contours and to shape honercomb by a variety of heal forming

tochniques. Conteci the nearest Hexcol Sales Othice for addition inlormation.

standerd Dimenelon

MPH. 10 honeycomb is avallable in the following standerd slzes with the tolorancos as indicanted.

\begin{tabular}{|c|c|c|c|c|c|}
\hline Products & $\mathbf{L}$ & $\mathbf{w}$ & $T$ maximum & T mmntmum & Par. Pt. \\
\hline \multirow[t]{3}{*}{ MAH. 10 Merertlath } & $4 \times+2$ & $86+6$ & 36- & $0.200^{\circ}$ & 29.3 \\
\hline & $40^{\circ} \pm 2$ & $96^{\circ} \pm 6^{\circ}$ & $36^{\circ}$ & $0.200^{\circ}$ & 32.0 \\
\hline & $52^{2} \pm 2$ & $110^{\circ} \pm 6^{\circ}$ & $36^{6}$ & $0.200^{\circ}$ & 39.7 \\
\hline HAH-1010X Motortals & $38^{\circ} \pm 2^{\circ}$ & $106^{\circ} \pm 6^{\circ}$ & $36^{-}$ & $0.200^{\circ}$ & 25.3 \\
\hline
\end{tabular}

- Tolerancess on an inicknoses ane as follow:

T $\quad 0.200^{\circ} 102.000^{\circ}$ tobrance will be $\pm 0.000^{\circ}$

$4.001^{-} 0$ d

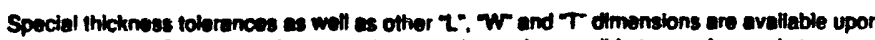
special request. For large volume nequihoments $\mathrm{i}$ may be possible to supply panels to your

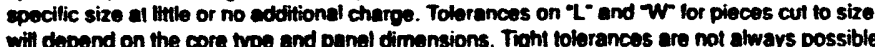
because of the nextble nature of this core type.

Epecticentione

Epectictions been evaluened and approved lor numerous corporete spectications end meets the requirements of SAE spectications AMS 37118 and Mil-C-B19.6.

Conflguratlon - The cell alze of hexegonal core will otve the nominal cell dimensions in inches ecross the filats (nodes) of the coll. Cell size delermination will be made by measuring the length of 10 consocutive calls in 6 random localions and evercaing the results. Dovble laps will be permined as tong as the core blankets are within densily tolorance. Unbondod cize is creat and the minimum mectenical properties ave obtainete.

Donelty - The rolerance on honeycomb density whon measured on a minkmum of 100 cubic inches of core will be $\pm 10 x$. Flome Aoterdance - HAH. 10 will moet the rell extinguishing" chasstication of FMM Air

Whor Migreftion - HRH-10 does not excosed 1 call water migration in 24 hours when tesied per MIL-STD-4018.

Mechanical Proportice - Teble I lisis the HAH-10 product line and mechenical propertios when lested per MIL-STD-4018 using 0.500 inch core thickness. The Typical values represent the mean average or erelativoly of lesting animum properties are guarenteed minimum individual values when lested at ambient conditions per MIL.STO.4018.

Thormel Conductwilly

DS -40004 of 4

Severat honeycomb cores heve been lested for thermel conductivity. The houre below sthows the results of this evaluation tor HRH-10. The thermal conductivity constamt varies with cell size and core thickness because the ait convection ariects inside the cells. Note the lollowing values were obrained with the heal flow from top to bot

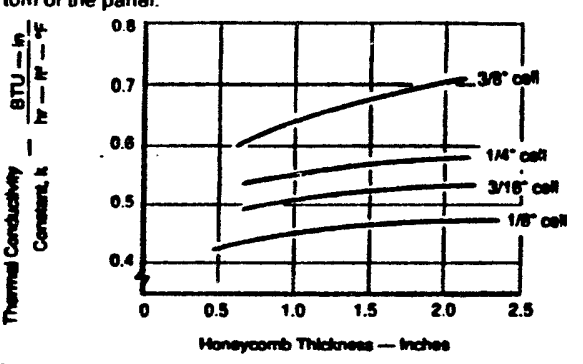

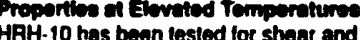

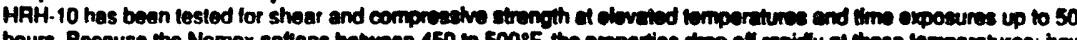
hours. Because the Nomex sonens betions, almost all ths original strength is regained.

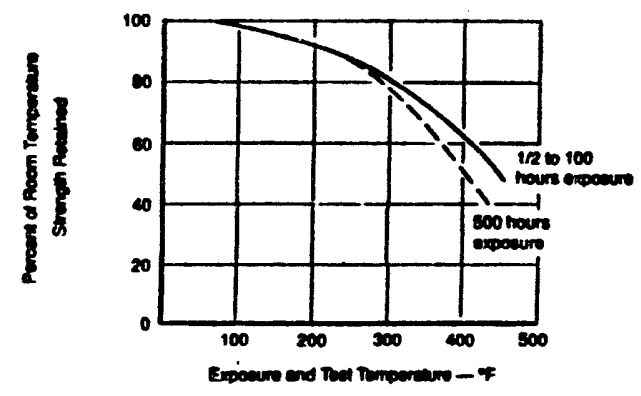

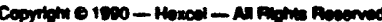

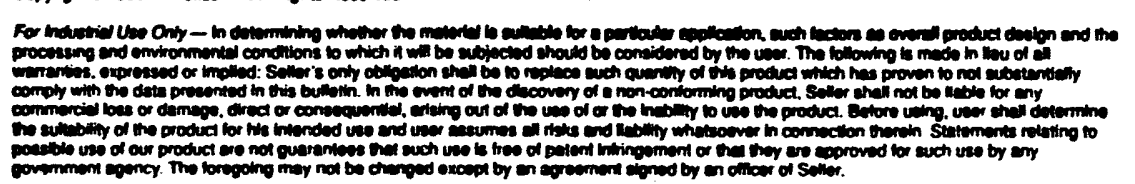

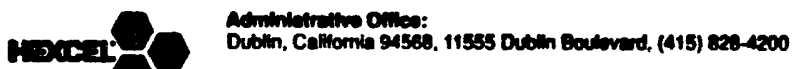

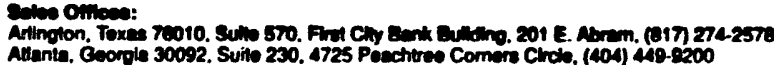

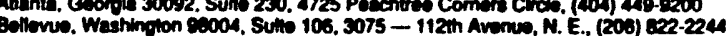

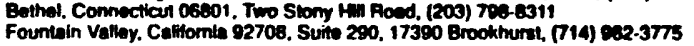

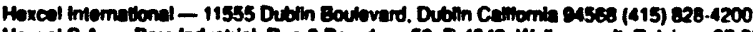

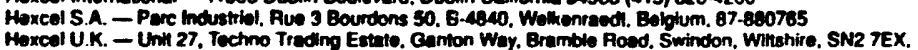

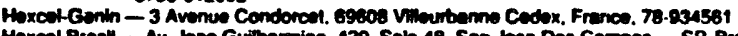

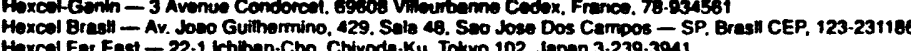




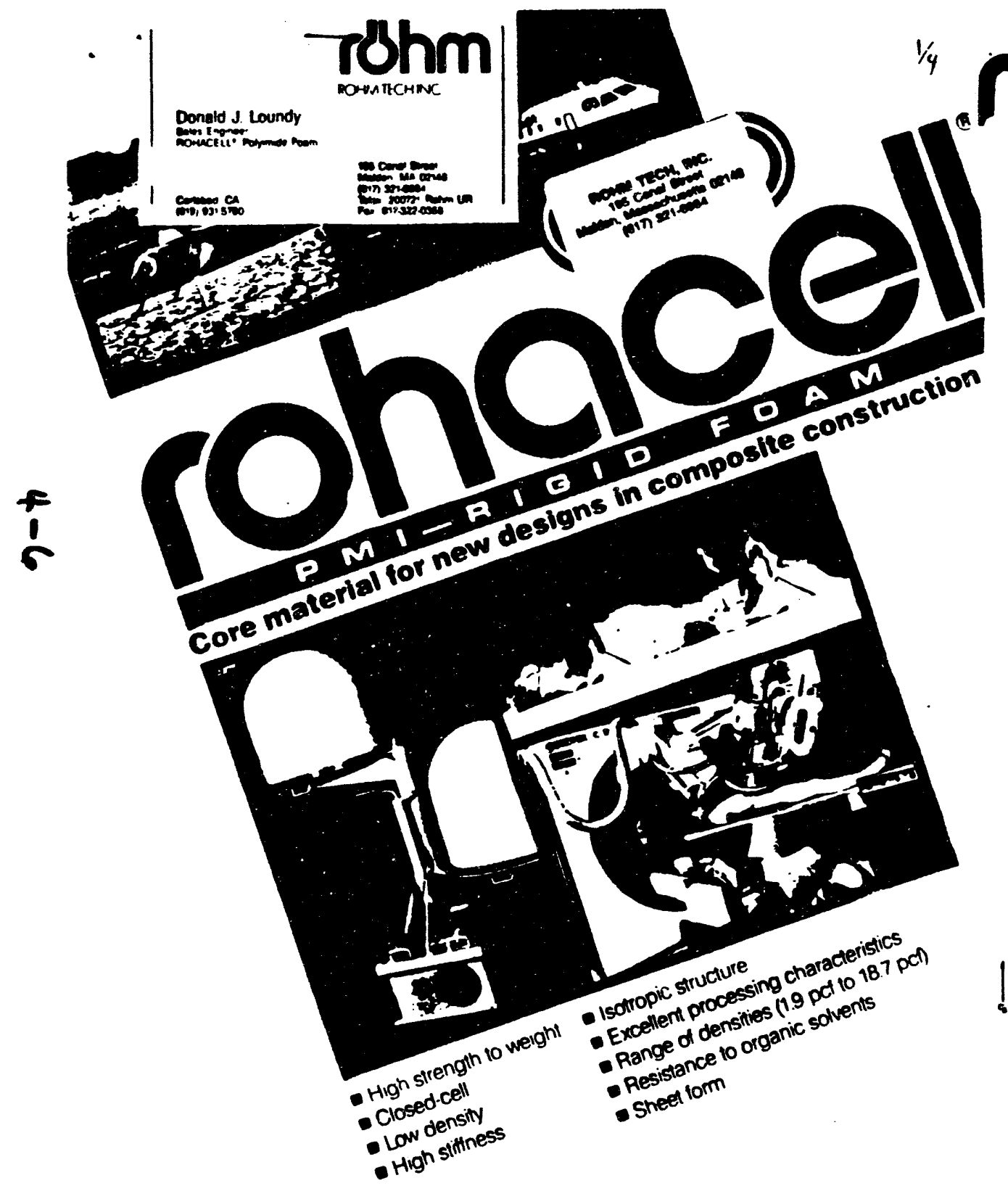

rohacellig (a)

Iypical mechanical properties CoWESTL DKNSITY

$\left(\mathrm{g} / \mathrm{m}^{3}\right)$

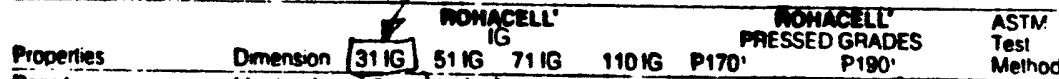

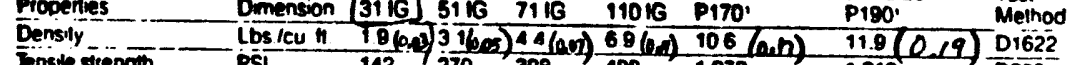

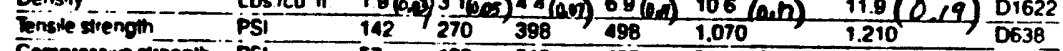

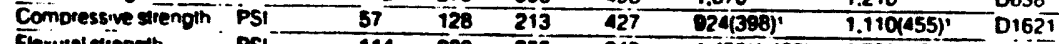

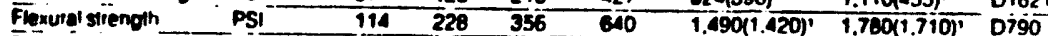

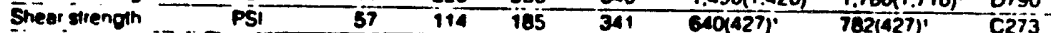

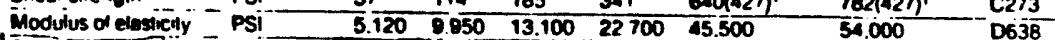

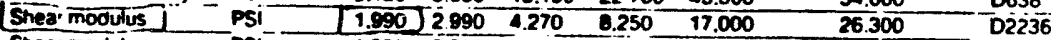

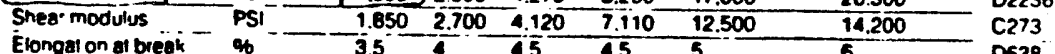
(5)

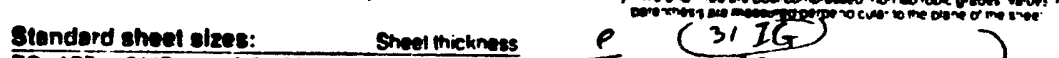

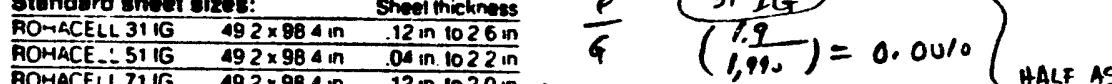
STrife in

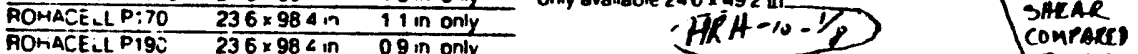

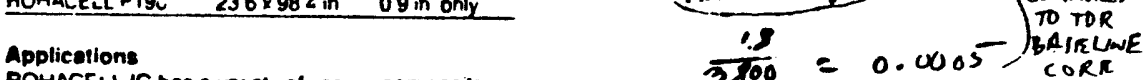
ROHACELL 16 has a variety of uses in composite Consivucion os a core malerial $\mathrm{eg}$

- Alrciat: constivcion

- Elecironics Canoe padoties cross county and downhtl skis eic

- Fregint cortaners

- Marne construction such as hults, docks. bulth - Meds ondrudcers - Mode' budding in industry and archinecture
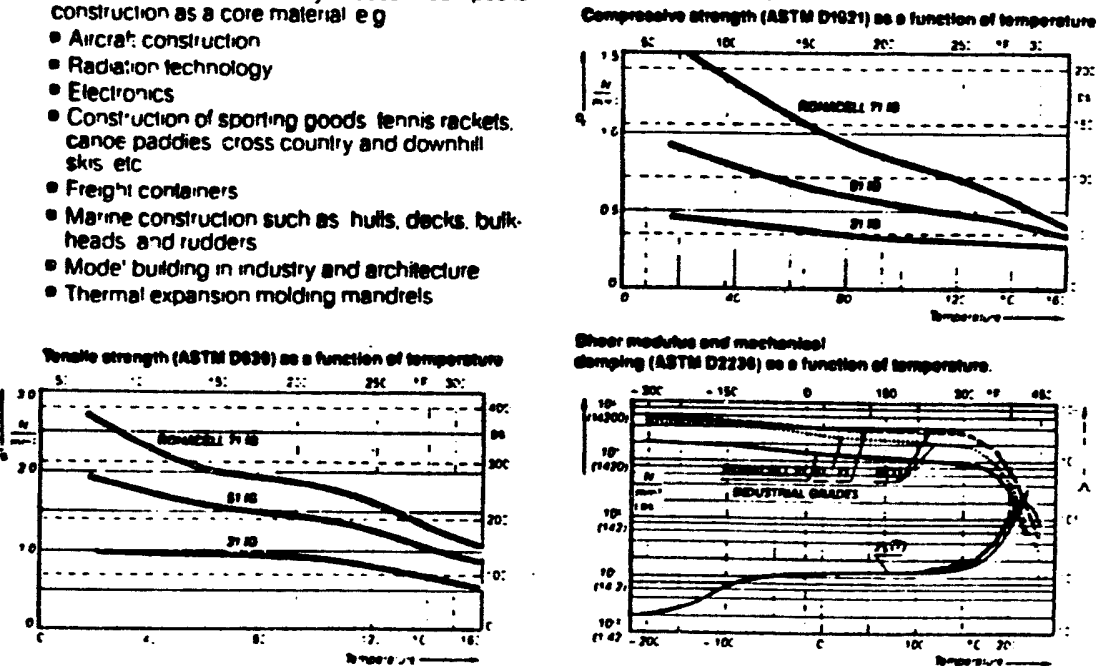

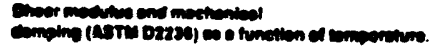

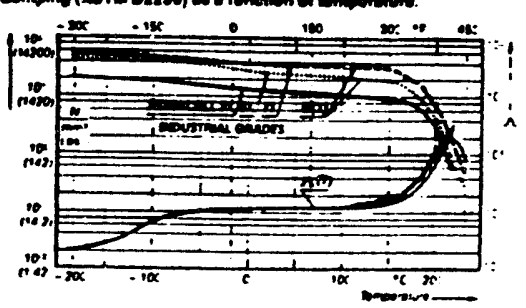




\section{rohacell wr}

AOHACELL' WF is a lightweighl, rigid. high-qualiy. polymethacnlimide foam II was developed to calisty the demand of the serospace ind ustry for a high strength core material for advanced composne constuction ROHACELL WF loom will with stond autoclave processing al temperalures up to $360^{\circ}$
and pressures UD to 100 DS' over o 2. hour time period (depending upon densily and heat (reatment) AOHACELL WF has an isolropic aructure. 20 pressure can be applied from afl directions with excellent dimensional stabiliny

Typleal mechancial propertios

\begin{tabular}{|c|c|c|c|c|c|c|c|}
\hline Properties & c mension & si WF & ELL' WF & $\begin{array}{l}\text { RADES } \\
110 \text { WF }\end{array}$ & $200 \mathrm{WF}$ & $300 \mathrm{WF}$ & $\begin{array}{l}\text { ASTM } \\
\text { Test } \\
\text { Melhod }\end{array}$ \\
\hline Densily & Los Icu n & 3170.15 & 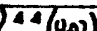 & $69(0,11)$ & 125620 & $187(029$ & 01622 \\
\hline Enste sliengih & PSI & 227 & 312 & 525 & 852 & 1.491 .29 & 0638 \\
\hline Compless ve sirength & PSI & 128 & 213 & 511 & 1.190 & 2.272 & 01621 \\
\hline Flexura' silengin & PSI & 227 & 412 & 738 & 1.704 & 2.840 & 0790 \\
\hline Shee- sliengir & BSI & 114 & 105 & 341 & 710 & 1.136 & C273 \\
\hline Mooj.js ó elast c Iy & PSI & 10650 & 14.910 & 25.360 & 34000 & 53000 & D638 \\
\hline Shea moou'us & PSI & 2840 & 9.686 & 8.236 & & & D223E \\
\hline Shea' moou'us & PSI & 2698 & 4.118 & 7100 & 21.000 & 12600 & C273 \\
\hline Elonpa: on al bieak & $o_{t}$ & 3 & 3 & 3 & 35 & & 0638 \\
\hline
\end{tabular}

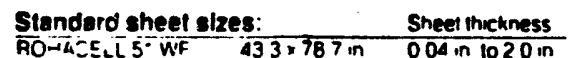

RO-AECLL 5. WiF 433.787 in 004 in 1020 in

AOHACEL: 71 WF $433 \times 787$ in 012 in 1020 in Merernits less than 016 in thick are

ROLACELL $110 \mathrm{VIF} 433 \times 787$ in OTO in $10177 \mathrm{n}$

ROA

Application:

- A.créc: combosne struclure

- He coste: roto. blades

- High tempera:ure suppor structures

- Egge members lor honeycomb

- Winding and looling mandrels

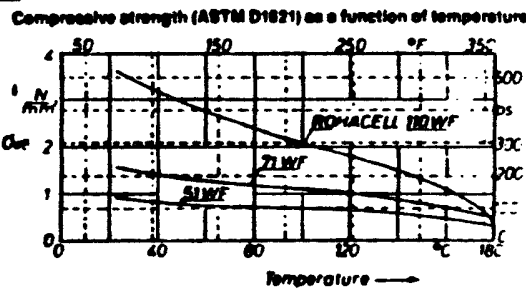

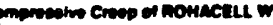

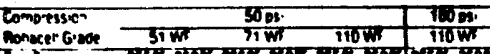

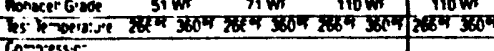

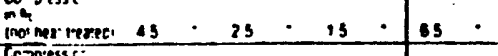

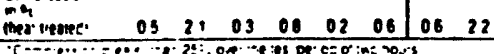

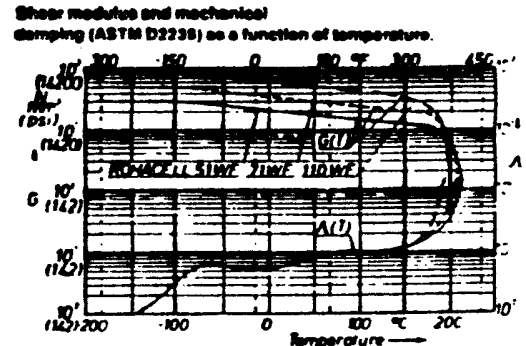

\section{"rohacell PMI foom}

Chemical Resistance

ROHACELL is resistani to many organic solvents

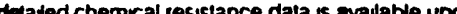

request

Fiammability Donte

ROHACELL produces a small amoum of omoke as burns but the lumes do no comban corrosive

peoducts of ROHACELL are no more loxic than

mose od burning wood. when lested according to

cocepled procedures the burning behavior varies

mong grades and debends in part on the thickness ot the material and the lacing materials When provded an subes Daragraph 25853 (a) and (b)

Characterigtice

Mochining. ROHACELL can be mochined on high speed woodworking and plasics machines Spect All product dus! should be removed trom the area

DUring machining
ROHACELL should nol be cul using a neated itla. men' since harmilui vapors may be formed

Thormotorming. ROHACELL loams are readily

mermolormed a: temperalures of 320

$\begin{array}{ll}\text { IG } & 320^{\circ} \mathrm{F} 10360^{\circ} \mathrm{F} \\ \text { WF } & 400^{\circ} \text { } 10420^{\circ} \mathrm{F}\end{array}$

WF nea: rrea'ec $410^{\circ} \mathrm{F}$ 10 $440^{\circ} \mathrm{F}$

However since the hear retention of the materval is

In addrito- 10 simple forming and shaping with de and carr, block ROHACELL can be formed by vacuum inermolorming blow molding and vacuum bag lechniaues
These methods

can be used to a limined extert tor 政

Meal Trealing of ROHACELL WF

The processing behavior of ROHACELL WF an ole

(a)

51 WF-4B hours at $360^{\circ}$

71 WF -48 hours al $360^{\circ} \mathrm{F}$
$110 \mathrm{WF}-20$ hours al $320^{\circ} \mathrm{F}$ and 28 haurs at $36 \mathrm{C}$ of

$200 \mathrm{WF}-20$ hours at $320^{\circ} \mathrm{F}$ and 28 hours at $360^{\circ} \mathrm{F}$

300 WF-24 houts al $360^{\circ} \mathrm{F}$

Hea: treated ROHACELL WF should enther be used

promply slored in a mosture impermeable titn

pouch or kept in an oven al 140\%.

Prot 10 torming or hea: trealing predry

ons iost

Conding. Most commercial adhesives are sunable Polvester and epoxy resins give lirm ngrd bonds o make sure the cells ave properly iflled with the bonding resin

Symthelic rubber based solvem adhesives are also trom adhesive systems musi be permined to hash on belore assembly as ROHACELL very ressistant to solven diflusion

porteriels in com.

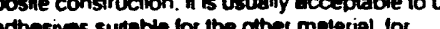

example
Metals-Epoxy resins. rubber or polyurethane methesives.

Acryic sheet-Morhecryic resins.

Fiberglass reintorced polyester (FRP) sthet-

Polyester or epoxy res polyestyurher adhesves cured skins or may be co-cured as required

noiming or vornienting. All commercial paints varnishes. end lacquers. including nirocellulose acauers may be sprayed or brushed onlo ROHACELL For a smooth. plassy surlace the material is lilled and sanded The high heal resistance of ROHACELL even allows coating with

FAP Lominatos. Usual laminating methods may be used $e 9$. hand lay up itber soreys and molding gosd peel strength ROHACELL loam can be CO

SinC ROHACELL LOm resst5 Styren

mecessery to seal its surtace when polyesier is nor are used

Thermophentes. ROHACELL toem may be co-moldeo whth both renthorced and unternforced imermoplasics Please contact ou

Important Notice

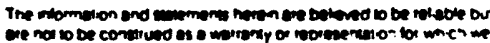

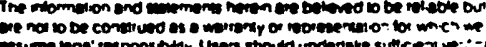

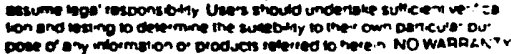

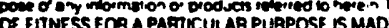

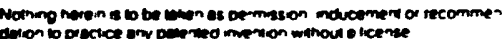

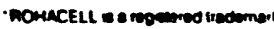

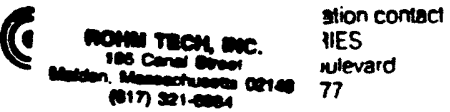


GEM TN-93-494

\section{Epoxy Filler Materials}

Contents:

Data sheet, Fiberite $954-3$ cyanate resin, $350 \mathrm{~F}$ cure temperature (2 pages)

Data sheet, Hexcel F185 epoxy resin, 250F cure temperature (6 pages)

Data sheet, Fiber-Resin FR-337/338 carbon or aluminum fiber reinforced RT epoxy (2 pages)

Data sheet, Ciba-Geigy Eprcast 1617 A/B syntactic RT epoxy (1 page)

Data sheet, Grace Eccofloat TG-24/24A low density syntactic (2 pages)

Mechanical data, Anocast low density syntactic (1 page)

Material comparison chart, Ref. GEM TN-93-460 (1 page)

\section{Summary:}

- Alternative material choices show the most promise of achieving mass reductions without compromising chamber stiffness and without increasing design complexity. Materiais having high stiffness-to-density ratios are needed only for load-bearing locations (under bolts, near support connections, etc.) thus requiring less material to carry a given load.

- Castable epoxies with high-modulus fillers are optimal for all load-bearing components.

- Ultra-low density materials are optimal for lightly loaded components.

- An optimal cathode strip chamber structural design simultaneously minimizes muon scattering (mass effects), shear deformations, gravity sag, stress levels, and complexity.

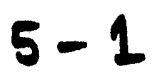


A Data Shoot from

\section{icl Fiaith}

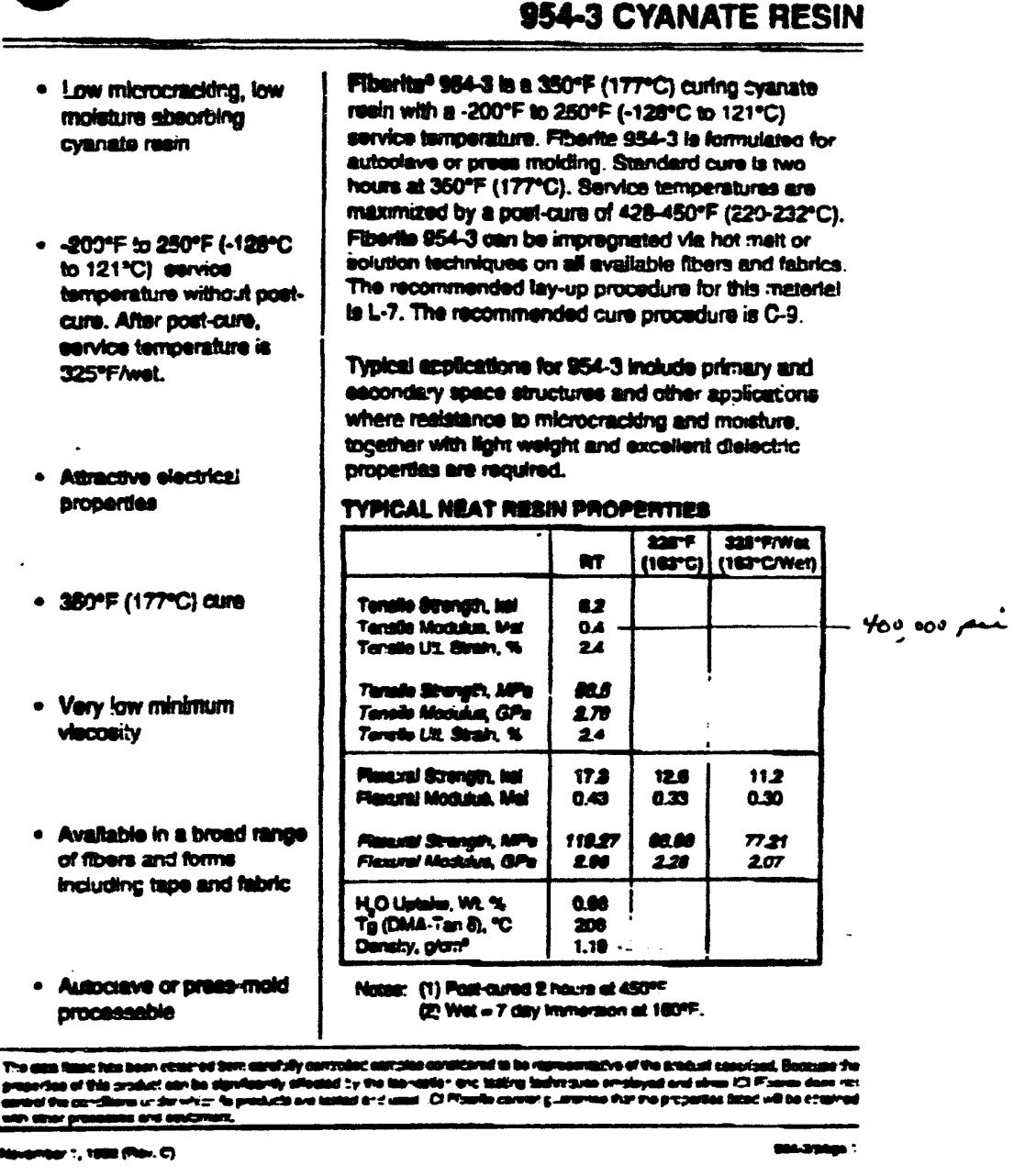

\section{A Dats Shoat from \\ (19) FiBgarta \\ FiBeATIZ० 054-3 \\ CYANATE RESIN}

Domovionel etamm

\begin{tabular}{|c|c|c|}
\hline \multirow[b]{2}{*}{ 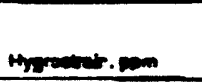 } & $m$ & en \\
\hline & on & weses \\
\hline 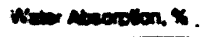 & e.10 & aro \\
\hline Cxe doms & ios & 106 \\
\hline
\end{tabular}

10.05:

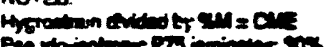

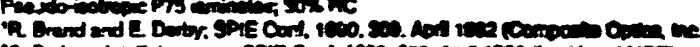

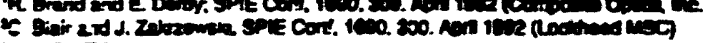
som nuteo

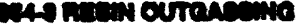

\begin{tabular}{|c|c|c|}
\hline & mas & im \\
\hline Tom & asen & $10 \mathrm{x}$ \\
\hline 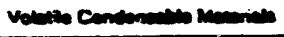 & Dork & a.r.x \\
\hline 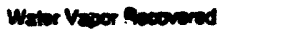 & $\operatorname{cosen}$ & - \\
\hline
\end{tabular}

Tores:

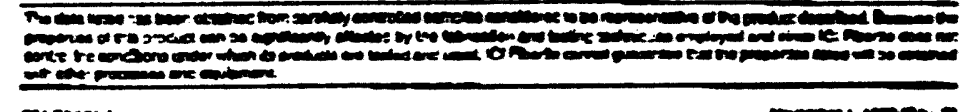

2 of 2 


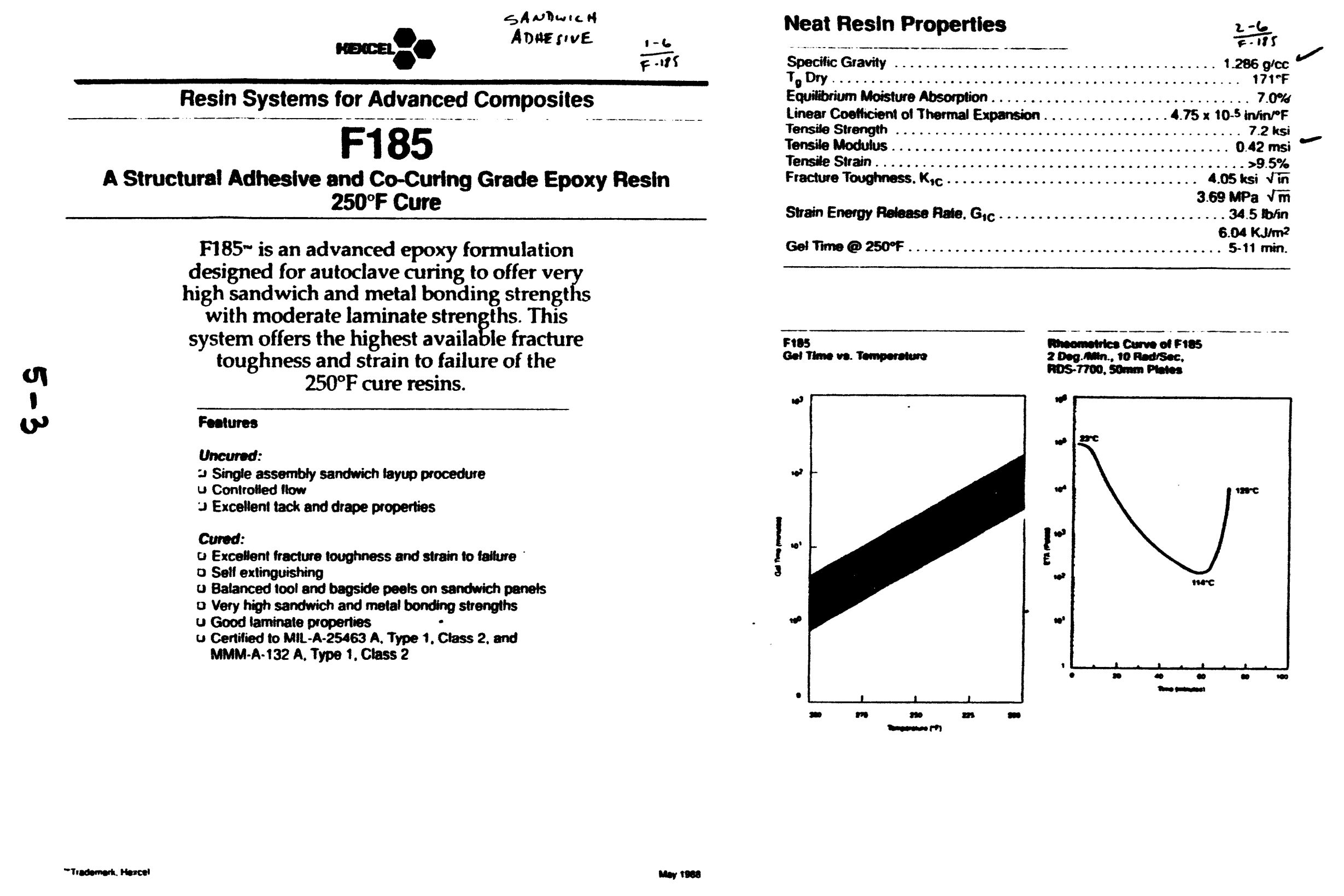



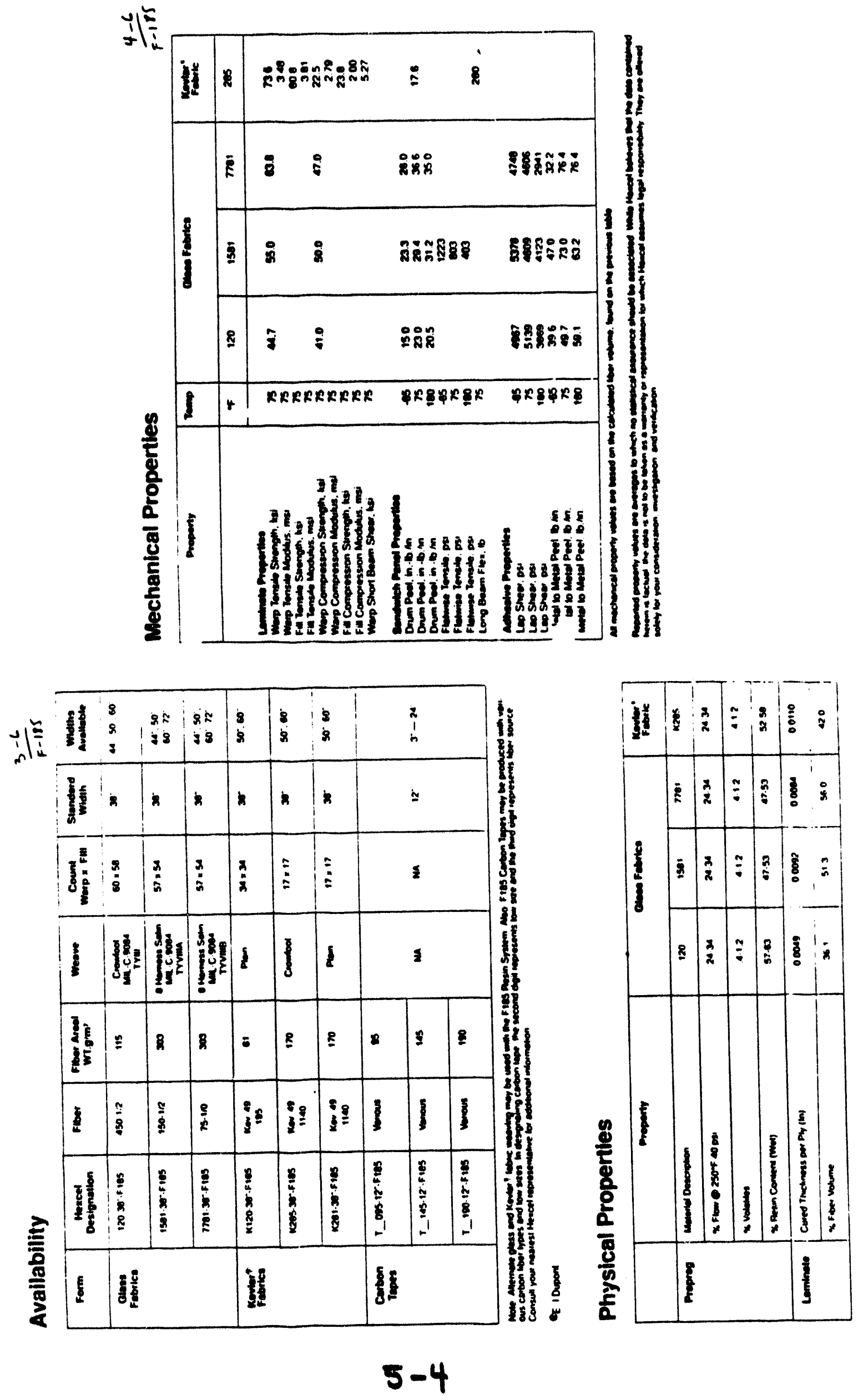


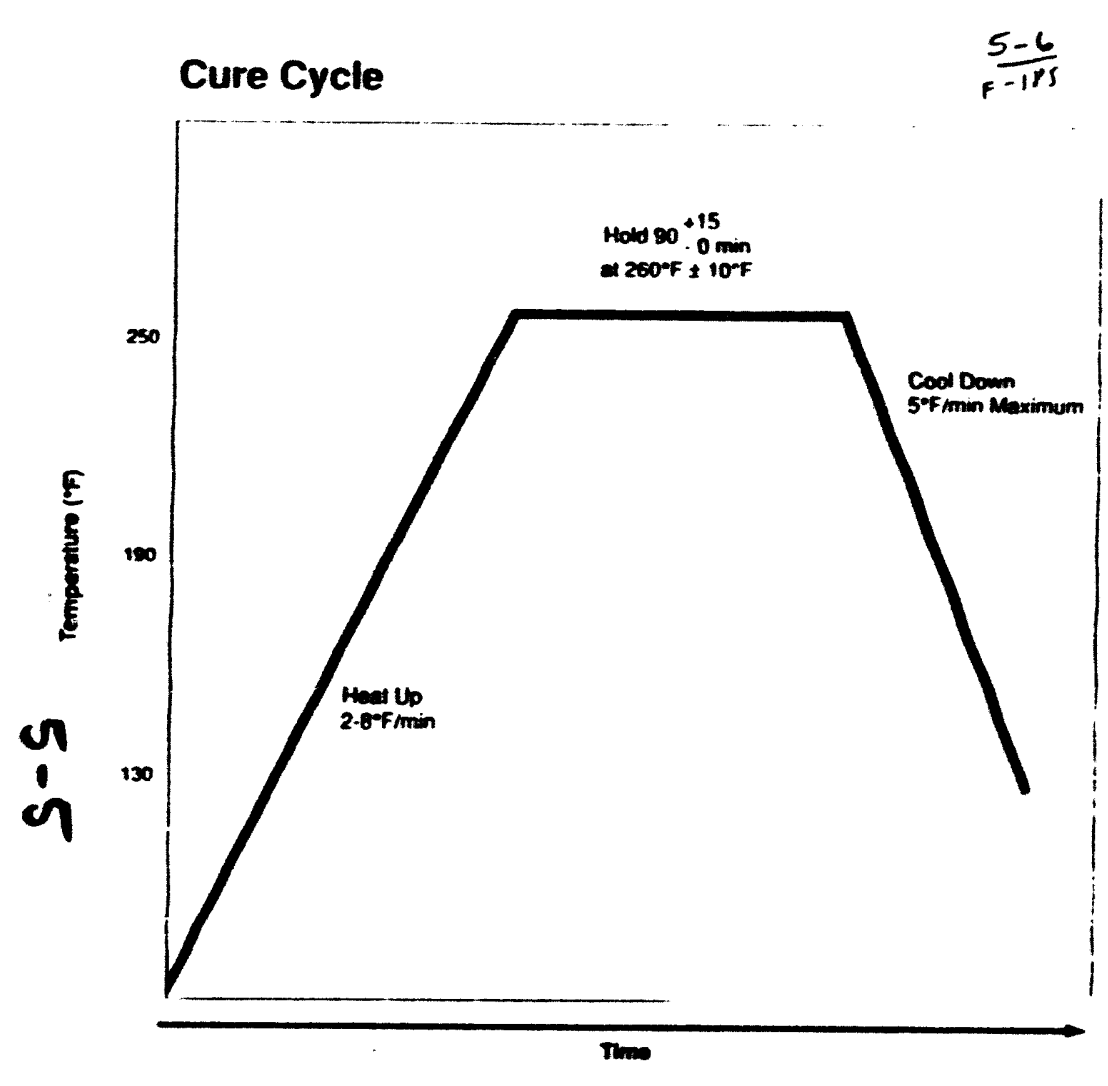

\section{Cure Procedure:}
A. Apply vacuum of 22 inches Ho minimum.
B. Apply $85+15$ - O PSIG pressure for laminetes.
C. Apply $45+15$ - O PSIG pressure tor sendwich.
D. Vent vacuum beg to almosphere when pressure reaches 20 PSI.
E. During cool down when the part temperature falls betow $140^{\circ} \mathrm{F}$. pressure can be relieved and the lest panel removed from the autoctave and debagged
-Typical tor HAH 10-1/8-3.0 honeycomb.

Handing Solety

$6-6$

The Hexcel Corporation recommends that each of its customers observe

established precautions for handing epoxy resins and ine fibrous materiats

Operators working with this product should wear clean impervious gloves to reduce the possibility of skin contact, also to prevent contamination of the

material.

Aittorne graphile es a resull of sawing. grinding. enc. can present eloctrical shorting hazards. reler to NASA Technical Memorandum 78652. For turther Intormation reler to the Material Salety Data Shoet.

\section{Sterese}

F185 prepreg should be sealod in a polyethylone beg and relingeraled, preter-

ably below $32^{\circ} \mathrm{F}\left(0^{\circ} \mathrm{C}\right)$. Following renol

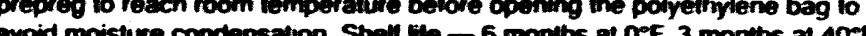

Shipping

Prepreg tabric and tape is conerally shipped in a sealod polyethylene beg in an insulated container packed with dy ice.

Olsposel of Serep

Disposal of this material should be in a secure bandili in accontance with State and Federal regulations.

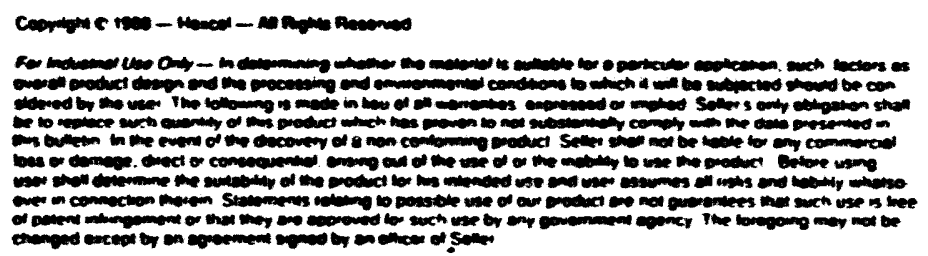

(1)

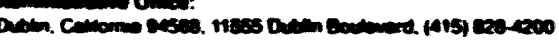

Thencos:

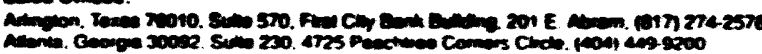

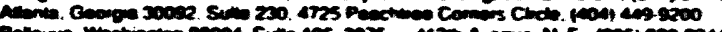

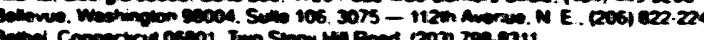

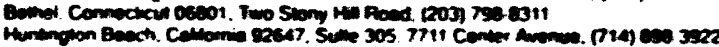

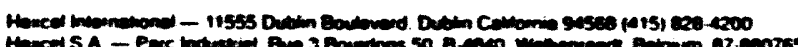

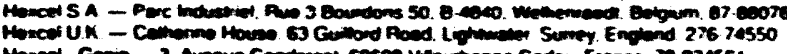

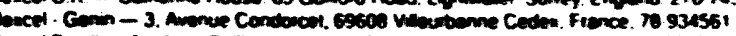

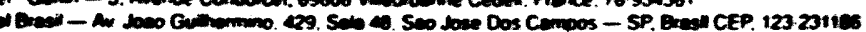




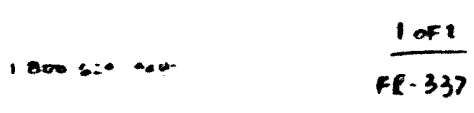

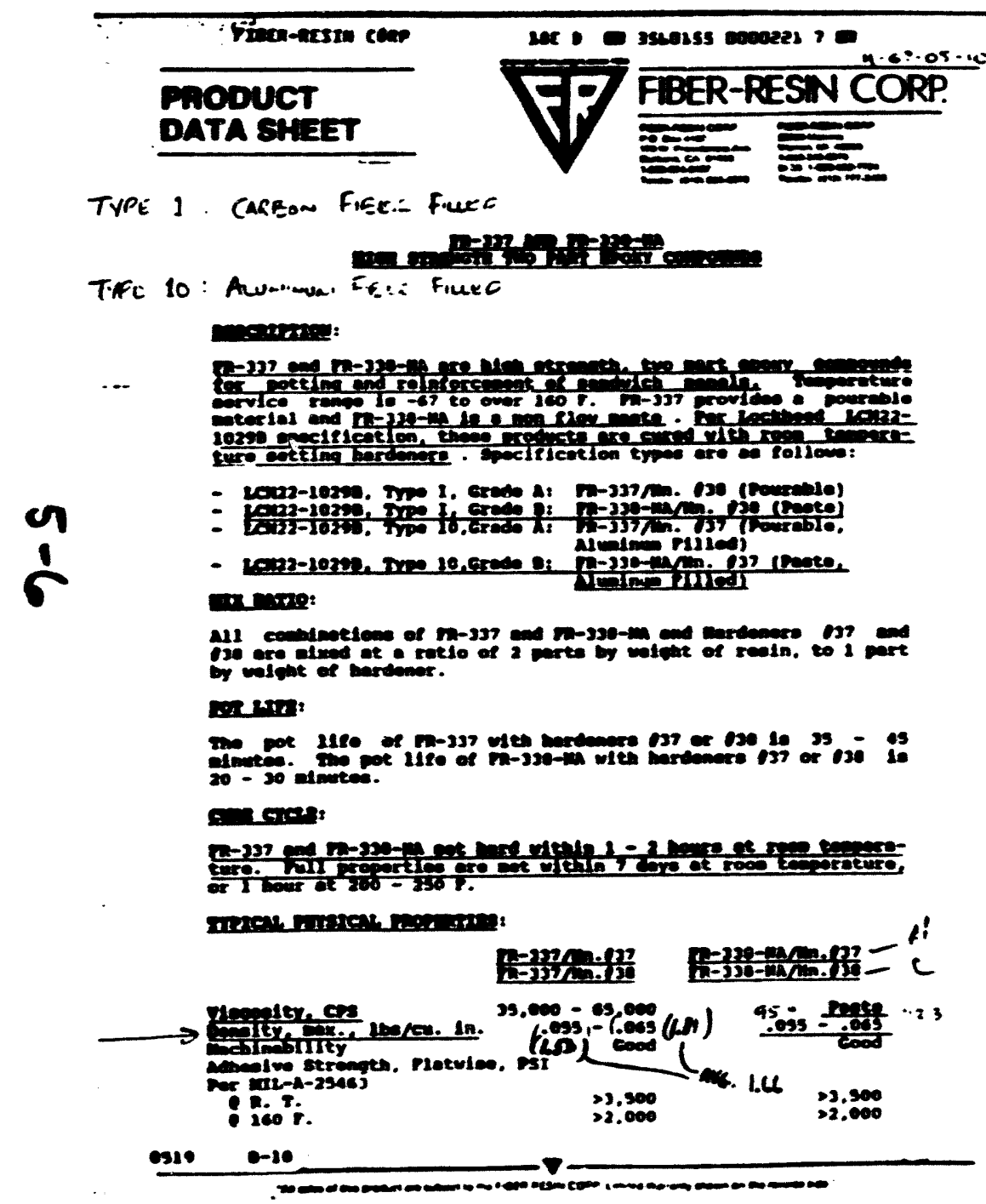

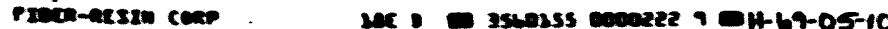
$2 \propto 2$

$m-337-330-m$

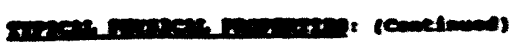

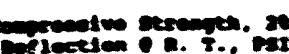

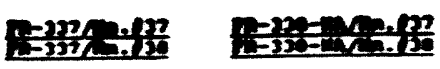

'>15.000 $>25.000$

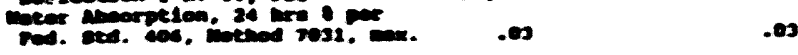

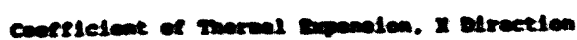

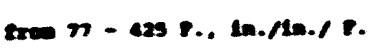

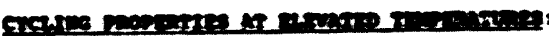

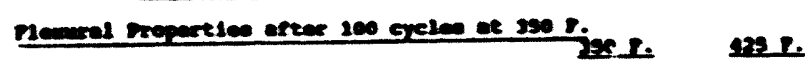

armen. 109

mener. 43.500 .20 .000$.

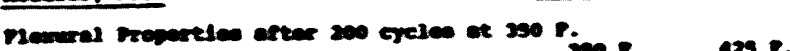

orengem,

2010

20252.

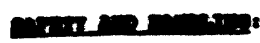

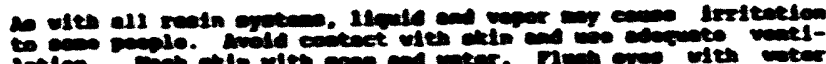

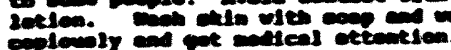

$\infty$ 


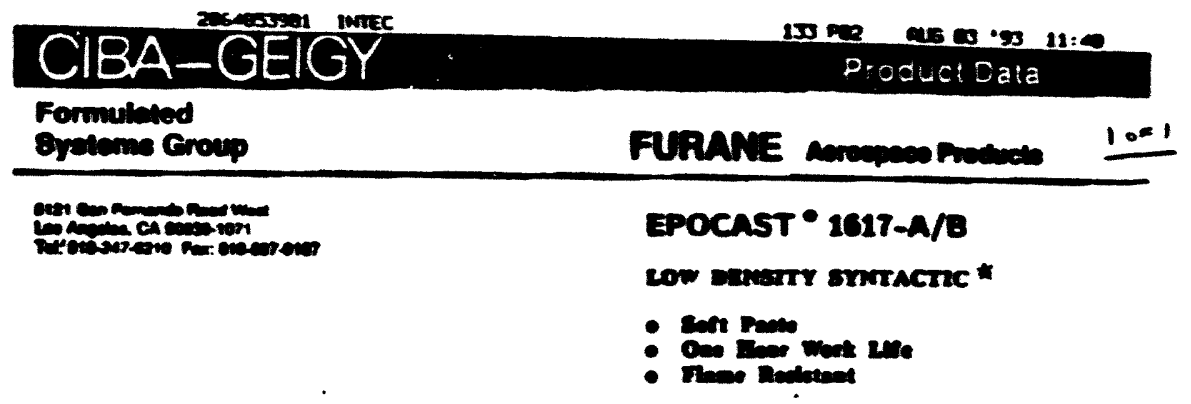

scarismon

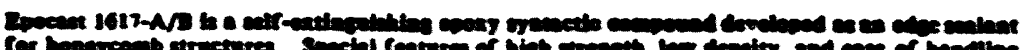

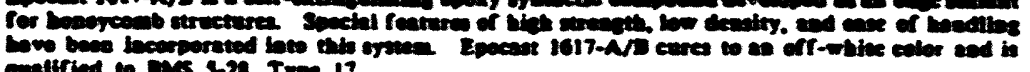
thes trat 17

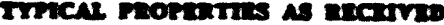

Eomeder

Colotiric grovity

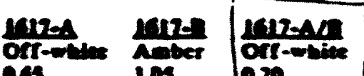

Theonth owity

Then point COC. $T$

tort iffe, 100

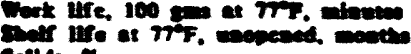

ortes

20030.000

ine

rene

colthe

$\operatorname{sex}$ antro

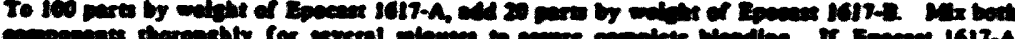

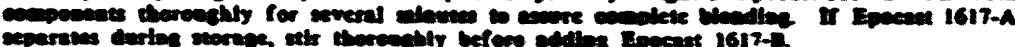

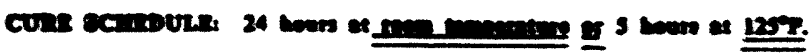

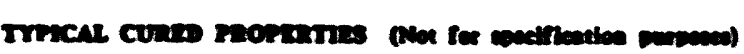

Com

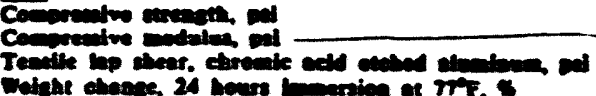

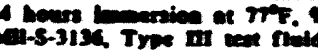

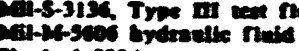

Dryedeol sean

Panemanumy

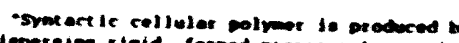

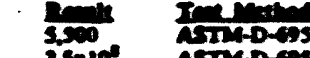

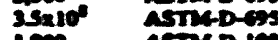

$\cos$

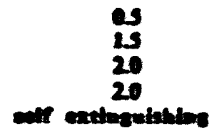

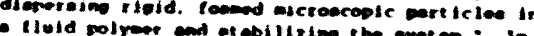

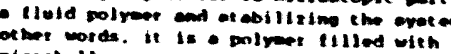


GRACE Syntactics

betra-ken ocosirn sminctic

$l=0.20 \%$

$E=0.18 \mathrm{mIL}$

\section{EGGOFBOAT TG.2AA}

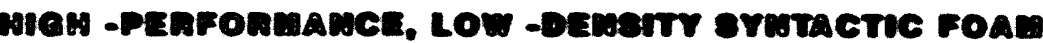
Eccoflont ro-2eA we wy wh

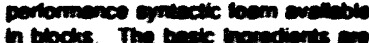
hydrospece-quality oless microbentoonse and mon-atrementon

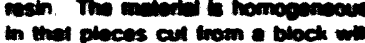
have the eamo properties as in ortenest block. except bor surteco

Caras

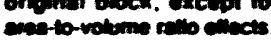

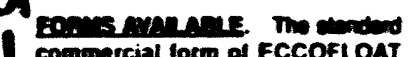

1G.2A

TG-24A ls molded becks ond hal

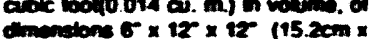
$305 \mathrm{~cm}=30.5 \mathrm{~cm}$ L 122 . $15.2 \mathrm{~cm}$ be mado by eolmative bondton or mochanicat extachment of those

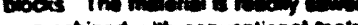
of machined winc convertionet wols. any preparation belote vese. Hendueve can bo menched wim bolls arechesive.

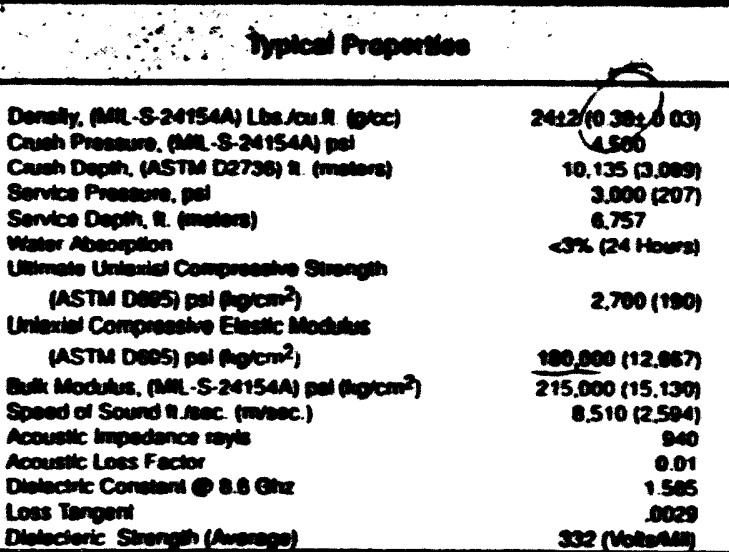

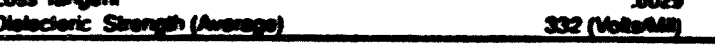

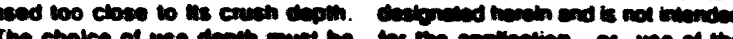

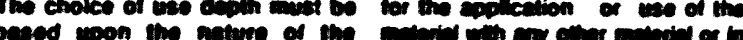

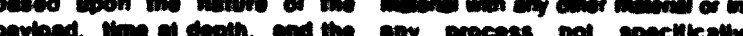

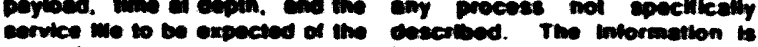

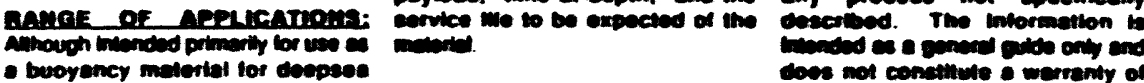
- buoyency melertal lor doppase.

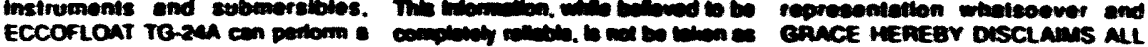

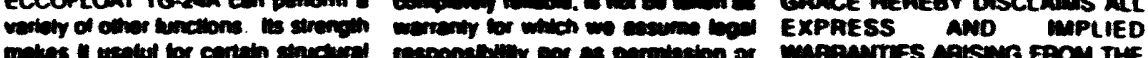

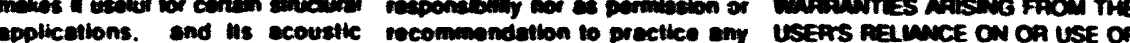

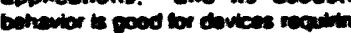
remeperency to sound in sea wate. wech as coner underews

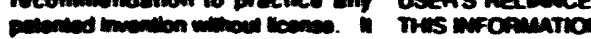

- olloved tor comalidoration.

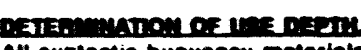

All syntactic buoyency materiats

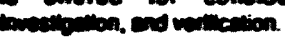
aram

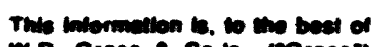

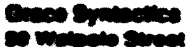
com minemeses

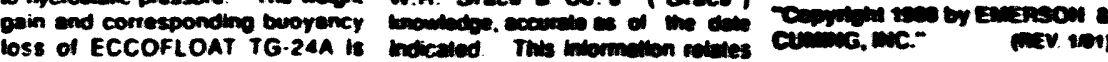
emell. provided the meterial is mot only to the sepecilic meteriel

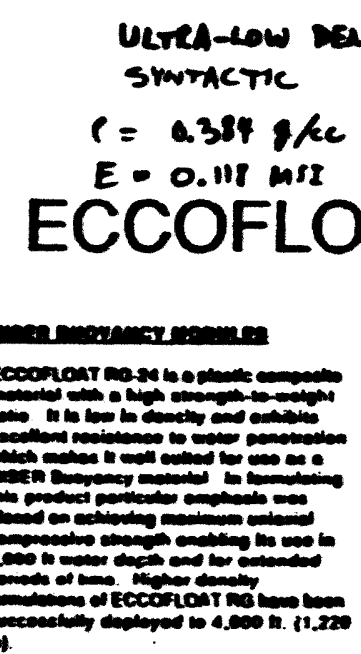

concunaserim

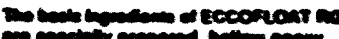

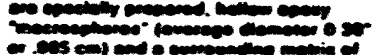

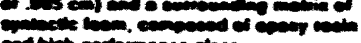

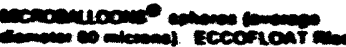

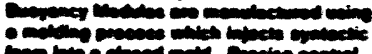

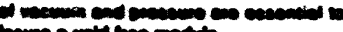

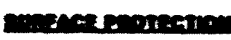

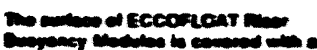

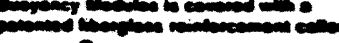

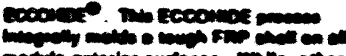
eccoinot (1) 19

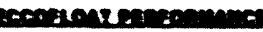

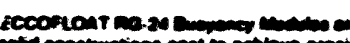
-

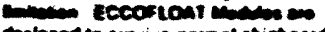

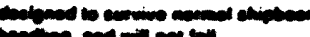

$2 \circ 2$

GRACE Syntactics

\section{$T^{\circledR} \mathrm{RG}-24$}

\begin{tabular}{|c|c|}
\hline Mornined Dansity, befau. fl (o/c) & $24(.384)$ \\
\hline 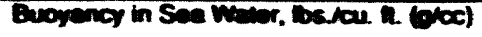 & $40(641)$ \\
\hline 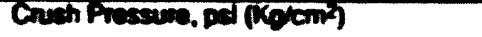 & $22.00(154.7)$ \\
\hline 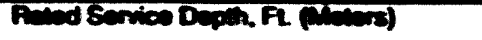 & 3500 (019) \\
\hline 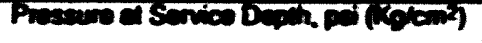 & 1300 (2035) \\
\hline 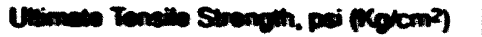 & $520(36.6)$ \\
\hline 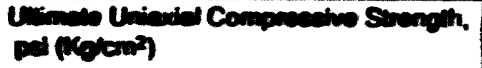 & $2010(241.3)$ \\
\hline 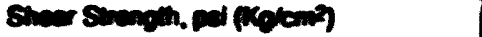 & 1000 (74.5) \\
\hline 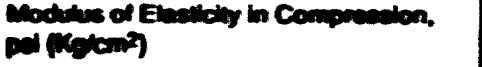 & 112.600 \\
\hline
\end{tabular}

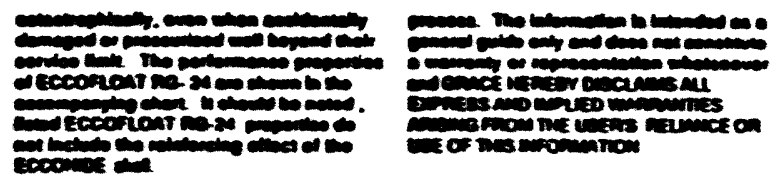

menom

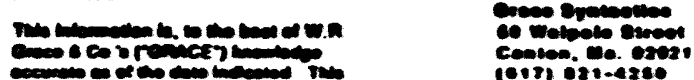

(2)

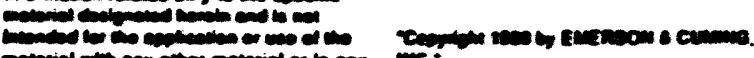




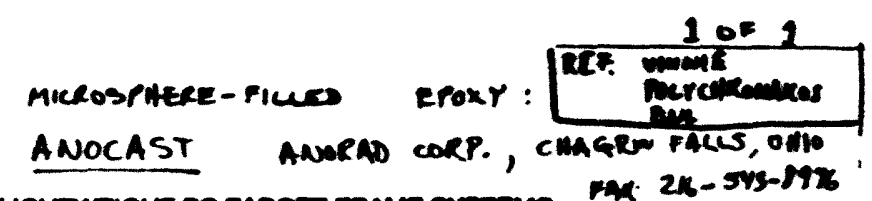

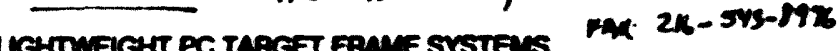

\begin{tabular}{|c|c|c|}
\hline \multirow{2}{*}{ PAOPEATY } & \multicolumn{2}{|c|}{ STSTEM } \\
\hline & 1 & 2 \\
\hline 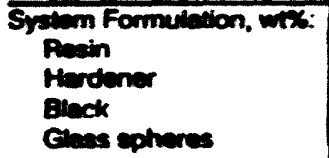 & $\begin{array}{c}30 \\
0 \\
1 \\
37\end{array}$ & $\begin{array}{c}94 \\
2 \\
24\end{array}$ \\
\hline Flewre Stengen, pai & 1225 & -- \\
\hline $\begin{array}{l}\text { Finoud Modutus of } \\
\text { Elasticity. psi }\end{array}$ & 139,500 & -- \\
\hline Compressivo Strengh, psi & 1755 & 3925 \\
\hline Young's Modutus, psi (E) & 99.395 & 142,700 \\
\hline Densily, lo/cu in & $\begin{array}{c}26.2 \\
(0.42)\end{array}$ & $\begin{array}{r}34.6 \\
(0.55)\end{array}$ \\
\hline Water Absorption, wix & & \\
\hline
\end{tabular}

\section{Mreast an.}

(Denulus Sumer)

$216-593-7975$

Dor aneracer

cAst or vize

Dut ow Be

Wirt preser

instrkeriem"

For. Yount's moveres $=E=98,395 \mathrm{mi}$

m rexwerle modutor $=E_{f}=139,500 \mathrm{mi}$

THEN, $\gamma=0.317$

where $E_{f}=\frac{E(1-\nu)}{(1+\nu)(1-2 \nu)}$ 
1 of 1

\begin{tabular}{|c|c|c|c|c|c|c|c|c|c|c|}
\hline \multicolumn{11}{|c|}{ Edge fillers (normallzed to G10 woven laminale) } \\
\hline maloctal & $\begin{array}{c}\text { tho } \\
\text { densilyy } \\
(g / \mathrm{cm} 3)\end{array}$ & $\begin{array}{c}E \\
\text { modulus } \\
\text { (kst) }\end{array}$ & $\begin{array}{l}\text { n } \\
\text { radiation } \\
\text { longth } \\
(\mathrm{cm}) \\
\end{array}$ & $\begin{array}{c}\text { n.ho } \\
\text { normatzed } \\
\text { density }\end{array}$ & $\begin{array}{c}n E \\
\text { normalked } \\
\text { moduluss }\end{array}$ & $\begin{array}{c}\text { n.I } \\
\text { normalized } \\
\text { radiation } \\
\text { length }\end{array}$ & 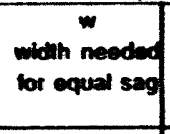 & $\begin{array}{l}m 1^{\circ} \\
\text { rower is } \\
\text { boller) }\end{array}$ & $\begin{array}{l}\text { ma" } \\
\text { (lower on } \\
\text { boller) }\end{array}$ & $\begin{array}{l}\text { nomalized } \\
\text { rhore }\end{array}$ \\
\hline Fiber-Aealn (FA-337) & 1.66 & 5.000 & 34 & 0.86 & 1.52 & 1.75 & 0.66 & 0.38 & 0.32 & 0.57 \\
\hline G10 woven leminate & 1.926 & 3.300 & 19.4 & 1.00 & 1.00 & 1.00 & 1.00 & 1.00 & 1.00 & 1.00 \\
\hline glass tiber fllled epoxy & 1.85 & 1600 & 21.2 & 0.96 & 0.48 & 1.09 & 2.06 & 1.89 & 1.81 & 1.98 \\
\hline Clba-Golgy $(1617) *$ & 0.7 & 350 & 56 & 0.36 & 0.11 & 2.89 & 9.43 & 3.27 & 1.19 & 3.43 \\
\hline $250 f$ epoxy (954-3) & 1.19 & 100 & 55 & 0.62 & 0.12 & 2.84 & 6.25 & 2.91 & 1.60 & 5.10 \\
\hline Anocast low-dens. & 0.42 & 100 & 91 & 0.22 & 0.03 & 4.69 & 33.00 & 7.04 & 1.53 & 7.20 \\
\hline \multicolumn{11}{|c|}{ (estimales bolow based on $25 / 75$ ratio of S102/Epoxy) } \\
\hline Cloa-Getgy (1617) & 0.7 & 350 & 66 & 0.36 & 0.11 & 3.40 & 9.43 & 2.77 & 1.01 & 3.43 \\
\hline Anocast low-dens. & 0.42 & 100 & 107 & 0.22 & 0.03 & 5.52 & 33.00 & 5.98 & 1.30 & 7.20 \\
\hline
\end{tabular}

Core Materlals (normalized to Hexcel HAH-1-1/B/1.)

\begin{tabular}{|c|c|c|c|c|c|c|c|}
\hline \multicolumn{8}{|c|}{ Core Materbals (normalized to Hexcel HAH-1-1/RI.n) } \\
\hline matertal & $\begin{array}{c}\text { tho } \\
\text { densthy } \\
(g / \mathrm{cm} 3)\end{array}$ & $\begin{array}{c}\mathbf{G} \\
\text { shoer } \\
\text { modulus } \\
\text { (kst) }\end{array}$ & $\begin{array}{c}\text { "l } \\
\text { radization } \\
\text { longth } \\
(\mathrm{cm})\end{array}$ & $\begin{array}{c}\text { normalized } \\
\text { density }\end{array}$ & $\begin{array}{l}\text { normalized } \\
\text { shear } \\
\text { modulus }\end{array}$ & $\begin{array}{l}\text { normalized } \\
\text { rediallon } \\
\text { length }\end{array}$ & $\begin{array}{l}\text { normallized } \\
\text { tho/s }\end{array}$ \\
\hline Aohacell 31 IG & 0.0305 & $\begin{array}{l}1.99 \\
3.50\end{array}$ & 1.400 & 1.06 & 0.5686 & $\begin{array}{l}1.00 \\
1.00\end{array}$ & $\begin{array}{l}1.86 \\
1.00\end{array}$ \\
\hline
\end{tabular}

REF. GEM TN-93-460 


\section{Radiation Length}

Contents:

Radiation length data for selected materials, ref. M. Marx, SUNY SB (1 page)

Routine for calculating rad. length of a compound, ref. T. Wenaus, LLNL (2 pages)

Radiation length estimates for typical CSC structural materials (1 page)

Summary:

Materials with high radiation lengths are most desirable for muon chambers. 


\section{RADIATION LENGTHS FOR SRLECTED MATERIALS}

$\begin{array}{lll}\text { REF. MIKE } & \text { MARX } \\ \text { SUNY } & S B\end{array}$

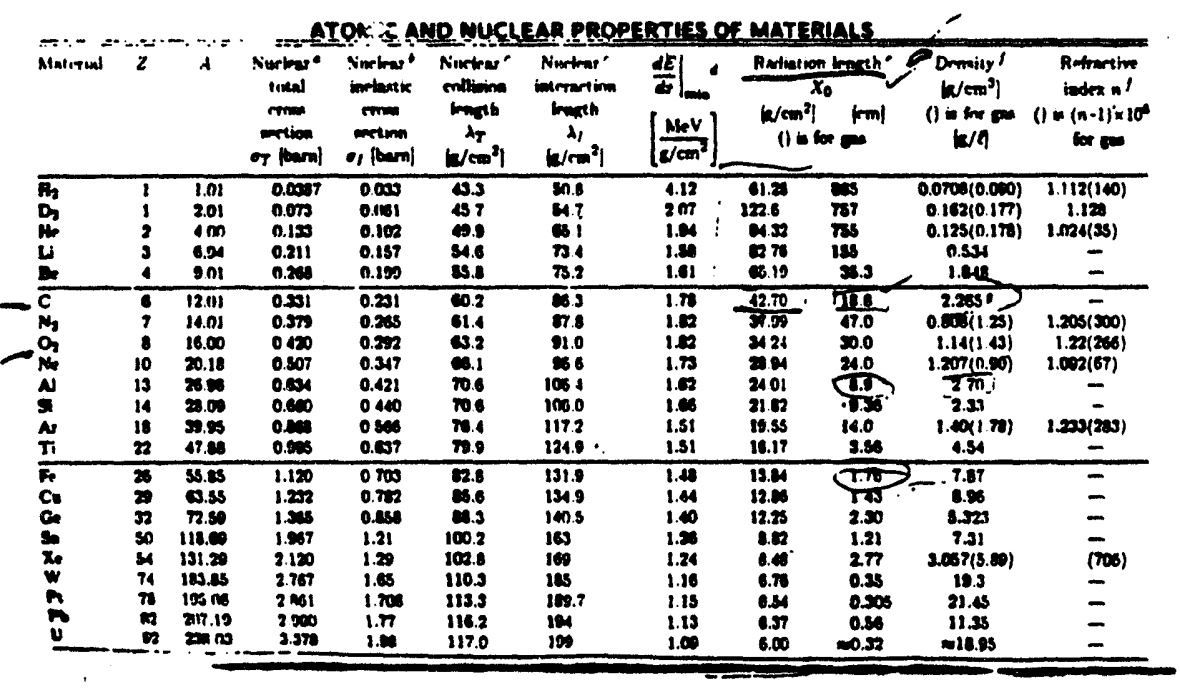

\begin{tabular}{|c|c|c|c|c|c|c|c|}
\hline 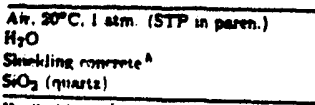 & $\begin{array}{l}62.0 \\
0.1 \\
67.1 \\
67.0\end{array}$ & $\begin{array}{l}901 \\
019 \\
99.9 \\
92 \\
92\end{array}$ & $\begin{array}{l}\lim _{2.10} \\
1.00 \\
1.72 \\
\end{array}$ & $\begin{array}{l}3.66 \\
x .100 \\
267 \\
27.06\end{array}$ & $\begin{array}{c}(30420) 10 \\
36.1 \\
10.2 \\
12.3 \\
\end{array}$ & 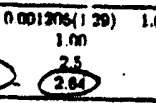 & $\begin{array}{l}1.00 \mathrm{~m} 79283) \\
1.20 \\
1.450 \\
\end{array}$ \\
\hline 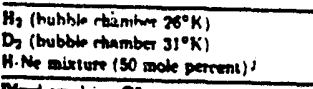 & $\begin{array}{l}49.3 \\
45.7 \\
6.0 \\
\end{array}$ & $\begin{array}{l}30.8 \\
34.7 \\
9.5\end{array}$ & $\begin{array}{l}4.12 \\
2.07 \\
1.04 \\
\end{array}$ & $\begin{array}{c}1128 \\
172.6 \\
7.70 \\
\end{array}$ & 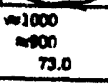 & $\begin{array}{l}=0.053^{\circ} \\
0.100^{\prime} \\
0.017\end{array}$ & $\begin{array}{l}2.100 \\
1.110 \\
1.002 \\
\end{array}$ \\
\hline 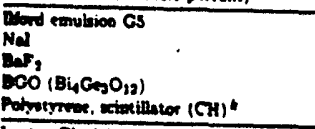 & $\begin{array}{l}6.0 \\
2.0 \\
2.1 \\
9.1 \\
94.4 \\
\end{array}$ & $\begin{array}{l}191 \\
132 \\
146 \\
136 \\
82.0\end{array}$ & $\begin{array}{l}1.44 \\
1.32 \\
1.35 \\
1.27 \\
1.06 \\
\end{array}$ & $\begin{array}{c}11.0 \\
0.0 \\
9.01 \\
7.00 \\
0.8 \\
\end{array}$ & $\begin{array}{r}2.00 \\
2.30 \\
2.06 \\
1.12 \\
4.1 \\
\end{array}$ & $\begin{array}{c}3.813 \\
3.67 \\
4.07 \\
7.1 \\
1.038 \\
\end{array}$ & $\begin{array}{l}1.7 \\
1.75 \\
1.46 \\
2.15 \\
1.501 \\
\end{array}$ \\
\hline 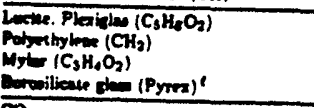 & $\begin{array}{l}60.2 \\
6.0 \\
6.2 \\
6.2 \\
\end{array}$ & $\begin{array}{l}0.6 \\
70.8 \\
05.7 \\
97.6 \\
\end{array}$ & $\begin{array}{l}1.26 \\
2.00 \\
1.06 \\
1.72\end{array}$ & $\begin{array}{l}0.35 \\
4.0 \\
20.06 \\
2.3 \\
\end{array}$ & $\begin{array}{r}0.4 .4 \\
-47.8 \\
29.7 \\
-127 \\
\end{array}$ & $\begin{array}{l}1.16-1.20 \\
0.22 \cdot 0.15 \\
1.10 \\
2.20 \\
\end{array}$ & $\begin{array}{c}1.40 \\
\overline{-} \\
1.474\end{array}$ \\
\hline 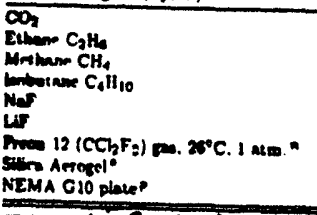 & 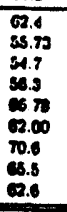 & $\begin{array}{l}90.51 \\
75.71 \\
71.0 \\
7.4 \\
9.37 \\
108.24 \\
10.7 \\
\infty .2\end{array}$ & $\begin{array}{l}1.08 \\
2.25 \\
2.11 \\
2.20 \\
1.06 \\
1.06 \\
1.62 \\
1.07\end{array}$ & 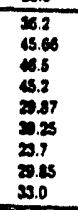 & 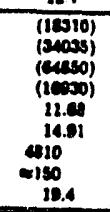 & 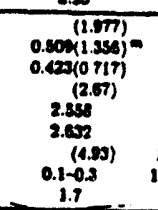 & $\begin{array}{c}(410) \\
(1.004) \\
(44) \\
(1270) \\
1.206 \\
1.002 \\
1.001000 \\
1.0+0.230 \\
-\end{array}$ \\
\hline
\end{tabular}


REF. TORRE WENAUS, GLNL

FORTRAN ROUMNE FOR COMPUTING RADAMION LEMTHA

\section{- Compute radiction longthe of compound miderialo.}

paramater (relenava.0470) I Palectron”-2"Navogadro aructure /doment

nats

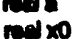

charector 15 name

and enructure

Ancturo /compound

inceger natom

record /olomonte

recordr

C.HONS

mecord /compound autil(20)

perambier (n_rohecolles)

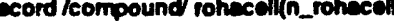

Rothechl e =

\section{paraneter (n_alozen)}

record/compound alo2(n_tio2)

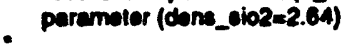

apha=1/137.

C.Z

C. $A=12$.
C.XO-42.7

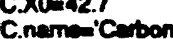

C..nem

H.A.

H.X0=61.20

H.narne-Hydrogen

$0.2 \times 6$.

$0.4=16$.

O.neme-'Oxyoen'

N.nem.

Nanicic

N.X0 37.90

N.neme-Ninrogen'

$S i Z=14$.

SiA $=28.00$

Si.X0-21.82

Si.name'Sllicon'

rohecell(1).etrac

rohecollt(1).nation

rohecel(i).

) Rohacell

rohacelll(3). $(3)=0$

roherall(3). natom

rohecell (4). Ot=N

POLYMETHACRYLIMIDE

$\mathrm{C}_{9} \mathrm{H}_{13} \mathrm{O}_{2} \mathrm{~N}$

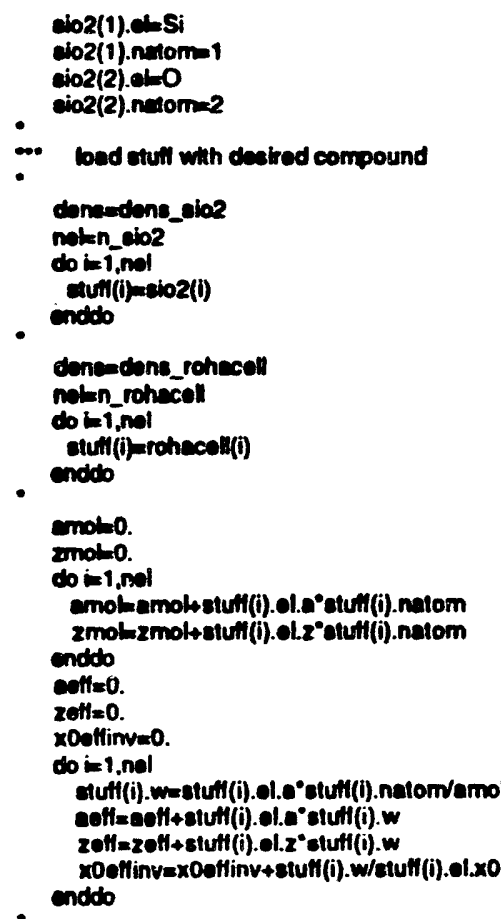

c. bed efull whth deatrod compound

conemdene_atior

noten_eio2

do $i=1$, nol

indio

denemedona_rotiecel

neten_rohecell

sturf (i) =rohecelly

- chodo

amoleo.

do $i=1$, nol

emolemolestutitio el a atum(i).netom

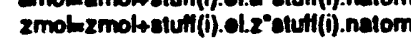

endito

celts $=0$.

zethe $=0$.

xodflimua.

$d 0=1, n a l$.

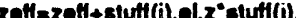

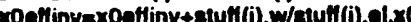

enddo

\section{azeabha'zoff}

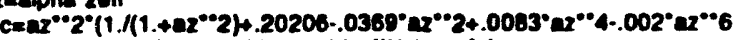

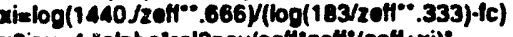

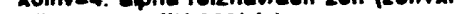

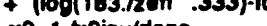

costrolnotions

print 'Material conetituente:

do i=1,nel

print "atutl(i).ol.namo,'Natomaz:'stut(i).natom

inddo

.print $\cdot$,az, lc,xi,xoinv, amol

print ":XO in cm. Formula: ':xO,' Woighed mixture: 'xOelf

end

Torro Wonaus LUNL GEMLI3 wonaus Olini.gov Paniculars: linger wonaus ellnl.gov
2 of 2

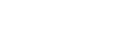




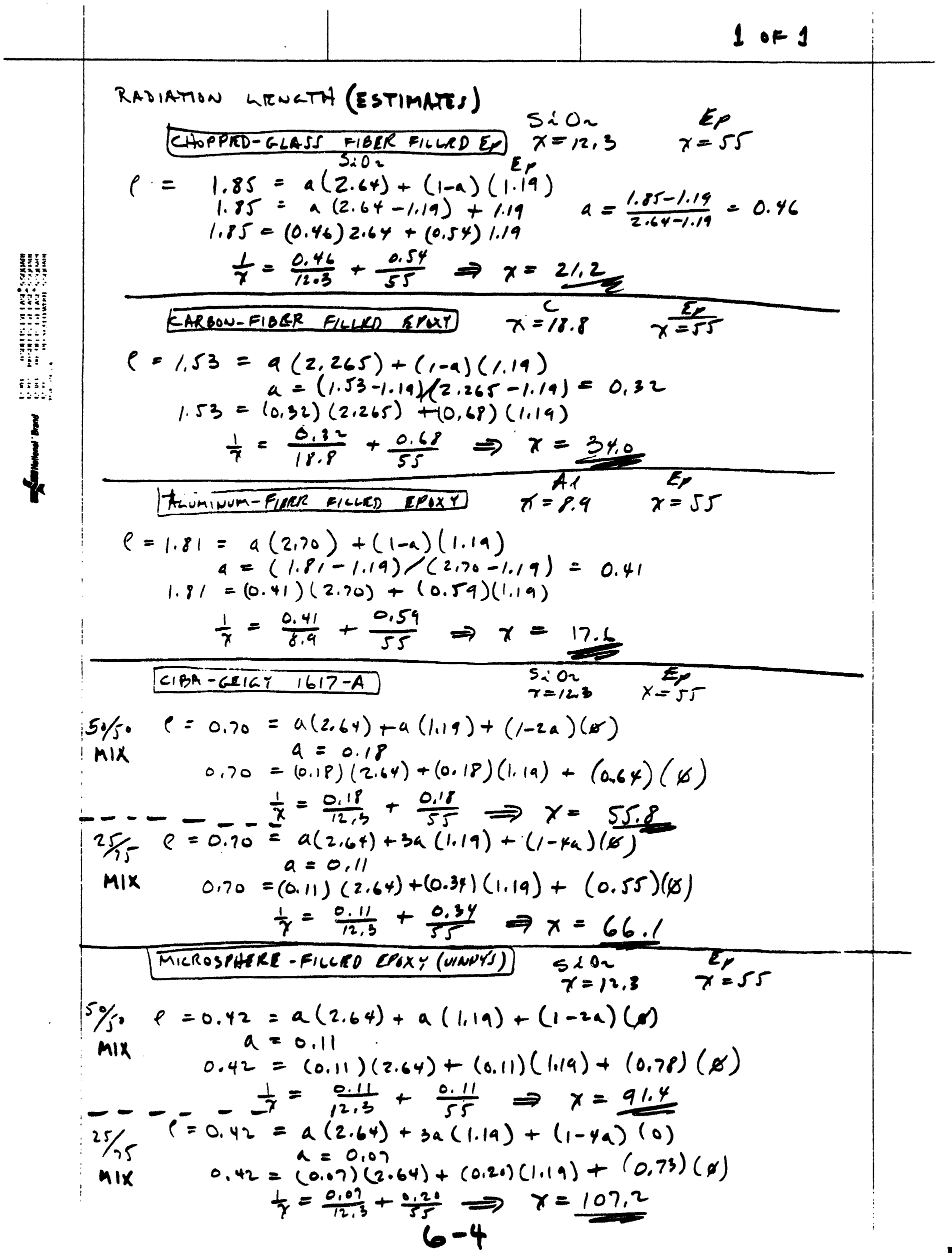


GEM TN-93-494

\title{
7. Comparison of Gap Frame Designs and Materials
}

\author{
Contents:
}

Analyses and recommendations regarding chamber gap frame design (18 pages)

\begin{abstract}
Summary:
An original design of a discrete post gap frame by Anatoly Gordeev is compared to the continuous gap frame design of the TDR Baseline chamber.

Ultra-low density castable materials suggested by Vinnie Polychronakos are compared to other syntactics and filled epoxies.

A method of determining the relative desirability of chamber materials in load-carrying and non load-carrying applications without detailed structural analysis is presented.

Based on comparative analyses, recommendations are made for the applicability of these suggestions in the context of maintaining adequate shear rigidity and minimum mass.
\end{abstract}




\section{Tnble of Contents}

1 of 18

1. Summary, and Conclusions

2. Background and Introduction

Fig. 1: Shear Deflection Due to "Slippine"

作

3. How Chamber Structure Innuences Gravily Sag

Tatile 1. Effectiveness of Chamber Components in "Pure Bending"

4. Evaluatton of Moterials

Fig. 3: Beam Used for Materisl Comparisons Table 2. Material Comparison

5. Comparison of Continuous and Discrete-Post Gep Frames Fif. 4: Quarter-Symmetric Finite Element Model

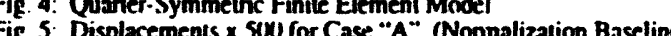

Tahle 3. Comparison of Gap Frame Designs and Materials

Fig. 6: Displacements $x$ Sixil for Case "H" Showing Loss of Gap Uniformity

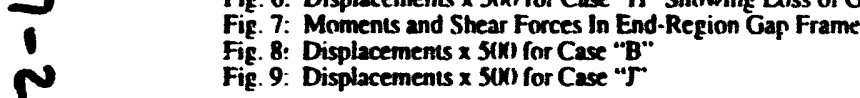

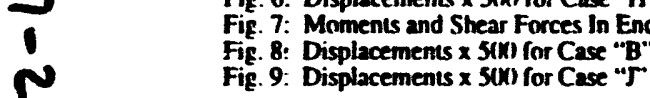

6. Continuous Gap Frame Detalls

Fig. 10: Isometric View of Continuous Gap Frame

7. Discrete-Post Gap Frame Detalls

Fig. 11: Isometric View of Discrete-Post Gap Frame

Fig. 12: Cross Section of Stack of Panels With Post

Fig. 13: Cross Section of a Discrele Post

Fig. 14: Lyonut of Perimeter Electronics for Ouver Superlayer CSC

8. Loads and Stresses
Fic. 16: Load and Shear Force Distribution

9. Practical Considerations

0. Design Recommendations

Fig. 17: Cross Section of Recommended Edge Design

11. Further Design and Amalysis Tasks
1. Summary, and Conctusions

The following key points summarize this paper:

- The reductions in chamber mass achieved by incorporating small. discrete posss in the gap frome cises

- Altemative material choices incorporared in a contimour gap frame design show the most promise of achieving mass reductions withour compromising chamber stijfmess and withou

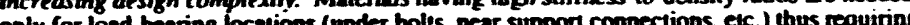

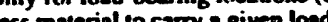

- Caseable epoxies with high-modulus fillers are optimal for all boad-bearing components of the gap frame region.

- Ultra-low- density materials are optimal for lightity loaded components.

- An optimal cathode strip chamher gap frame design simulrameous/ $y$ minimizes muon scanering (mass effects), shear deformations. gravity sag. stess levels. and complexity.

In addition. from the design perspective it is important to avoid clase imerdependence berween elecrical and structural component details along the perimeter of the chamber if there is no significant mass reduction.

- The developoment of an optimal design for structural and electrical systems is greatly complicated if booth are expecied to shore the some

- Separase zomes alomg the chamber perimeter for electrical compoments and structural derails permirs flecibilin during the design process wo accommodave she inevilable changes in electrical component sizes and lavoun.

- A design incmporating o perimeser bolting pantem ourside of the gap seal is easier in

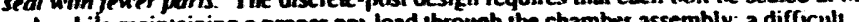
cesien lask that is more expensive to implement.

2. Bactground and Introduction

An un-optimized. "continunus" eap frame design (similar to Fig. 17) was prepared for the GEM P.A.C. Review held in May 1993. This design incorporated a continuous shear connection. Pe the necessary shear connection.

An ahermate design was subsequently proposed (Fig. 15) which incorpornted discrete posts Wetween panels in a chamber assembly. Bnlis, which passed through the center of the posis from one panel to the nexL established the shear connection in the assembly. The posts were located inside the perimeter gap frame seal and shared real estatc with annde electrical components in a zome along the prerimeter of the chamber. The dimensions of the perimeter region of the chamber were reduced thus reducing overall mass. 


\section{3 of 18}

In GEM TN-93-350. Graviry Sag of Sandwich Panel Assemblies as Applied in Precision Cathode Srip Chamber Structural Dessign. Jul. 12. 199.3. we saw that high modulus/low density gap nothing in the structure (excepl around bolts). However, the beam bending thenry used in that paper also predicted that the gravity sag of a stack or seven sandwich pancls would be 39 rimes higher if slipping necurred herween pasels. In outer words. disrupting the shear connection around the perimeter hetween panels could increase local gravity sag hy as much as a factor of 39

In GEM TN-93-350. we also saw that shear "slipping" hetween sandwich panels in the gap region results in stear deflection as well as local distortions of chamber cross soctions. In ""pure produces the increased gravity sag seen in Fig. Ib.
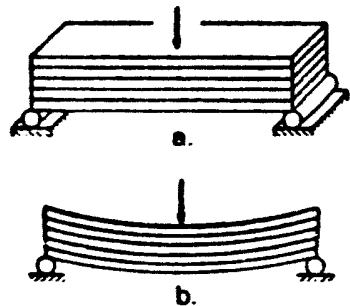

Figure 1: Shear Deflection Due To "Slipping"

The portion of this "worst-case factor of 39" that occurs depends on. among nther things. chamher perimeter region design and material choices. The undertying assumption of heam theng is that all frame will not permit slipping hetween sanduich panels.

Desipns meant to reduce chanter mass may also increase shear deformation. One must maintain bending and shear structural rigidiny to comirol gravity sag when lightening the chamber. Changing

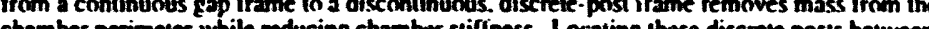
chamber perimeter whike reducing chamher stifiness. Locating these discrete possts hetween electronic components is possible only if sufficiem space is avemlabile. The remosial of material uken from a finite element malysis of a structurally inadequate gap frame design, ckearly illustrates the loss of cross-section flatmess near a comer support point.

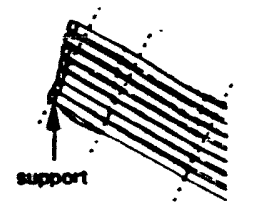

Figure 2: Loss of Cross Section Flatness Due To Shear
This paper is a follow-up to that eartier wook. We evaluate the shear deflection companemt of gravin sas and use it to compare the structural adoquacy of chamher perimeter desiens and materials. We amalyze ten combinations of two perimeter desiens and six malerials for their effectiveness in reducing mass without compromising chamber stifness. Matenal removal. relocation. or sutsstitution are the only mass-reduction vectmiques considered here. We ever loss in structural rigidity that occuss for these sen chamber perimeter design and moterial invertigation of "externa" stiffening techniques.)

\section{How Chamber Structure infuences Gravity See}

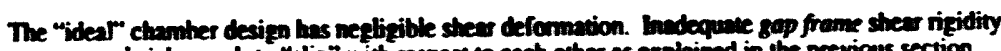
causes sandwich ponels to "slip" with respect to each other as expiained in the previous section.

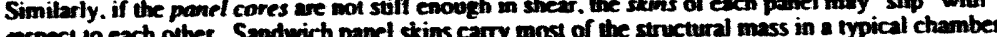
desien. Tabte I shows the dominance of the panel stins as a hending-load carrier. The application of heam hending theory to a banrel region ouner superiayer chamber with a elass-fither filled cpoxy gap frame and an unfilied-epaxy core edefe filler produced the results in Table 1 .

The high-modulus components. if located approprimely. will cary a brger share of the lobst load. Tahte I shows the mass distribation and load sharing for a chamber in "pure bending" for the material choices listed.

Table 1. Eflectiveness of Chamber Components in "Pure Bending"

\begin{tabular}{|c|c|c|c|}
\hline component & $\begin{array}{c}\text { 9 of loon } \\
\text { chamher mass } \\
\text { added by crmponent }\end{array}$ & $\begin{array}{l}\text { \%or tonal } \\
\text { champler mass } \\
\text { corried by componem }\end{array}$ & $\begin{array}{l}\text { To of mass carried } \\
\text { minus } \\
\text { of of mass added }\end{array}$ \\
\hline $\begin{array}{l}0.3 \mathrm{~mm} \\
\text { Gio laminate } \\
\text { panel stims }\end{array}$ & (2) & 77 & 38 \\
\hline $\begin{array}{l}25 \mathrm{~mm} \\
\text { unfilled epoxy } \\
\text { core edde filler }\end{array}$ & 18 & 7 & -11 \\
\hline $\begin{array}{l}25 \mathrm{~mm} \\
\text { glass-fiher / epoxy } \\
\text { sap frame }\end{array}$ & 12 & 9 & -3 \\
\hline $\begin{array}{l}0.017 \mathrm{~mm} \\
\text { copper } \\
\text { conhode planes }\end{array}$ & 4 & 7 & 3 \\
\hline $\begin{array}{c}19 \operatorname{lom} \text { Nomex } \\
\text { honeycomb } \\
\text { core }\end{array}$ & 11 & - & -11 \\
\hline $\begin{array}{l}\text { 25kg } \\
\text { hordurare } \\
\text { and milinies }\end{array}$ & 16 & - & -16 \\
\hline
\end{tabular}

In an "ideal" chamber with negligithe shear deflection. the panel skins carry about 779 of the load but add only 397 to the toual mass. However. some resulks in Tahte I are deceptive. The gap 
Inad These components do not play a diroct rok in bending stiffmess, thet they are the primary components of shear stiffress.

The ullimate senceurol effectivemess of candidate gap frome maserials can be estimated in advance of any detailed analyses hy using a simple beame evaluation method as shown in the next section. The finite element andyses summarized biter in this paper calculate changes in shear stiffmess. We then explore how mech materid we can salely remove f $m m$ a component, and the relative Coments mectanical properies.

\section{Eveluation of Molertals}

bn this section. we observe the following:

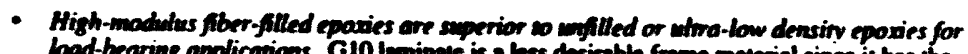
load-bearing applications. G10 brnimate is a bess desinetle frame material since it has the in-plane shear properties of unfiliced epoxy. requires a 250MF cure. and is mol castatile.

- Caspable ghass-fither filled epoxy is the most ponmising of the romm-kemperature (R.T.)
cured. electrically-insulating materials considered.

- - Carton-finer filled eproxy is ided as a homeycomb cone edfe filler where its electrical

- Ulma-low densiry moverial is ideal for lighty loaded components. The ultra-kow density material evaluated here also has very low modulus. The amount of this material needed carry a given liod is larger, so the size (and mass) of hizher-density components atached

- High-modulus low-densin fibers are the most desirahte epoxy fillers. Some examples are carhon. aluminum. glass, or kevlar fithers.

We know that a desinthe chamber frame maverial has low densing, high madulus, and high radiation limgon. However. mn single parameter is meaningful in isolation. For instance.

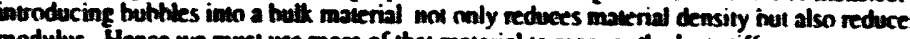
modulus. Hence we must use more of that maverial to recover the lost siffness.

The following analysis combines material density. mndulux, and radiation length into $m^{*}$ values that are proportional in the deteverious mass effects of that material on the muxn system. Suppose we consiruct the rectangular cross-section beam shown in Fig. 3 from one of the candidate crials listed below.

1. carbon-fiber filled epoxy such as Fiber-Resin FR-337 (castable. cure O R.T.) 2. G10 woven-glass laminate such as Epoxy Gillfob 100J (plies, cure 250 of) 3. glass- Fither filled epoxy (castable. cure E R.T.)

4. synuctic epoxy such as Cibo-Geigy 1617-A (castahte. cure Q R.T)

5. unfilled epoxy such as Fiberite SSL-3 (castable. cure $P$ 350 of

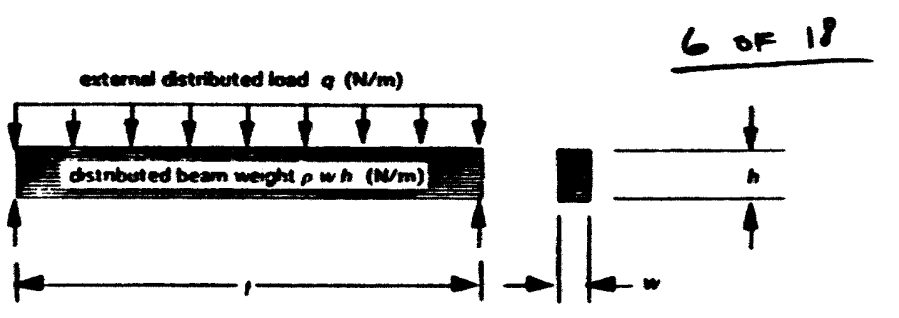

Fgure 3: Beam Used for Material Comperisons

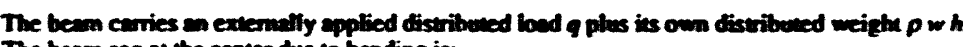
cencer dne to bending is:

$$
\text { beam sog }=K \frac{\left(q+p_{w}\right)}{E_{w}}=K 1 \frac{q}{E_{w}}+x 2 \frac{Q}{E}
$$

where $q$ is an exvernal distribured bad. $\rho$ is the bean densiny. $w$ is the beam with. $h$ is beam

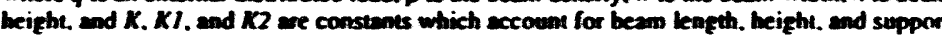
conditions. Exch of the two load sources. $q$ and $\rho$ w' h. contributes lo beam sag.

When the distritured loed ereatly exceeds the bean weizth $(q>>p w \cdot h)$. when :

$$
\text { beam sog }=X I \frac{q}{E_{W}}
$$

and we reduce hean sag hy minimizing 1 (AE w). The width of a beam (that produces the same gravity sag as the haseline for nomalization) divided by the radiation length. $l_{f}$. produces the parameter $m I^{*}$ which is:

$$
m ! *=\frac{w}{T_{k}}=\frac{E_{b} w_{b}}{E_{k}}
$$

Where we sutscripa b denoves the properties used for the boseline for normalization. The parameter $m I^{\circ}$ ( small for 2 tean with low width and high rediation length) is a valid indicator when the distribued load greatly exceeds the hean weight ( $q>>p w h$ ).

When the bean weight greally exceeds the distribued load ( $\rho$ w $h$ > > q). then:

$$
\text { beom sog }=20 \frac{2}{E}
$$

and we reduce besm sof by minimiziag $\rho / E$. The rmio of $\rho / E$ divided by the redionion length produces the parameter m2* which is:

$$
m 2^{*}=\frac{\theta}{E_{n}}
$$

where $m 2^{*}$ (small for a beam with low density. high modulus, and high radiation lengeb) is 2 valid indicator if the beam weight greally excoeds the disuritured $k$ had $(\rho: h>>q)$. 
7 of 18

The results are summarized in Table 2 for the six materials. (Quantivies nomalized are with respect

Teble 2. Material Comparison

\begin{tabular}{|c|c|c|c|c|c|c|}
\hline & 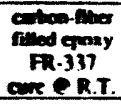 & 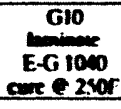 & 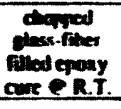 & 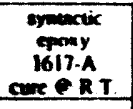 & 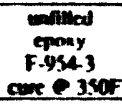 & 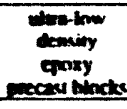 \\
\hline$\underbrace{p}_{100}$ & 1.60 & 1.93 & 1.05 & 0.70 & 1.19 & 0.42 \\
\hline $\begin{array}{c}\text { Eutus } \\
\text { Modir Pasil }\end{array}$ & $\begin{array}{l}34,500 \\
13.000\}\end{array}$ & $\begin{array}{l}22.260 \\
13.3001\end{array}$ & $\begin{array}{r}11.030 \\
11.000\}\end{array}$ & $\begin{array}{l}2,410 \\
\text { 13501 }\end{array}$ & $\begin{array}{l}2.700 \\
10001\end{array}$ & $\underset{10001}{600}$ \\
\hline 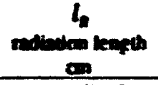 & 340 & 194 & 21.2 & $\begin{array}{c}16.66 \\
0\end{array}$ & 59 & $\begin{array}{c}91 \cdot 1 \mathrm{~m} \\
(?\end{array}$ \\
\hline$\rho / E$ & -.57 & 1.00 & 1.98 & 3.43 & 5.10 & 7.20 \\
\hline $\begin{array}{l}\text { required } \\
\text { wideh } \\
(e>p \rho-n)\end{array}$ & 0.66 & 1.00 & 2.06 & 9.43 & 8.25 & 33.0 \\
\hline 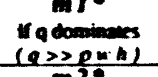 & C.38 & 1.00 & 1.09 & 2.77 (in $^{3.27}$ & 2.91 & 5.96 in $^{1.04}$ \\
\hline 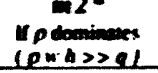 & 0.32 & 1.00 & 1.81 & $1.01 \dot{0}^{1.19}$ & 1.80 & $1.30 \dot{m}^{1.53}$ \\
\hline
\end{tabular}

Tathe 2 mones:

$m / \bullet$ and required widh are VALID WDICATORS IF $(q)>\rho n \cdot h)$

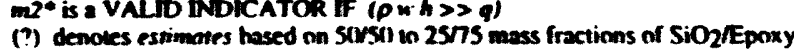

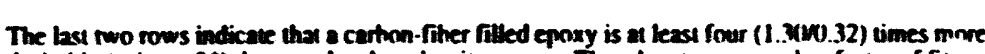

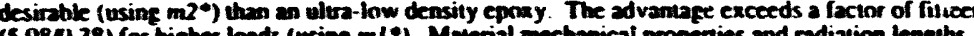
meed additional verification.

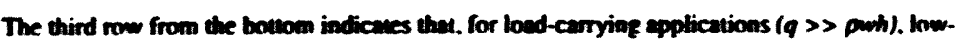

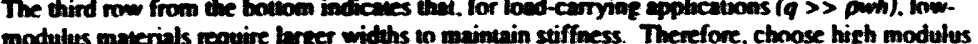
modulus materials require larger widhs in maine
5. Comparison of Comtinumos and Dherete-Pest Gop Frames

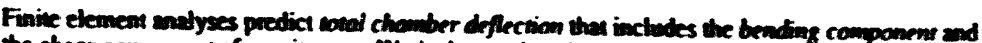

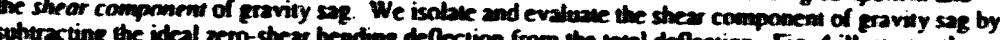

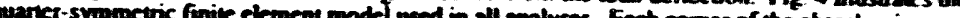

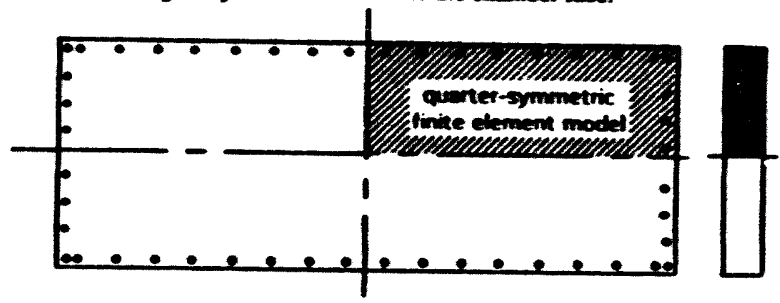

Figure 4: Quarter-Symmetric Finite Element Model

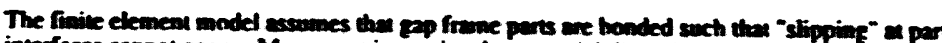

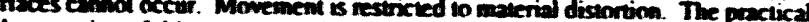
implementation of this essumption is achieved hy hals. friction. motor whesive at pen interfaces.

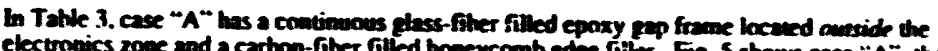

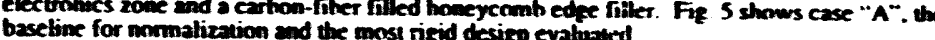

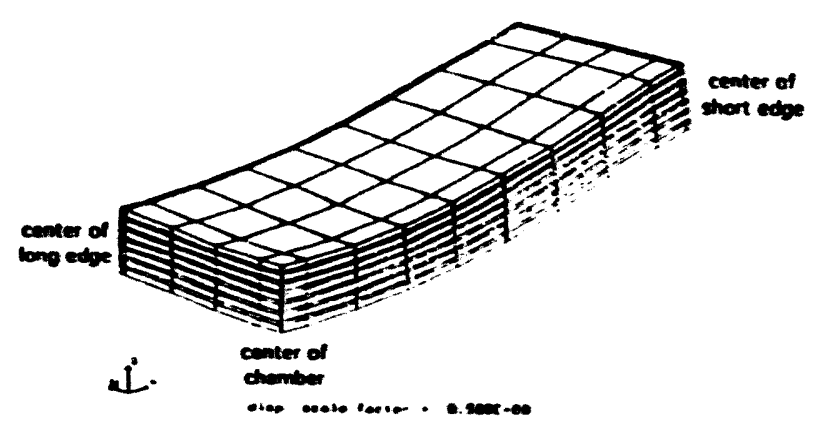

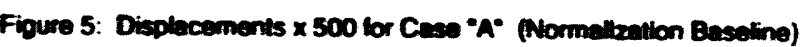


9 or 18 Table 3 summarizes the resules of friste element and heam bending grovity sae calculation.

Table 3. Compartson of Gap Frame Designs and Materials

\begin{tabular}{|c|c|c|c|c|c|c|}
\hline case & $\begin{array}{l}\text { (Nove I) } \\
\text { ap frame }\end{array}$ & $\begin{array}{c}\text { (Nowe 2) } \\
\text { sondwrich cone } \\
\text { edpe miller }\end{array}$ & 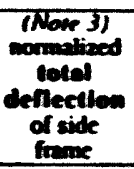 & $\begin{array}{l}\text { (Nowed) } \\
\text { pescem } \\
\text { Eheor } \\
\text { deflection } \\
\text { of side } \\
\text { frome }\end{array}$ & $\begin{array}{l}\text { (Note S) } \\
\text { mormalized } \\
\text { totel } \\
\text { mess }\end{array}$ & $\begin{array}{l}\text { (Note 6) } \\
8 \text { chenge } \\
\text { in mass }\end{array}$ \\
\hline$A$ & $\begin{array}{l}\text { Condineows } \\
\text { fluss-rober } \\
\text { flled eppayy }\end{array}$ & $\begin{array}{l}\text { comdlowous } \\
\text { caboon-fiber } \\
\text { rilled epouy }\end{array}$ & 1.00 & 10 & 1.00 & - \\
\hline B & $\begin{array}{l}\text { comentinuous } \\
\text { gless-fiber } \\
\text { fillod epoxy }\end{array}$ & $\begin{array}{l}\text { comelingeous } \\
\text { fhes-fither } \\
\text { rilled epouxy }\end{array}$ & 1.48 & 16 & 1.02 & +2 \\
\hline C & $\begin{array}{l}\text { continguous } \\
\text { unfilled } \\
\text { eppoxy }\end{array}$ & $\begin{array}{l}\text { conthrous } \\
\text { mafilled } \\
\text { epoxy }\end{array}$ & 1.73 & 24 & 0.92 & -8 \\
\hline D & 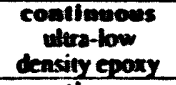 & $\begin{array}{l}\text { Continuous } \\
\text { ulva-low } \\
\text { densiny epoxy }\end{array}$ & 1.86 & 37 & 0.81 & .19 \\
\hline $\mathbf{E}$ & $\begin{array}{l}\text { Comlinowows } \\
\text { ultra-kow } \\
\text { densing cpoay }\end{array}$ & $\begin{array}{c}\text { continumous } \\
\text { unfilled } \\
\text { copoxy }\end{array}$ & 1.82 & 30 & 0.89 & -11 \\
\hline $\mathbf{F}$ & $\begin{array}{l}\text { Comfinuous } \\
\text { Elass-Fher } \\
\text { filled epoxy }\end{array}$ & $\begin{array}{l}\text { continuouss } \\
\text { unfilled } \\
\text { eppaxy }\end{array}$ & 1.67 & 21 & 0.95 & .5 \\
\hline G & $\begin{array}{l}\text { Comtimenous } \\
\text { class-finer } \\
\text { filled eppoxy }\end{array}$ & edee fatler & 2.21 & 47 & 0.83 & -17 \\
\hline H & 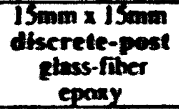 & $\begin{array}{l}\text { Ther-post } \\
\text { whra-kow } \\
\text { density epoxy }\end{array}$ & 2.25 & 49 & 0.78 & -22 \\
\hline I & $\begin{array}{c}60 \min \times 15 \sin \\
\text { discrele-post } \\
\text { Elass-fher } \\
\text { coosy }\end{array}$ & $\begin{array}{l}\text { hoter-post } \\
\text { ulter-inw } \\
\text { density epoxy }\end{array}$ & 2.13 & 45 & 0.80 & -20 \\
\hline J & $\begin{array}{l}\text { Gomam x ismom } \\
\text { discrete-post } \\
\text { Elass--Ther } \\
\text { epoxy }\end{array}$ & $\begin{array}{l}\text { Doter-post } \\
\text { cartan-fiter } \\
\text { frlled epoxy }\end{array}$ & 1.04 & 18 & 0.93 & -7 \\
\hline
\end{tabular}

Table 3 motes:

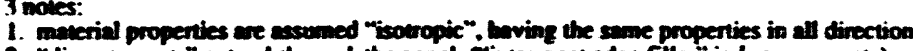

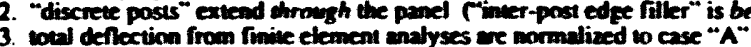

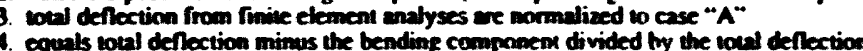

includes $25 \mathrm{ke}$ for chamber vilities and added width for continumes pap frome can

6. F. change in the sum of sandwich panel. gap frame. honeycomb ed fe filler mass. and wilities (25kg for all cases)

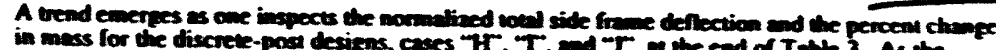

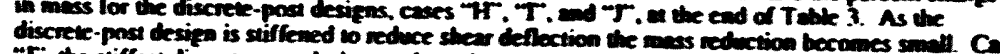

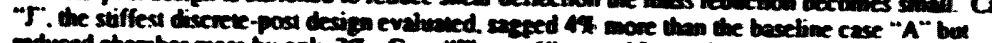

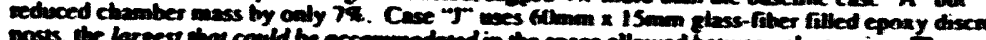

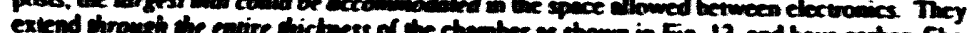

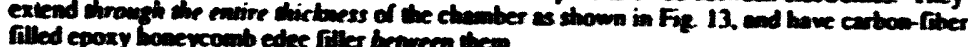

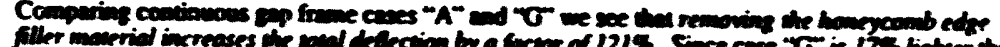

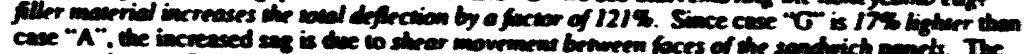

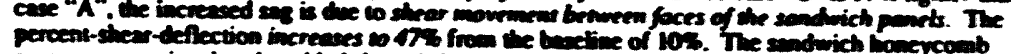

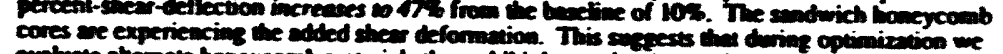

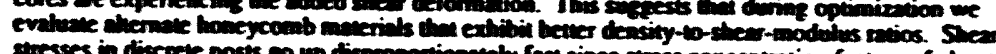

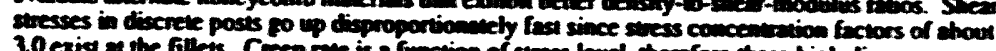

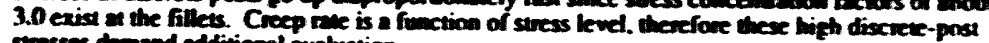
aresses derand adtitional evaluation.

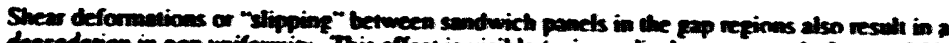

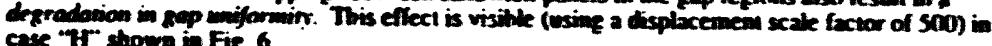

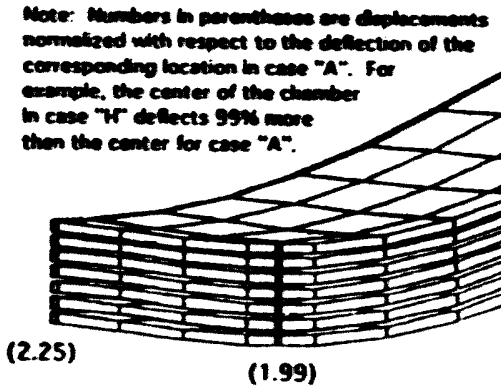

(1.99)

Figure 6: Displacements $\times 500$ for Caes "Yr Showho Loss of Gep Unitomity

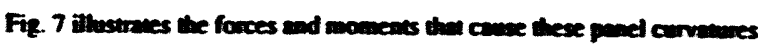

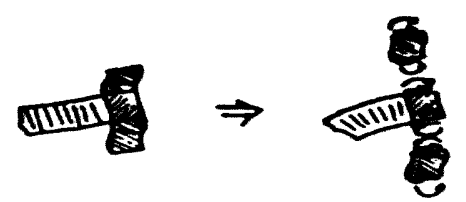

Figure 7: Moments and Shear Fonces in Endflegion Gap Frame 


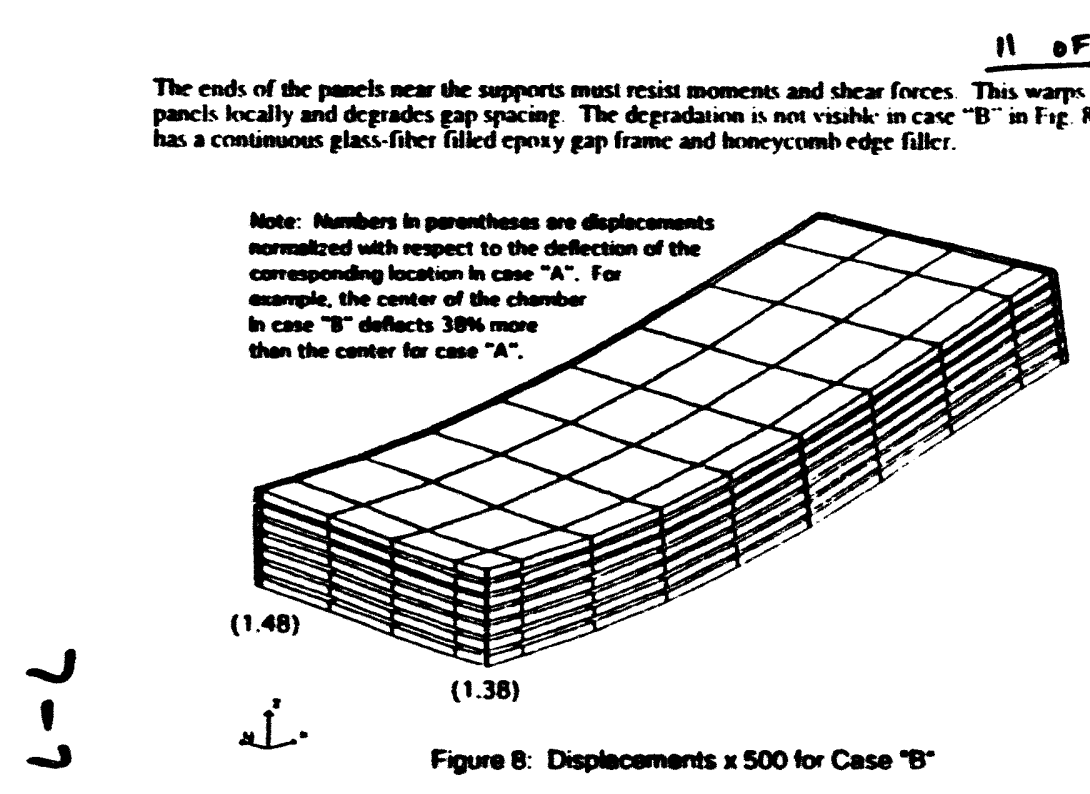

The degredeion in eap specing is visithe on the right in Fif. 9 for casc " $T$ " with deflections magnifixed S(X) times.

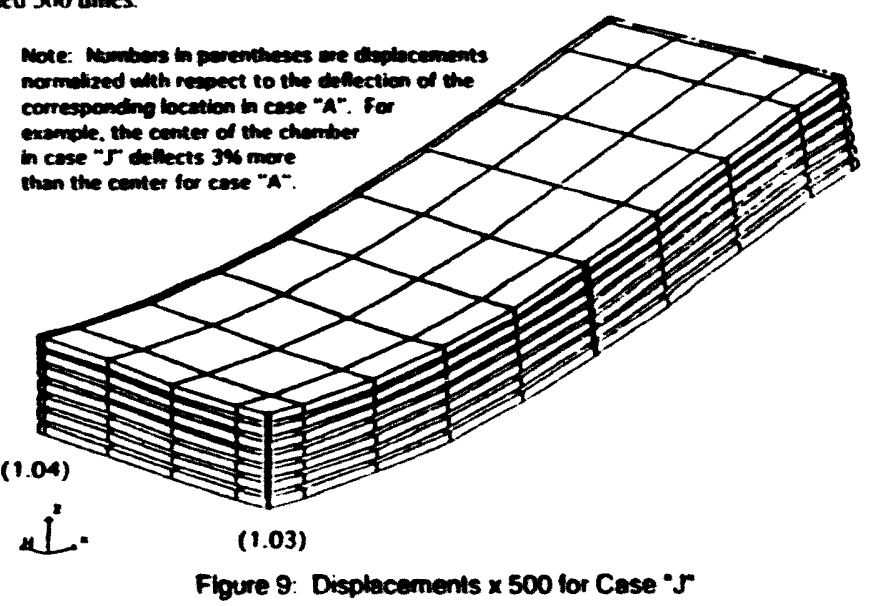

12 of 18

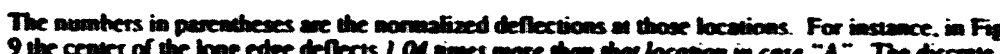

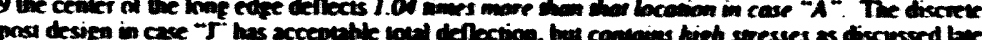
in section 8 .

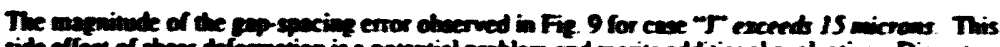

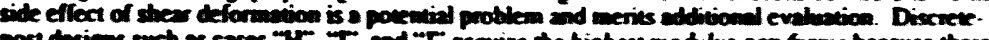

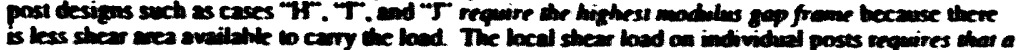

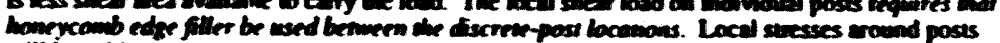

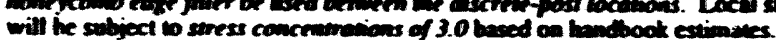

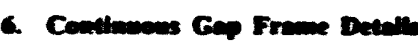

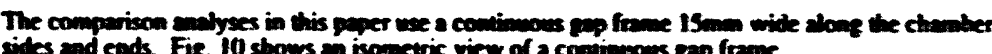

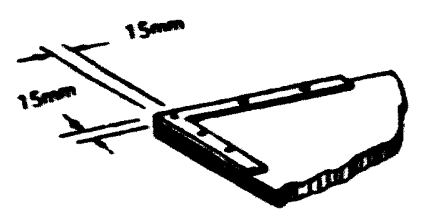

Figure 10: bometric View of Continuous Gap frame

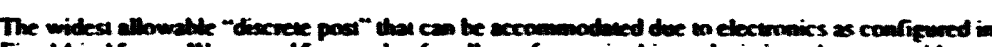

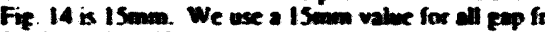
fair hasis for stiflness compenson.

7. Dberete-Peat Ges Freme Detalls

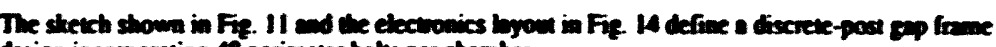
desiga incerporating is perimeter tolls per chanther.

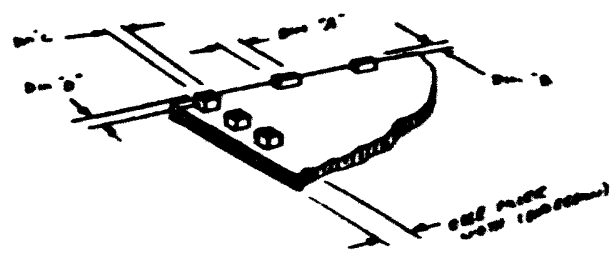

Figure 11: sometric View of Discrete-Post Gap Frame 

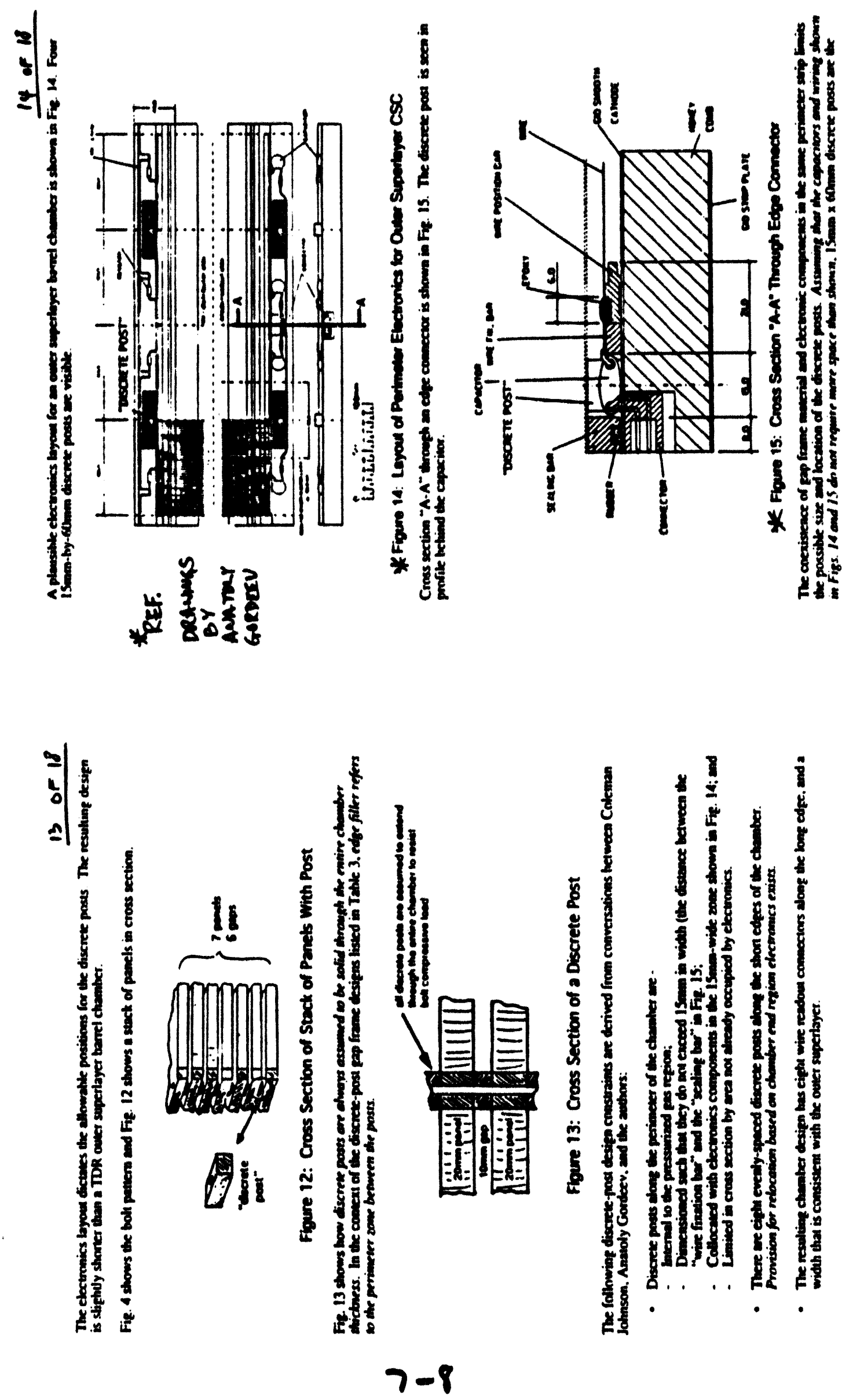


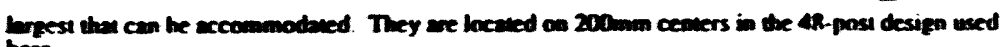
The electrical layour in Fie 14 is for the onder sepperbyer only. Simibr byouts wonld be reapined

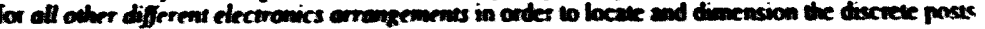
for those chamiters

\section{- Lond and Streswes}

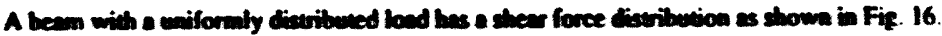

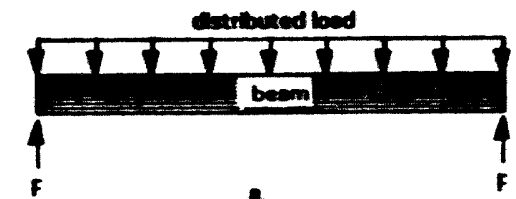

1

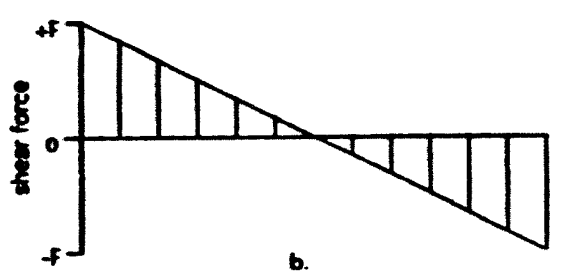

Figure 16: Load and Shear Force Distribution

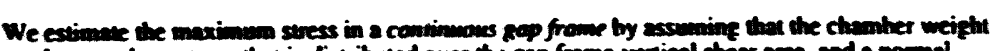

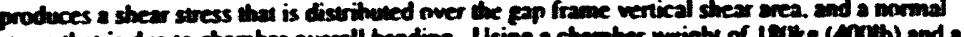

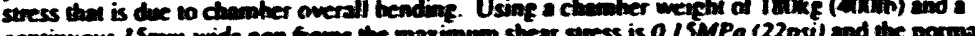

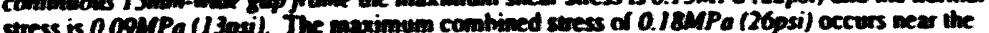
ctress is d. supports ss seen in Fig. 16. The errevity vector is assemed to the mormal to the panets for this capports as soention.

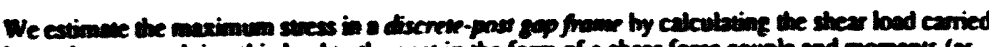

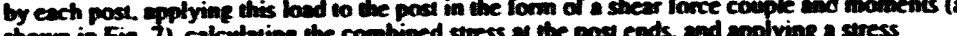

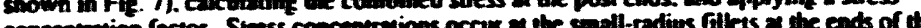

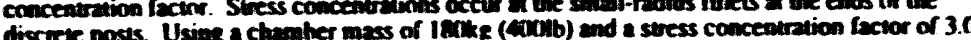

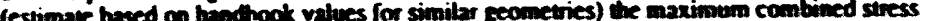
(hendine plus strear) in a $15 \mathrm{~mm} \times 6(6 \mathrm{~mm}$ discrete post is $5.38 M P$ a (780psi). This occurs at the fillets in the discrete posss wear the chamher ends
16 of 18

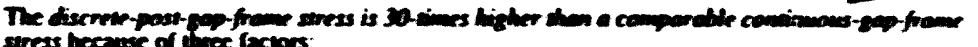

1. He noduced strem ore

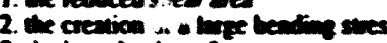

stress concentration.

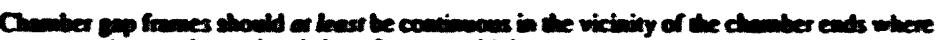

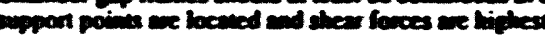

9. Practied Conditermenen

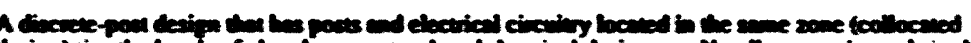

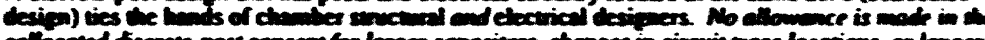

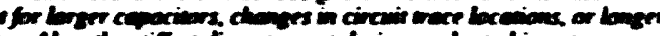

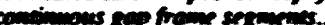

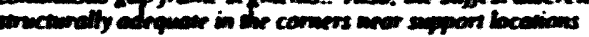

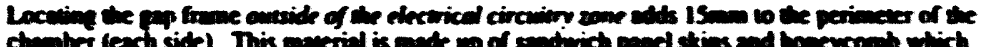

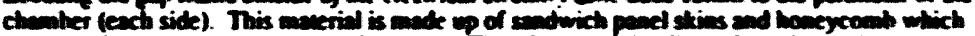

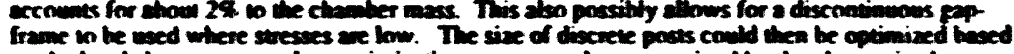

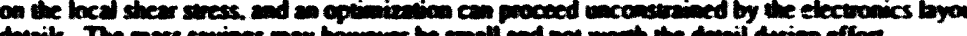

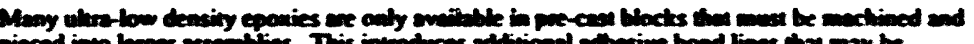

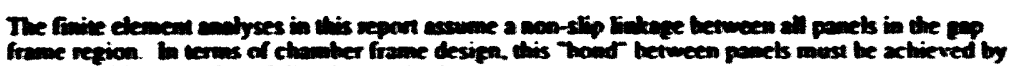

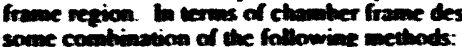

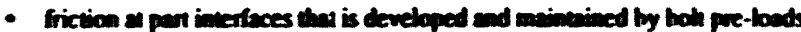

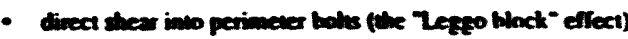

- allesive

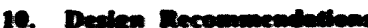

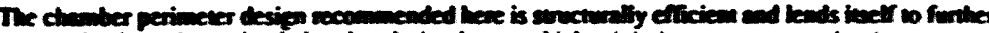

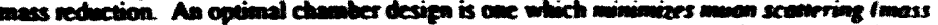
effectsl sheer deform

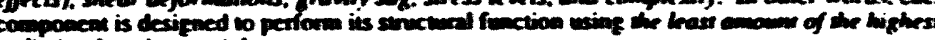
nedrion-lenget maverials

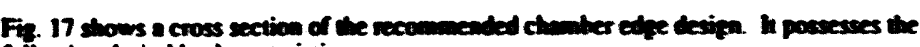
Following desirente chenceriatics:

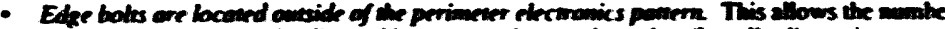

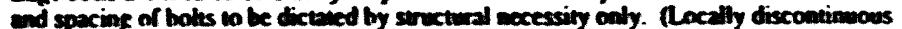


17 of 11 gap-frame designs that reduce mavrial in the low-stress regions can he considered in the

- Edge bolis ave hocoued nueside of the chomber gas seal. This etiminates the noed for gas

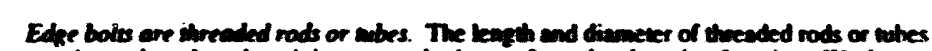

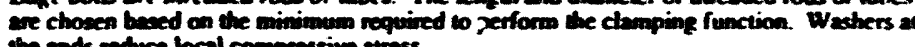

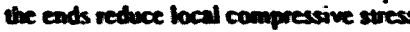

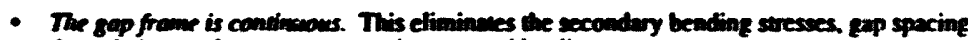
degredation, and stress concentrations cansed hy discreck posts.

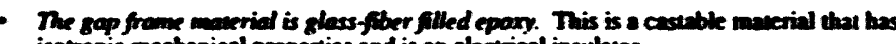
isolopic mochanical properties and is to electrical insulator.

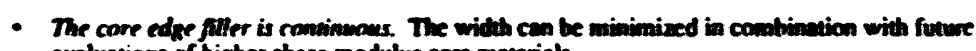
evaluations of higher shenr-modulus core muxerials.

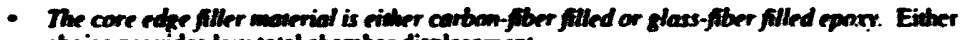
choice provides low mell chember displaceeneen.

- Moverials with Wigh modulus-wo-densing rotins end high modulus values are used for loodcorrving conponeres. This reduces the volume of material in a component and in all other components wat musa the ateached in in

- Uhra-bow densiry moverials core used far lighrly-boded components. The wire fixation bars and wire position bass are to he mode from the liethess competert maserial.

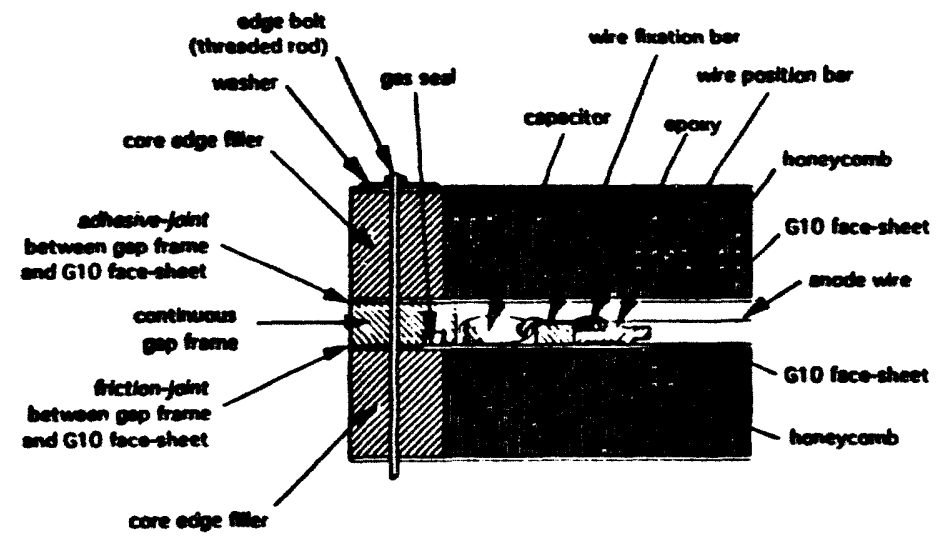

Figure 17: Cross Section of Recommended Edge Design

11. Furtwer Dedien and Anoblyts Tests

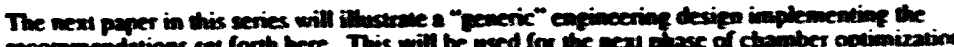

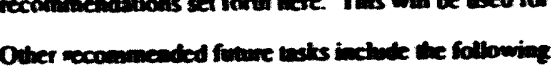

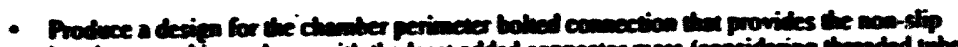

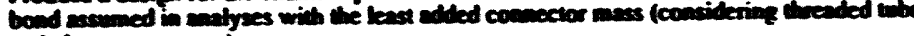

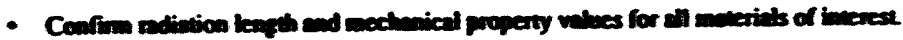

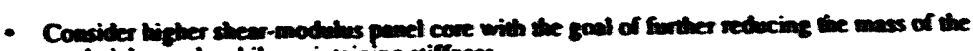
sondrich pinets while maimaining stiffeess.

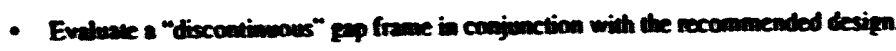

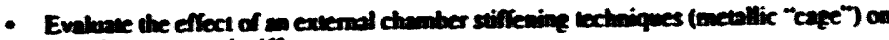
Chamber ass and stiffness. 
GEM TN-93-494

\section{Gravity Sag as a Function of Sandwich Core Material}

Contents:

Summary of gravity sag results for three core materials (1 page)

Analysis of TDR Baseline HRH-10-1/8-1.8 "Nomex" core (7 pages)

Analysis of WR-II-3/8-2.5 "Shelter Core" (7 pages)

Analysis of WR-II-3/8-4.0 "Shelter Core" (7 pages)

\section{Summary:}

On the basis of gravity sag alone, the stiffer WR-II-3/8-2.5 "Shelter Core" is the best choice. However, since the density is $2.5 \mathrm{lb} / \mathrm{ft} 3$ as opposed to the $1.8 \mathrm{lb} / \mathrm{ft} 3 \mathrm{for}$ the TDR Baseline HRH-10-1/8-1.8 core material, the benefit of the slight added stiffness is erased.

The density of the sandwich core material heavily influences the performance of the muon system, hence higher density core materials must provide a much larger stiffness improvement in order to be considered. 


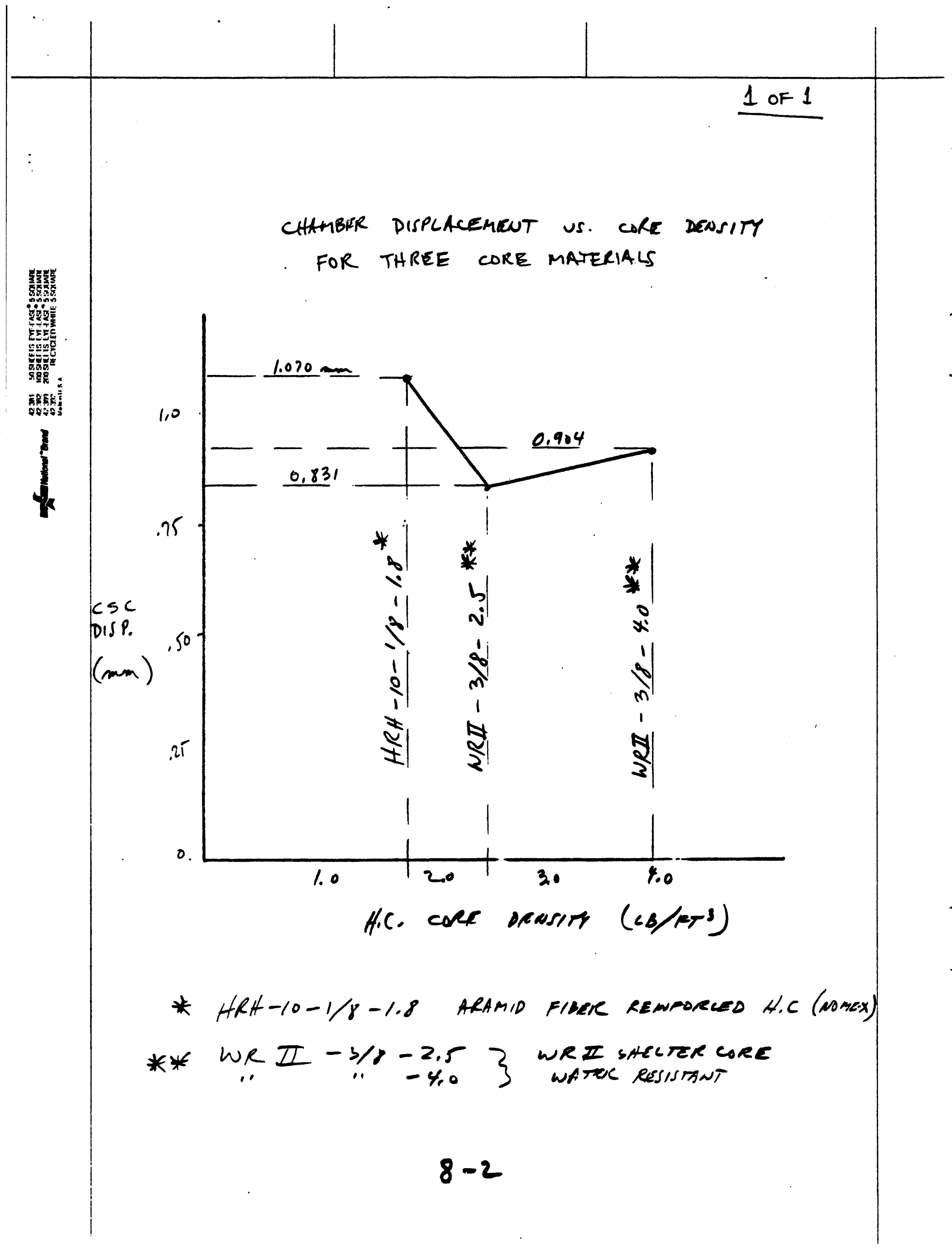




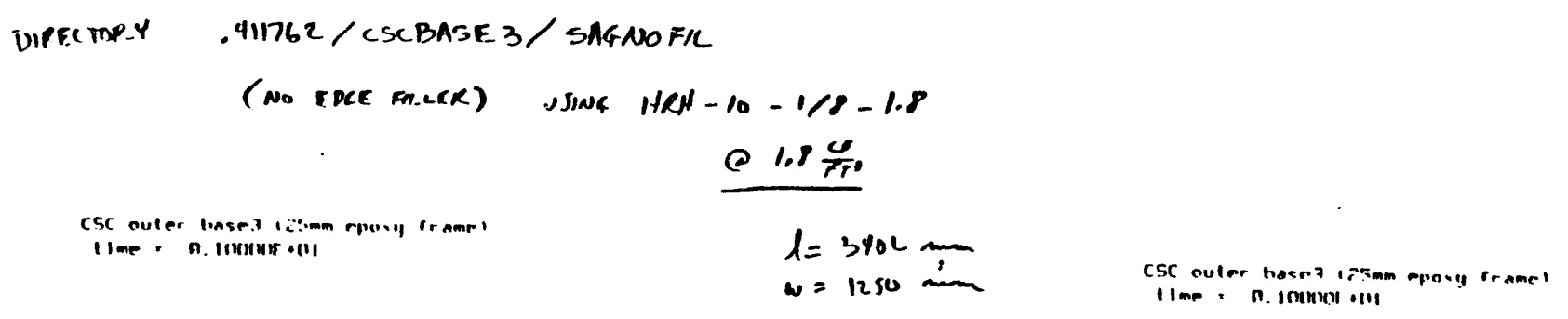

SAGNOFIL

1 of?

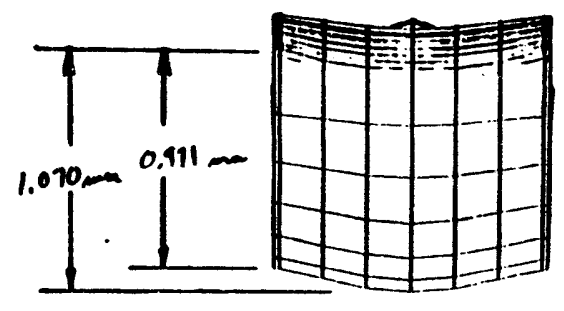

1.

disp. scale bactor, D. Inot 04

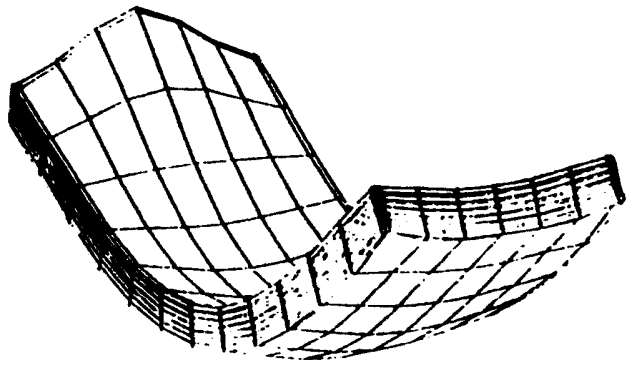

$U^{2}$
SAGNOFK

2 of 7 


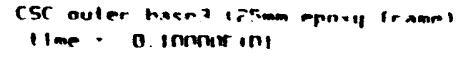

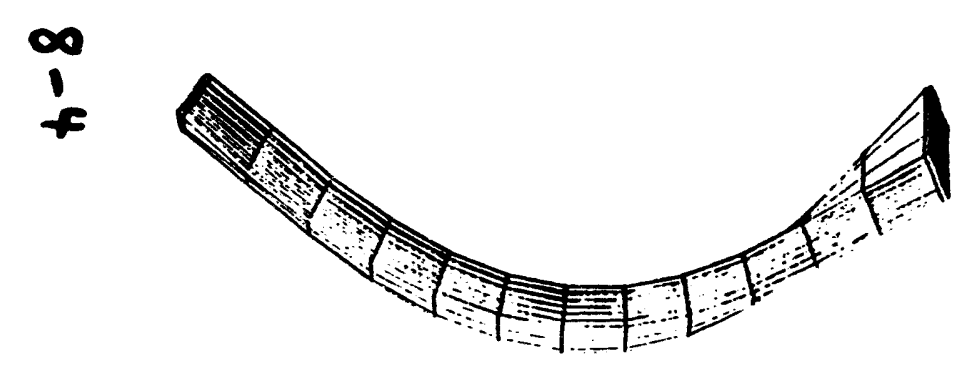

E.

alsp. scale inctor, n. Jonedon

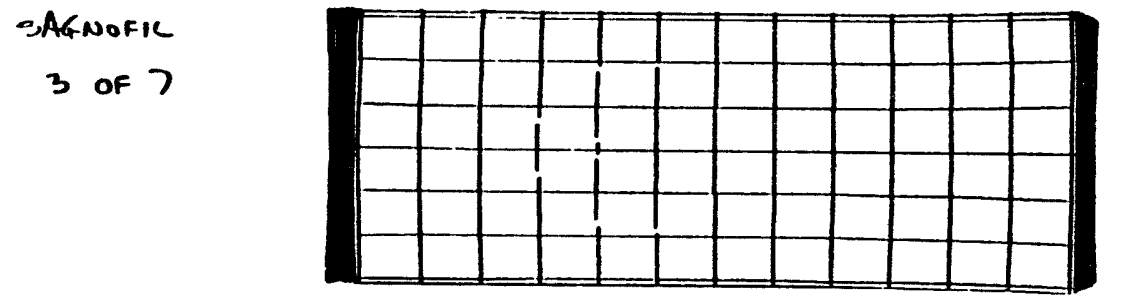

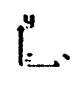

SAGNOFIC 4 or? 

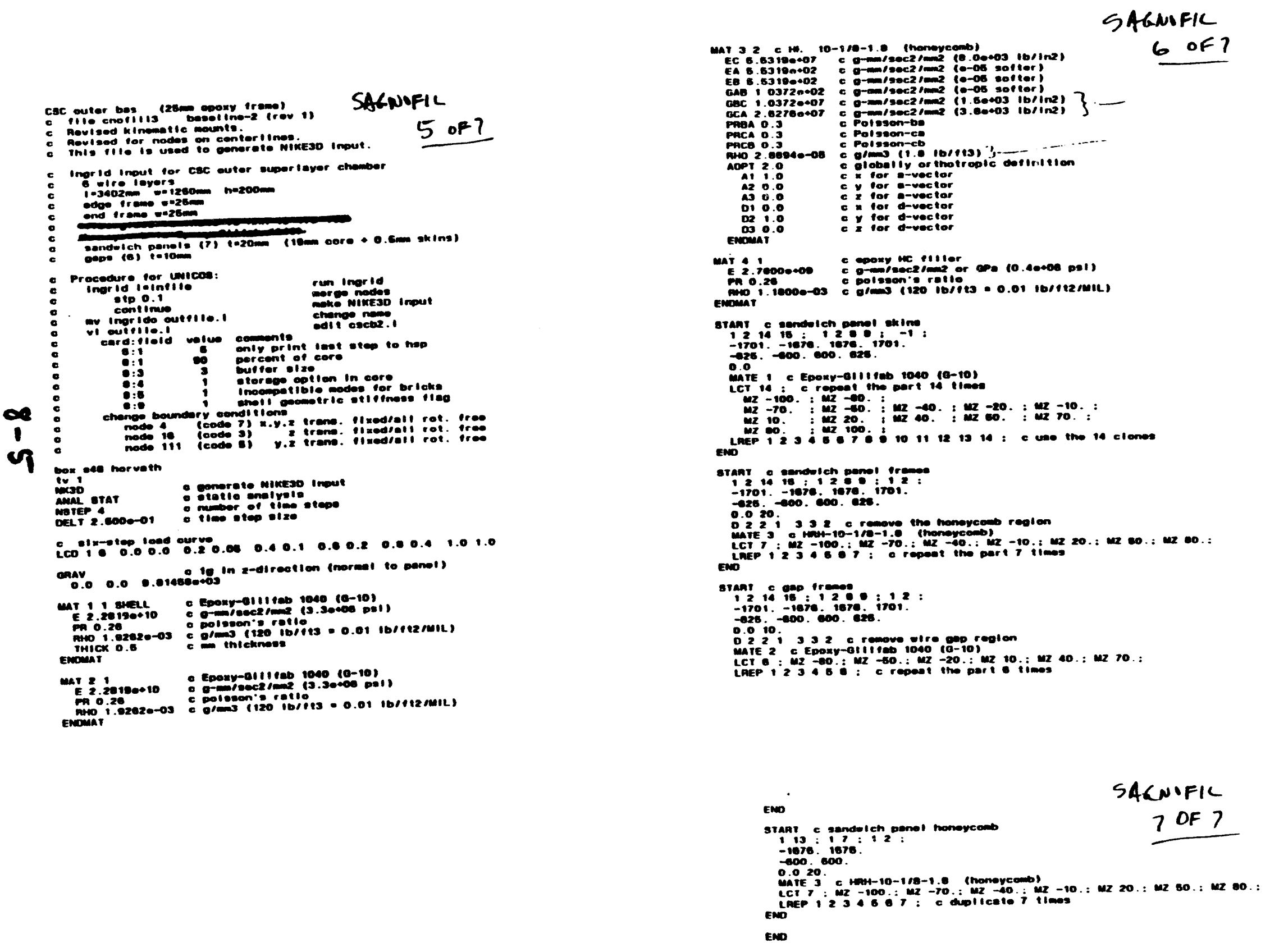
DiReCTORY .411762/CSCBASE3/SAGNENATE

(No rove Fllere), W.SING WRII - 3/8 - 2.5

C $2.5 \mathrm{ces}$

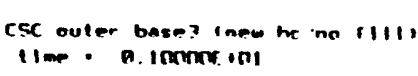

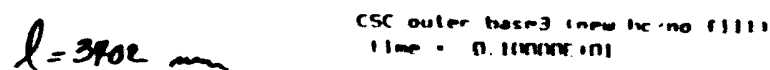

$\omega=1200 \mathrm{man}$

$\infty$

1

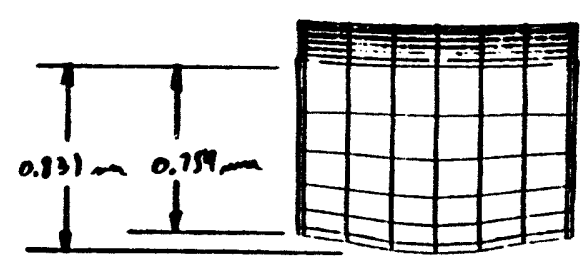

SAGNEWHC

1 of $?$

4.

Alsp. scole factor P. O. 10ec •nd

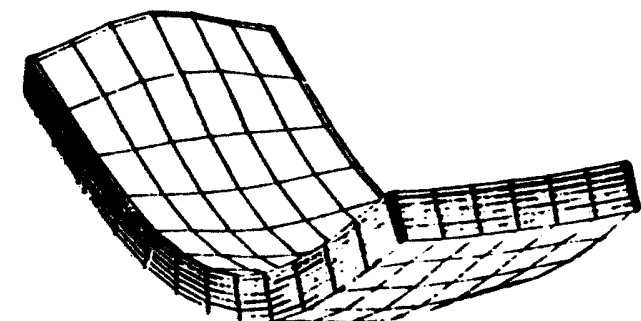

SACNEWHAC

2 of 7

$j^{2}$

Niep. scale cector a n. lonkthe 


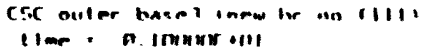

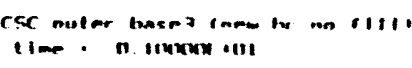

SAkNEWHC

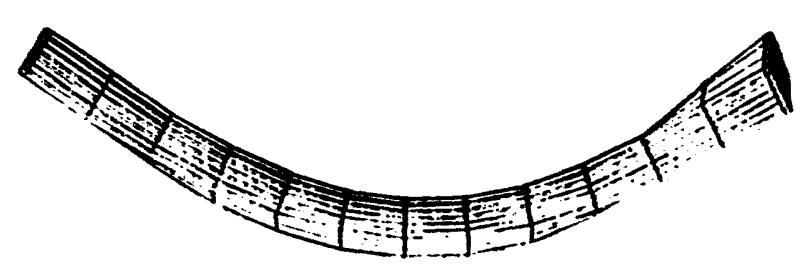

3 of 7

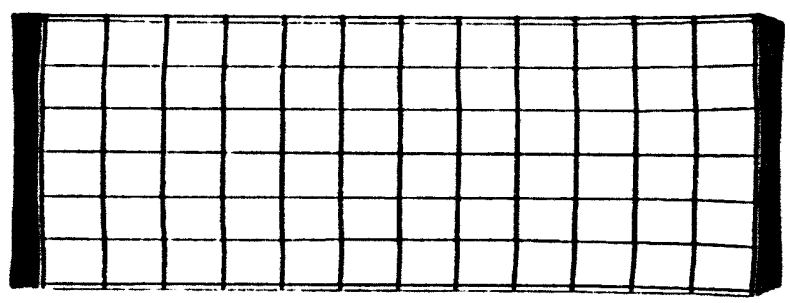

$l=$

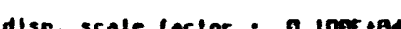

SAguentle 4 or 7
4

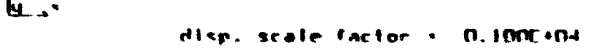

$\infty$ 

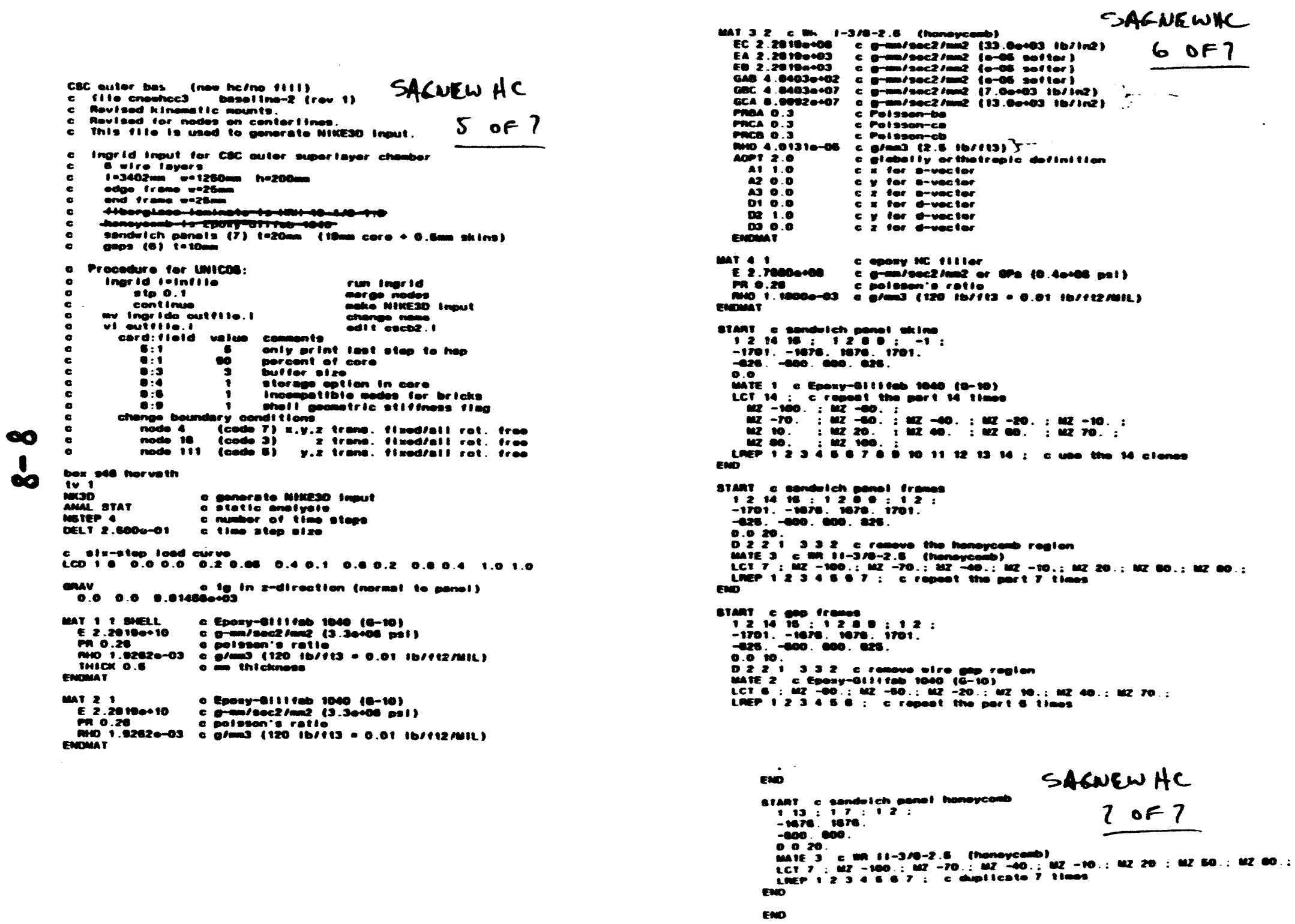


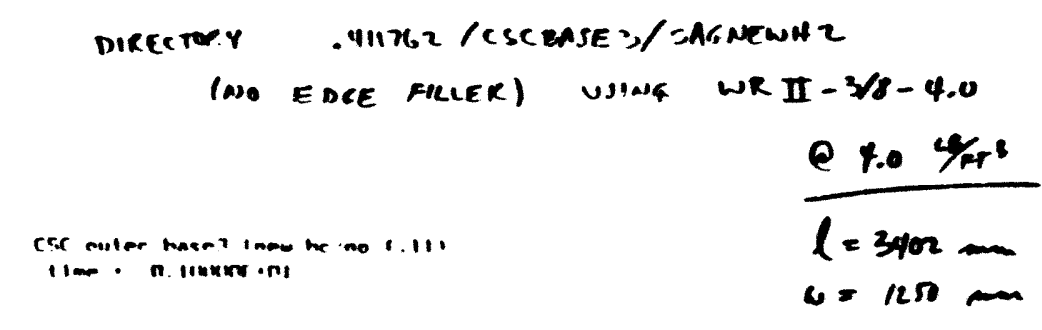

\section{1}

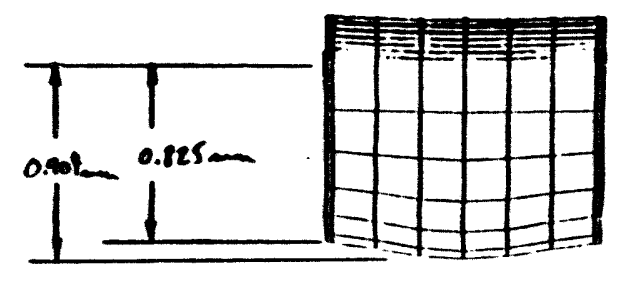

SHGNENH 2

1 or 7

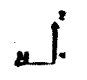

hlsp. srele iectme O. $1000+04$

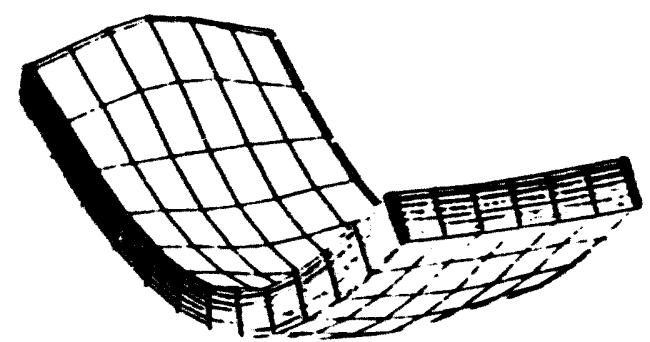

4
SAcuroul 2

2 or 7 

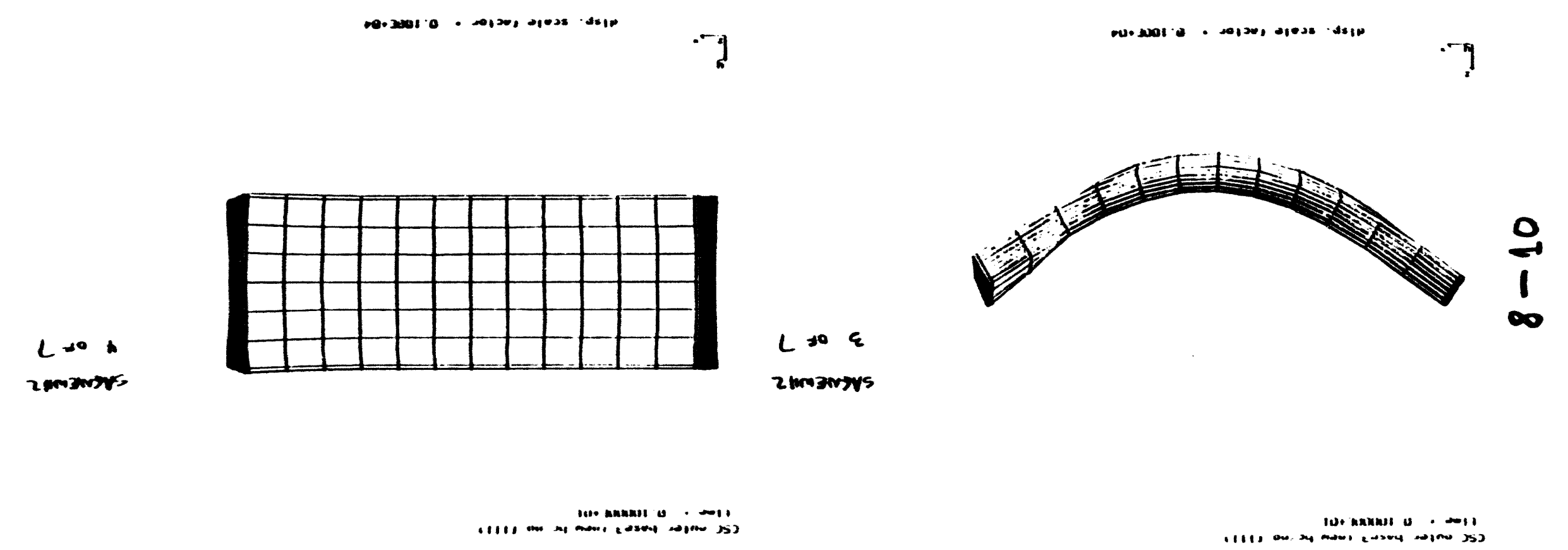

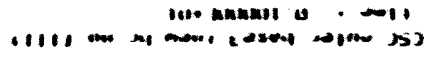

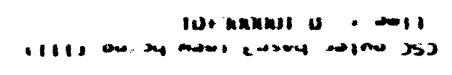



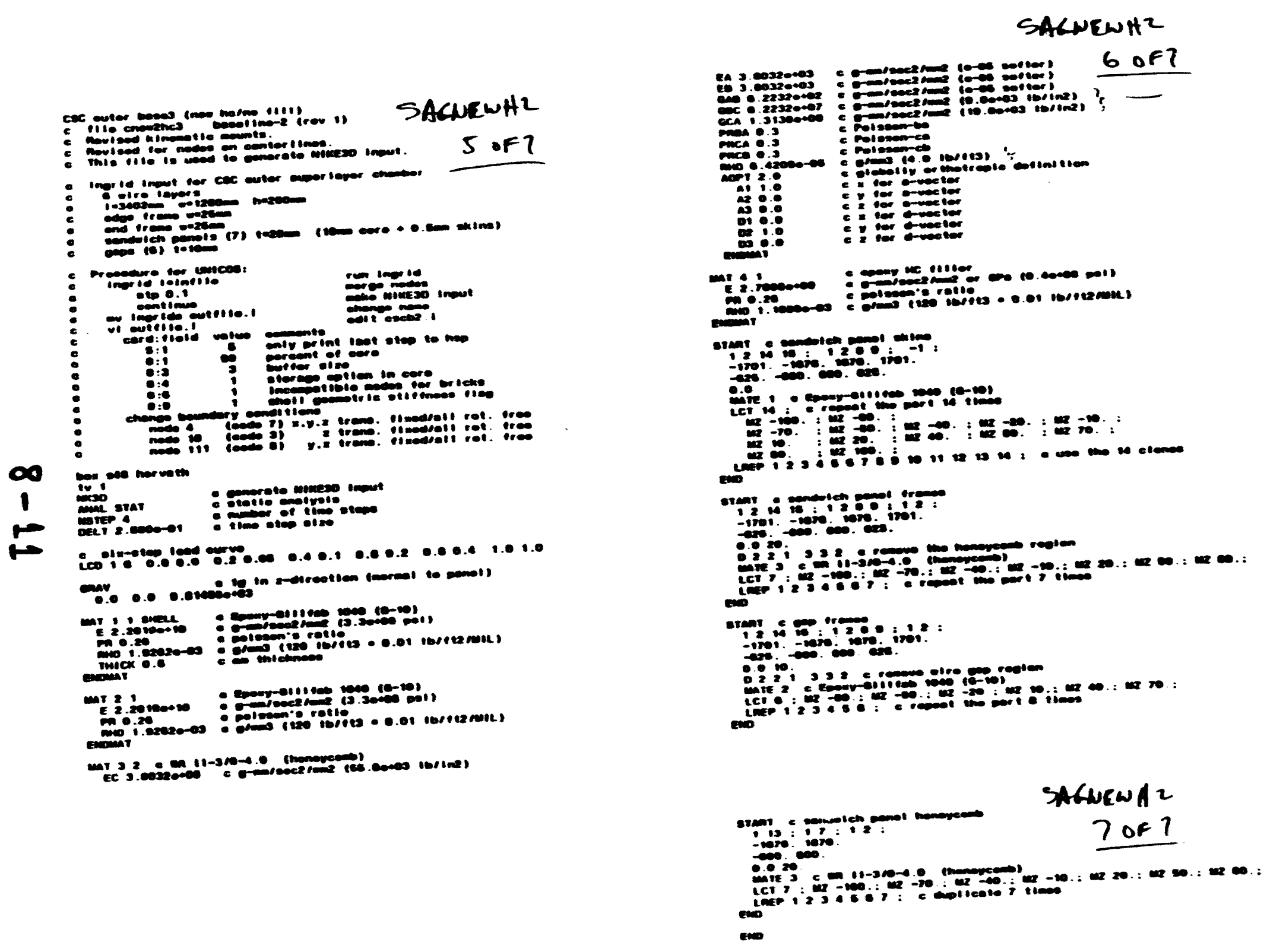
GEM TN-93-494

\section{Parametric Studies}

Contents:

SL-3 CSC with and without $10 \mathrm{~mm}$ thick $\times 25 \mathrm{~mm}$ wide aluminum stiffeners (2 pages)

Gravity sag as a function of chamber design parameters ( 9 pages)

\section{Summary:}

$10 \mathrm{~mm}$ thick by $25 \mathrm{~mm}$ wide aluminum stiffeners added to the top and bottom of the side frames in the long direction reduce SL-3 barrel chamber gravity sag by $40 \%$ while adding $9.5 \mathrm{~kg}$ of mass.

The location of the support points away from the ends of the chamber has the greatest effect on the gravity sag (see the section on support locations).

Frame width has little effect on gravity sag since mass is added at non-optimum locations near the section neutral plane.

Sandwich panel overall thickness has a large effect on gravity sag since increasing cure material has little effect on mass.

Increasing the central sandwich panel thickness has some heneficial effect with no change in mass.

Adding G-10 extensions has a moderate effect on gravity sag. 


\begin{tabular}{|c|c|c|}
\hline & motric & Engleh $(n, B)$ \\
\hline chamber $w(\mathrm{~mm})$ & 1330 & 52.362 \\
\hline chamber longth $(\mathrm{mm})$ & SBOo & 137.795 \\
\hline sandwich $h(\mathrm{~mm})$ & 20 & 0.787 \\
\hline sendwich lece (man) & 0.8 & 0.020 \\
\hline $\operatorname{gep} h(\mathrm{~mm})$ & 10 & 0.394 \\
\hline $\begin{array}{l}\text { opp tram w }(\mathrm{mm}) \\
\text { core treme } w(\mathrm{~mm})\end{array}$ & 25 & $\begin{array}{l}0.984 \\
0.984\end{array}$ \\
\hline extension $w(\mathrm{~mm})$ & 0 & 0.000 \\
\hline oxtension h $(\mathrm{mm})$ & 0 & 0.000 \\
\hline $\begin{array}{l}\text { Cu plating w (mm) } \\
\text { precise calh. cx. (x) }\end{array}$ & $\begin{array}{l}1200 \\
86.6\end{array}$ & 77.244 \\
\hline coarse calh, cwr. $(x)$ & 100 & \\
\hline Cu plating I (mm) & 0.017 & 0.001 \\
\hline proc.colh.subsir. I (mm) & 0.000 & 0.000 \\
\hline crs.cath substr. I (mm) & 0.000 & 0.000 \\
\hline herdmare+ulititias (n) & 25000 & 55.0 \\
\hline
\end{tabular}

\begin{tabular}{|c|c|c|c|c|c|}
\hline \multirow{3}{*}{$\begin{array}{l}\text { chamber h }(\mathrm{mm}) \\
\text { sancivich } w(\mathrm{~mm}) \\
\text { core } \omega(\mathrm{mm}) \\
\text { cone } \mathrm{h}(\mathrm{mm})\end{array}$} & \multirow{3}{*}{$\begin{array}{c}200.0 \\
1330.0 \\
1200.0 \\
19.0\end{array}$} & & & \multirow{2}{*}{$\begin{array}{l}\text { MAT10 } \\
\text { MaT5 } \\
\text { MATS } \\
\end{array}$} & \multirow{2}{*}{$\begin{array}{c}\text { nomex } 1.00 \mathrm{~m} \text { - } \\
\text { cooper } \\
\text { mover }\end{array}$} \\
\hline & & & & & \\
\hline & & modo-1 l log = & 18.5 & hentz & \\
\hline
\end{tabular}

\begin{tabular}{|c|c|c|c|c|c|}
\hline \multicolumn{2}{|c|}{ Clowable movorial cholcas } & $E(\omega)$ & $E\left(P_{0}\right)$ & 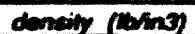 & denoly $(0 \operatorname{com} 3)$ \\
\hline MATI & G10 beninew & $3,300,000$ & 22.759 & 0.069 & 192014 \\
\hline мAT2 & Alase-Inbentepony & 1.000 .000 & 11.034 & 0.067 & 1,05 \\
\hline MaT3 & C-berdopoxy (FR-337) & $5,000,000$ & 34.483 & 0.060 & 1.66 \\
\hline Mata & shominx & $10,000,000$ & 68.966 & 0.098 & 2.710 \\
\hline mats & coppor & $18,000,000$ & 124.138 & 0.322 & 6,0317 \\
\hline mat6 & epory (F 954-3) 350F & 100,000 & 2.759 & 0.043 & 119 \\
\hline MAT7 & ullaratow densily & 100,000 & 690 & 0.015 & 0.42 \\
\hline MATE & smeactic (CG 1617-A) & 350,000 & 2.414 & 0.025 & 0.7 \\
\hline MAT9 & myiax & 550,000 & 3.793 & 0.050 & 1.3009 \\
\hline MAT10 & nomex $1.80 \mathrm{~mm}$ & 0 & $\mathbf{0}$ & 0.001041673 & 0.020894 \\
\hline
\end{tabular}

1 of 2

DR

bastlune

WITHOU7

ACuminum

EXTENIOUS

\begin{tabular}{|c|c|c|c|c|c|c|c|c|c|}
\hline \multirow{2}{*}{$\begin{array}{l}\text { sandwich w (mm) } \\
\text { core } \omega(\mathrm{mm}) \\
\text { come } \mathrm{h}(\mathrm{mm})\end{array}$} & \multirow{2}{*}{$\begin{array}{c}1330.0 \\
1280.0 \\
19.0 \\
\end{array}$} & & & MATS & mor & 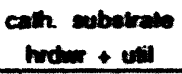 & $\begin{array}{l}0.0 \\
15.7 \\
\end{array}$ & $\begin{array}{l}0.0 \\
0.0 \\
\end{array}$ & \multirow{2}{*}{$\begin{array}{c}0.0 \\
-15.7 \\
0.0\end{array}$} \\
\hline & & $\operatorname{moda}-1$ tean & 18.5 & heriz & & lotats $=$ & 100.0 & 100.0 & \\
\hline & condrich aling & sep trome & cone odpe thor & extentions & sandmich cone & cathode & camode subatrets & Todes & \\
\hline 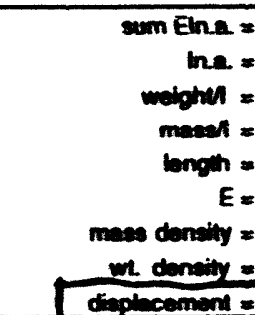 & $\begin{array}{c}7.829 E+11 \\
3.440 E+07 \\
0.1755 \\
17.9340 \\
3.500 \\
22.750 \\
0.061926 \\
1.025 E-05 \\
0.726 \\
\end{array}$ & $\begin{array}{c}.717 E+10 \\
7.900 E+06 \\
0.0543 \\
5.5500 \\
3.500 \\
11.034 \\
0.001850 \\
1.810 E-05 \\
0.729\end{array}$ & $\begin{array}{c}6.659 E+10 \\
2.414 E+07 \\
0.0774 \\
7.9135 \\
3.500 \\
2.759 \\
0.001190 \\
1.164 E-05 \\
0.726\end{array}$ & $\begin{array}{c}0.000 E+00 \\
0.000 E+00 \\
0.0000 \\
0.0000 \\
3.500 \\
68.066 \\
0.002710 \\
2.660 E-05 \\
0.000\end{array}$ & $\begin{array}{c}0.000 E+00 \\
0.000 E+00 \\
0.0481 \\
4.9189 \\
3.500 \\
0 \\
0.000029 \\
2.827 E-07 \\
\text { ceed bed }\end{array}$ & $\begin{array}{c}7.375 E+10 \\
5.941 E+05 \\
0.0199 \\
2.0291 \\
3.500 \\
124.130 \\
0.000932 \\
0.740 E-05 \\
0.726\end{array}$ & $\begin{array}{c}0.000 E+00 \\
0.000 E+00 \\
0.0000 \\
0.0000 \\
3.500 \\
3.793 \\
0.001387 \\
1.357 E-05 \\
0.000\end{array}$ & $\begin{array}{c}1.010 E+12 \\
6.700 E+07 \\
0.3752 \\
38.35 \\
\ldots . \\
233.448 \\
0.018032 \\
1.765 E-04 \\
\ldots\end{array}$ & 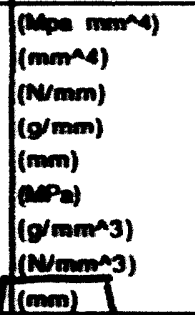 \\
\hline 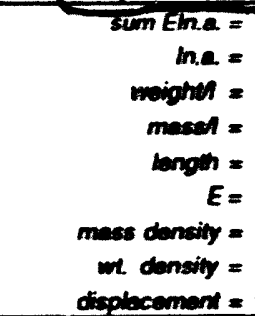 & $\begin{array}{c}2.727 E+0.0 \\
02.65 \\
1.00 \\
2.504 E-03 \\
137.00 \\
3.300 .000 \\
1.797 E-04 \\
0.069 \\
20.50\end{array}$ & $\begin{array}{c}.037 E+07 \\
18.90 \\
0.31 \\
8.026 E-04 \\
137.00 \\
1.000 .000 \\
1.726 E-04 \\
0.067 \\
28.50\end{array}$ & $\begin{array}{c}2.320 E+07 \\
58.00 \\
0.44 \\
1.144 E-03 \\
137.00 \\
400.000 \\
1.110 E-04 \\
0.043 \\
20.50\end{array}$ & $\begin{array}{c}0.000 E+00 \\
0.00 \\
0.00 \\
0.000 E+00 \\
137.00 \\
10.000 .000 \\
2.530 E-04 \\
0.098 \\
0.00\end{array}$ & $\begin{array}{c}0.000 E+\infty \\
0.00 \\
0.27 \\
7.114 E-04 \\
137.80 \\
0 \\
2.696 E-06 \\
0.001 \\
\text { cond bed }\end{array}$ & $\begin{array}{c}2.509 E+07 \\
1.43 \\
0.11 \\
2.934 E-04 \\
137.00 \\
10.000 .000 \\
8.333 E-04 \\
0.322 \\
20.50 \\
\end{array}$ & $\begin{array}{c}0.000 E+00 \\
0.00 \\
0.00 \\
0.000 E+00 \\
137.00 \\
550.000 \\
1.294 E-01 \\
0.050 \\
0.00 \\
\end{array}$ & $\begin{array}{c}.520 E+00 \\
161.05 \\
2.14 \\
5.546 E-03 \\
\ldots . \\
\cdots \\
1.622 E-03 \\
0.650 \\
\ldots \\
\end{array}$ & 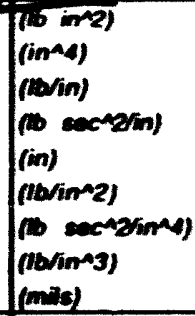 \\
\hline 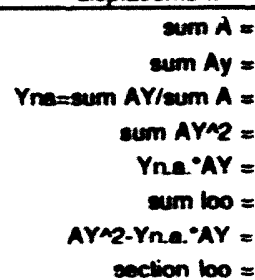 & $\begin{array}{l}.3100 E+03 \\
9.3100 E+05 \\
1.0000 E+02 \\
1.2750 E+08 \\
9.3100 E+07 \\
1.9396 E+02 \\
3.4401 E+07 \\
3.4401 E+07\end{array}$ & $\begin{array}{l}3.0000 E+03 \\
3.0000 E+05 \\
1.0000 E+02 \\
3.7875 E+07 \\
3.0000 E+07 \\
2.5000 E+04 \\
7.6750 E+06 \\
7.9000 E+06\end{array}$ & $\begin{array}{l}6.6500 E+03 \\
6.6500 E+05 \\
1.0000 E+02 \\
9.0440 E+07 \\
6.6500 E+07 \\
2.0005 E+05 \\
3.3940 E+07 \\
2.4140 E+07\end{array}$ & $\begin{array}{l}0.0000 E+00 \\
0.0000 E+00 \\
0.0000 E+00 \\
0.0000 E+00 \\
0.0000 E+00 \\
0.0000 E+00 \\
0.0000 E+00 \\
0.0000 E+00\end{array}$ & $\begin{array}{l}1.7024 E+05 \\
1.7024 E+07 \\
1.0000 E+02 \\
2.3153 E+09 \\
1.7024 E+09 \\
5.1214 E+06 \\
6.1266 E+08 \\
6.1799 E+08\end{array}$ & $\begin{array}{l}2.2717 E+02 \\
2.2717 E+04 \\
1.0000 E+02 \\
2.6658 E+06 \\
2.2717 E+06 \\
5.4711 E-03 \\
5.9407 E+05 \\
5.9407 E+05\end{array}$ & $\begin{array}{l}0.0000 E+\infty 0 \\
0.0000 E++00 \\
0.0000 E+\infty 0 \\
0.0000 E+\infty 0 \\
0.0000 E+\infty 0 \\
0.0000 E+00 \\
0.0000 E+\infty 0 \\
0.0000 E+\infty 0\end{array}$ & $\begin{array}{c}1.694 E+05 \\
\cdots \\
\cdots \\
2.574 E+08 \\
\cdots \\
5.347 E+06 \\
\cdots \\
6.850 E+08\end{array}$ & 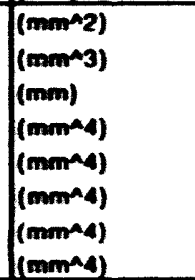 \\
\hline
\end{tabular}

\begin{tabular}{|c|c|c|c|c|c|c|}
\hline \multicolumn{2}{|c|}{ composition } & component & $x$ of lool w & $x$ of lot caried & xcaried-xm & mess (n) \\
\hline MAT2 & glass-liberlopoxy & \multirow{8}{*}{ 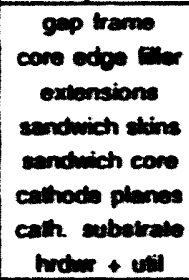 } & 12.2 & 8.6 & -3.6 & 19.43 \\
\hline MAT6 & epoxy (F 954-3) 350f & & 17.4 & 6.6 & -10.8 & 27.70 \\
\hline MATA & cuminum & & 0.0 & 0.0 & 0.0 & 0.00 \\
\hline MATI & G10 uminate & & 39.4 & 77.5 & 38.1 & 62.77 \\
\hline MATIO & nomex $1.00 \mathrm{~min}$ & & 10.8 & 0.0 & -10.8 & 17.22 \\
\hline Mar5 & cooper & & 4.5 & 7.3 & 2.8 & 7.10 \\
\hline \multirow[t]{2}{*}{ MATS } & more & & 0.0 & 0.0 & 0.0 & 0.00 \\
\hline & & & 15.7 & 0.0 & -15.7 & 25.00 \\
\hline & & lotals $=$ & 100.0 & 100.0 & & 9.21 \\
\hline
\end{tabular}


\%.w.

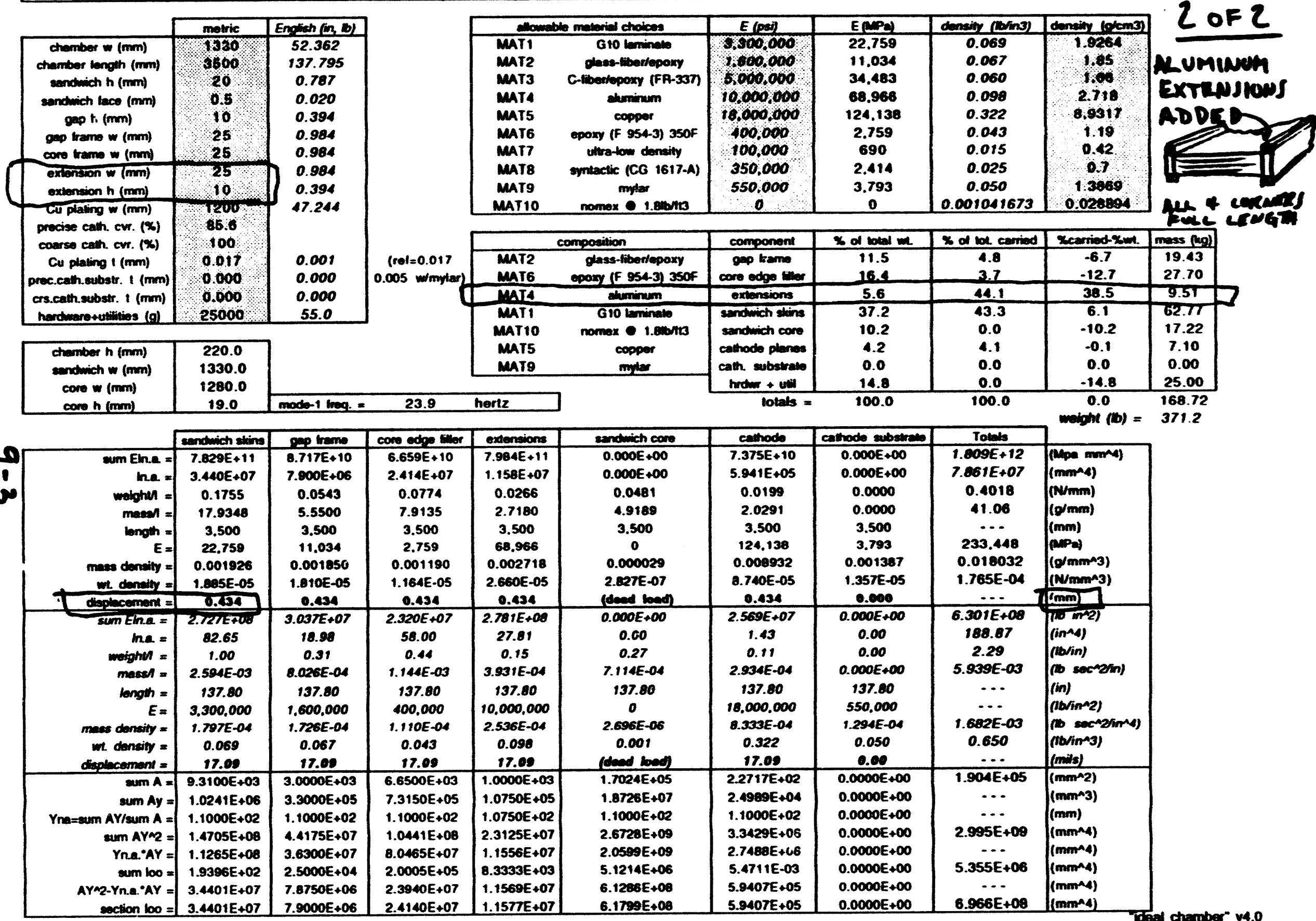




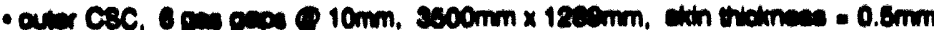

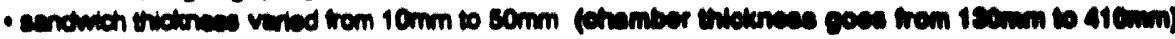

- Tremo water veried trom $10 \mathrm{~mm}$ to comm

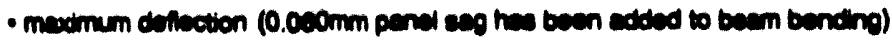

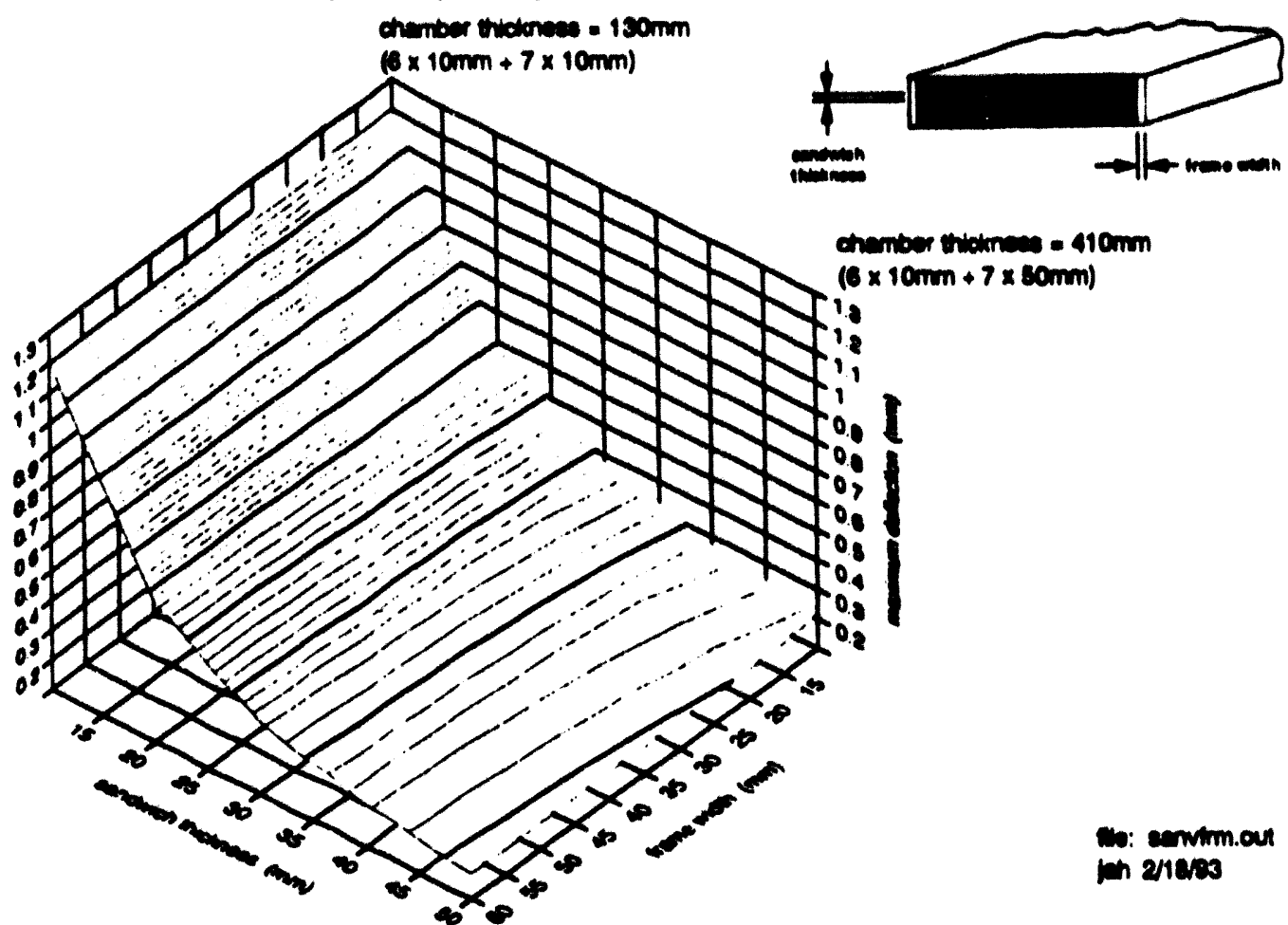

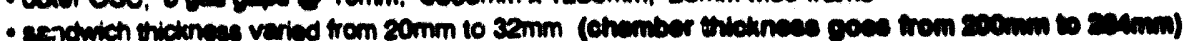

- akin thickneas varied from $0.8 \mathrm{~mm}$ to $8.0 \mathrm{~mm}$

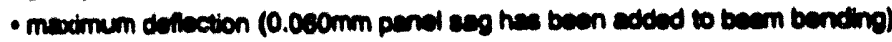
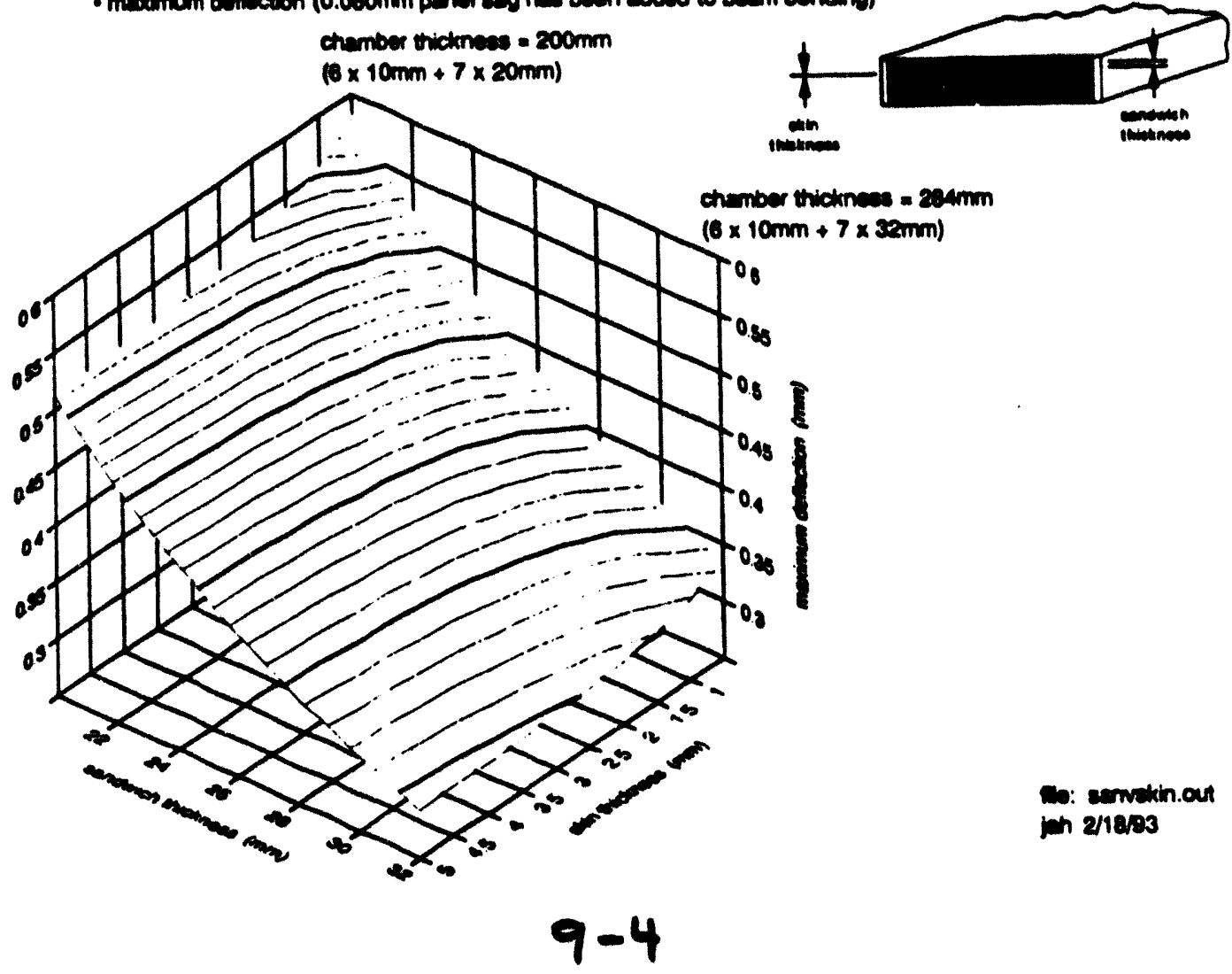
- inner CSC, 6 os gaps @ $5 \mathrm{~mm}, 3000 \mathrm{~mm} \times 700 \mathrm{~mm}, 25 \mathrm{~mm}$ wide treme

- sandwict thickness varied from $20 \mathrm{~mm}$ to $32 \mathrm{~mm}$ (chember thicknces goes from $170 \mathrm{~mm}$ to $284 \mathrm{~mm}$ )

- skin thickness varied from $0.5 \mathrm{~mm}$ to $5.0 \mathrm{~mm}$

- maximum deflection $(0.060 \mathrm{~mm}$ panel seg has been added to beam bending)

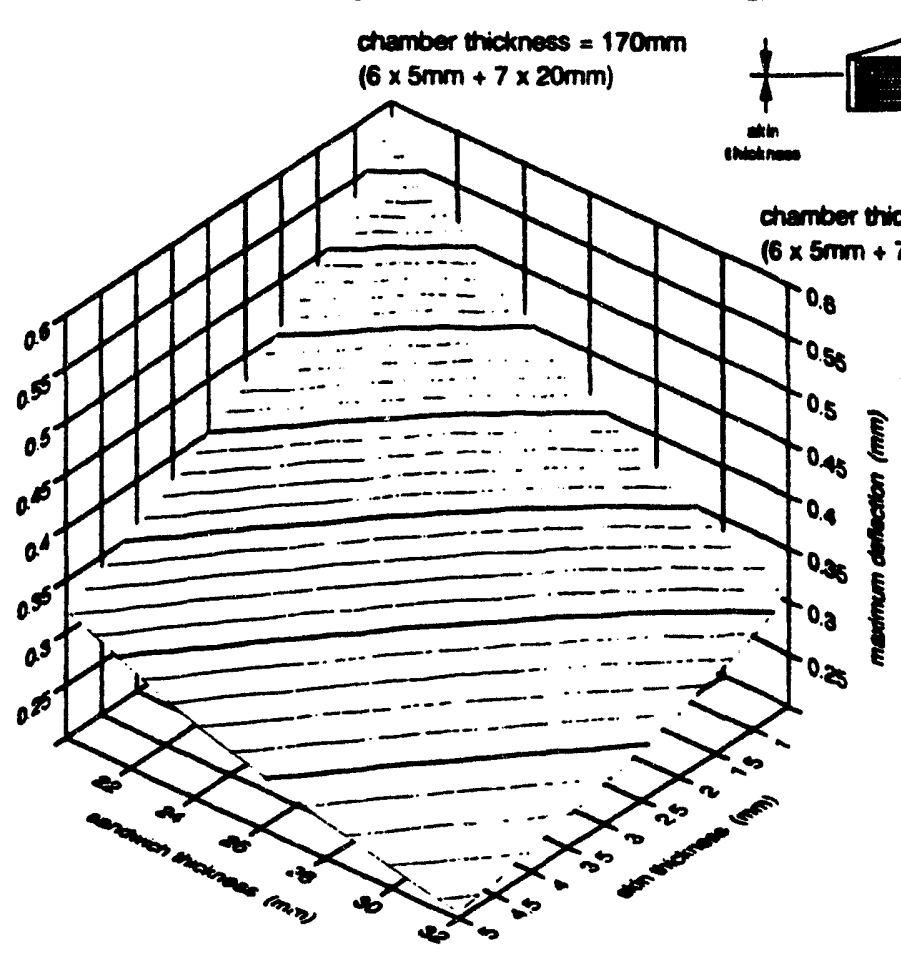

We: envinin

$\operatorname{lin} 2 / 18 / 93$

- avier CSC, 6 gas gaps @ 10 10mm, 3500 $\mathrm{mm} \times 1200 \mathrm{~mm}$, treme wioth $=25 \mathrm{~mm}$

- central sandwich thickness veried from $20 \mathrm{~mm}$ to $80 \mathrm{~mm}$ (chamber thictenies hadd conetent co $200 \mathrm{~mm}$ )

- skin thickness varied from $0.5 \mathrm{~mm}$ to $5.0 \mathrm{~mm}$

- maximum dellection $(0.080 \mathrm{~mm}$ panel seg has been added to baem bending)
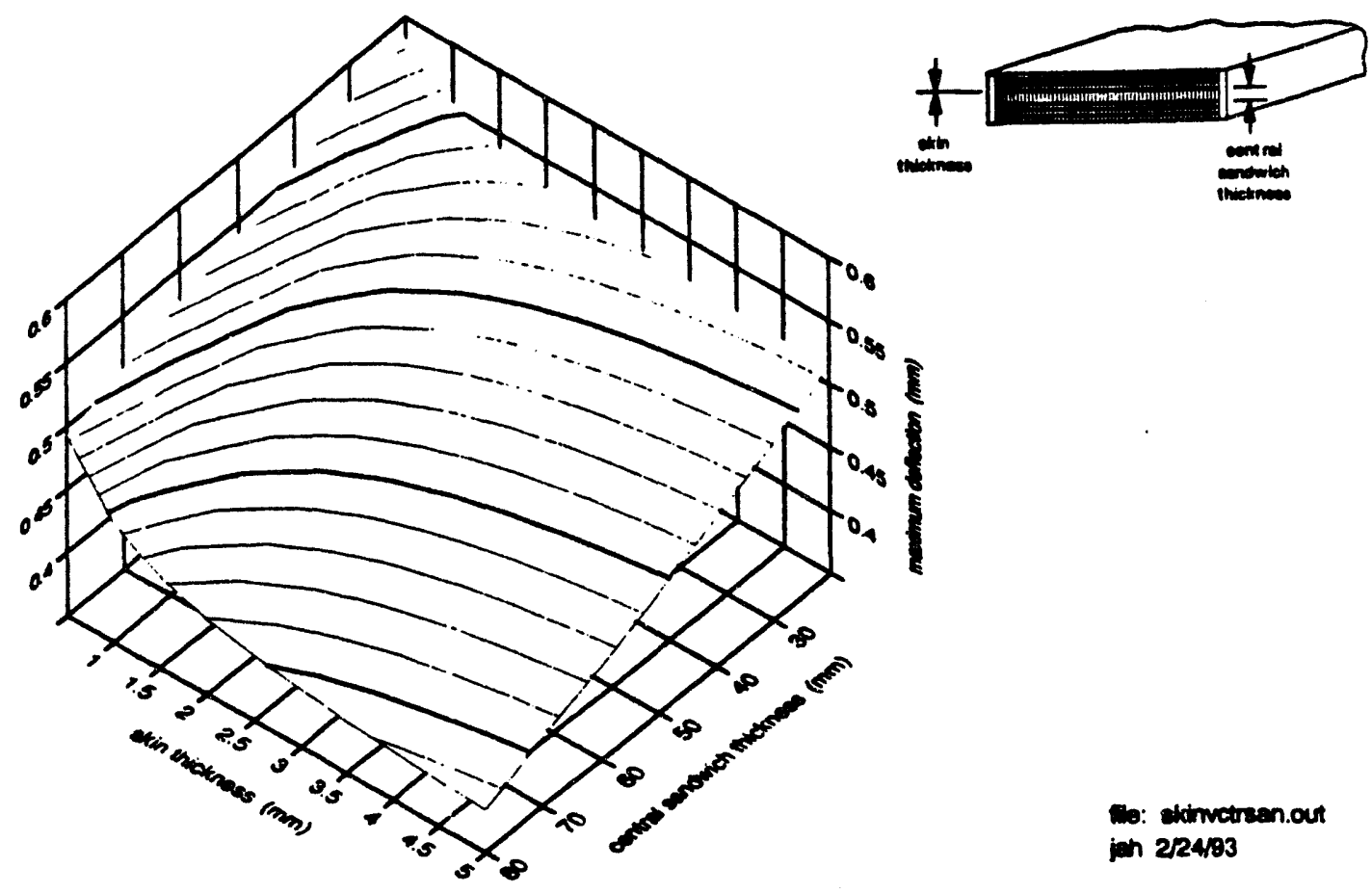

To: dirmetisen.out ing $2 / 2483$ 
- aver CSC, $6 \mathrm{ges}$ geps (10 10mm, 1209mm wide, $25 \mathrm{~mm}$ wide trame, atin thk. $=0.8 \mathrm{~mm}$

- chamber lenoth veried from $3000 \mathrm{~mm}$ to $3500 \mathrm{~mm}$

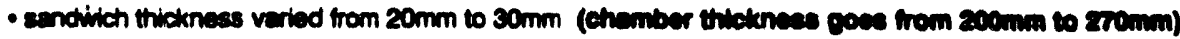

- meximum deflection (0.060mm penci sag hes been added to beam bending)

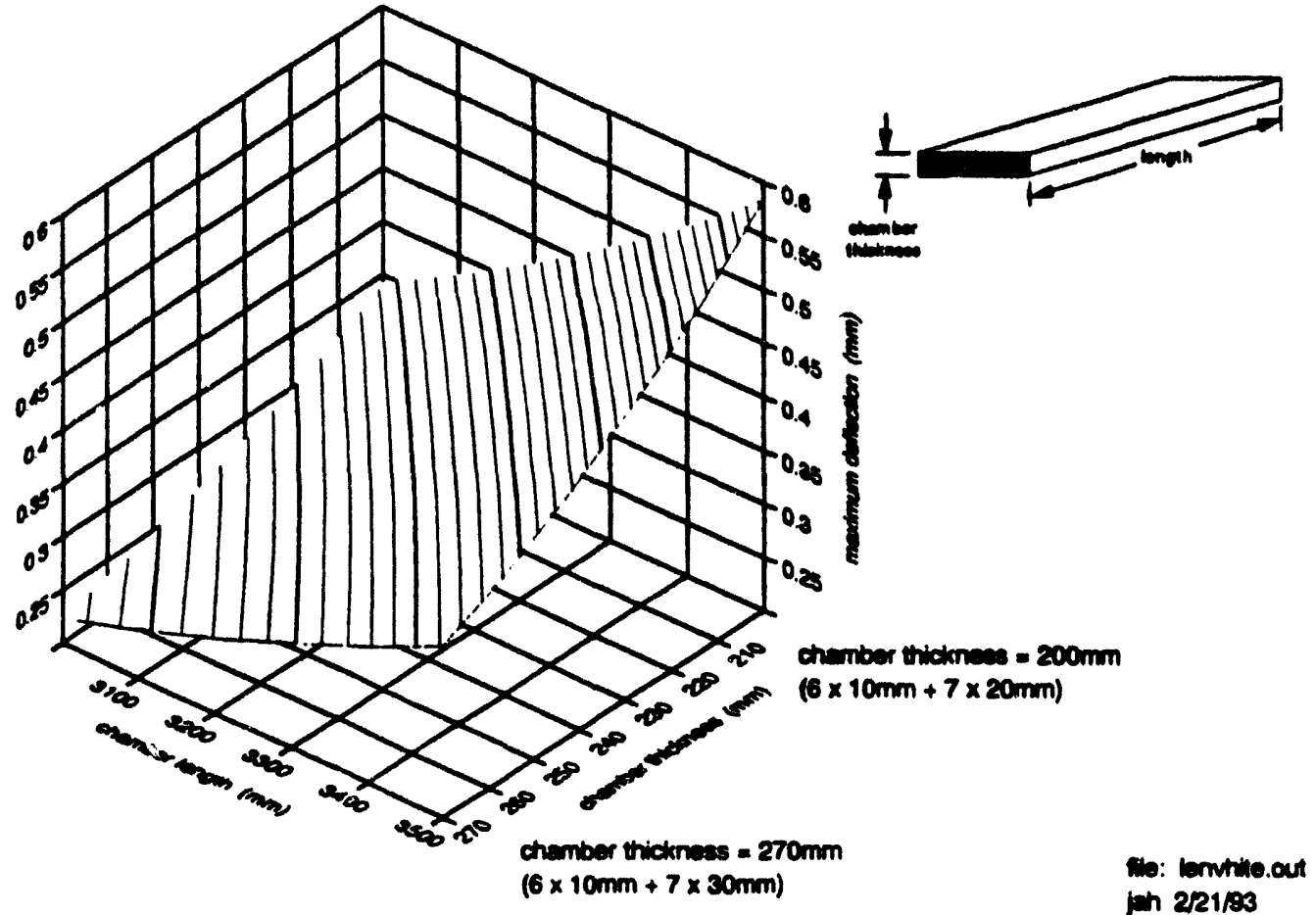

ing 2/21/33

Outer CSC. 6 ges gaps, 7 pands @ $20 \mathrm{~mm}, 3600 \mathrm{~mm} \times 1280 \mathrm{~mm} \times 200 \mathrm{~mm}$

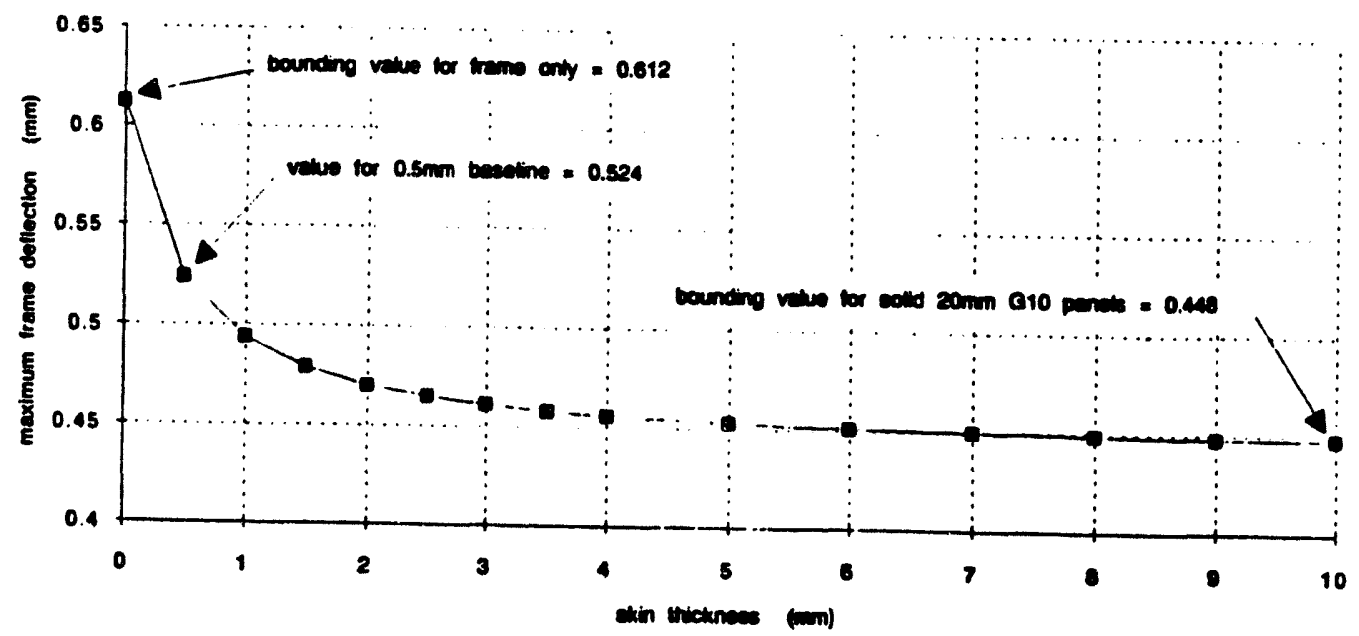

definction ve. atin thictines

$$
9-6
$$




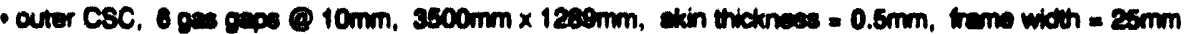

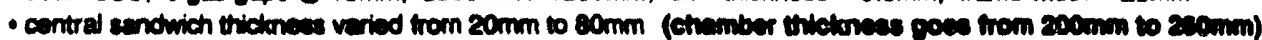

- extersion neight varied trom 0 to $60 \mathrm{~mm}$

- maximum doflection $(0.060 \mathrm{~mm}$ pendel sag has been edded to beam bending)

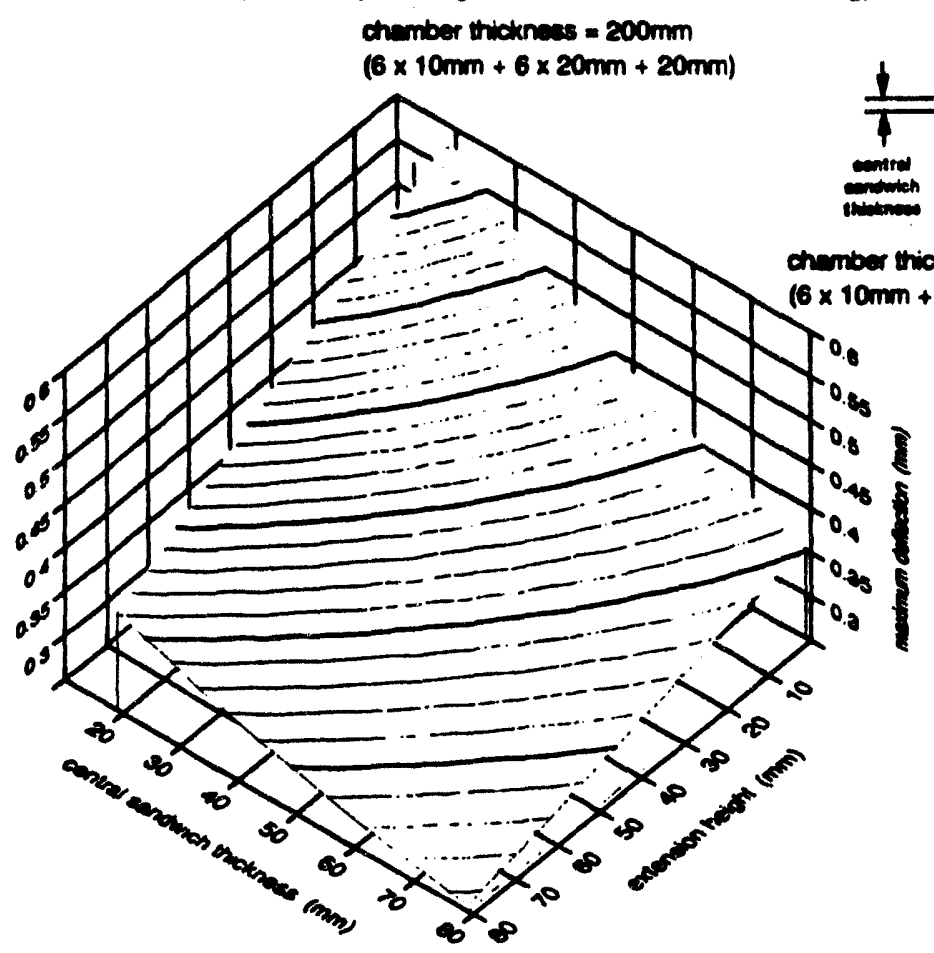

Th: ctrsenvextout

in 2/18/93

- ovier CSC, 6 gess oeps @ 10 10mm, 3500mm x 1289mm, $25 \mathrm{~mm}$ wide trame

8 of 9

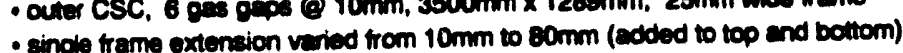

- skin thickness vertod from $0.5 \mathrm{~mm}$ to $5.0 \mathrm{~mm}$ (chamber thickneas hald concterte al $200 \mathrm{~mm}$ )

- maximum deflection (0.060mm penel eag has been adoded to bes am bending)

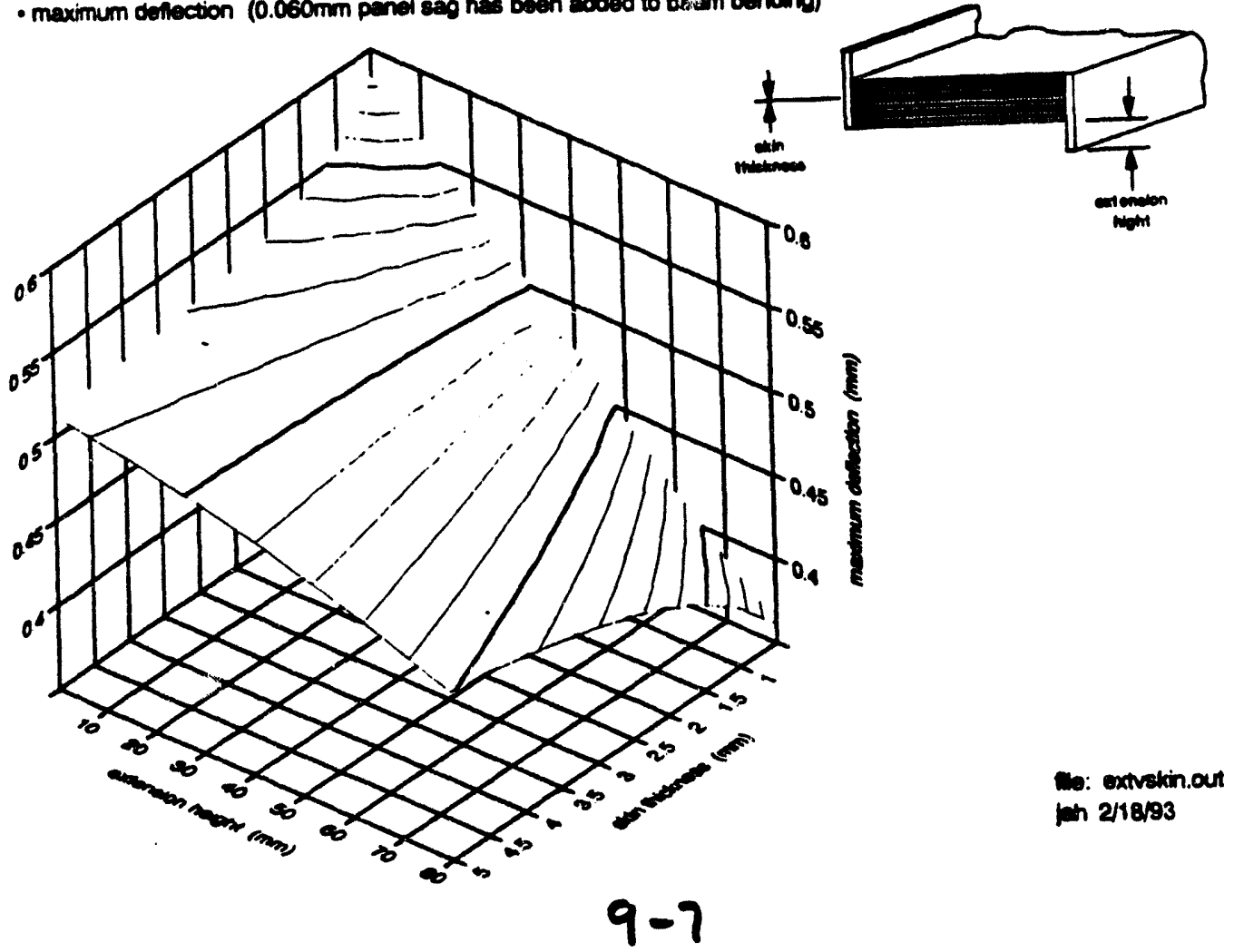


- inner CSC. $6 \mathrm{ges}$ gepe $95 \mathrm{~mm}, 3500 \mathrm{~mm} \times 700 \mathrm{~mm}, 28 \mathrm{~mm}$ wide trame

- treme extenaion veried trom 0 to $80 \mathrm{~mm}$ (edded to top and bottom)

- skin thickness varied trom $0.5 \mathrm{~mm}$ to $5.0 \mathrm{~mm}$ (chamber thickneas held oonetent a $17 \mathrm{cmn}$ )

- maximum dorlection $(0.080 \mathrm{~mm}$ penter eag has been added to baem bending)

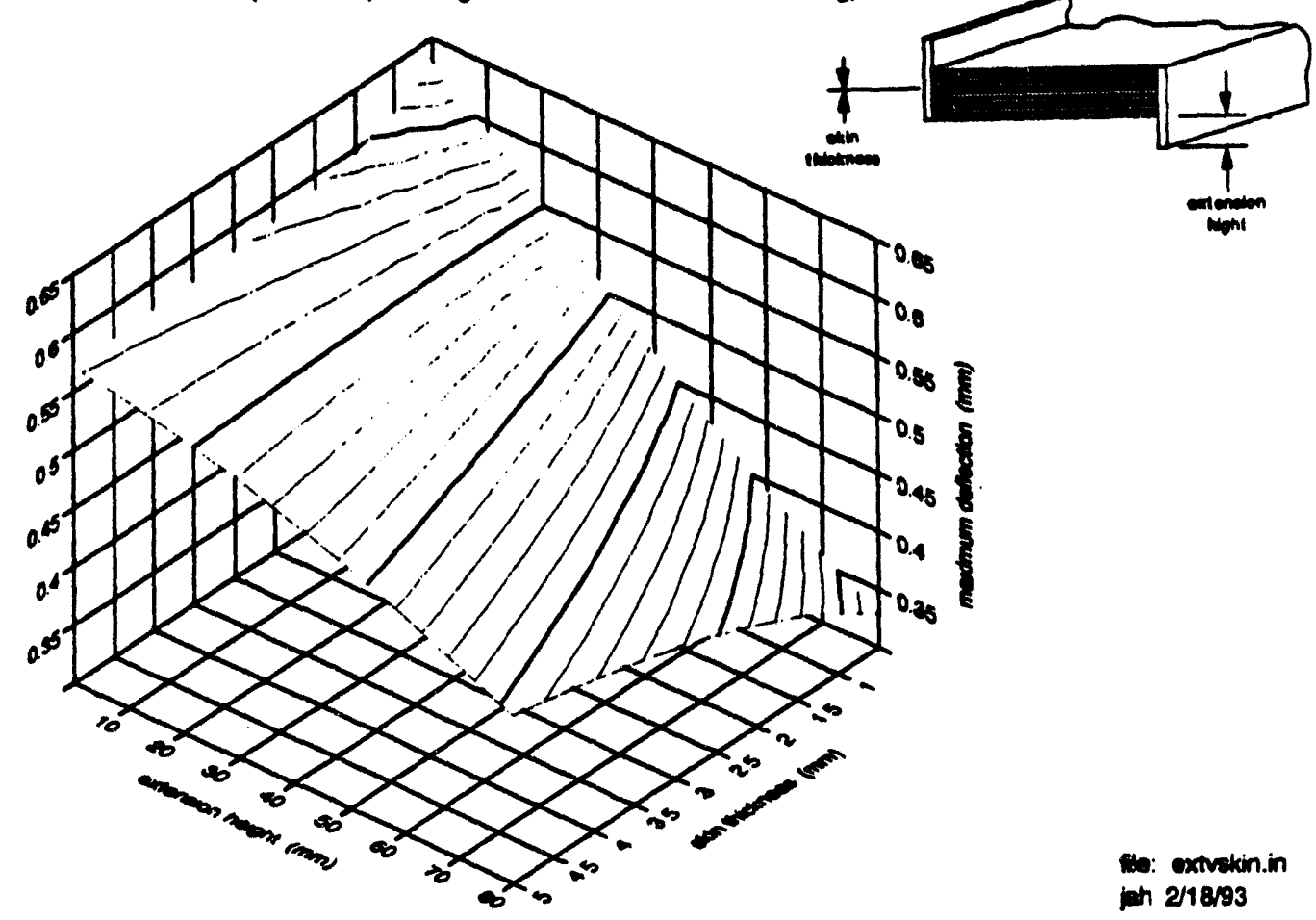


GEM TN-93-494

\title{
10. Thermal Deformation
}

\author{
Contents:
}

Summary viewgraph (1 page)

Slab thermal deformation calculation (2 pages)

\section{Summary:}

Thermal deformation of a slab is proportional to the first power of temperature and CTE, the second power of length and width, and inversely propoitional to the first power of slab thickness. 


\section{Thermal Deformation Levels Are Acceptable}

- Thermal deflection of a homogeneous slab subjected to a linear temperature gradient through its thickness is

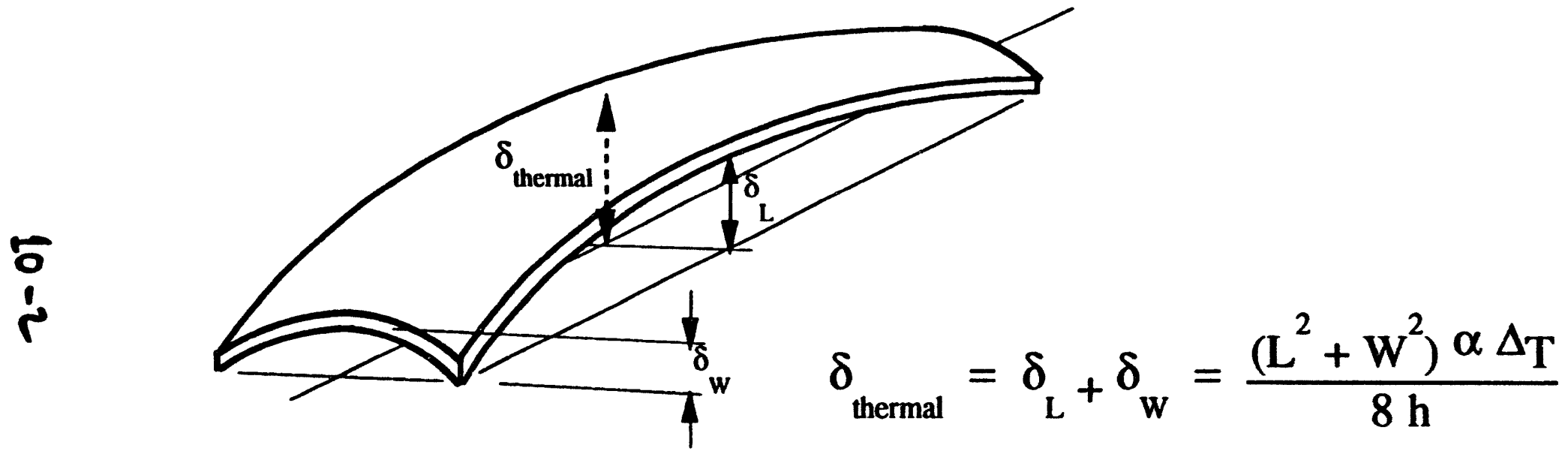

where, $L=$ length

$\mathbf{W}=$ width

$\alpha=$ coefficient of thermal expansion $=11.3 \times 10^{-6} / \mathrm{C}$

$\mathrm{h}=$ thickness

${ }_{\mathrm{T}}=2 \mathrm{C} / 9.0 \mathrm{~m} \times$ thickness

\begin{tabular}{|c|c|c|c|c|}
\hline chamber & length $(\mathrm{mm})$ & width $(\mathrm{mm})$ & thickness $(\mathrm{mm})$ & deflection $(\mathrm{mm})$ \\
\hline outer superlayer & 3500 & 1300 & 200 & 0.004 \\
middle superlayer & 2600 & 1100 & 188 & 0.001 \\
inner superlayer & 3500 & 770 & 170 & 0.004 \\
\hline
\end{tabular}




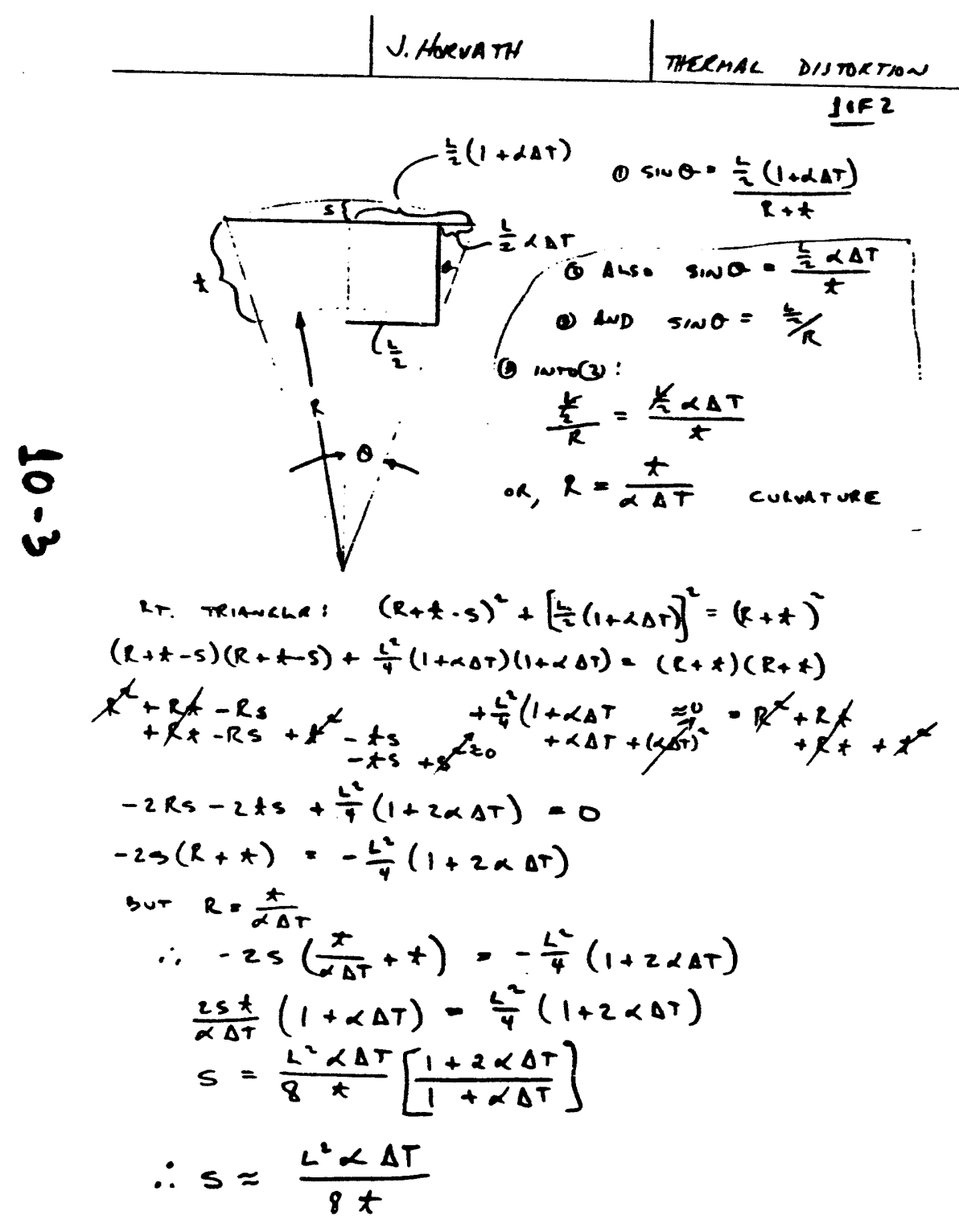

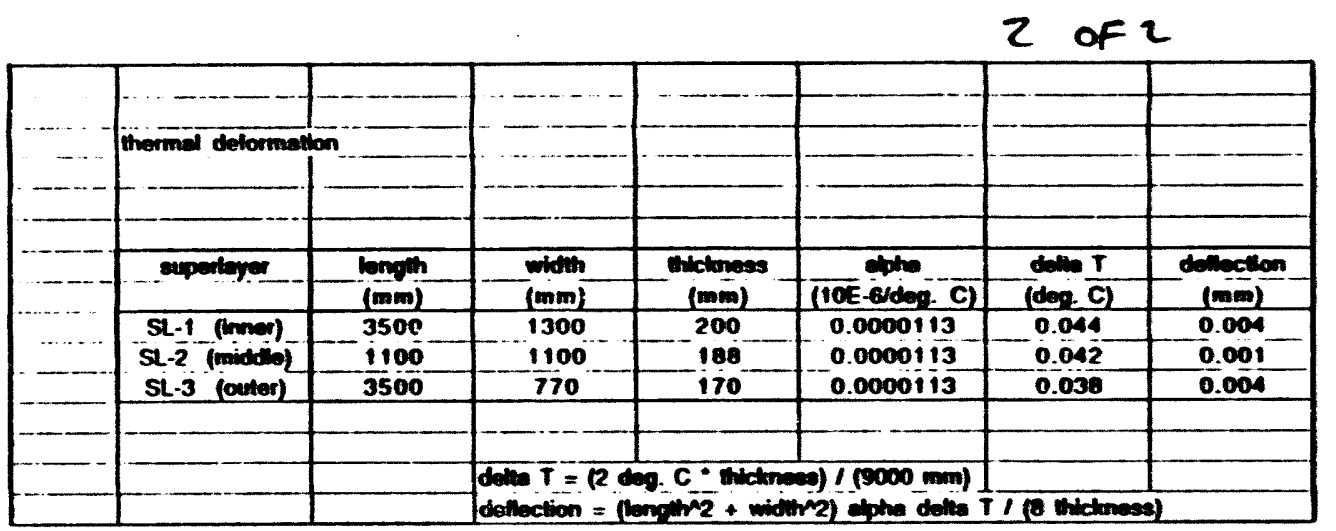




\section{Support Point Location and Gravity Sag}

Contents:

Analysis of gravity sag of TDR SL-3 barrel chamber vs. support point location (3 pages)

Calculation of shear, moment, curvature, and deflection functions (6 pages)

Beam deflection "special cases" chart, ref. Don Carter, LLNL (1 page)

Summary:

The optimum support points for a uniformly loaded beam are located $0.223 \mathrm{~L}$ from the ends of the beam.

Support at the extreme ends results in a gravity sag 48.6 times higher than the optimum. 
GRAvITI SAC IE Rlakr SUPmer is KEPT AT END AUD 1 OP 3 bEEr eupcokr is Moveo INWARD.

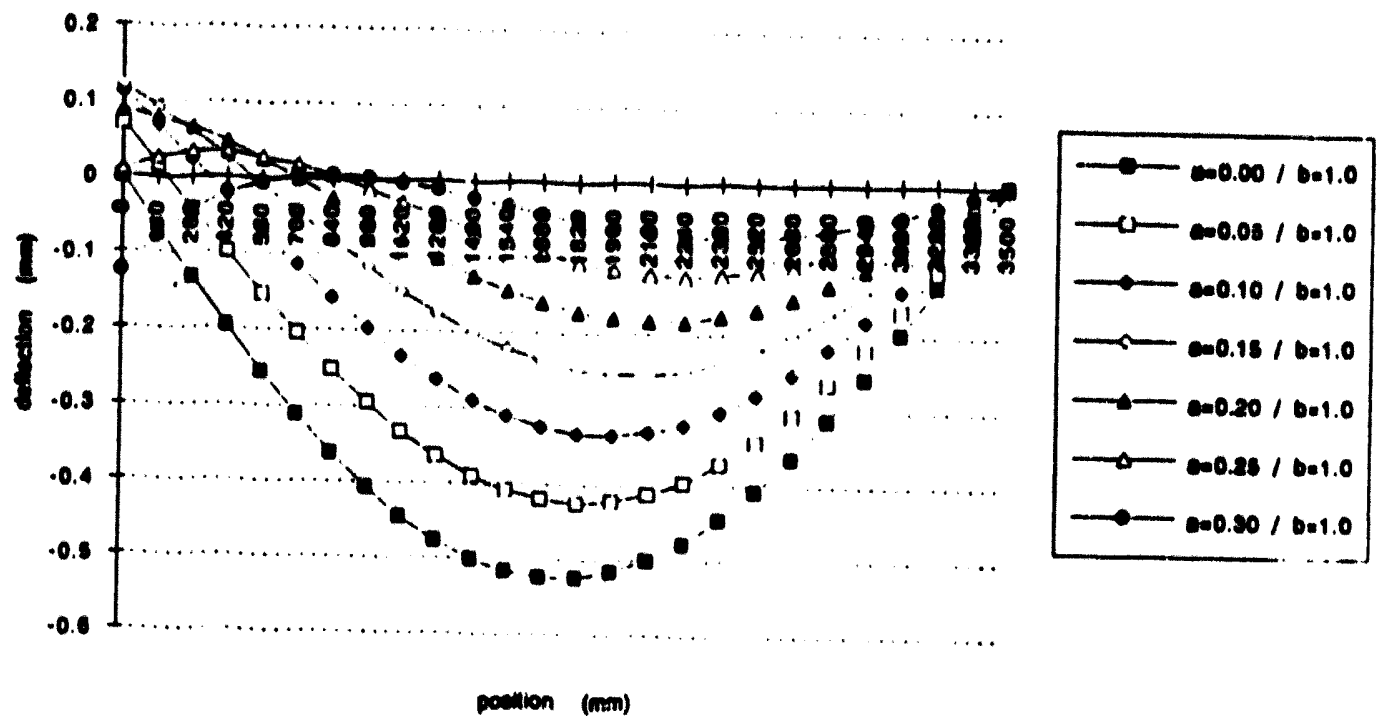

encimedien v. un uppon

GRAVITY SAG IF BEFT SUPPORT IS KEPT AT ASL AND RICAT SUPPORT IS MOVED INWARD.

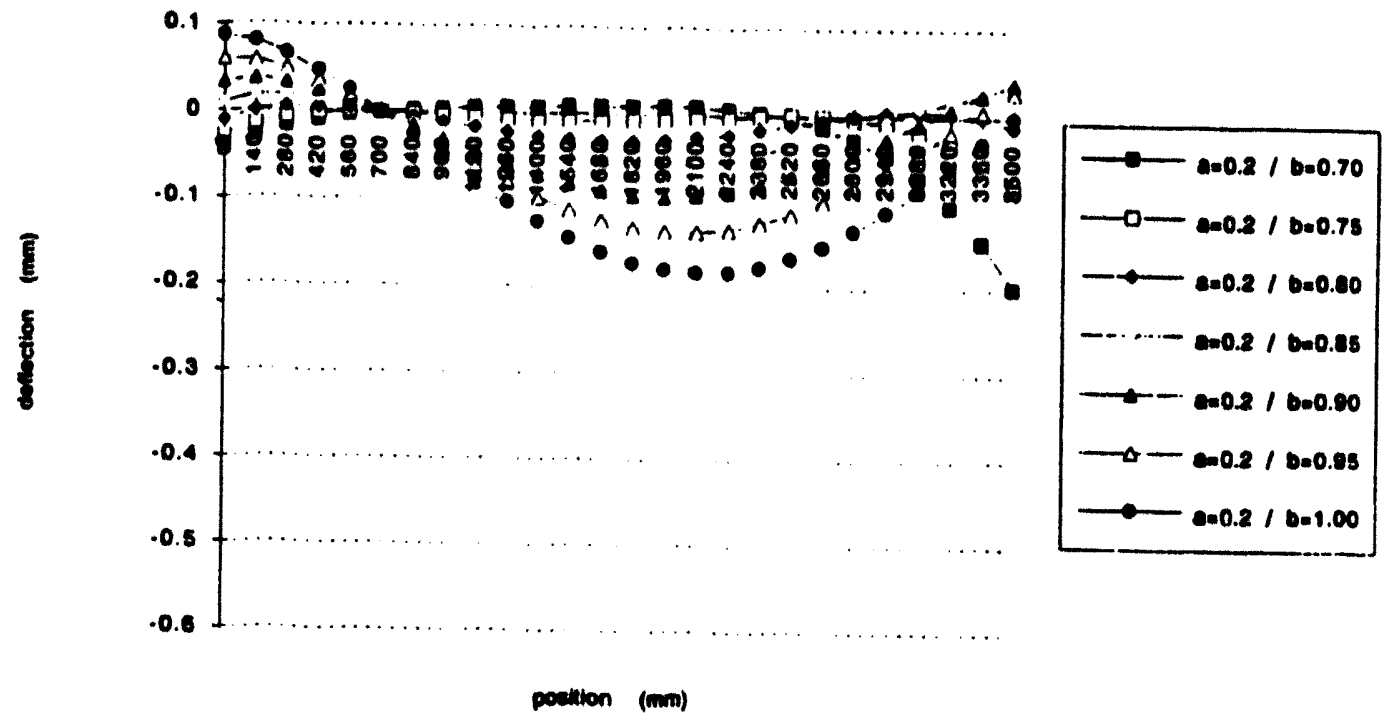




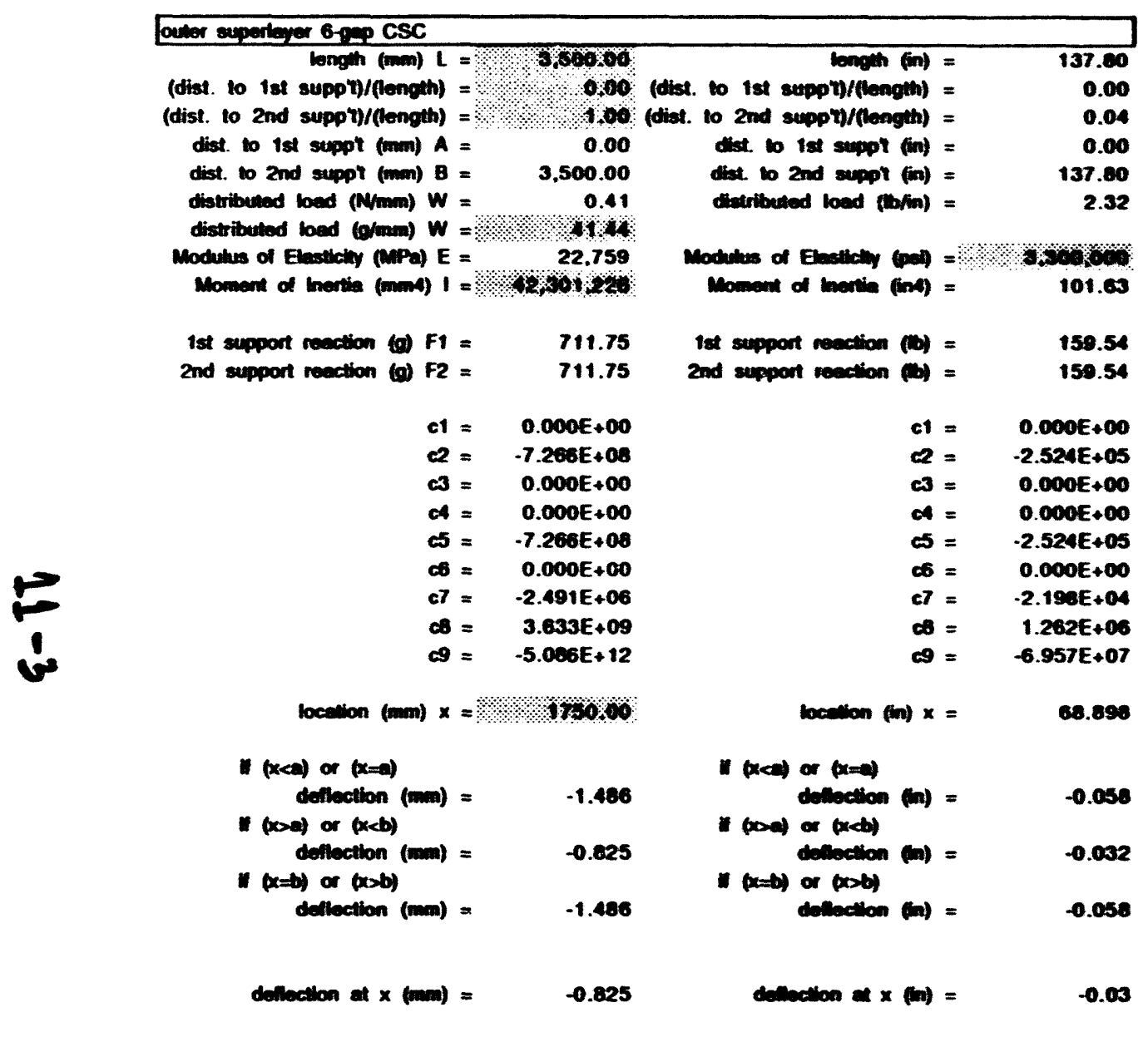

3 op 3

\begin{tabular}{|c|c|c|}
\hline \multicolumn{2}{|l|}{ bection $x$} & doflection \\
\hline 0.825 & 3500 & \\
\hline - & & 0.000 \\
\hline 100 & & -0.075 \\
\hline 200 & & -0.150 \\
\hline 300 & & -0.223 \\
\hline 400 & & -0.294 \\
\hline 500 & & -0.363 \\
\hline 600 & & -0.420 \\
\hline 700 & & -0.490 \\
\hline 000 & & -0.548 \\
\hline 900 & & -0.601 \\
\hline 1000 & & -0.649 \\
\hline 1100 & & -0.692 \\
\hline 1200 & & -0.729 \\
\hline 1300 & & -0.761 \\
\hline 1400 & & -0.766 \\
\hline 1500 & & -0.005 \\
\hline 1600 & & -0.010 \\
\hline 1700 & & -0.025 \\
\hline 1800 & & 0.025 \\
\hline 1900 & & -0.818 \\
\hline 2000 & & -0.005 \\
\hline 2100 & & -0.786 \\
\hline 2200 & & -0.761 \\
\hline 2300 & & -0.729 \\
\hline 2400 & & -0.692 \\
\hline 2500 & & -0.649 \\
\hline 2600 & & -0.601 \\
\hline 2700 & & -0.548 \\
\hline 2000 & & -0.480 \\
\hline 2900 & & -0.428 \\
\hline 3000 & & -0.363 \\
\hline 3100 & & -0.294 \\
\hline 3200 & & -0.223 \\
\hline 3300 & & -0.150 \\
\hline 3400 & & -0.075 \\
\hline 3500 & & \\
\hline
\end{tabular}

\section{ASSUMED SECMOW PRORERMES AND DIMENSIONS}

(APPROXIMATE TOR SL-3 BARREL CHAMBER) 


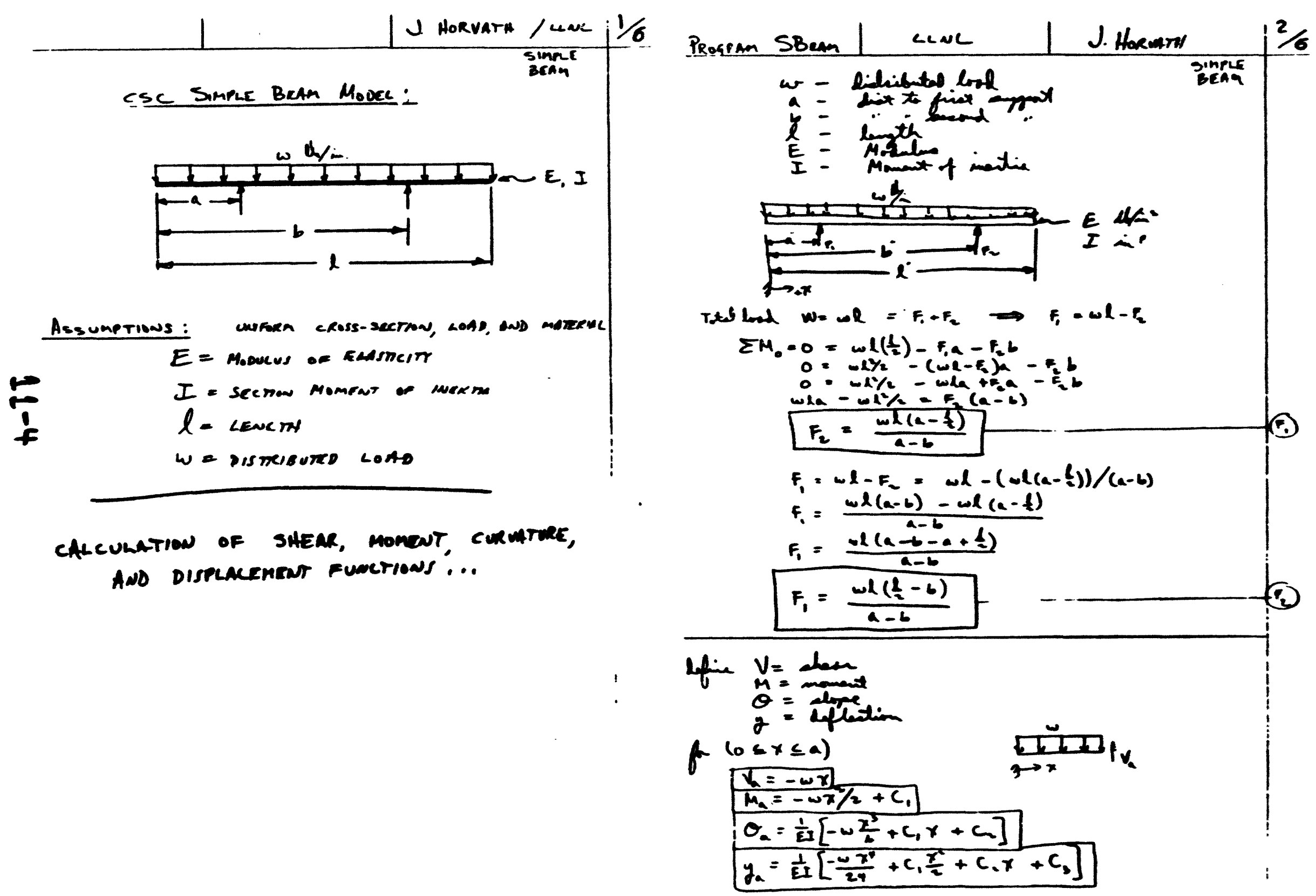




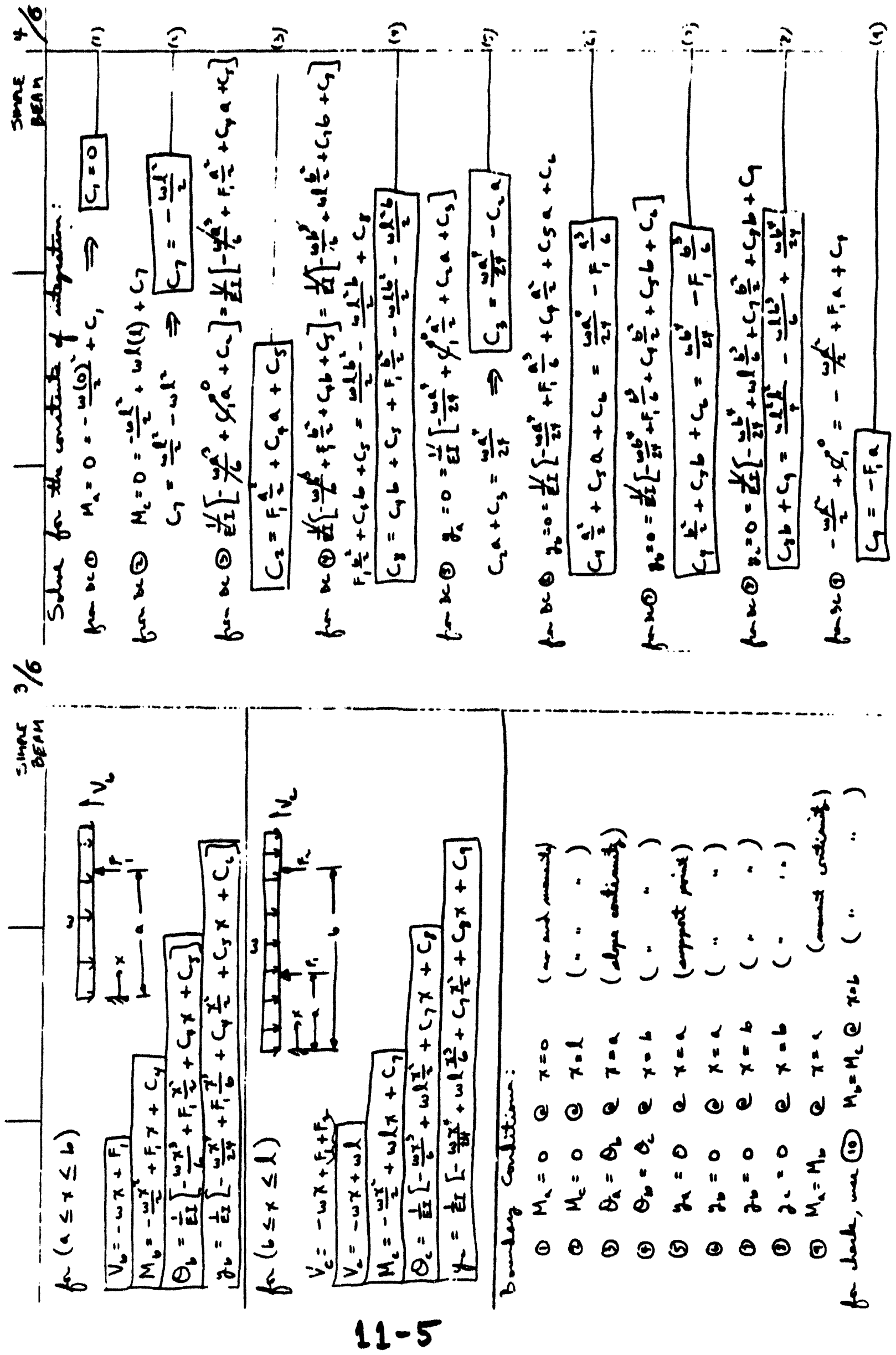




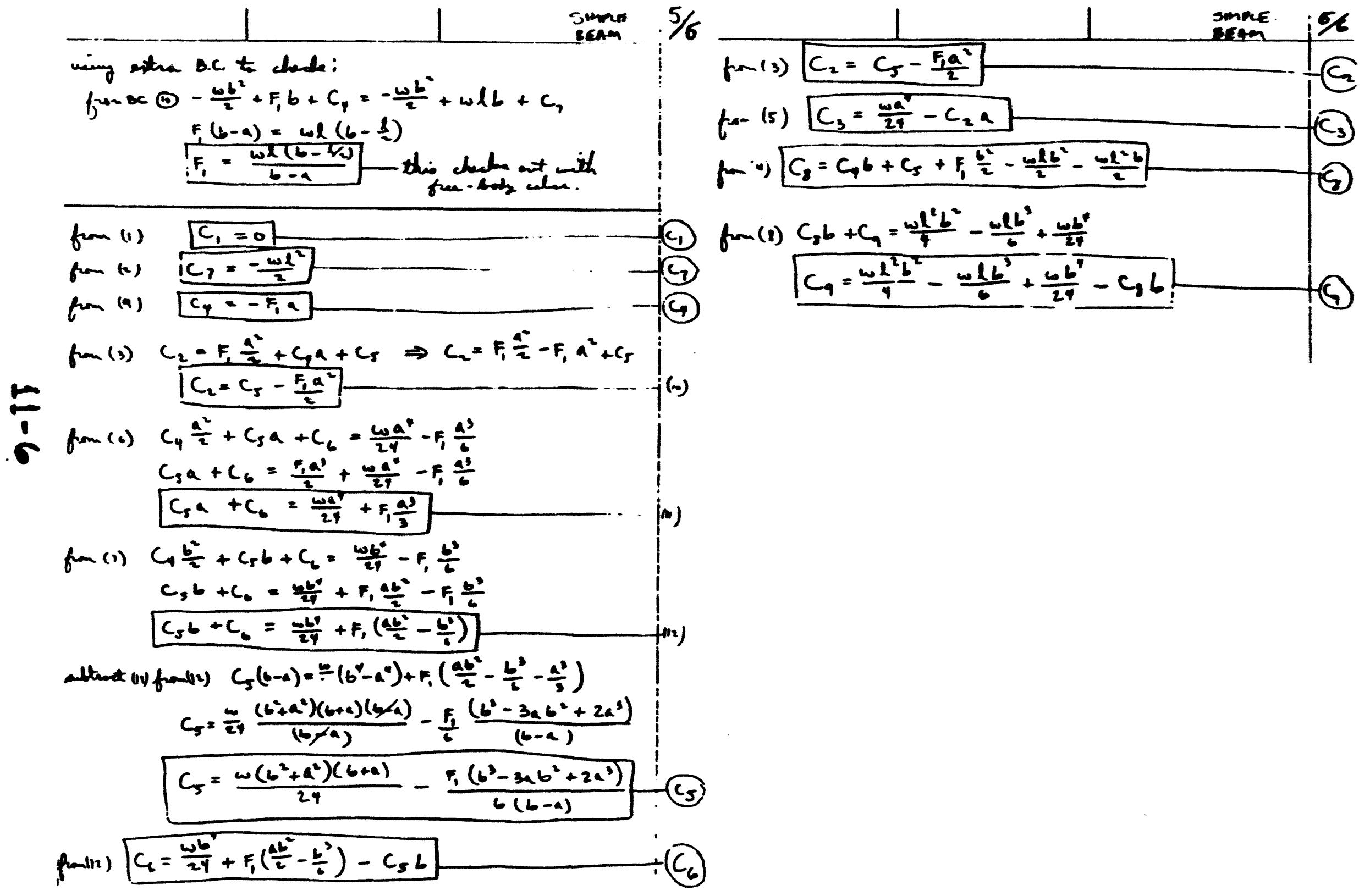




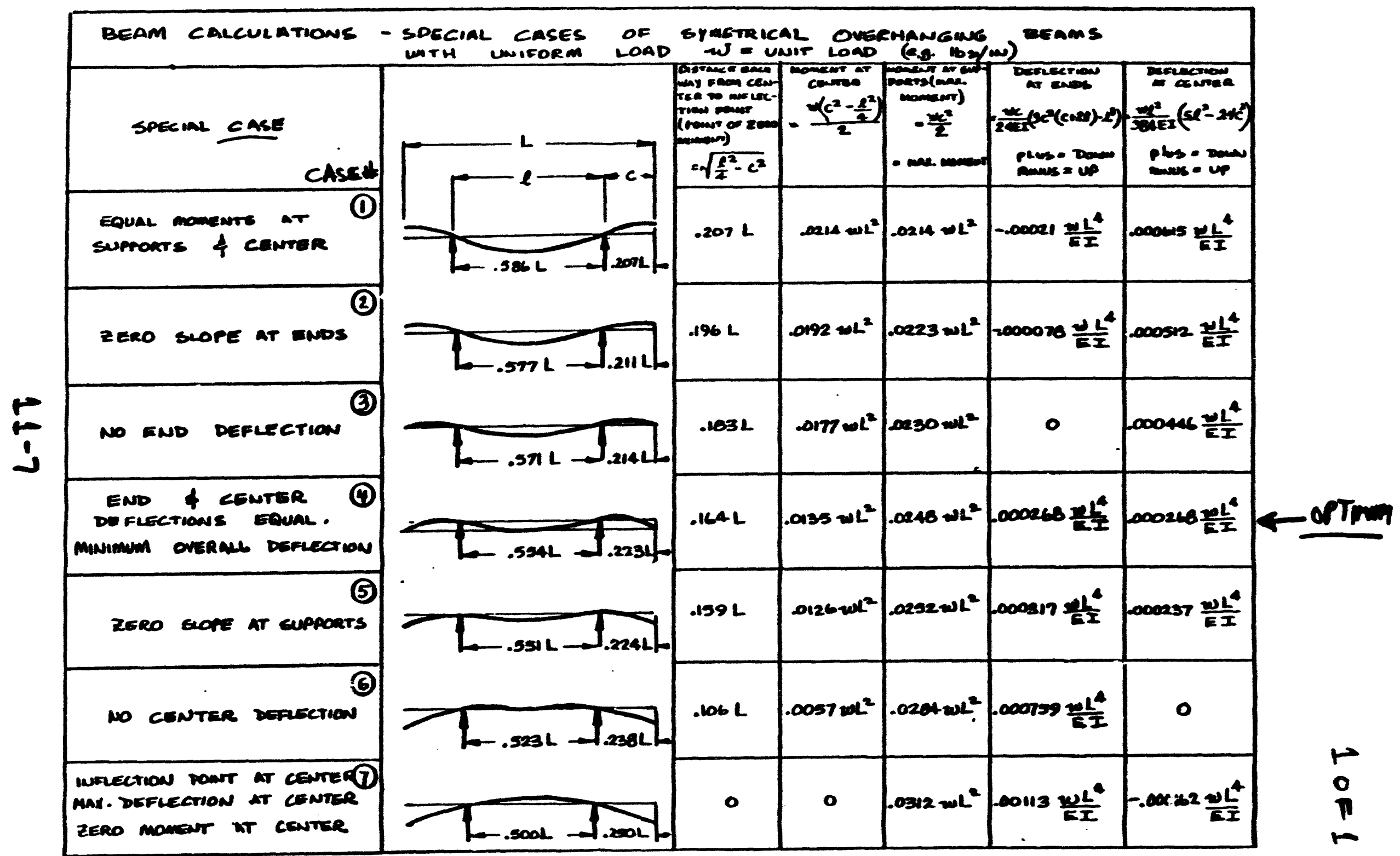

REF. DON CARTER, LLNL 


\section{Bulge Due To Internal Pressure}

\section{Contents:}

Summary viewgraphs (4 pages)

Chamber with external plenum, quarter-symmetry model and deflection results (10 pages)

TDR Baseline with 3 internal posts, quarter-sym. model and deflection results (8 pages)

Chamber without plenum or posts, quarter-sym. model and deflection results (7 pages)

Hand calculation of bulge using simply-supported edges for upper bound value ( 3 pages)

Spacer post design detail and comments (1 page)

\section{Summary:}

Panel bulge is proportional to the 4th. power of unsupported span, 2nd. power of outermost sandwich thickness, and 1st. power of outermost sandwich skin thickness. A hand calculation using simply-supported edges (no edge moments) provides an upper bound to the expected value $(0.359 \mathrm{~mm}$ for SL-3 TDR Baseline chamber). A finite element model provides the actual value and the deflected shape $(0.064 \mathrm{~mm}$ for SL-3 TDR Baseline chamber). The internal spacer posts carry high tensile loads to react the pressure load.

An external plenum, or bladder, eliminates the bulge on all cathode planes and transfers it to the external bladder itself. Spacer post tensile loads are reduced to the minimum amount needed to maintain contact for controlling the cathode-to-cathode spacing. 


\section{External Plenum Simplifies Spacer Posts}

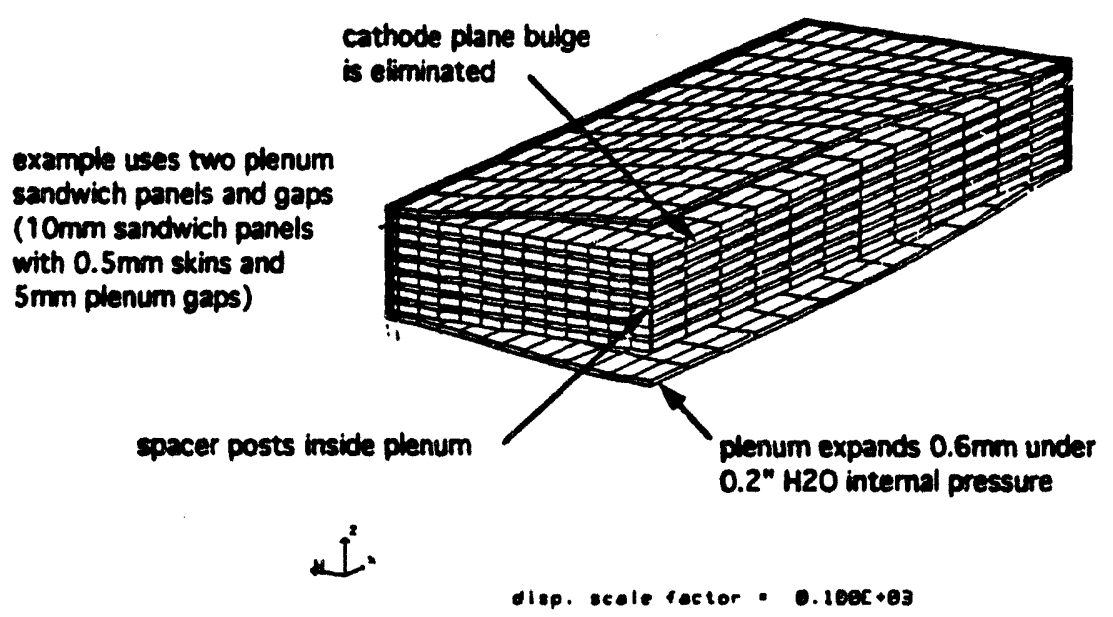

- External plenum eliminates bulge on all cathode plane sandwich panels

- Spacer post design is simplified since only small tension is needed to pull panel stack together (no internal honeycomb reinforcements are needed)

- Leak-tightness requirement is eliminated since spacer posts would terminate inside the plenum

\section{Effect of Internal Pressure on Baseline Chamber}

- A finite element model of an outer superlayer chamber with a $25 \mathrm{~mm}$ epoxy honeycomb edge filler and a $25 \mathrm{~mm}$ G10 gap spacer frame produces a 64 micron bulge for a 0.2 inch $\mathrm{H} 2 \mathrm{O}$ positive internal pressure.

- A finite element model of an outer superlayer chamber without spacer posts predicts a 175 micron bulge for the same internal pressure. There is a sensitivity to panel edge moment restraint.

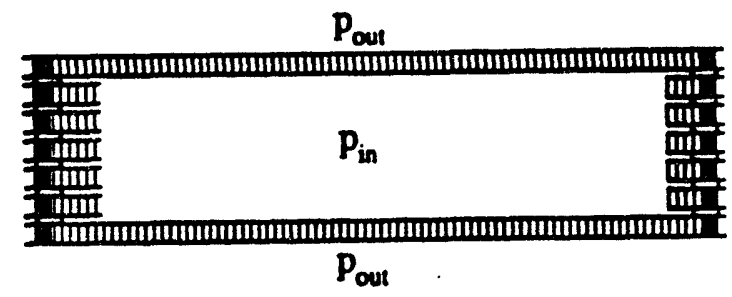

- Panel bulge is proportional to

4th. power of unsupported width

2nd. power of outermost sandwich thickness

1st. power of outermost sandwich skin thickness

- Outside plenum or additional internal posts being evaluated 


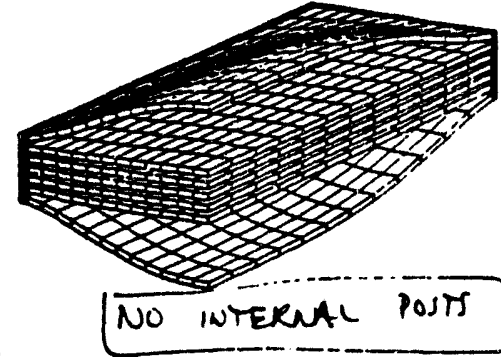

i.

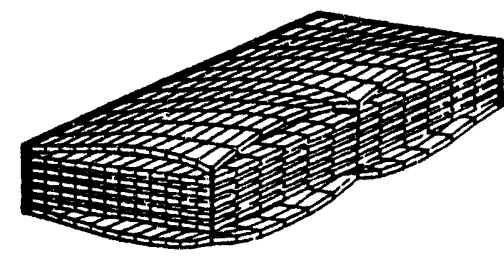

WITH INTERWAL POSTS

i.

- Outer superlayer chamber without spacer posts bulges 175 microns under 0.007 psi $\left(0.2^{\prime \prime} \mathrm{H} 2 \mathrm{O}\right)$ internal pressure

- Three spacer posts reduce the maximum bulge to 64 microns

- In both cases only the external sandwich panels bulge since pressure is equilibrated on both sides of the internal panels

- Chamber internal pressure produces tension in the spacer posts

- Spacer posts must be designed to restrain against overpressures without damage

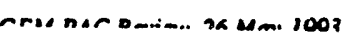

JA. Horvash

\section{Spacer Posts Limit Bulge Locally}
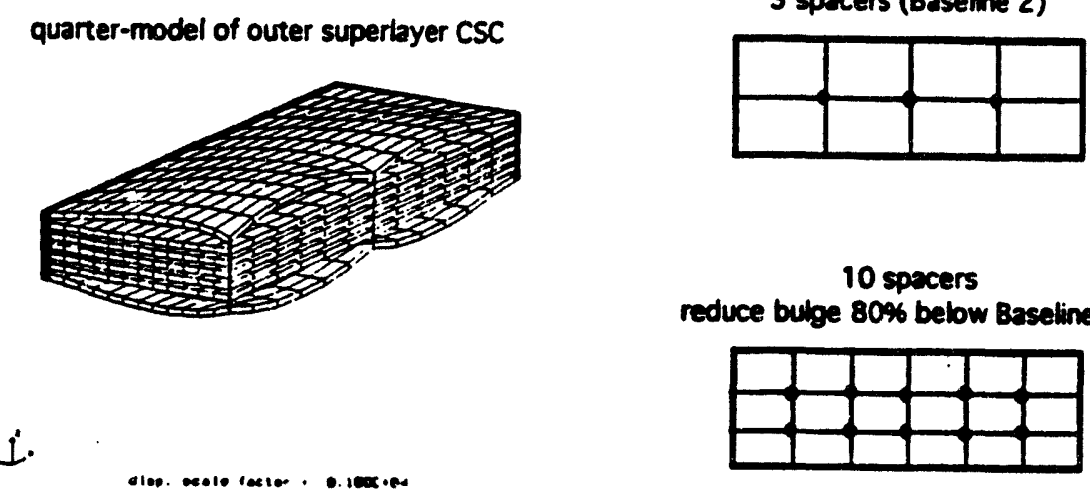

10 spacers

reduce bulge $80 \%$ below Baseline 2

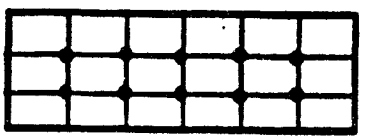

- Internal spacer posts limit panel bulge by applying restraint at discrete points

- A plenum at the outer surfaces would uniformly restrain bulge without spacer posts 


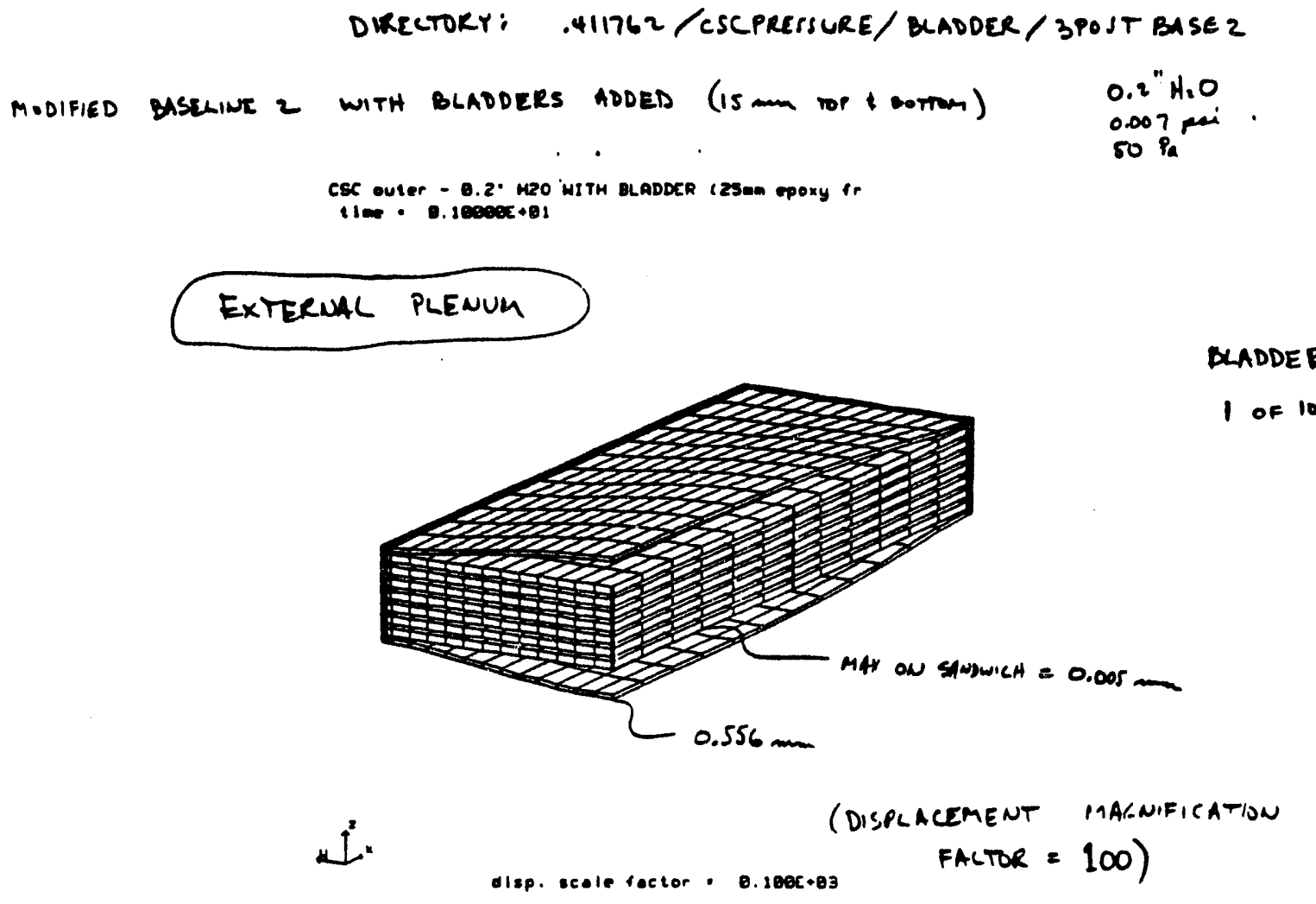

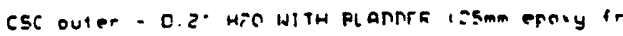

time. $0.100005 \cdot 01$

BLADPER

2 of 10

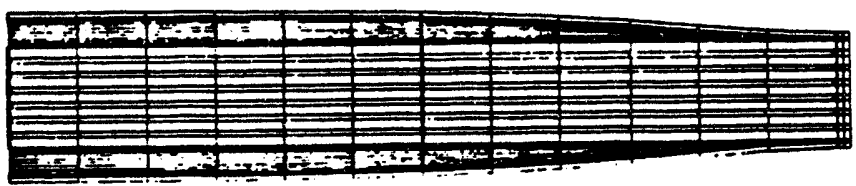

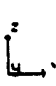

(DISP. MAG. $=100$ )

Hisf. scole rector, 0.1006 03 
CSC outer - $0.2^{\circ}$ HEO WITH BLADDEF IESmm ePONy ir IIme. O. $1000 \mathrm{OC}+01$

\section{BUAODER \\ 3 of 10}

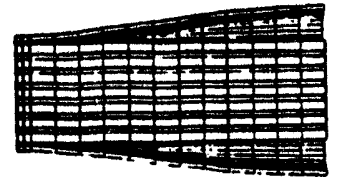

(DISP. MAG $=100$ )

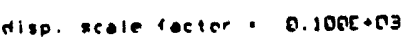

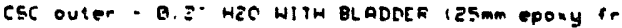

time $0.10000 \mathrm{C} \cdot \mathrm{nI}$

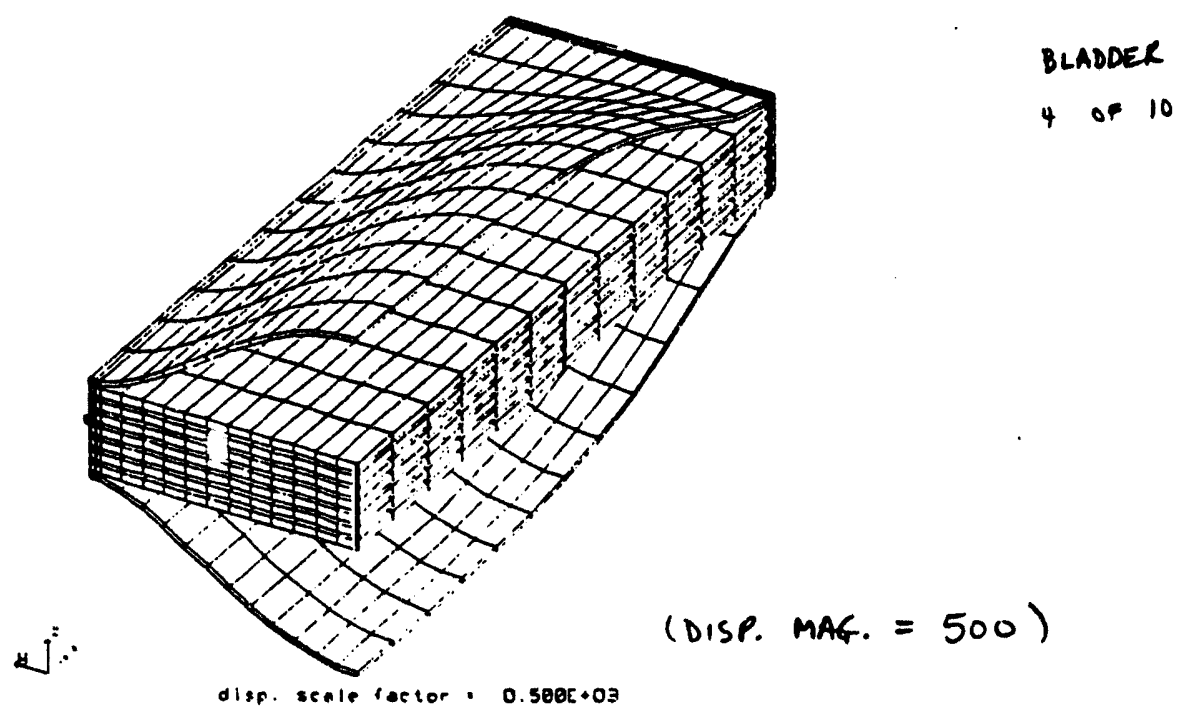

$12-5$ 


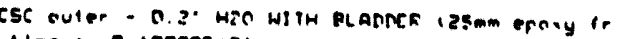

llone. $0.10000 \mathrm{c}+01$

BLADOER

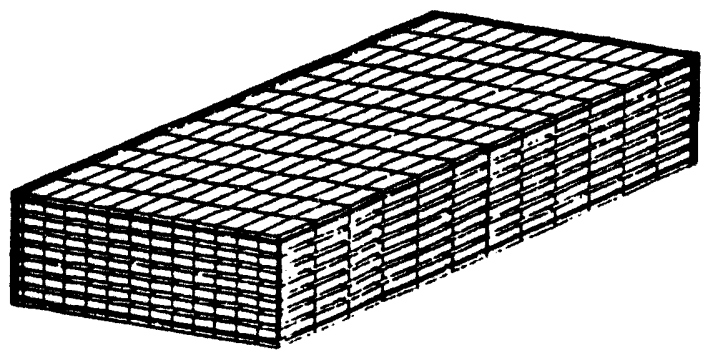

5 of 10

DISPLACEMENT SAHE FACTOR $=1.0$

(No manficatron)

L.

disp. scole factor. O. 1000.01 ineteult' 

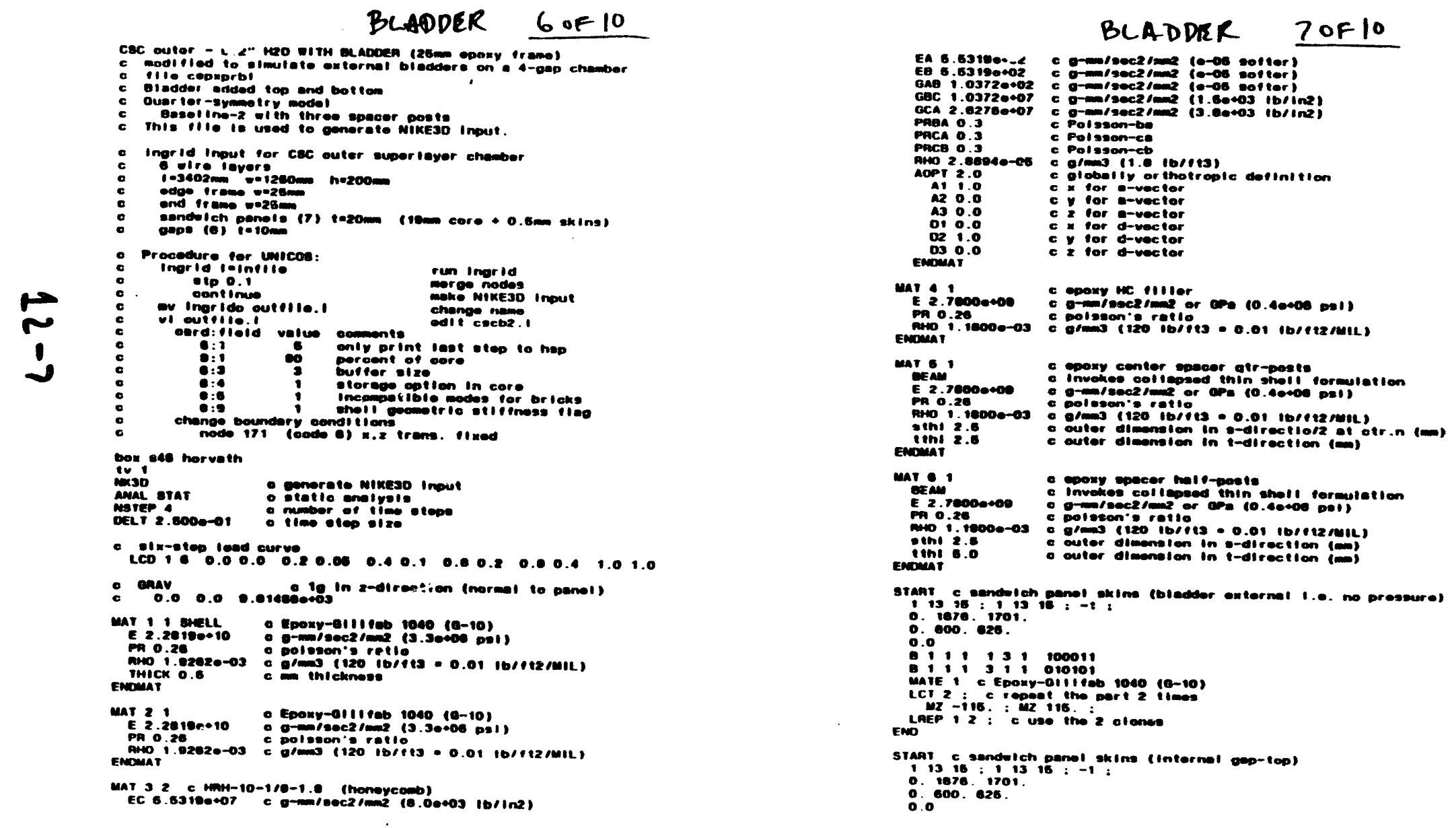

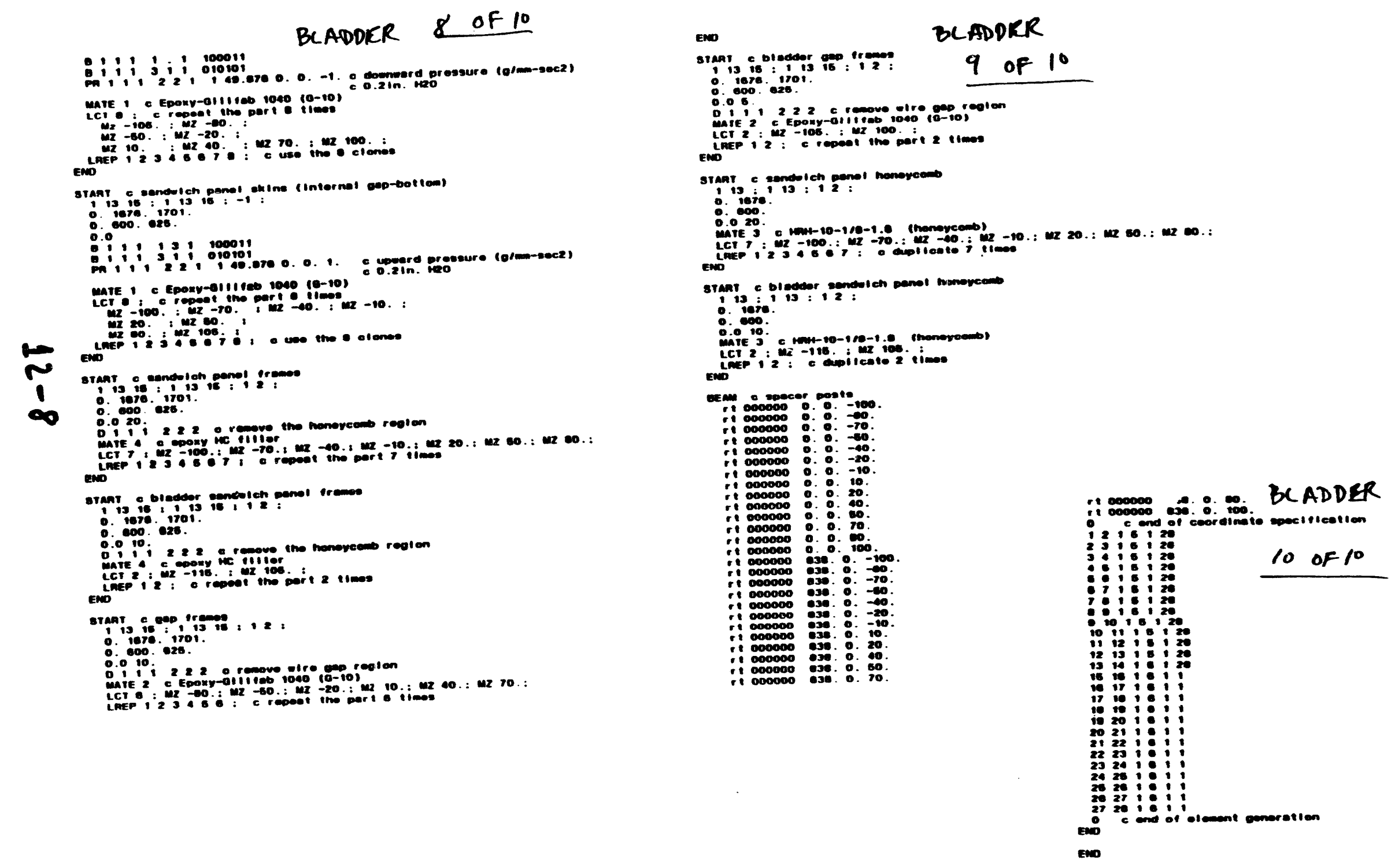
DIRECTORY: . YIT62/CSC PRESPURE/ BPOST MASE 2

BASELINE 2 (WITH 3 SPACKR POSTS)

$0.2 " 1,0$ 0.007 نس So $\mathrm{Pa}$

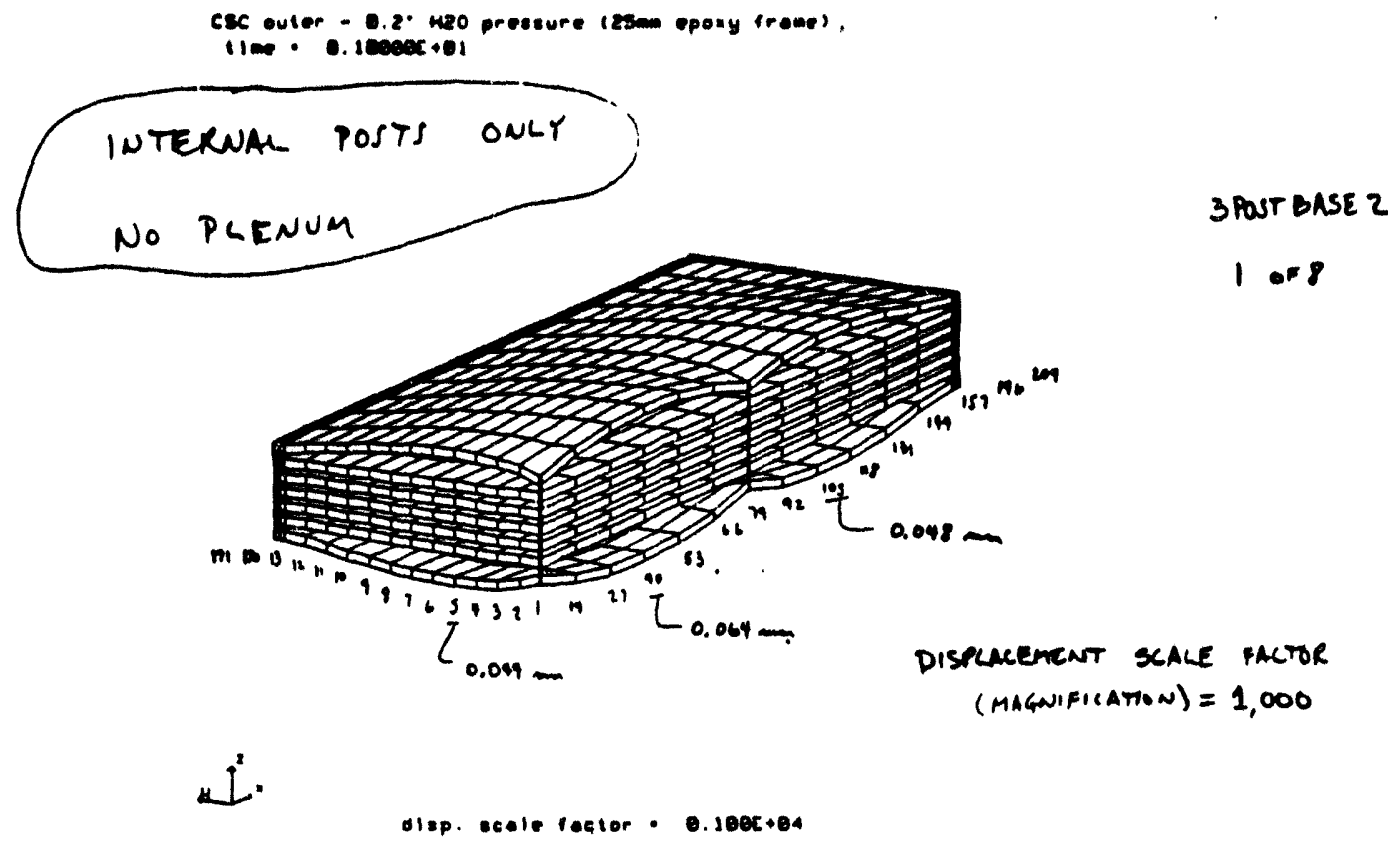

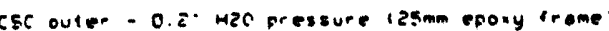

time. O. 1 10000 0 :

3POST BASE2

2 of 8

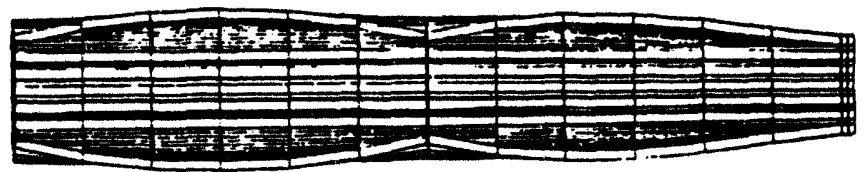

(DISP. mat. $=1,000$ )

disf. scele tactor a. $100 \mathrm{cc}+84$ 
3 POST BASE 2

3 of 8

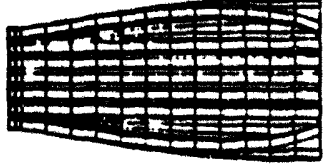

(DISP. WAG $=1,000)$

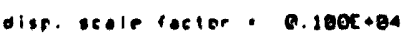

CSC outer - O.z HZO pressure $135 \mathrm{~mm}$ eposy (romes

tlme. 10000t.01

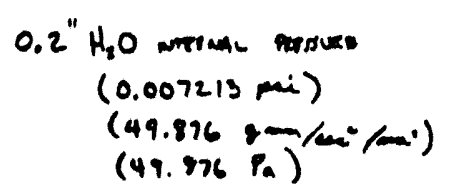

3POSTBASE 2

4 or 8

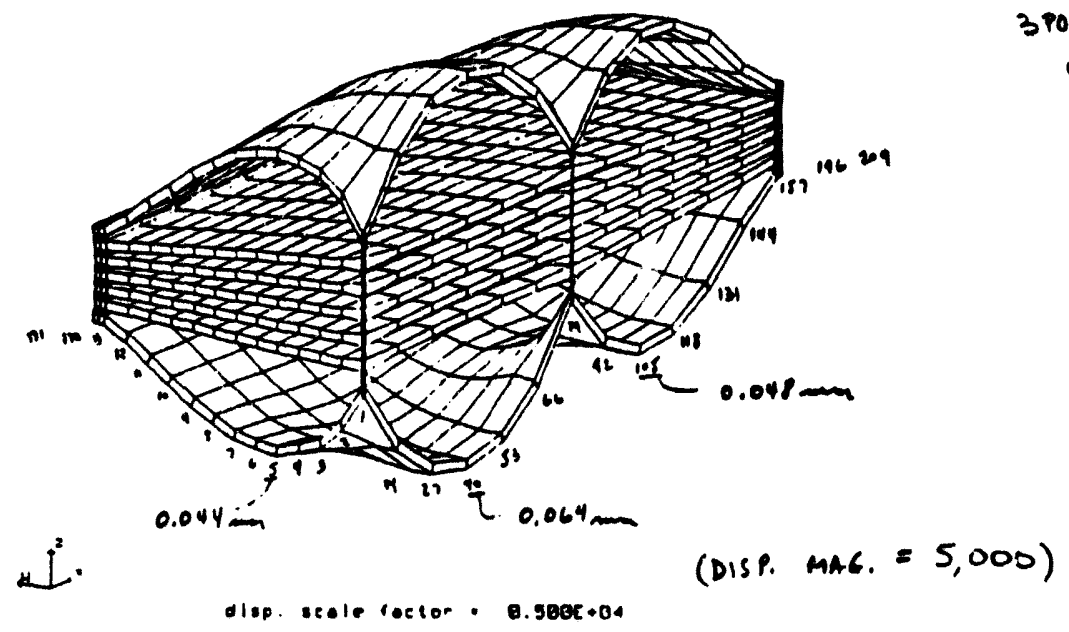



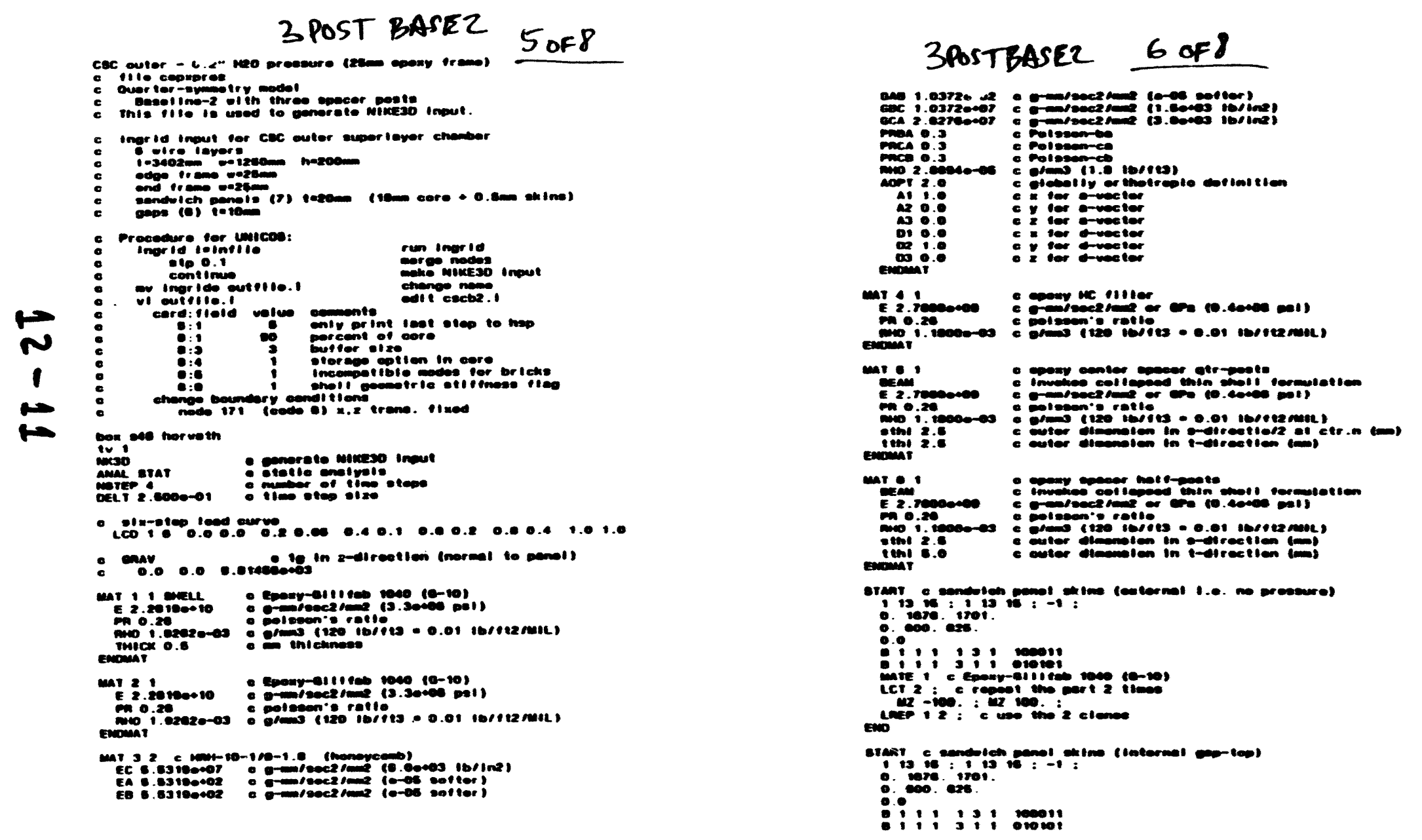

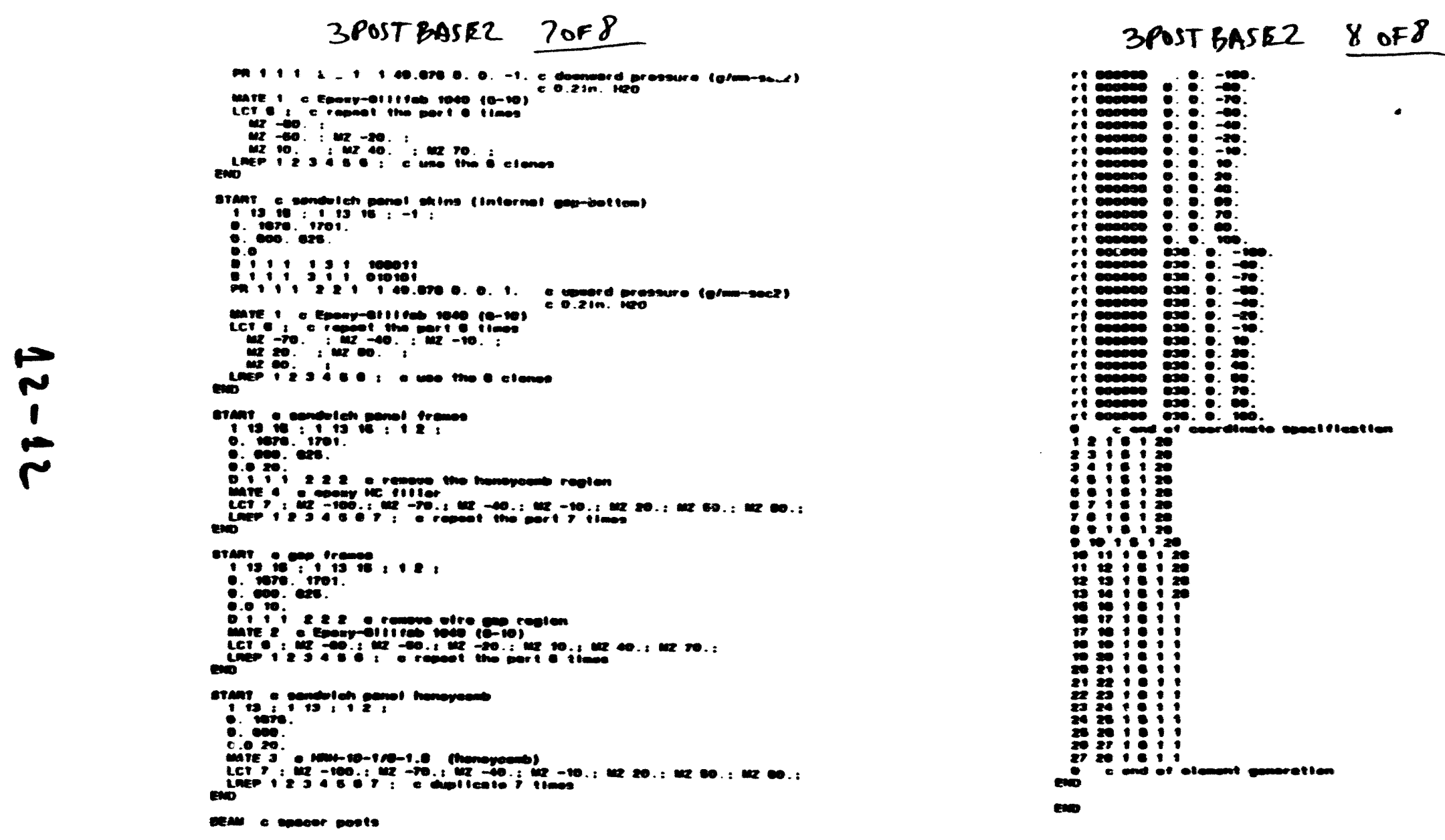


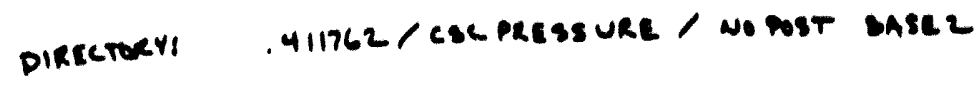

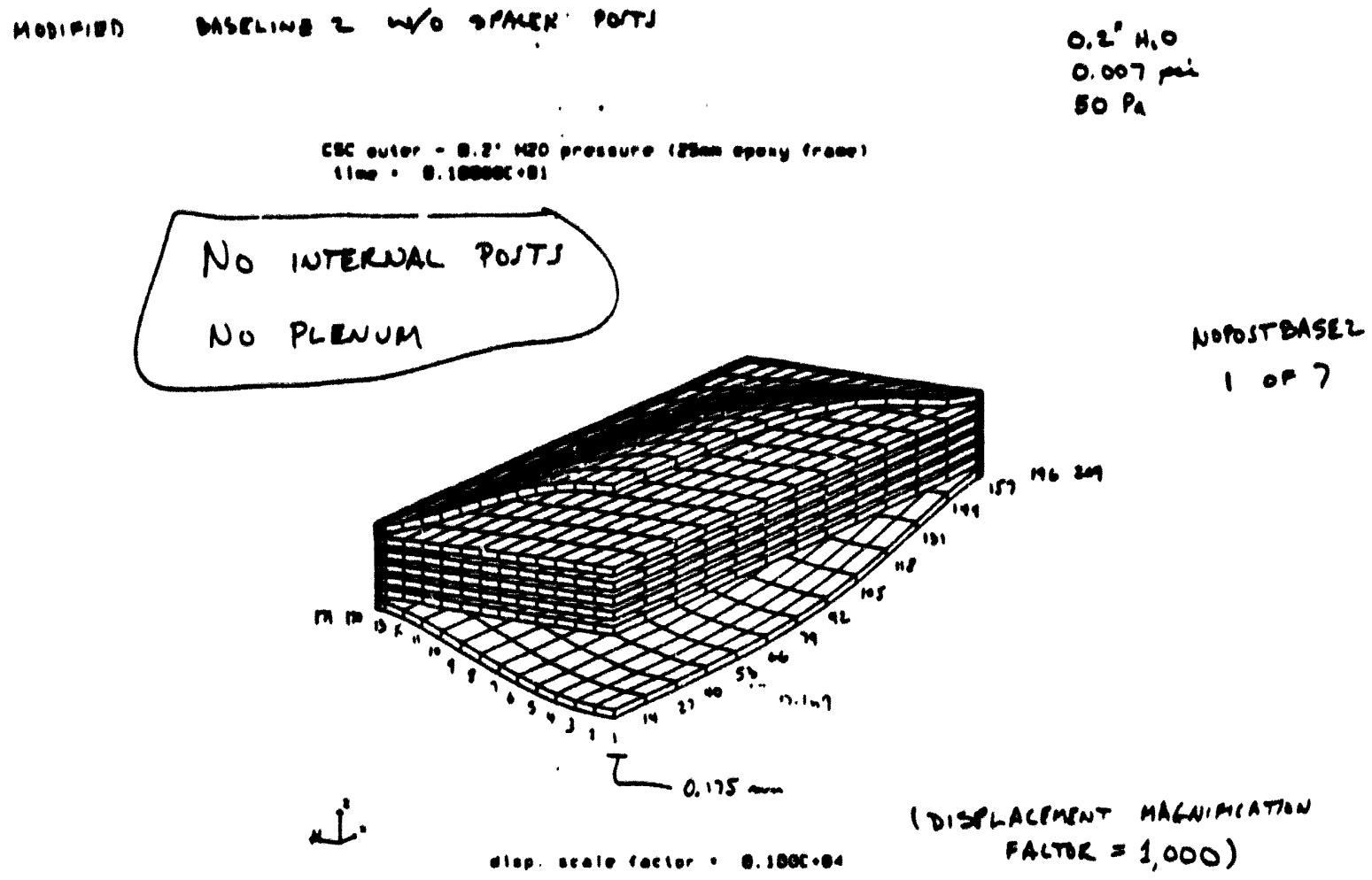

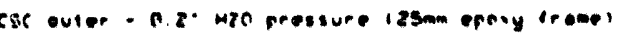

lime.0.10000C.0

NOPOST BASE?

2 of 7

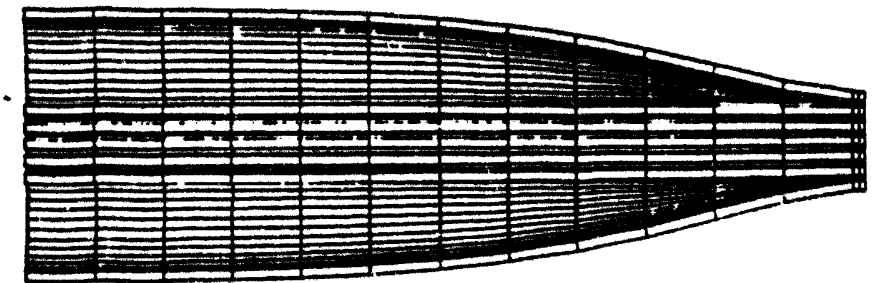

(Disp. mat. $=1,000)$

Nise. scele lactor. P.1806+84 


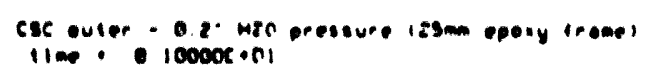

$$
\begin{gathered}
\text { NOPOST BASE } 2 \\
3: ?
\end{gathered}
$$

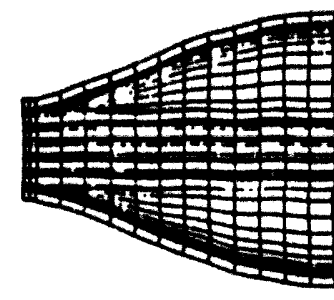

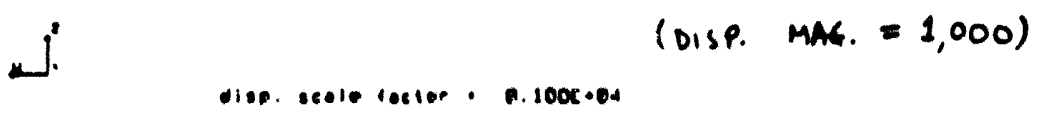

$12-14$ 

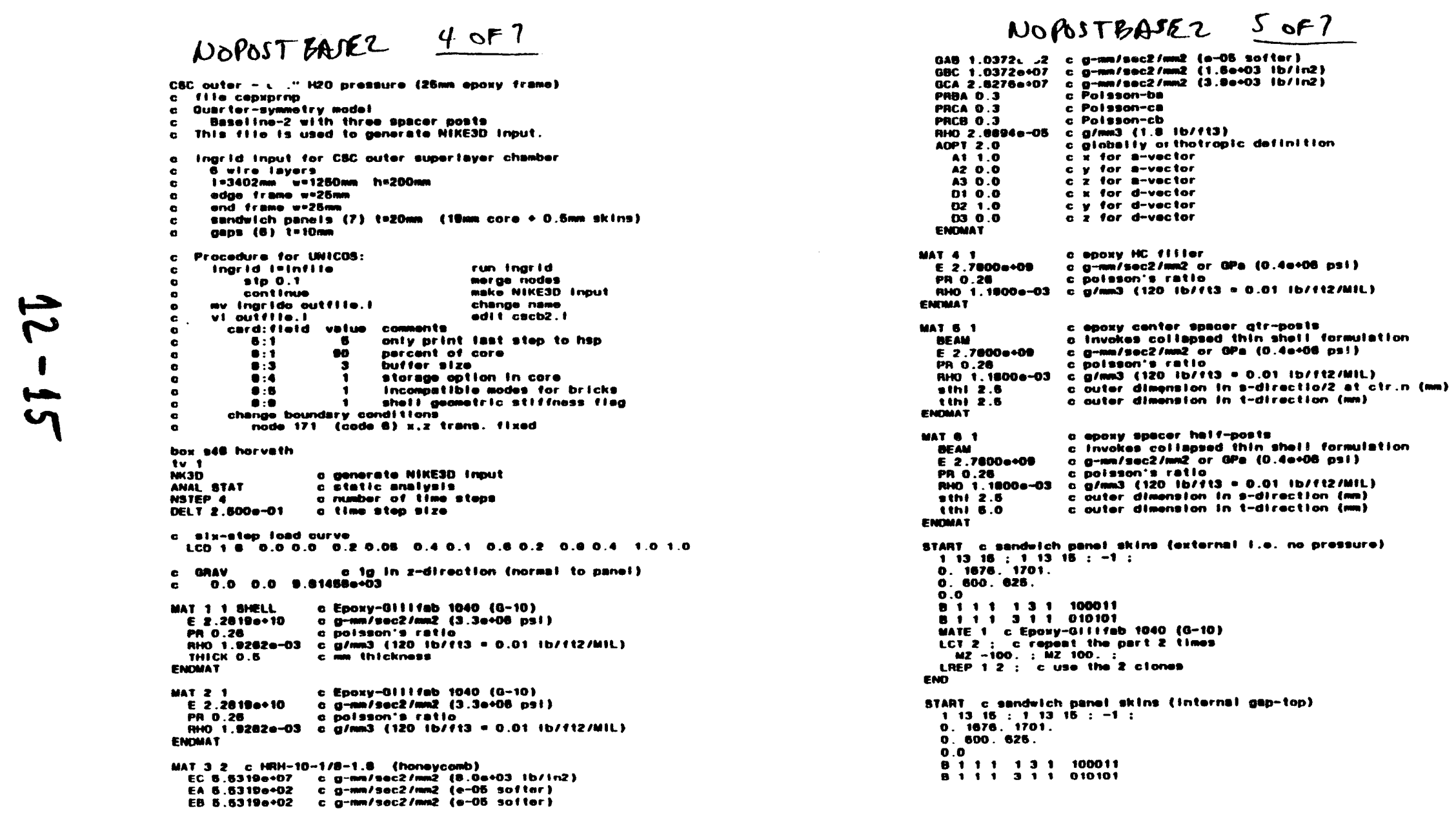

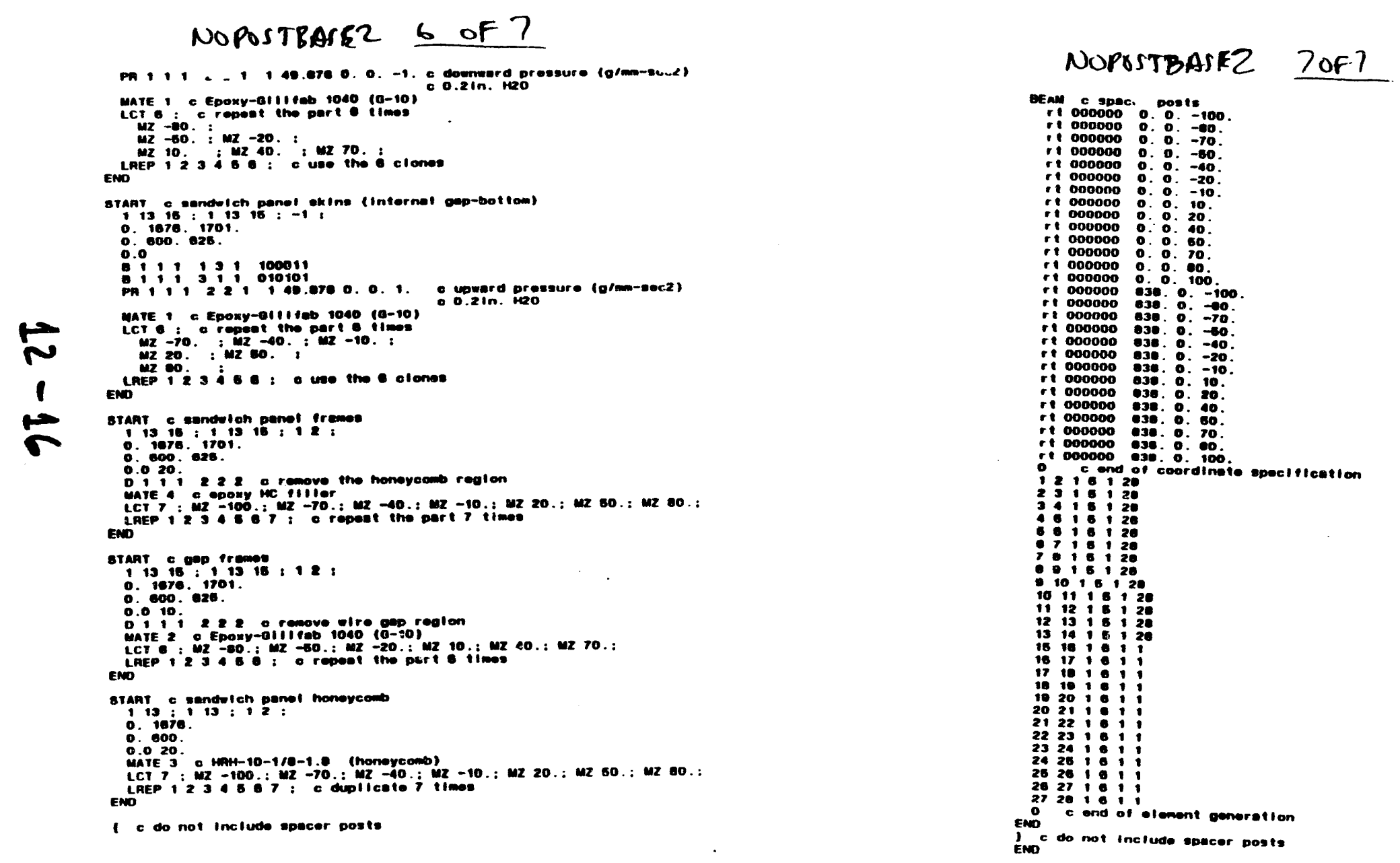


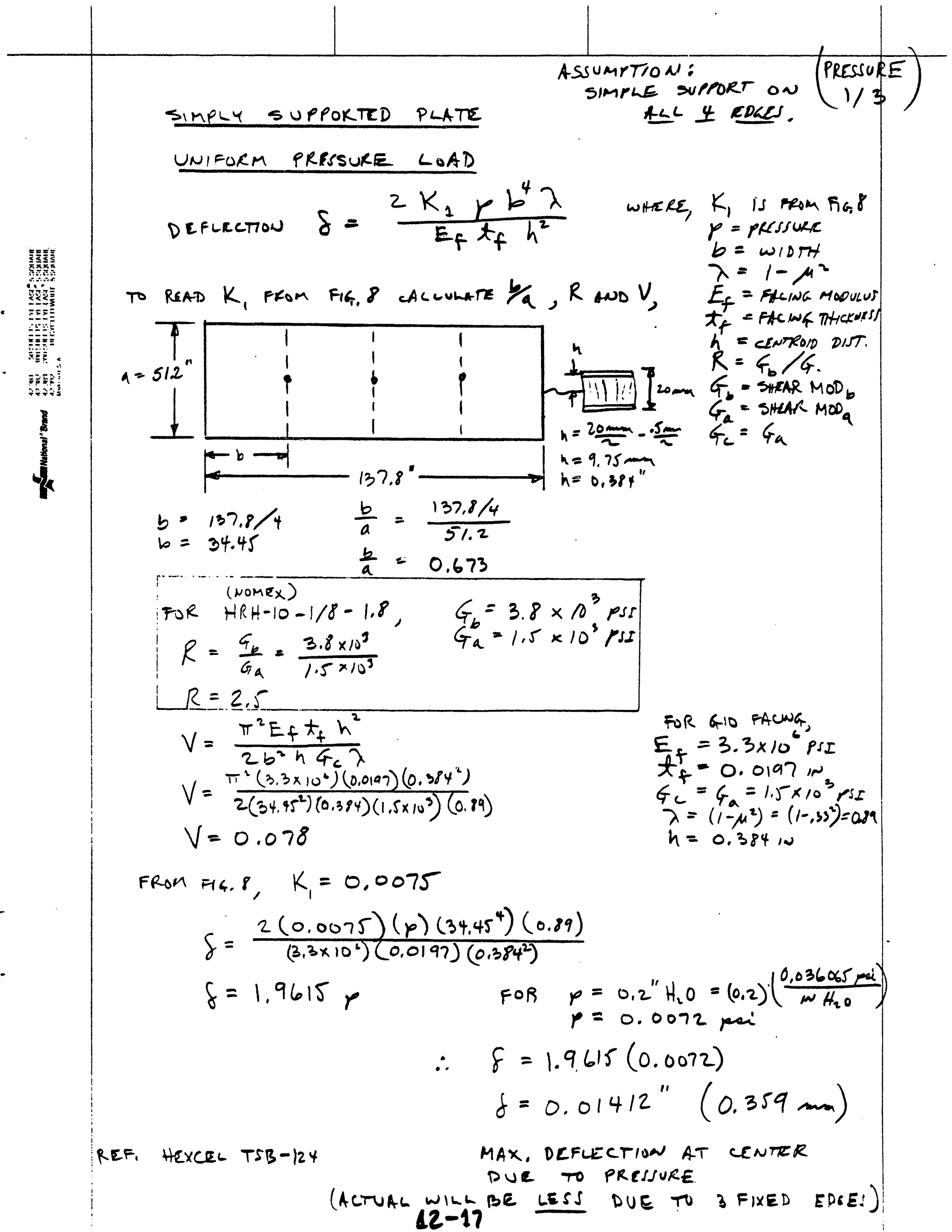


Sample Problems

B. Simply Supported Plate (from MIL. HDBK-23)
SANDWICH PANEL bULGE UNDER UNIFORM PRESSURE LOAD (REF. HEXCEL TSB-124)

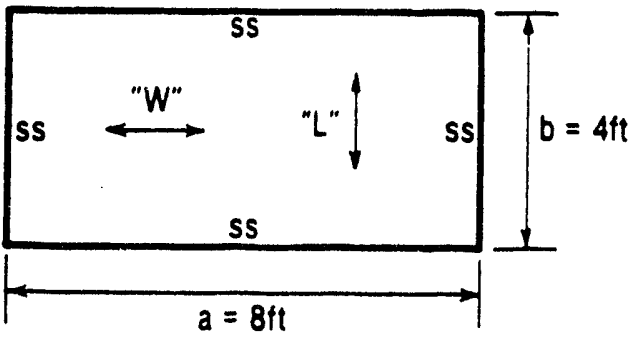

$a>b$
Uniform Load

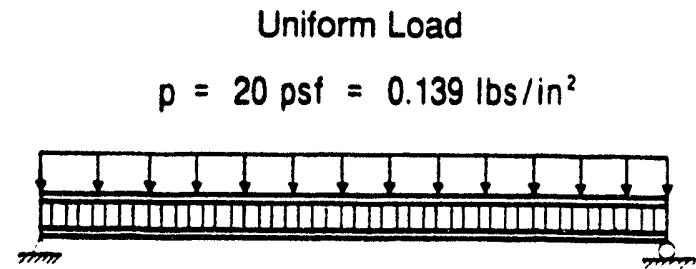

Simply supported all four edges

SAMPLE ASSUMRS Al 50:2 H.C. CORE

\section{Determine Plate Coefficients:}

$\frac{b}{a}=\frac{48}{96}=0.50$

$R=\frac{G_{b}}{G_{a}}=\frac{43,000}{21.200}=2.03$

USE $R=2.5$ (see Figure 8 )

$V=\frac{\pi^{2} E_{f} t_{f} h^{2}}{2 b^{2} h G_{c} \lambda}$

$V=\frac{\pi^{2}\left(10.1 \times 10^{6}\right)(0.020)(1.020)^{2}}{2(48)^{2}(1.020)(21.200)(0.89)}=0.023$

FROM FIGURE $8 \quad K_{1}=0.0105$

FIGURE $9 \quad K_{2}=0.103$

FIGURE $10 \quad K_{3}=0.37$
4. Check Core Shear Stress:

$T_{c}^{w}=\frac{K_{3} p b}{h}=\frac{(0.37)(0.139)(48)}{1.020}=2.42 \mathrm{psi}$

F.S. $=\frac{85(0.93)^{\bullet}}{2.42}=32.7$

"Correction Factor for 1" Thick AI. H/C, TSB 120

5. Check Facing Dimpling:

$\sigma_{c k}=\frac{2 E_{f}}{\lambda}\left[\frac{t_{f}}{s}\right]^{2}$

$\sigma_{\text {CR }}=\frac{2\left(10.1 \times 10^{\circ}\right)}{0.89}\left[\frac{0.020}{0.375}\right]^{2}=64,560 \mathrm{psi}$

64,560 psi $>24,000 \therefore$ NOT CRITICAL!

\section{Check Panel Deflection:}

$\Delta=\frac{2 K_{1} \rho b^{4} \lambda}{E_{1} t_{f} h^{2}}$

$\Delta=\frac{2(0.0105)(0.139)(48)^{4}(0.89)}{\left(10.1 \times 10^{6}\right)(0.020)(1.020)^{2}}=0.066$

3. Check Facing Stress:

$$
\begin{aligned}
& \sigma_{f}=\frac{K_{2} p b^{2}}{h t_{f}}=\frac{(0.103)(0.139)(48)^{2}}{(1.020)(0.020)}=1.617 \mathrm{psi} \\
& \text { F.S. }=\frac{24.000}{1.617}=14.8
\end{aligned}
$$

\section{Check Facing Wrinkling:}

$\sigma_{c R}=0.82 E_{f}\left[\frac{E_{c} t_{f}}{E_{f} t_{c}}\right]^{1 / 2}$

$\sigma_{c R}=0.82\left(10.1 \times 10^{\circ}\right)\left[\frac{(70.000)(0.020)}{\left(10.1 \times 10^{6}\right)(1.000)}\right]^{1 / 2}=97,500 \mathrm{psi}$

97,500 psi $>24,000 \therefore$ NOT CRITICAL!

\section{Check Factor-of-Safety:}

MINIMUM F.S. (FACE YIELDING) $=14.8$

\section{$12-18$}


Figure 8 -. $K_{1}$, for determining maximum deflection. $\Delta$. of flat rectangular sandwich panels $a>b$

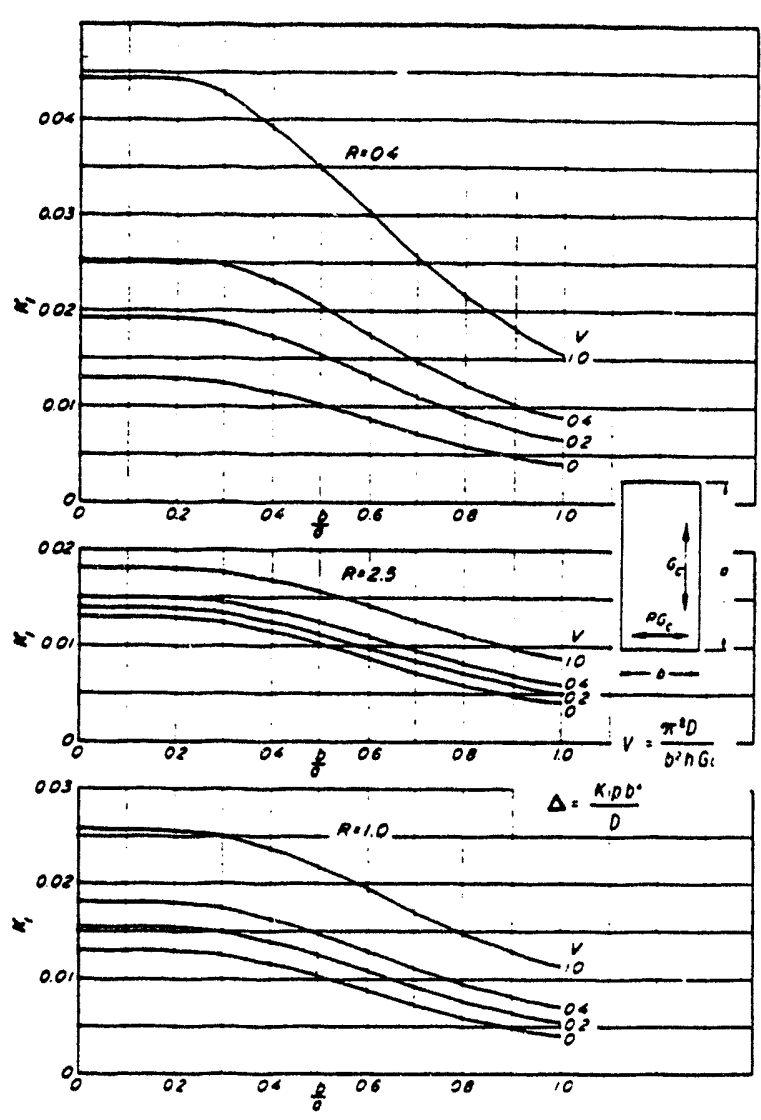

Figure $9 \quad-K_{2}$, for determining facing stress, $\sigma_{1}$ of flat rectangular sandwich panels $a>b$

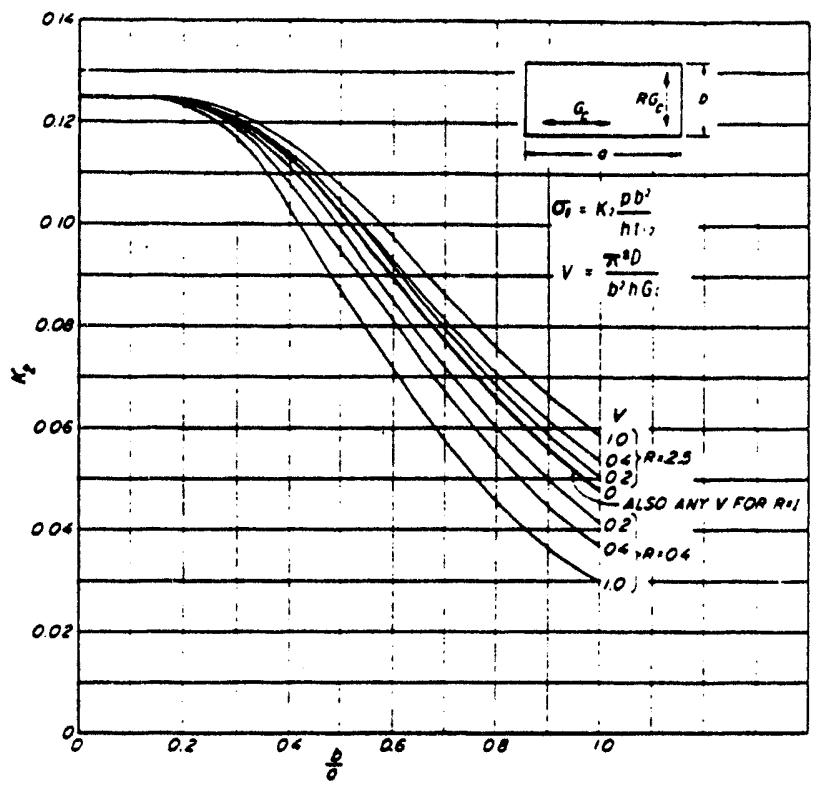

Figure $10 \ldots K_{3}$, for determining core shear stress. $T_{c}$. for flat rectangular sandwich panels $a>b$
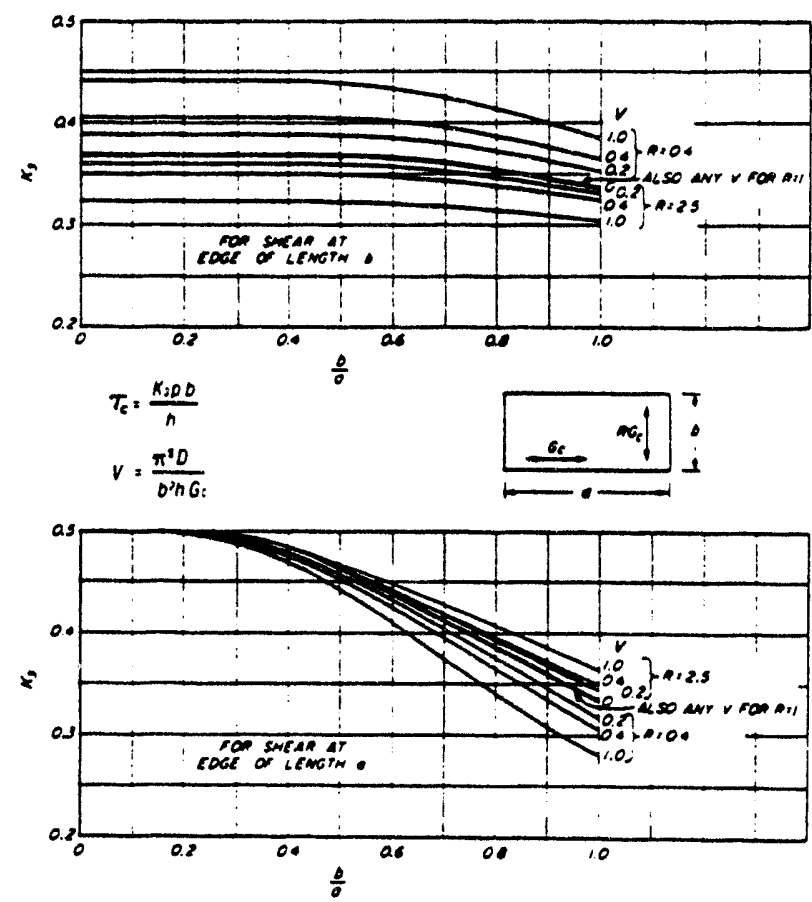


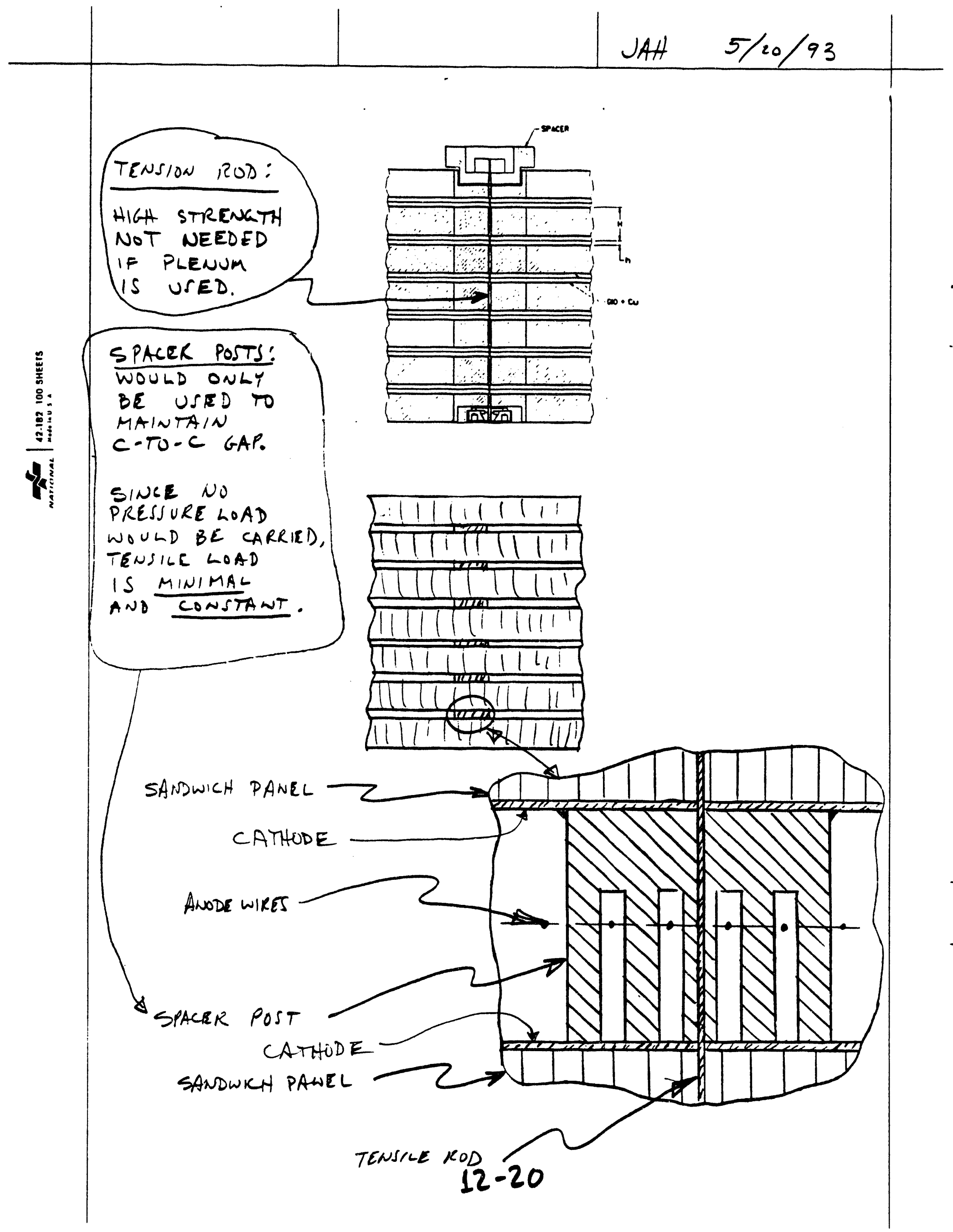


GEM TN-93-494

\title{
13. Chamber Mode Shapes and Natural Frequencies
}

\author{
Contents:
}

Summary of TDR chamber natural frequencies (1 page)

TDR chamber with G10 frame, outer superlayer, details of mode shapes ( 7 pages)

TDR chamber with $\mathrm{G} 10$ frame, middle superlayer, details of mode shapes (7 pages)

TDR chamber with G10 frame, inner superlayer, details of mode shapes (7 pages)

TDR chamber with epoxy frame, outer superlayer, details of mode shapes (6 pages)

Summary:

Natural frequencies of $3.5 \mathrm{~m}$ long chambers tend to be low due to their length and limited thickness (limited by overlap of chambers and maximum muon track lever arm). The limited thickness produces a low stiffness. Adding mass to increase stiffness also produces particle scattering and thus should be avoided.

Changing the "frame" material from relatively "stiff" G10 to "soft" epoxy reduces the lowest natural frequency by $25 \%$ due to loss of shear stiffness in the chamber. This linkage between frame design and chamber stiffness is documented in GEM TN-93-460, Comparison of Gap Frame Designs and Materials for Precision Cathode Strip Chambers. 


\section{Bare Panel ${ }^{*}$ Natural Frequencies Begin At $19 \mathrm{hz}$}

\begin{tabular}{|c|c|c|c|c|c|c|c|}
\hline * No ADded mass & FOR & $\begin{array}{l}\text { ELECTROAICS } \\
\text { frequency }\end{array}$ & AND & UTルL & des & S wourd & DROP SLGNTCY) \\
\hline mode \# & 1 & 2 & 3 & 4 & 5 & 6 & \\
\hline outer superlayer & 20.6 & 22.4 & 30.0 & 57.4 & 61.3 & 63.8 & \\
\hline middle superlayer & 28.9 & 38.9 & 45.6 & 90.3 & 90.6 & 92.0 & \\
\hline inner superlayer & 19.7 & 32.0 & 66.8 & 77.6 & 83.4 & 113.7 & \\
\hline
\end{tabular}

- Bare panels are sandwich panels, edge fillers, and gap frames.

(Not included are detector wires, copper plating, circuit boards, gas pipe, heat sinks, bolts, cables, or connectors.)

- Bare panel frequencies are within $5 \%$ of loaded panel values.

The effect of added mass is estimated using the expression for a spring/mass system.

$$
f=\frac{1}{2 \pi} \sqrt{\frac{k}{M}}
$$

An increase in chamber mass of $10 \%$ will decrease the natural frequency by $5 \%$. 


\section{Outer Superlayer Chamber: First Six Modes}

SDIRECTORY . 411762 /CSCBASE2/KINEMODE/ OUTERRND

$\{$ KINEMATL SUPPORT AT ENDS

(12.5 mm SOLID G10 FRAMT ASSUMED

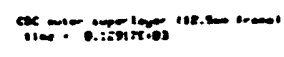

$20.6 \mathrm{hz}$

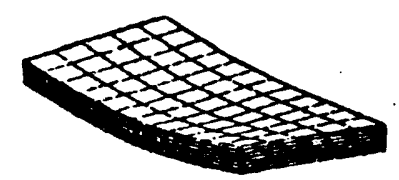

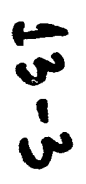

(1)

$57.4 \mathrm{hz}$

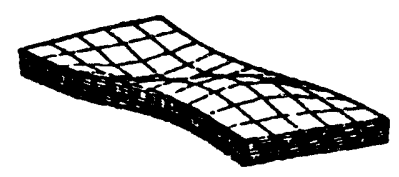

s

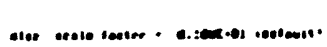

chis:

$22.4 \mathrm{hz}$

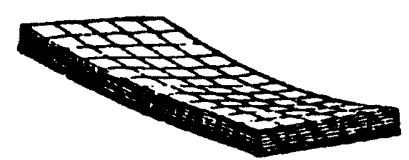

j

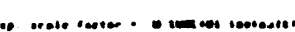

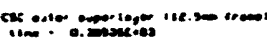

$61.3 \mathrm{hz}$

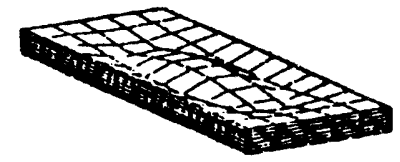

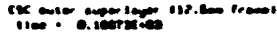

$30.0 \mathrm{hz}$

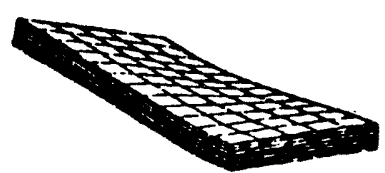

s

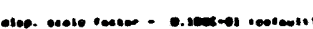

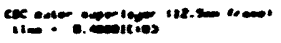

$63.8 \mathrm{hz}$

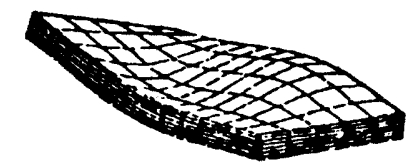

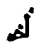

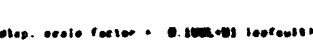



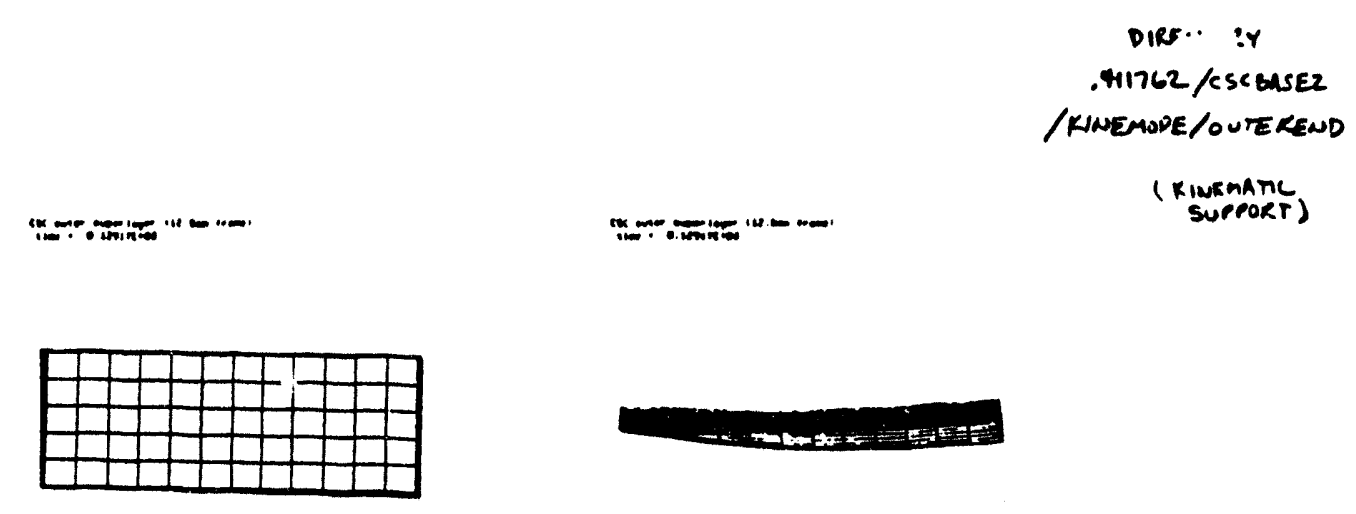

L.

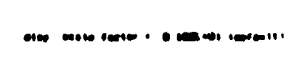

i.<smiles>C1CCCC1</smiles>

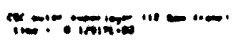

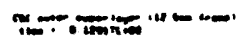

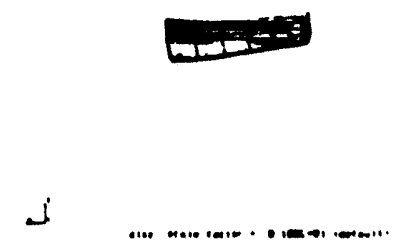

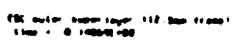

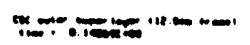
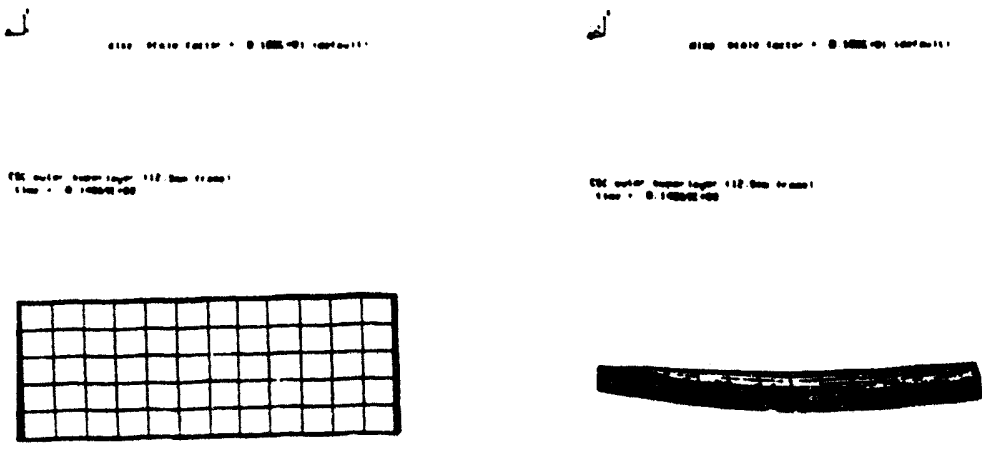

MODE $1 \sim$

$20.6 \mathrm{~b}$

c

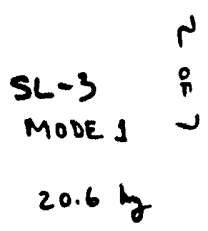

L.

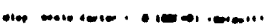

L.

(n)

$\checkmark$

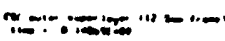

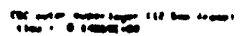
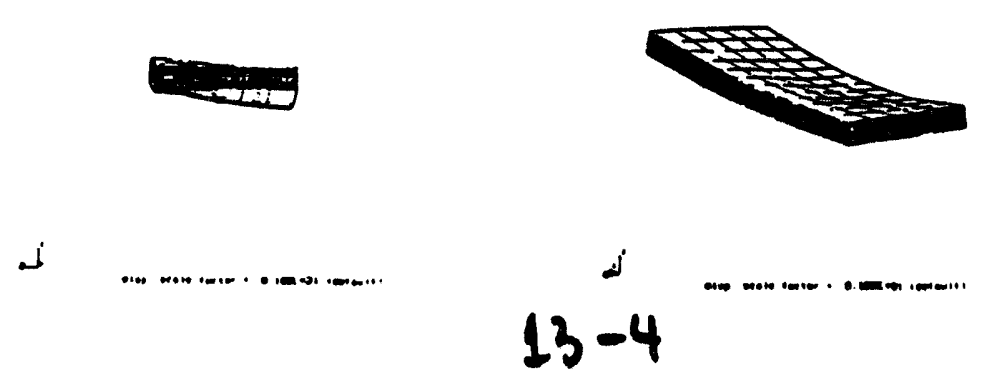

管

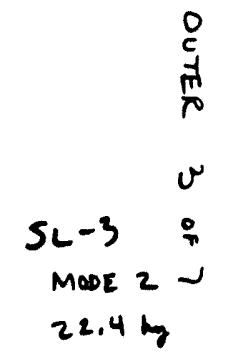




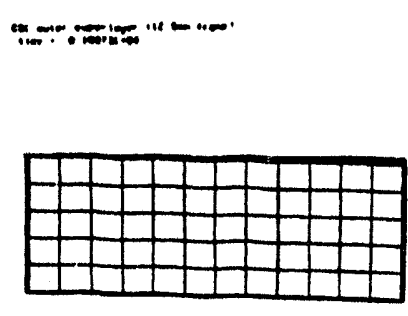

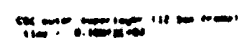

L.

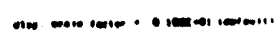

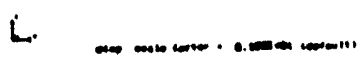

T-10.

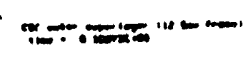
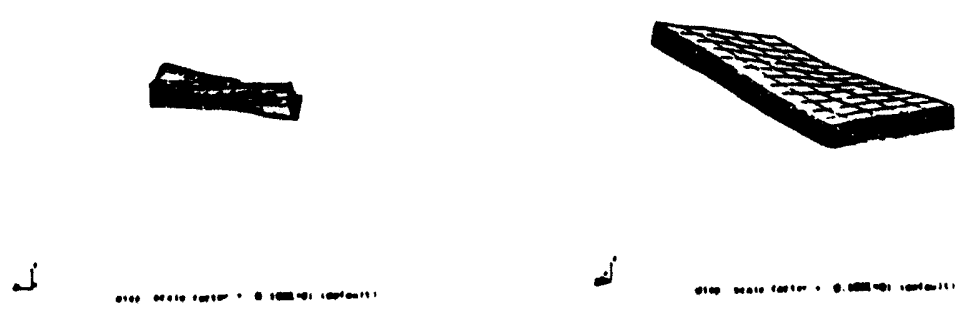

0
$c$
1
0

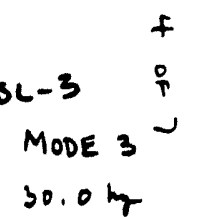

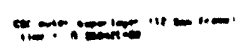

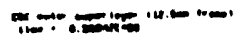
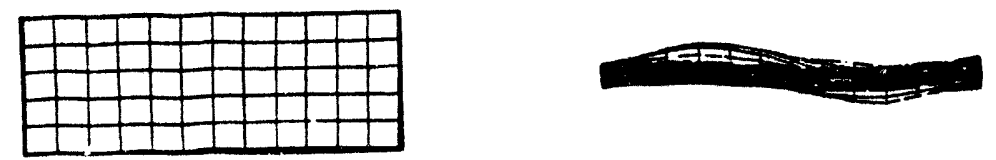

L.

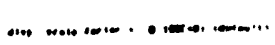

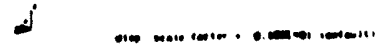

$30.0 \mathrm{mg}$

L.

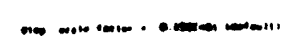

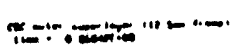

x-...
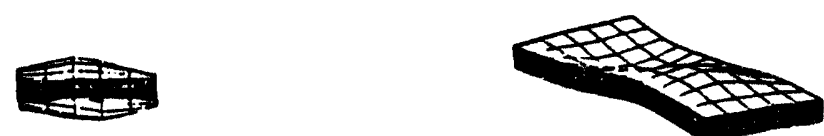

0
$c$
$m$
$n$

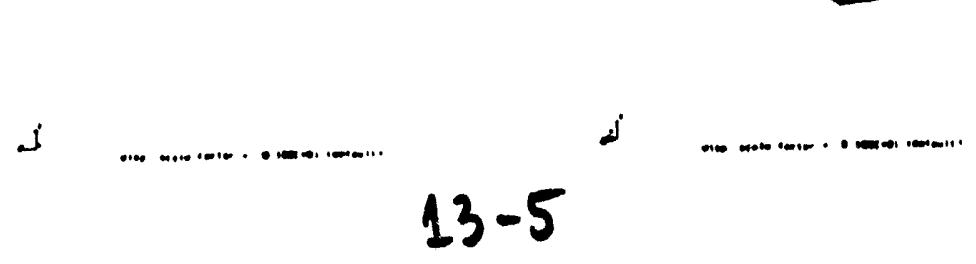

SL 3 O
MODE 4 i
57.4 by 


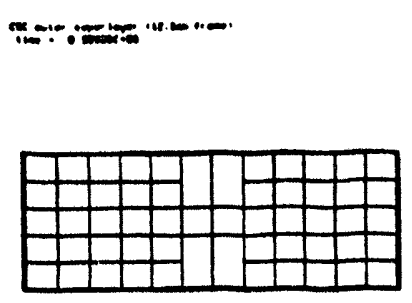

$\div 0$

l.

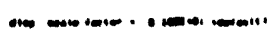

L.

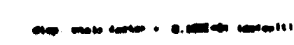

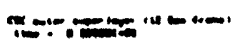

W0.

xim

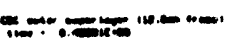
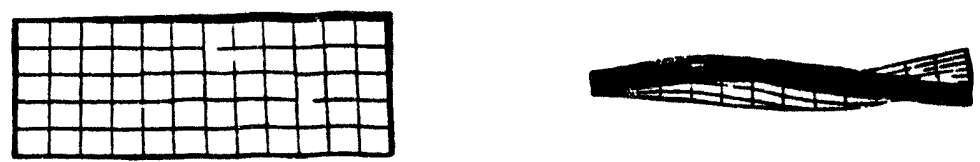

l.

1.

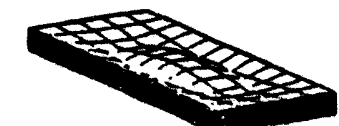

0
$c$
$m$

$s c-3 \quad \sigma$

MODE 5 ;

$61.3 \mathrm{~h}^{2}$
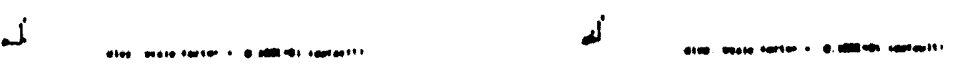

$61.3 \mathrm{~h}$

Tே.

incon
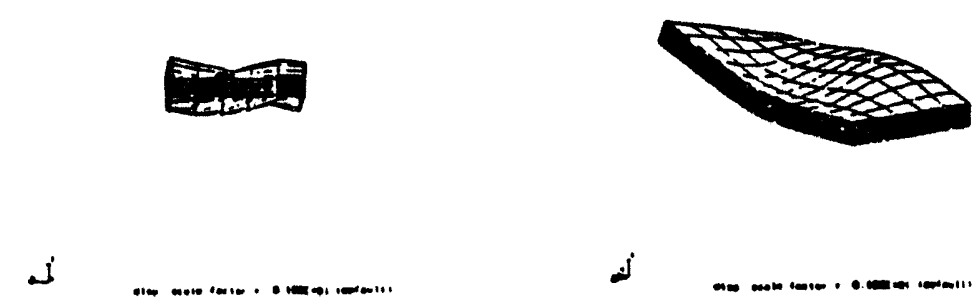

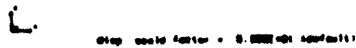

$13-6$

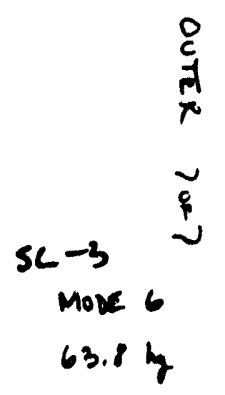




\section{Middle Superlayer Chamber: First Six Modes}

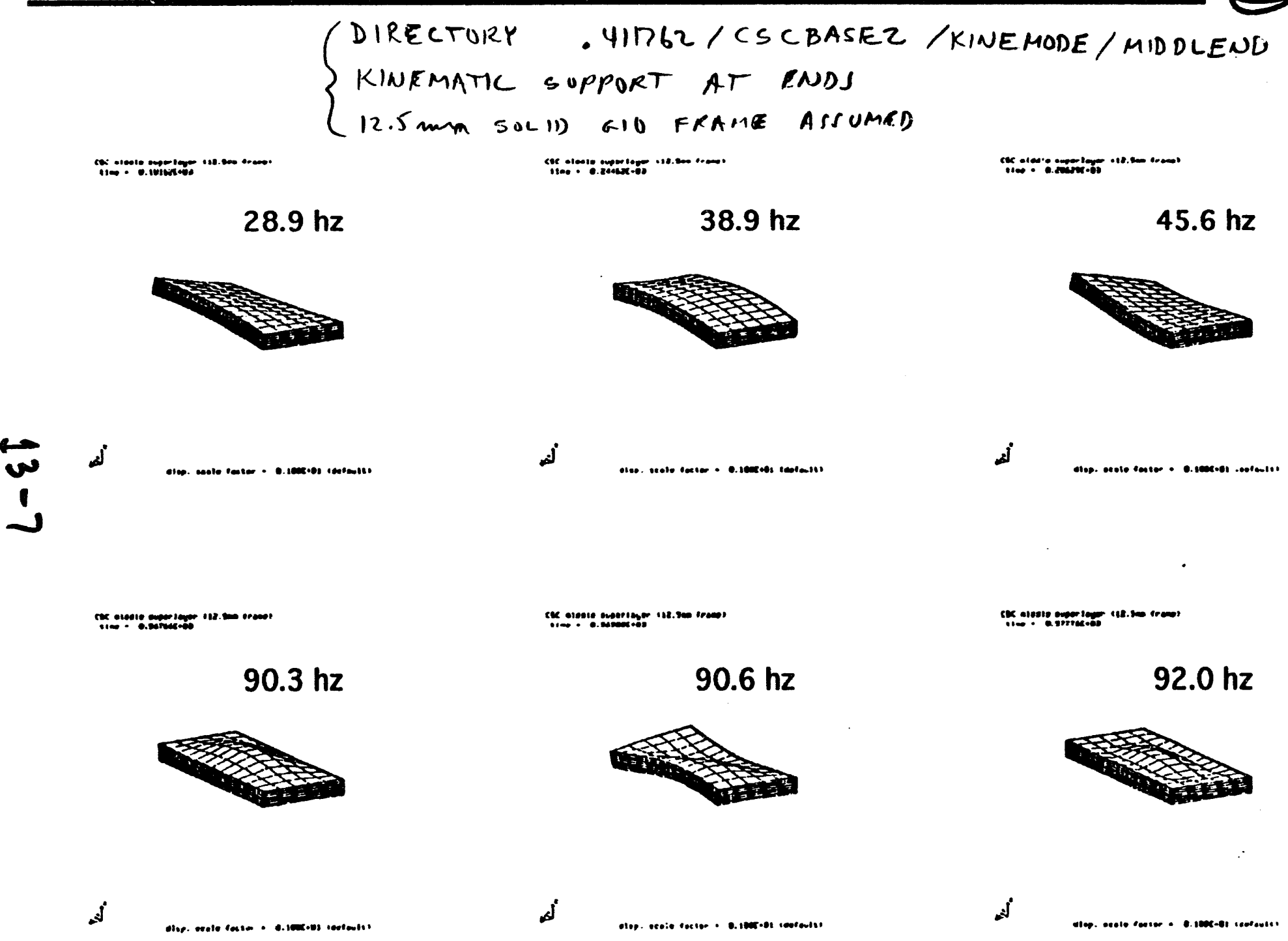




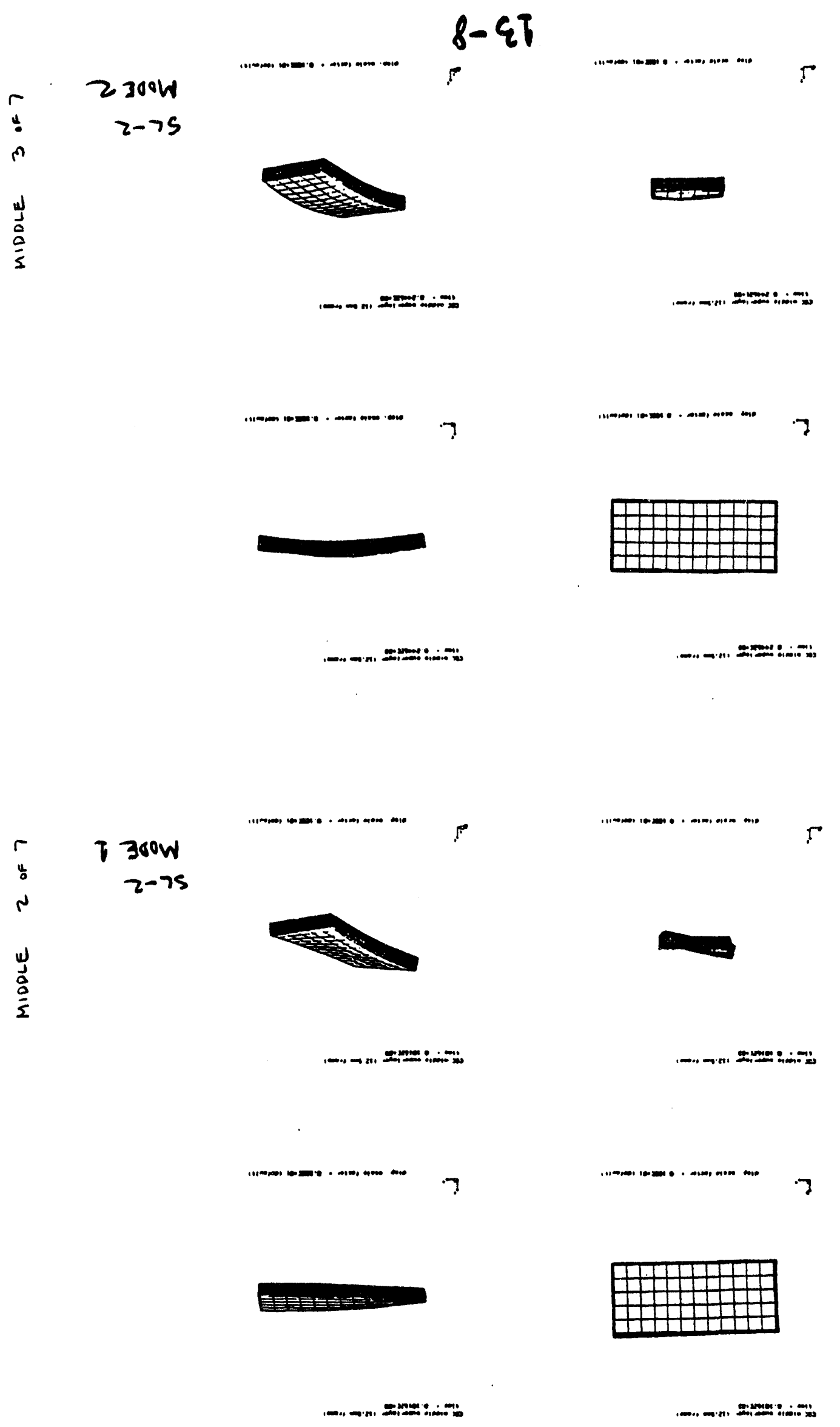




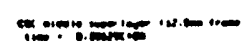

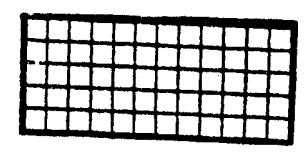

L.

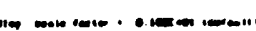

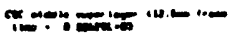
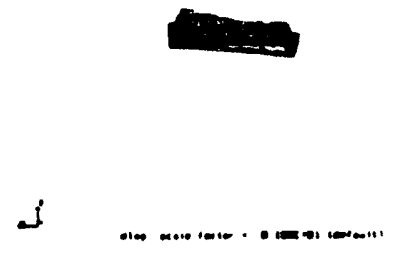

cx.1.

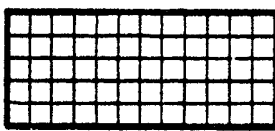

L.

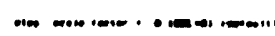

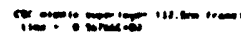
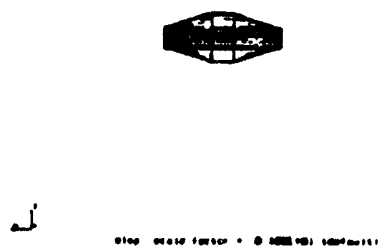

0

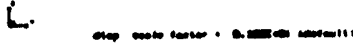

דיט:

SL- 2

MODE 3

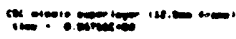

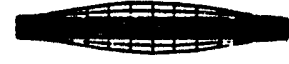

L.

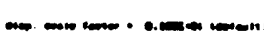

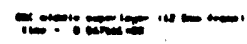

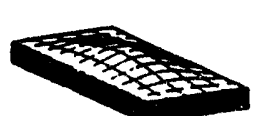

U1

SC-2 i

MODE 4

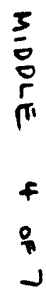

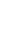


10.0

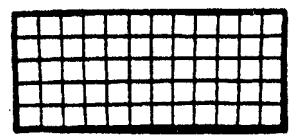

l.

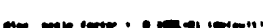

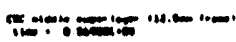

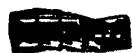

"...

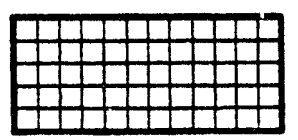

L.

and

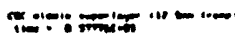
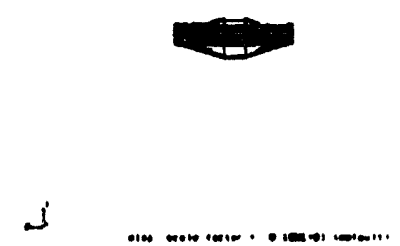

番

i.

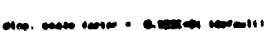

ำกำ

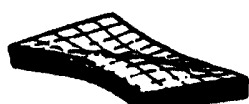

3
5
0
5
1

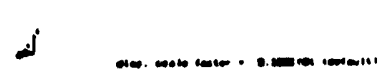

SL- 2

MODE 5

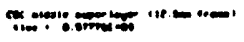

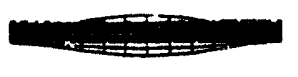

i.

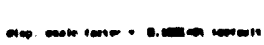

Taי

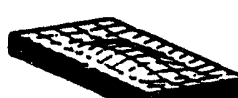

3
0
0
11

$S L-2$

MODE 6 r

i

$\checkmark$ 


\section{Inner Superlayer Chamber: First Six Modes}

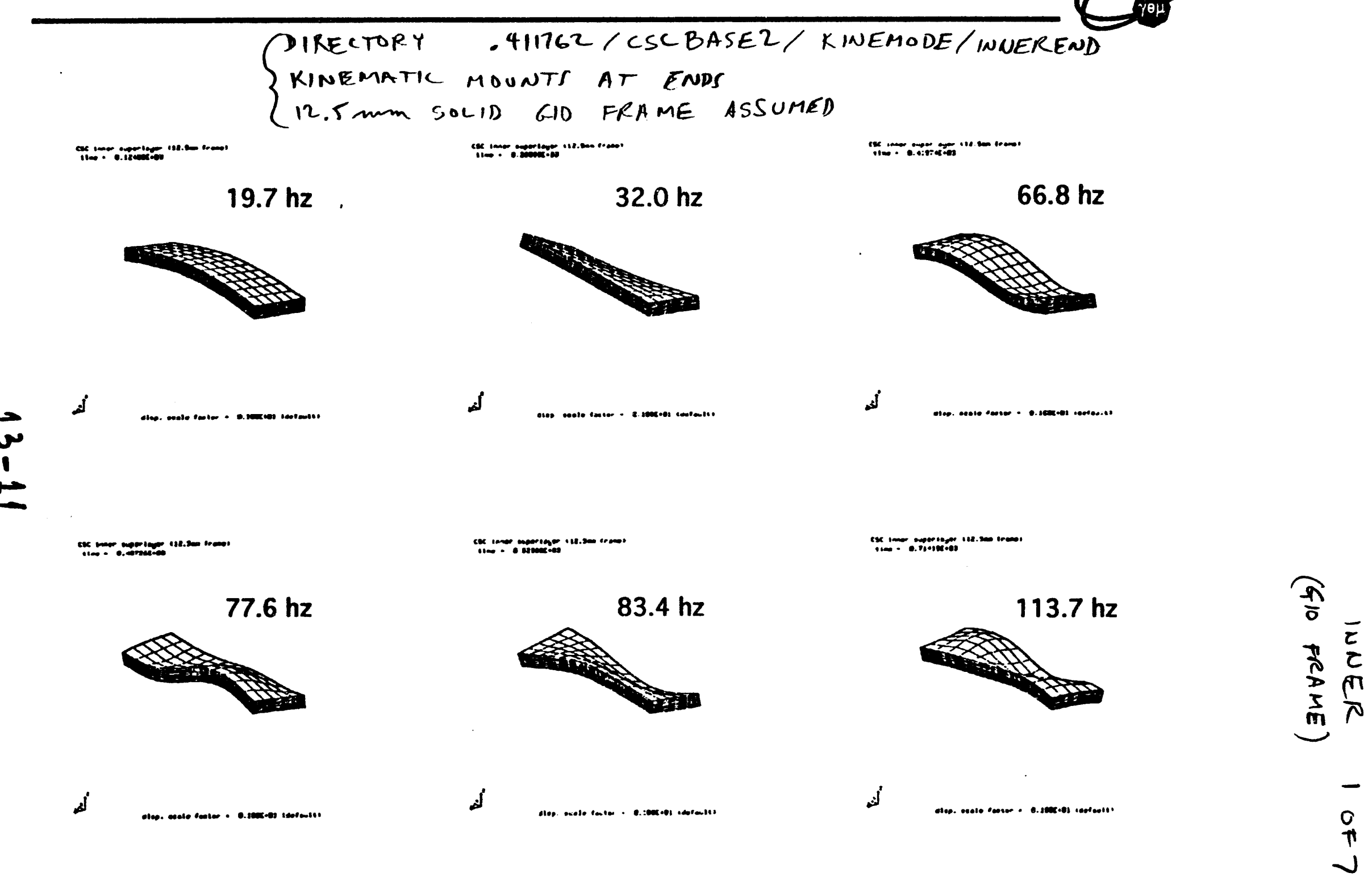




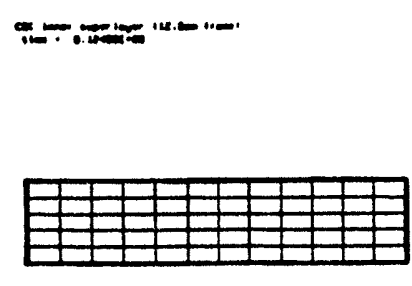

L.

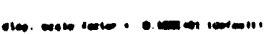

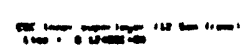

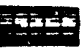

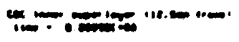

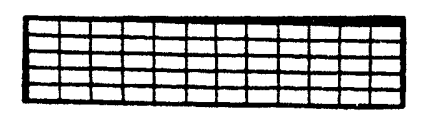

L.

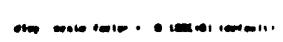

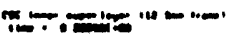

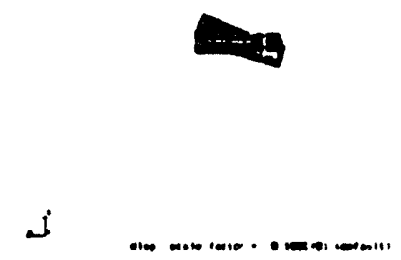

$\therefore-x+4=0-1$

L.

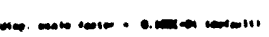

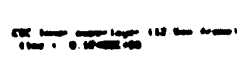

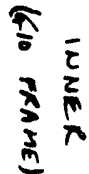

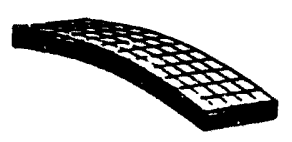

$S L-1$

MODE 1

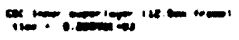

L.

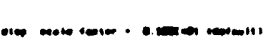

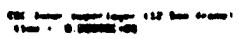

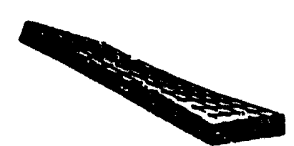

$\cdots+$ 


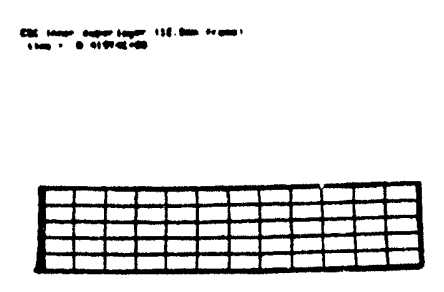

L.

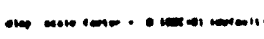

II-

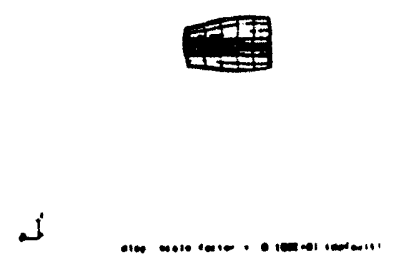

Cxim

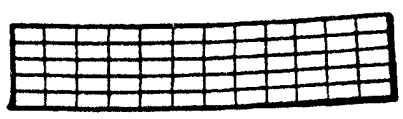

L.

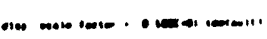

1."

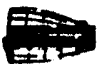

j.<smiles>[3H]CCC</smiles>

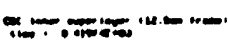

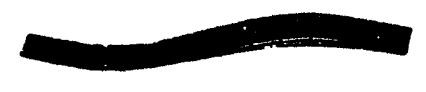

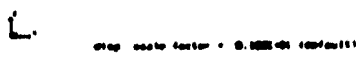

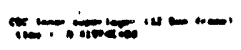

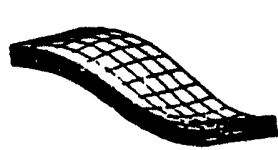

$\begin{array}{ll}\frac{1}{5} & \\ 7 & 2 \\ \frac{2}{3} & \pi\end{array}$

SL-1

MODE 3 I

뜨.

L. Con

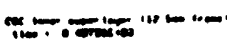
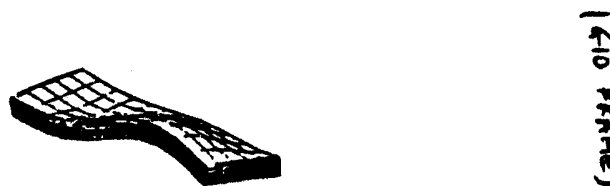

$\frac{1}{0}$

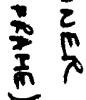

$5 L-1$

MODE 4

$\checkmark$<smiles>CCCCCCC</smiles>

$13-13$ 


$$
h \tau-\varepsilon \tau
$$

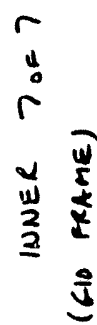
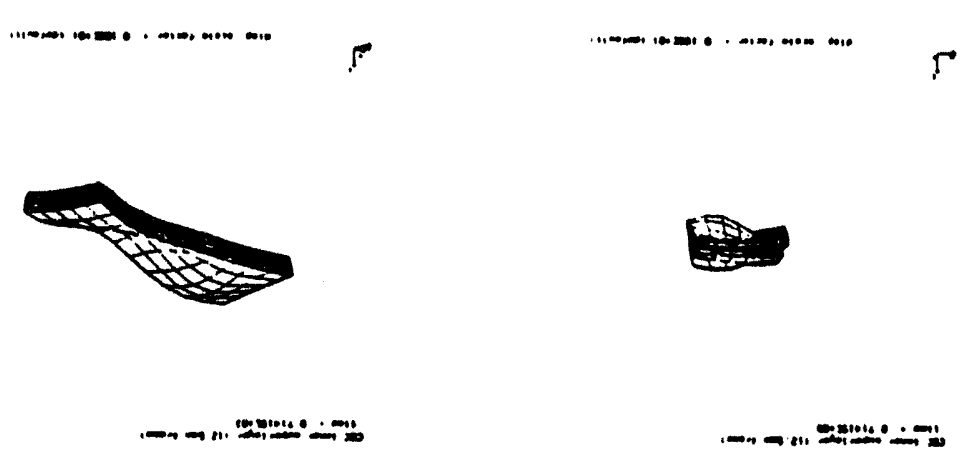

11100

7
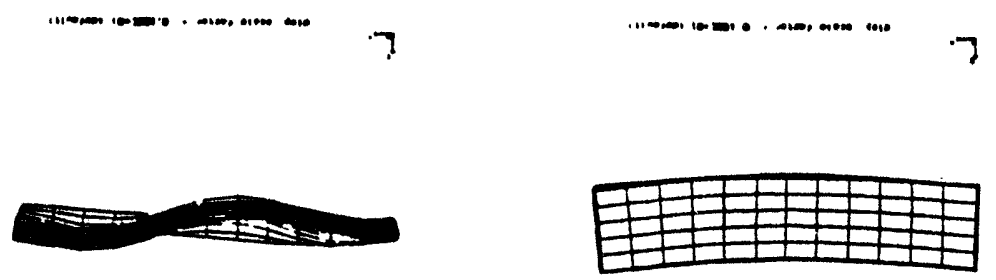

ט.

.

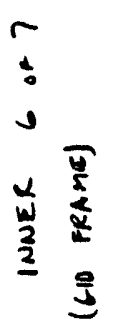

$5300 w$ 7-7s
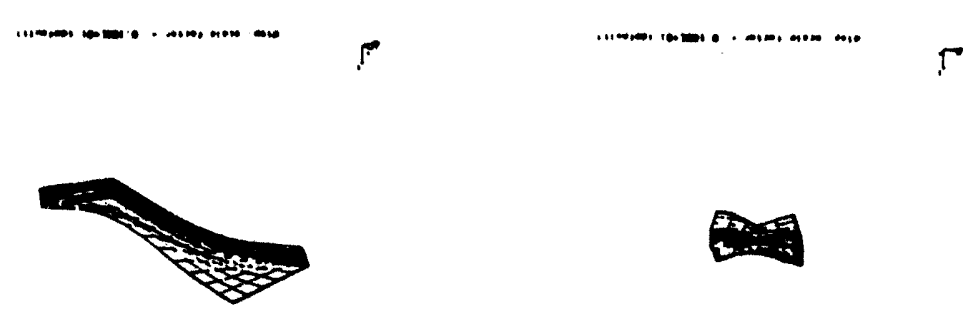

,

"-m

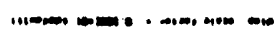

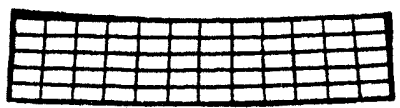

0.

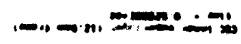




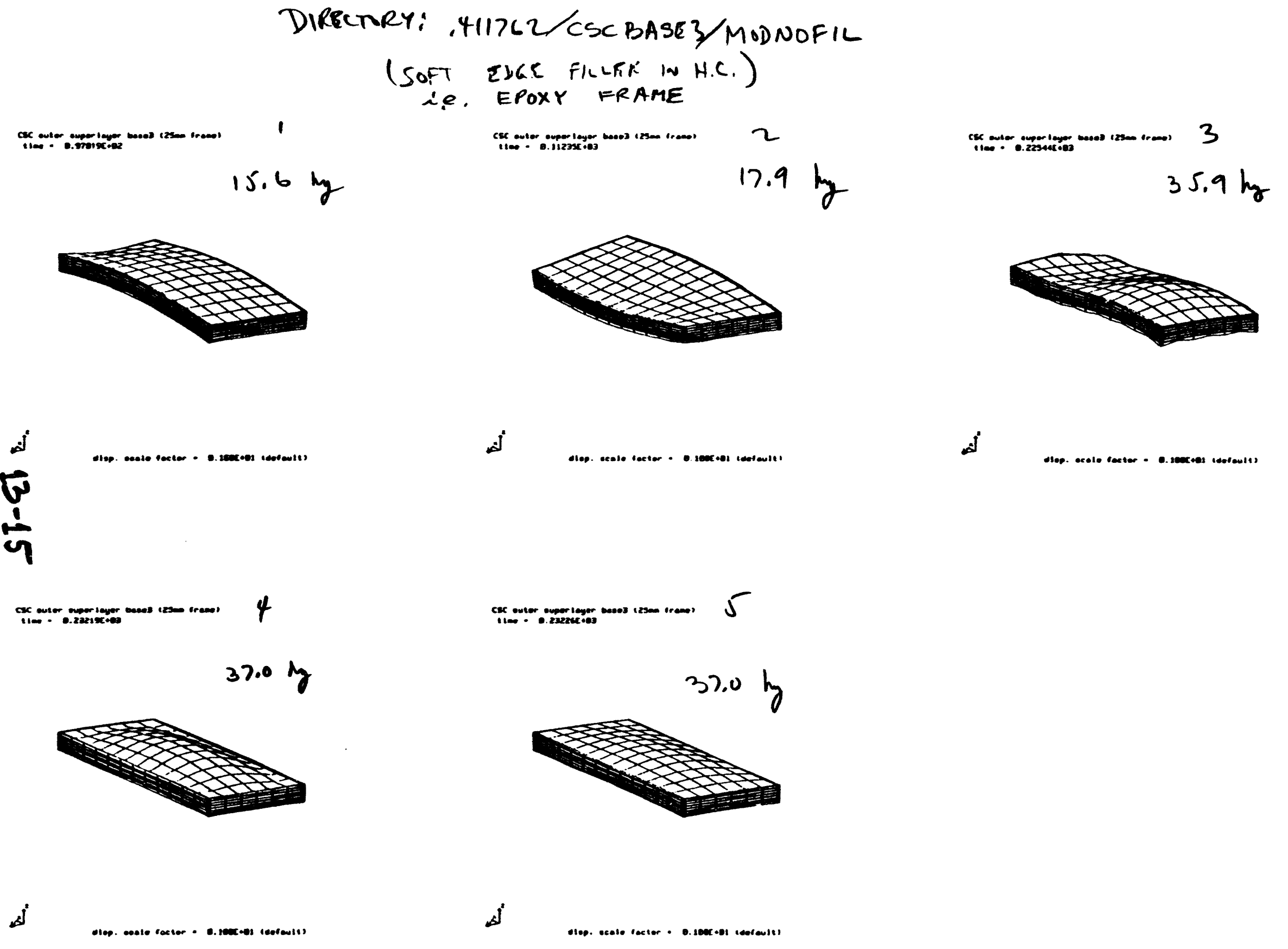


$m-m=0$

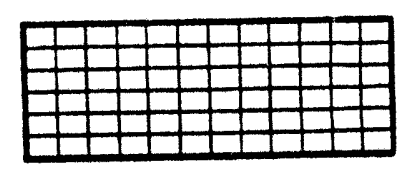

L.

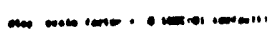

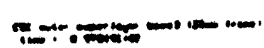

:...

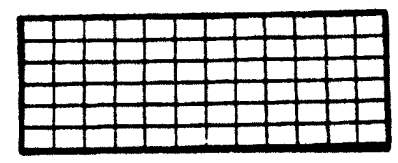

L.

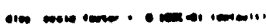

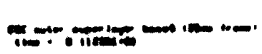

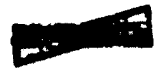

i

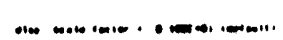

xum

L.

10.

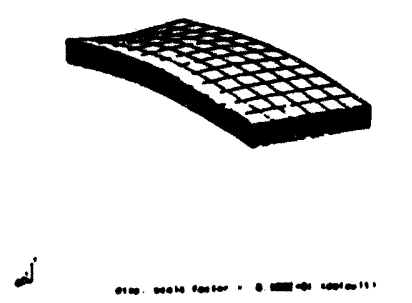

EPOXY

FRAML

$5 L-3$

MODE 1

*an

$3+x=5$

L.

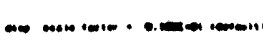

7.-.

EPAXY FPAME

$m$
$\vdots$
$\vdots$
$\vdots$

$\begin{array}{ll}5 L-3 & \\ \text { MODE } 2 & \end{array}$ 


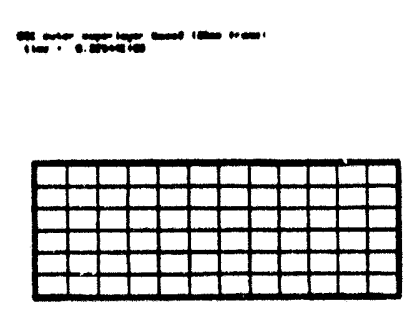

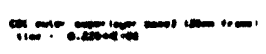

L.

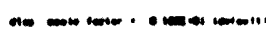

L

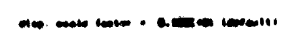

I.

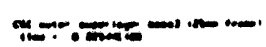
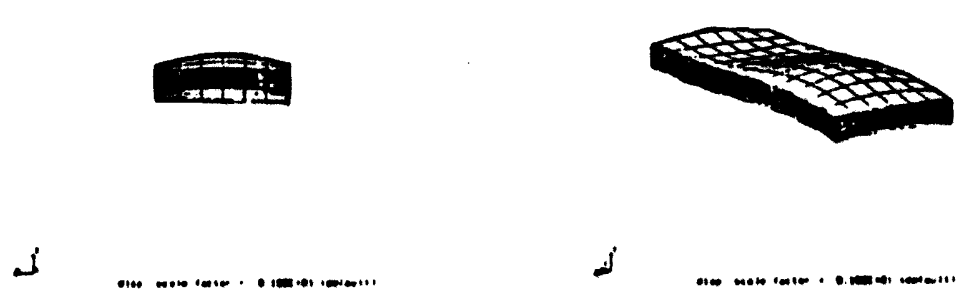

EPOXY

prane

$5 L-3$

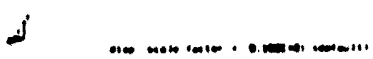

$\begin{array}{ll}5 L-3 & f \\ \text { MODE } 3 & h\end{array}$

ind

ind

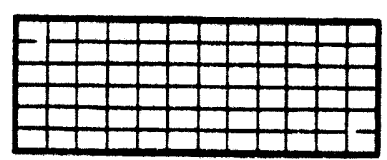

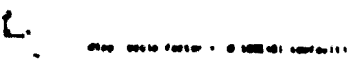

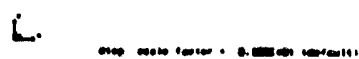

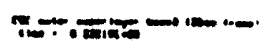

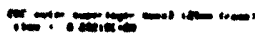
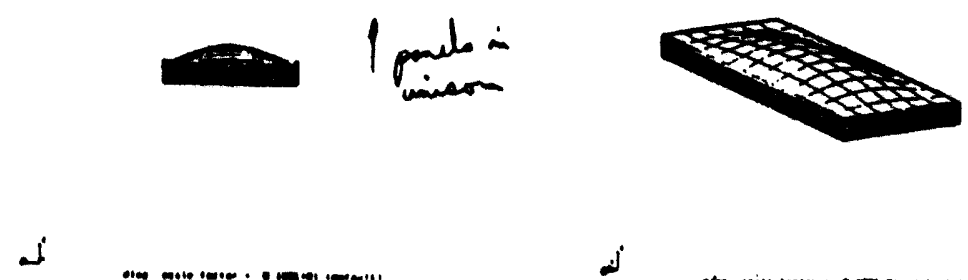

EPoXY

FRAME

$96-3$

$\stackrel{m}{2}$

$\frac{n}{3}$

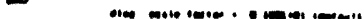




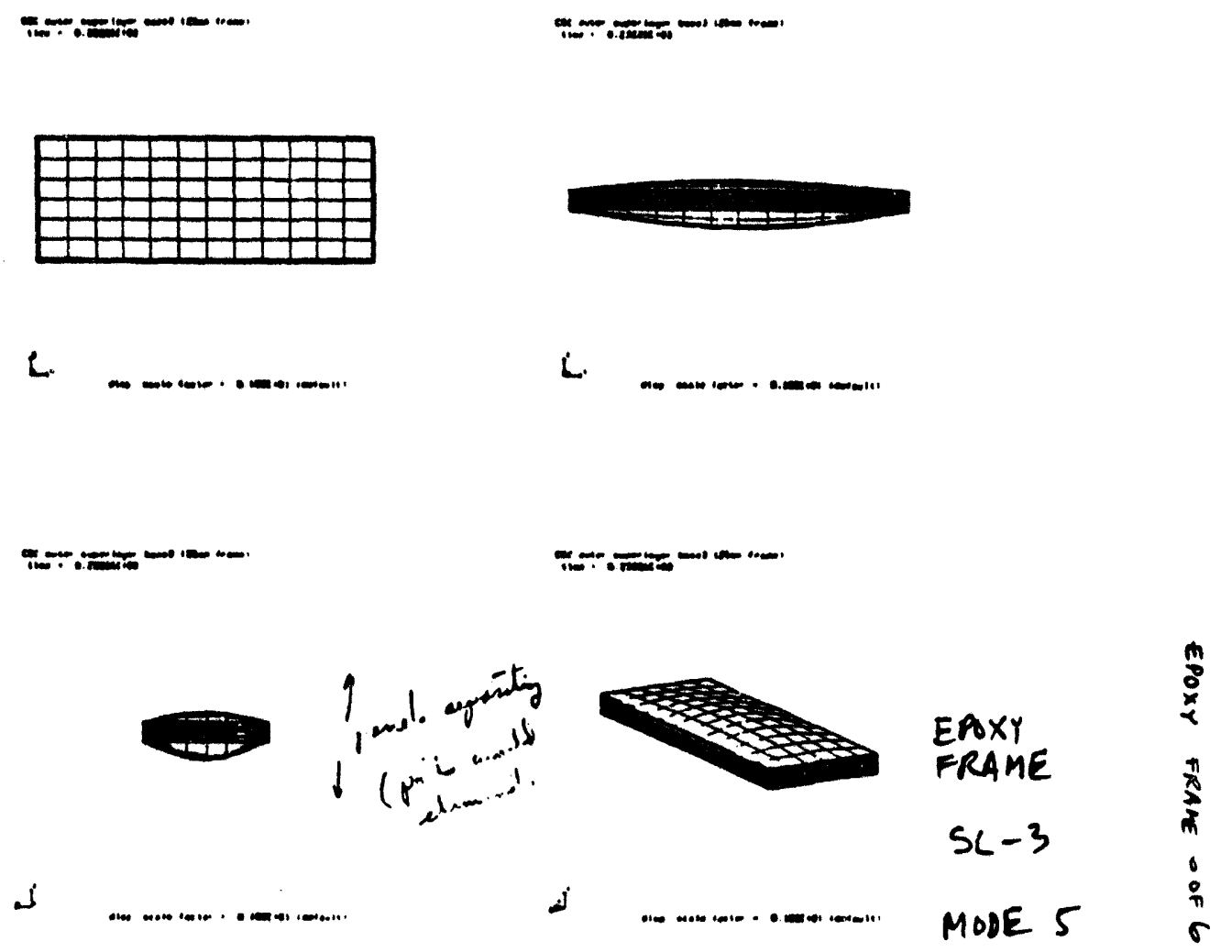


GEM TN-93-494

\section{Chamber Twist}

Contents:

Summary of results and requirements for TDR Baseline ( 3 pages) .

Analysis of chamber twist due to an applied force-couple ( 3 pages)

Calculation of chamber torsional rigidity from applied torque and observed twist (4 pages)

Description of finite element analysis model (4 pages)

Edge straightness for 4-corner support with imposed $1 \mathrm{~mm}$ corner displacement (2 pages)

\section{Summary:}

An applied torque produces a twist value. This information produces torsional rigidity values for each superlayer chamber which can be used to predict chamber twist for various mounting orientations and offsets of the center of gravity.

TDR Baseline chambers were extremely stiff in torsion due to their continuous side frame which formed a closed section beam.

When all four corners are supported in $z$ (quasi-kinematic) and a $1 \mathrm{~mm}$ displacement is imposed on one corner, the long edges remain straight to within 2 microns. 


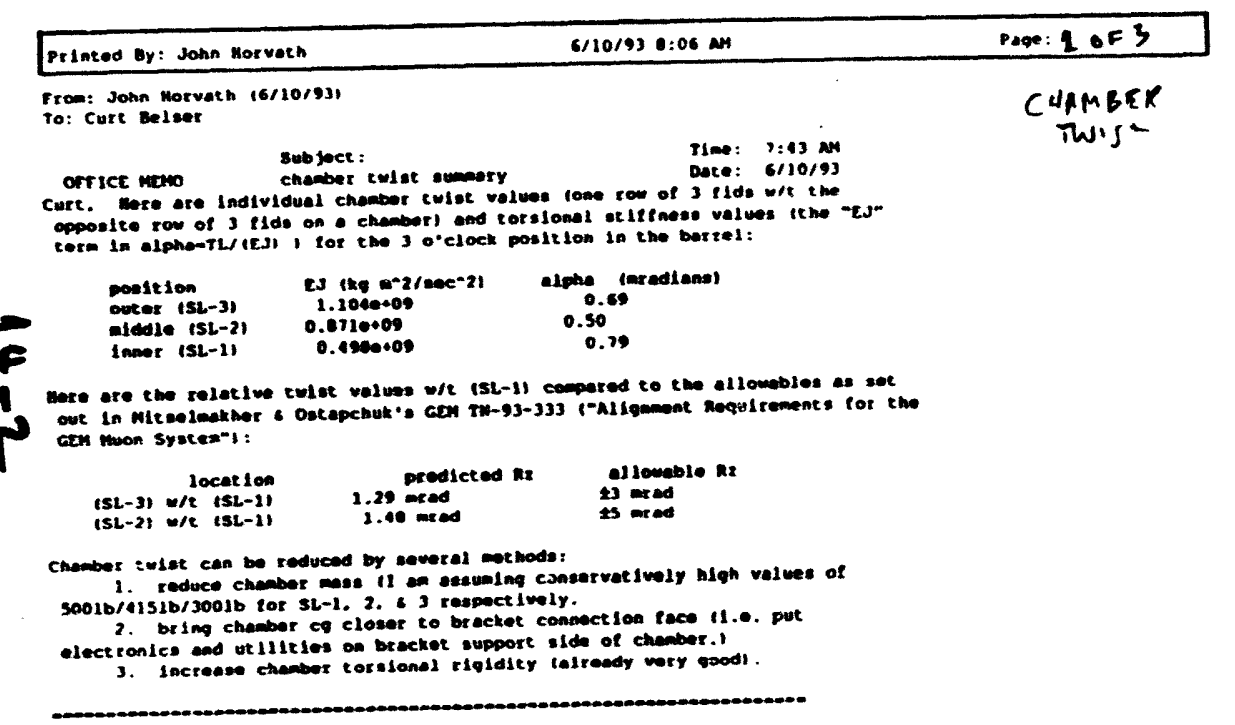

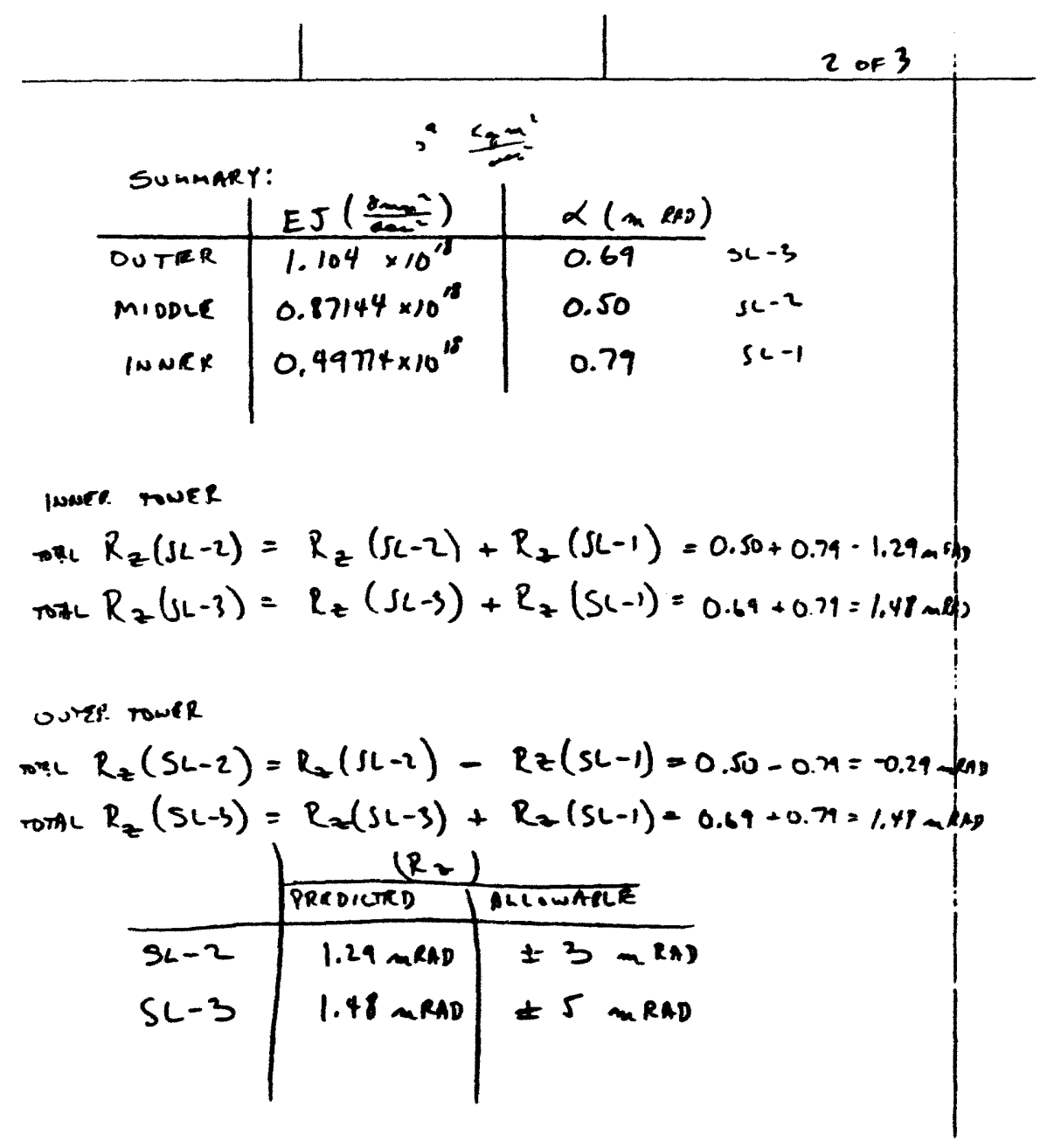




\section{Alignment Requirements for the GEM Muon System}

REF. GEM TN-93-333

Table 2: The local alignment reqirements $\left(\sigma_{z}^{\text {out }}=30 \mathrm{~mm}\right)$

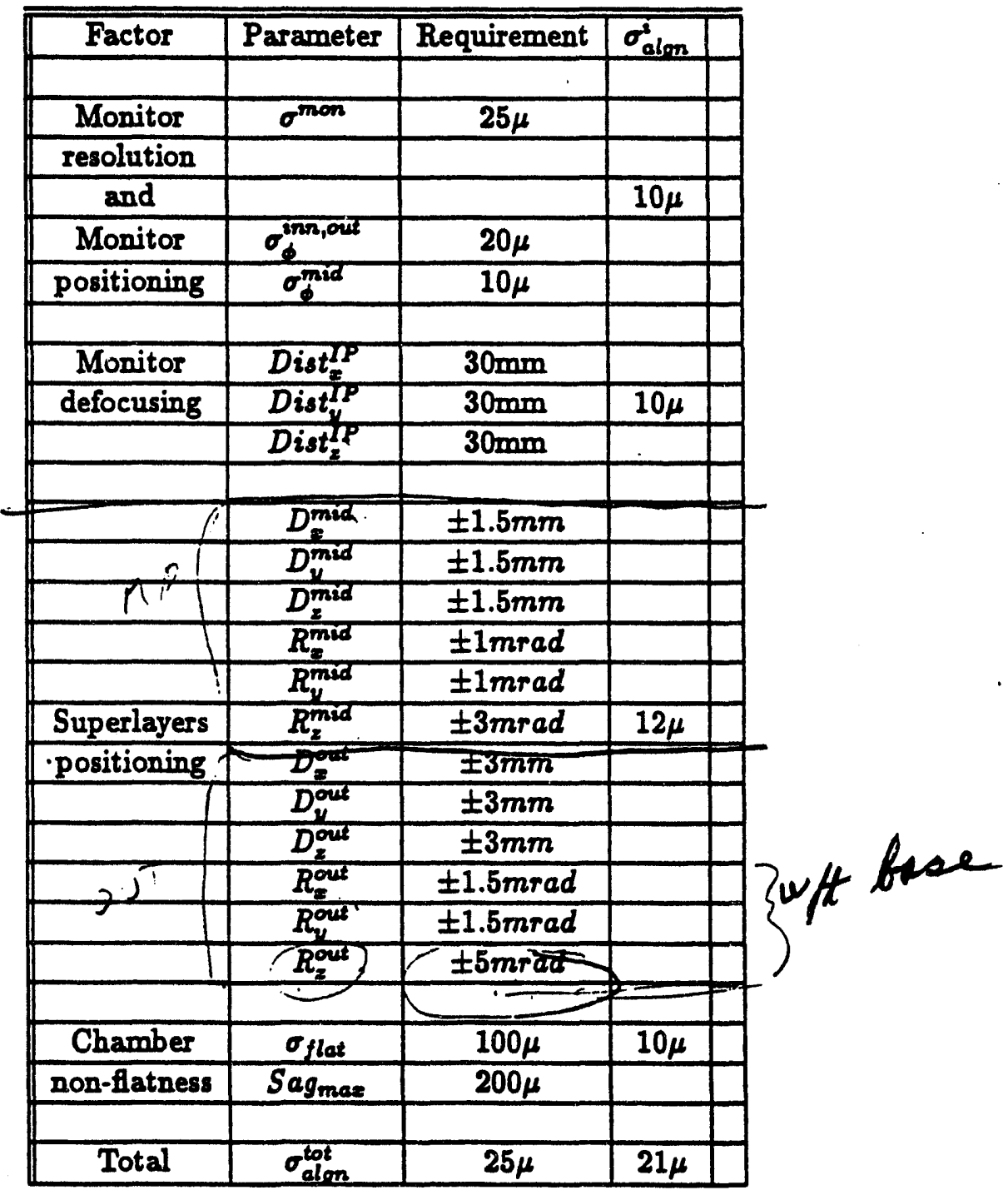




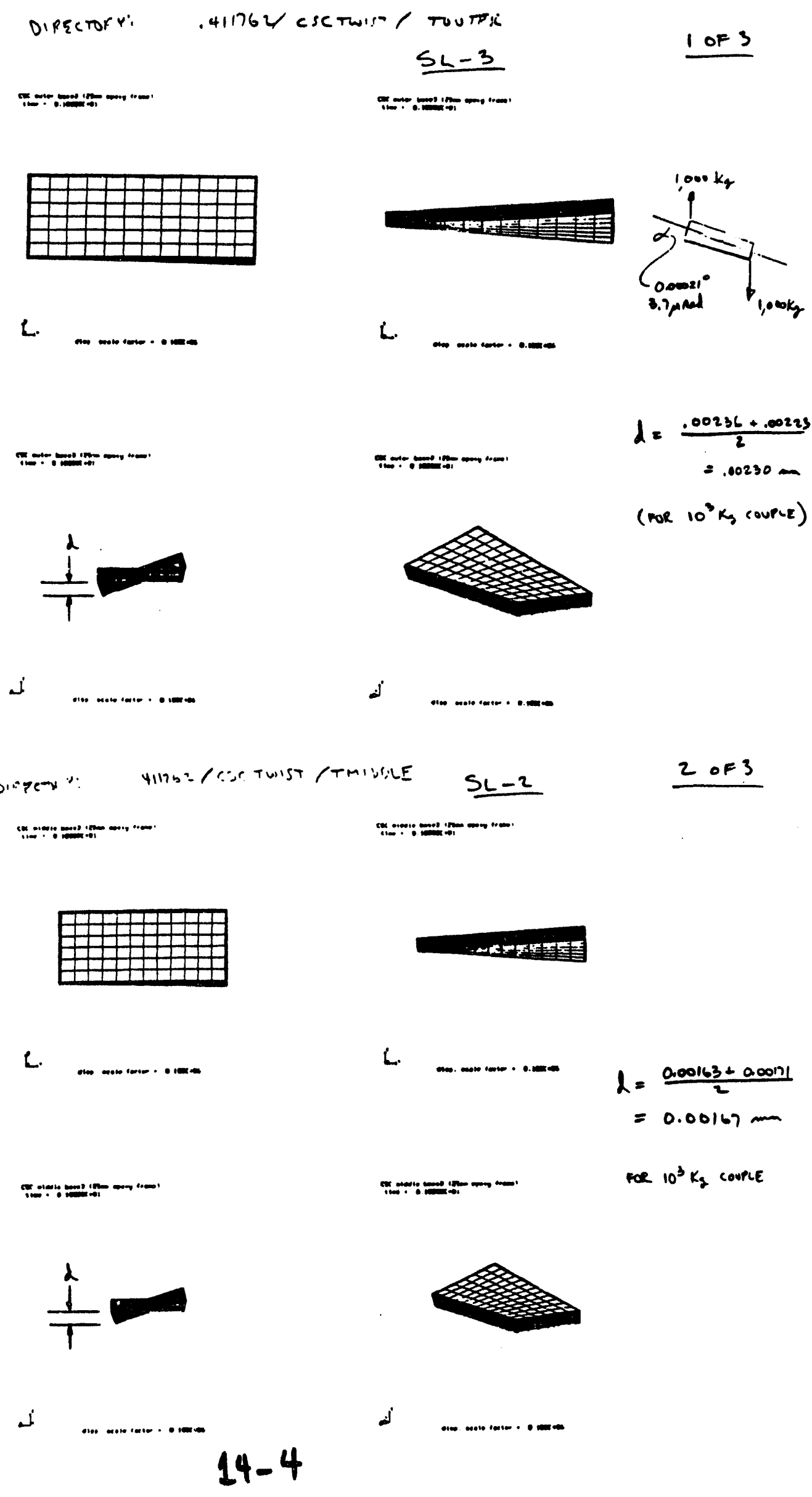


DIRECTRY $\quad 41762 /$ CSC TWIST /TIUNRR

inder

$x-x=$

3 OF 3
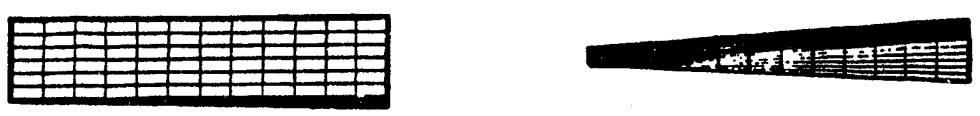

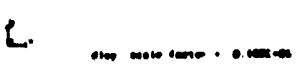

s.r.m.

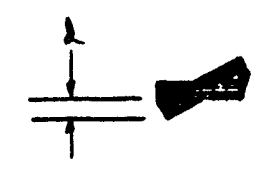

$\sqrt{2}$
L.

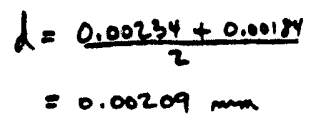

5-1.

For $10^{3} \mathrm{Ko}$ COUPLE

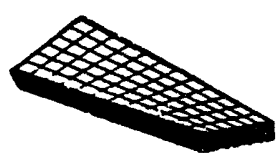

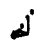

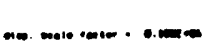

$14-5$ 


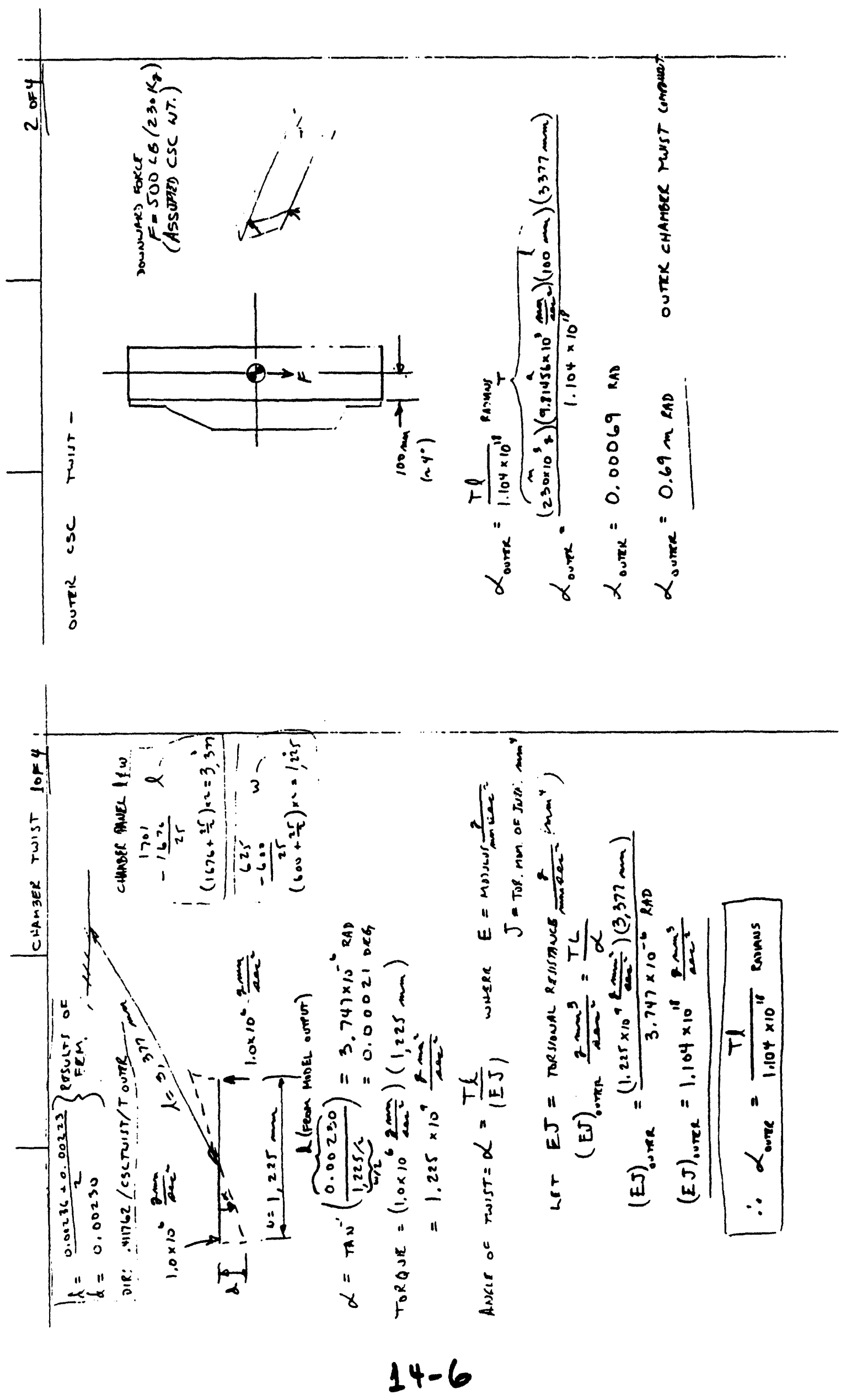




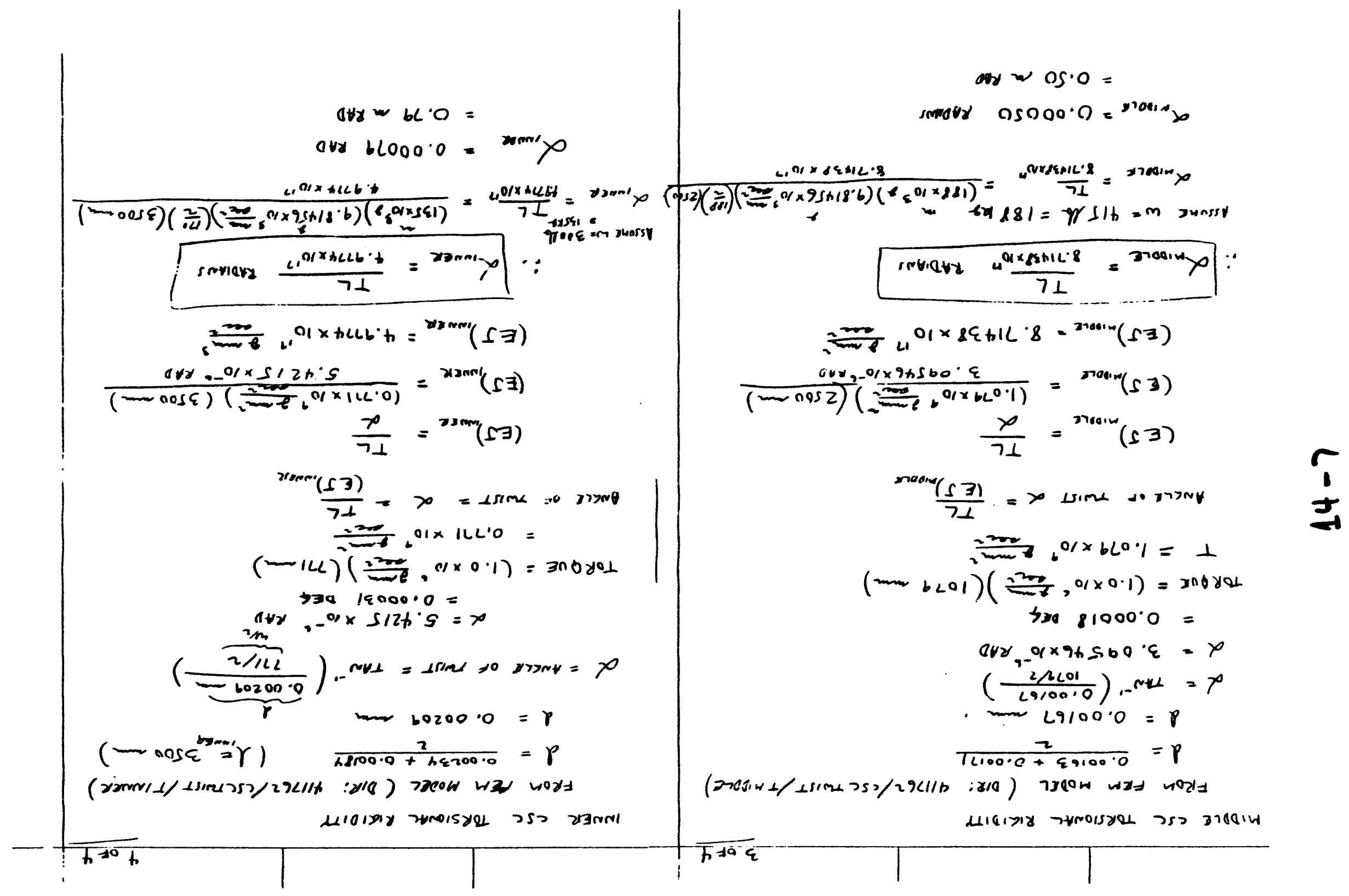




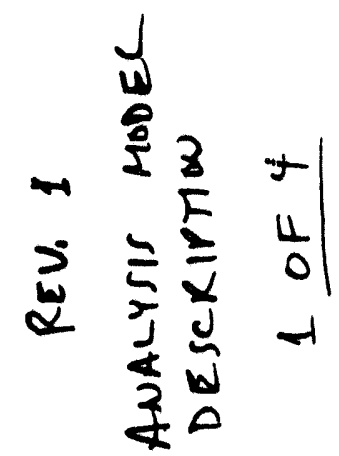

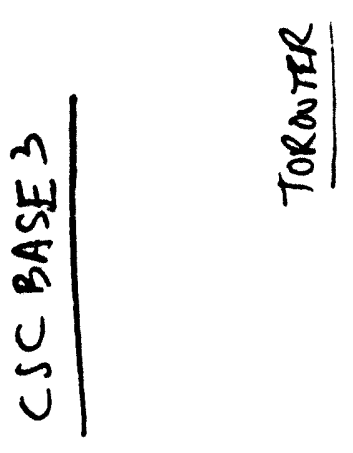

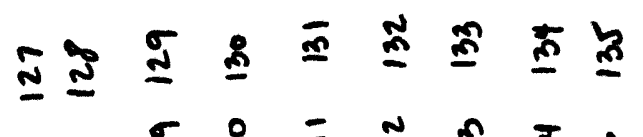
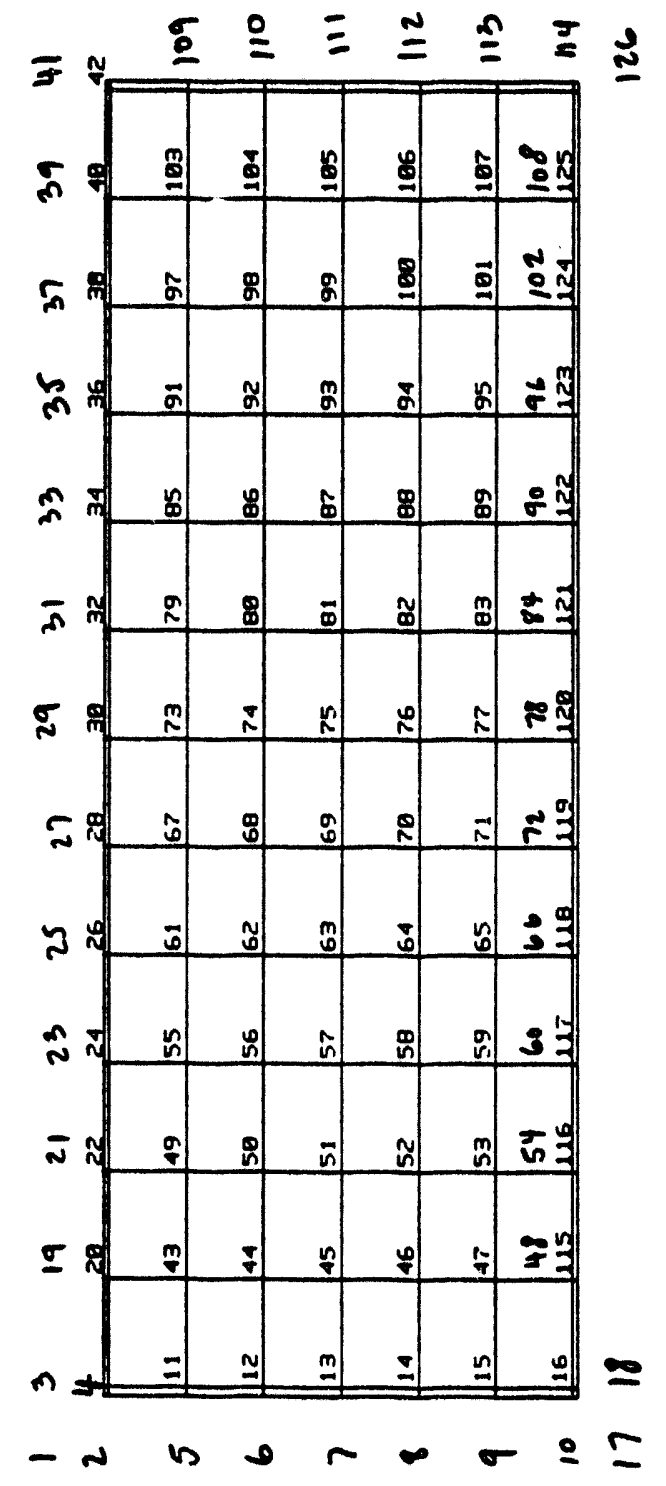

$14-8$ 

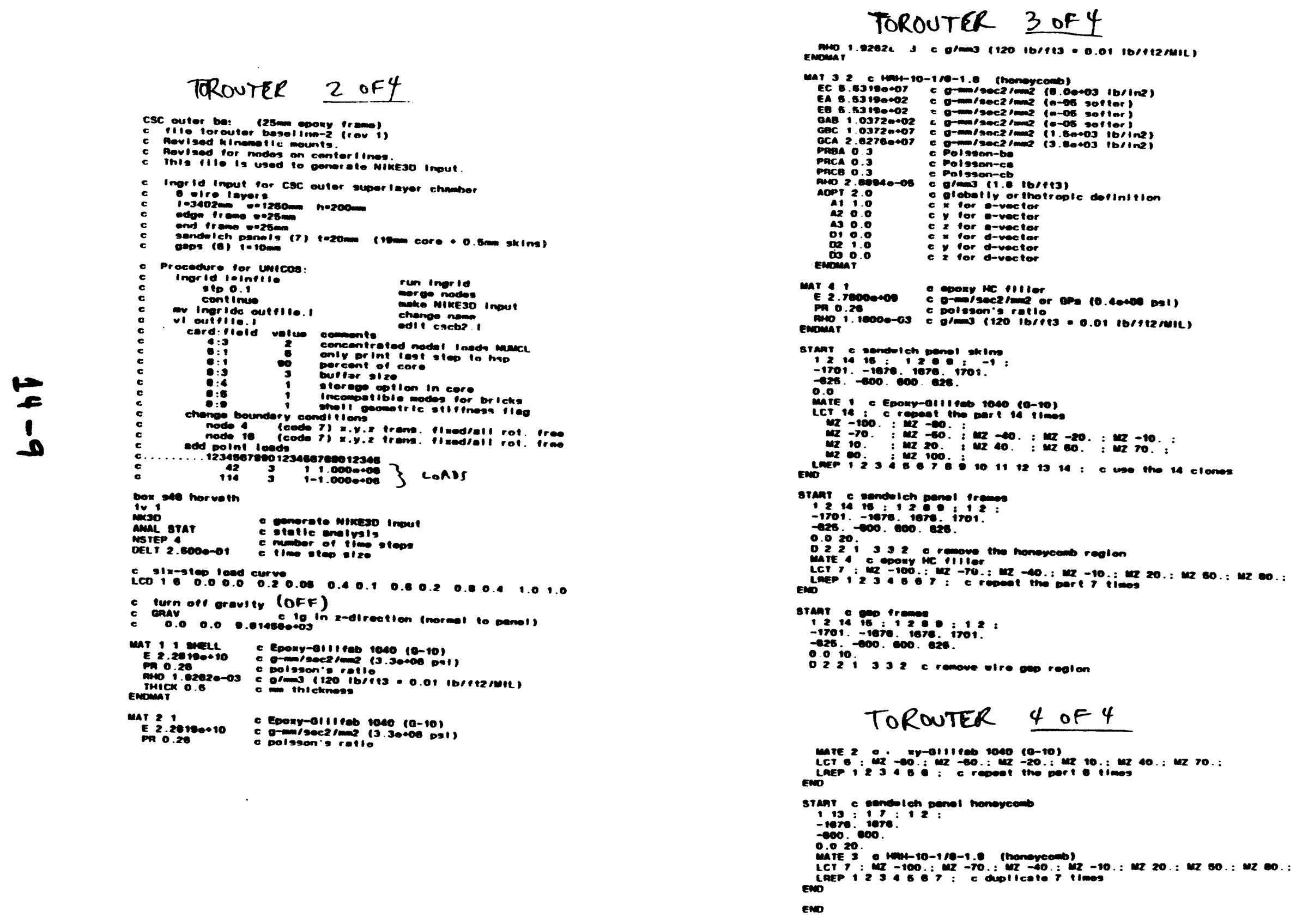


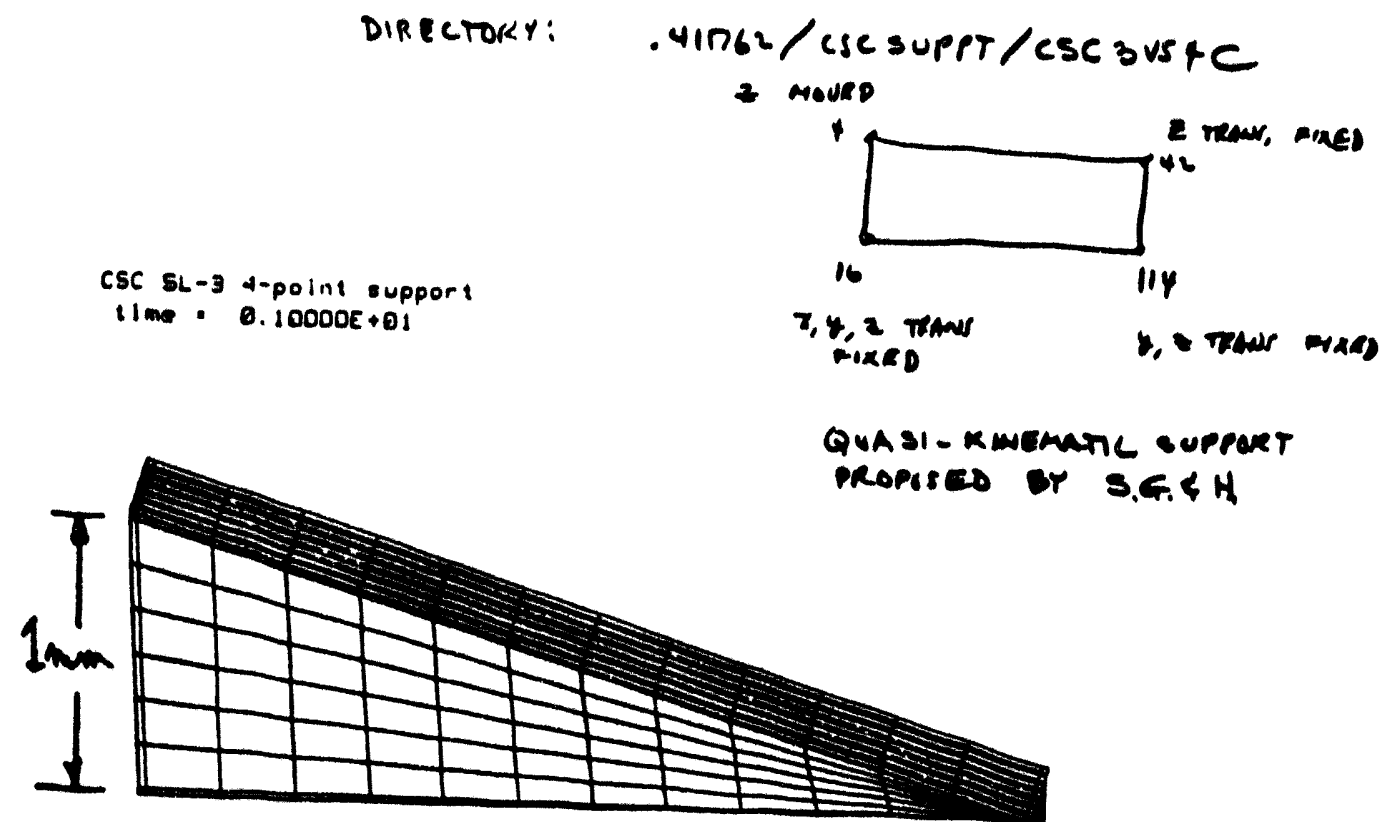

$1 \mathrm{~mm}$ FORCED CORNER DISPCACEMENT All onter corners HELD Down in e

$\bigsqcup_{4}^{2}$

disp. scele ractor, 0.100E+03

CSC SL-3 4-point support

tine - $10000 E+01$

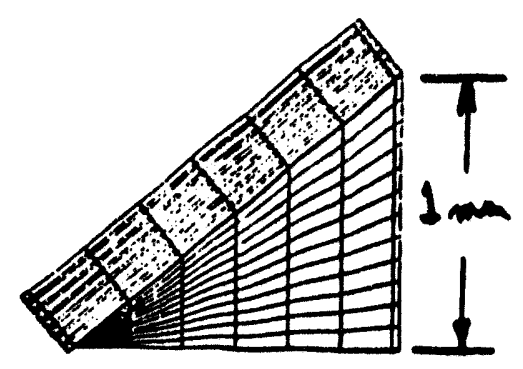

$4 \int^{2}$

disp. scale ractor. B.100C+B3

$14-10$ 


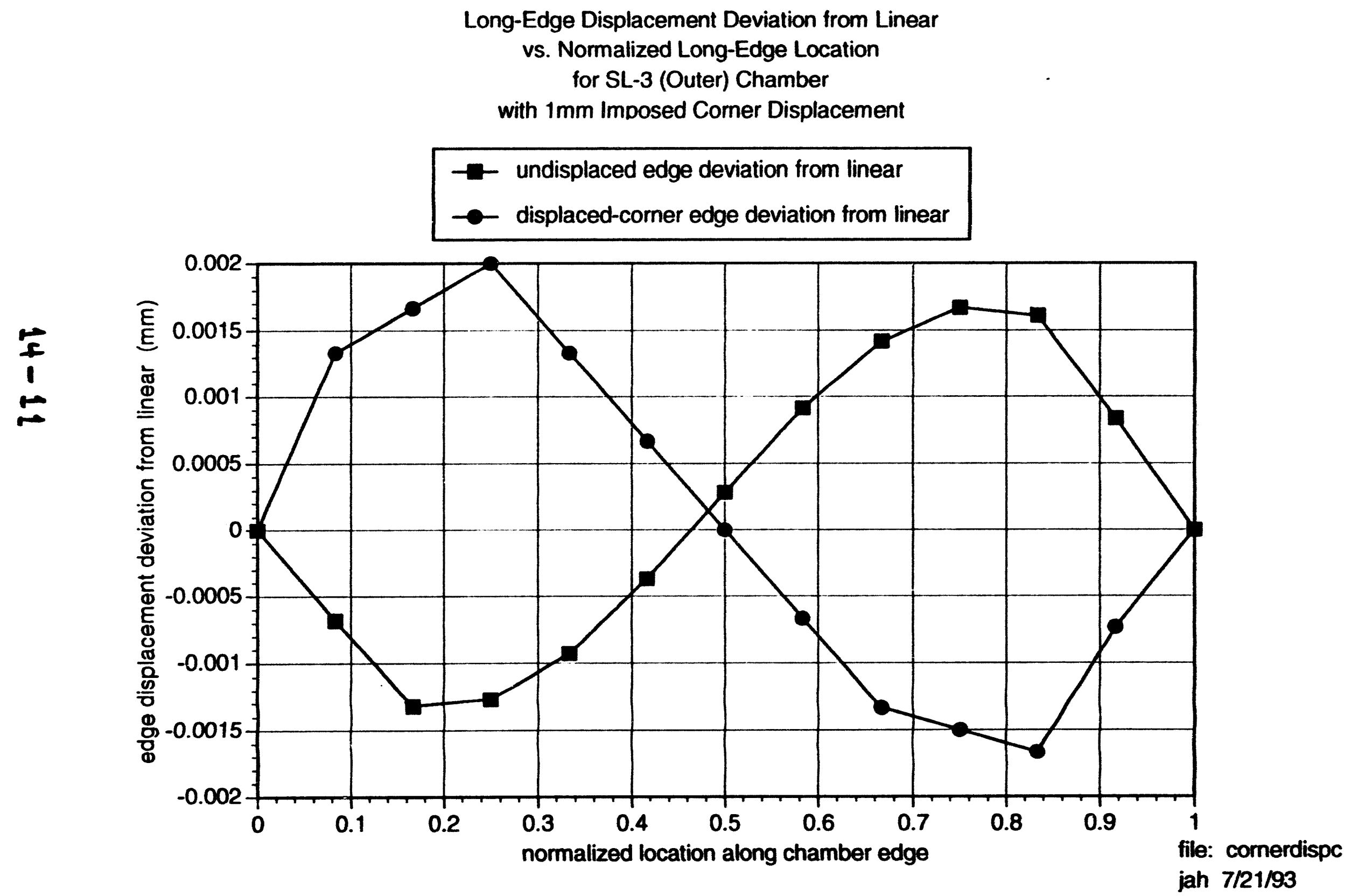




\title{
15. Copper-On-Mylar Cathodes
}

\author{
Contents: \\ Summary viewgraph for SL-3 CSC with Cu-on-mylar cathodes (1 page) \\ Deflection as a function of mylar thickness for $5 \mu$ and $7 \mu$ copper cathodes (1 page) \\ Spreadsheet bending analyses showing mass distribution (2 pages)
}

Summary:

Copper-on-mylar cathodes have very little effect on chamber gravity sag.

The thickness of the mylar and adhesive must be accounted for in determining cathode-tocathode gap size.

Only the precision cathodes need to be copper-on-mylar since the coarse cathodes do not have precise etched patterns. 


\section{Structural Effects of Mylar/Cu Cathodes *}

Minor structural effects of mylar/Cu cathodes

\section{sc-3}

- $5.4 \%$ increase in bending deflection (for outer superlayer CSC)

- $4.3 \%$ increase in chamber mass (for outer superlayer CSC)

component

$500 \mu \mathrm{G} 10$ panel skins glass/epoxy gap frame epoxy edge filler

$5 \mu$ copper cathode

$100 \mu$ mylar film honeycomb core hardware \& utilities

ma
$(\mathrm{kg})$
62.8
27.7
19.4
2.
7.0
17.2
25.0

mass added

(kg)

(\%)

38.9

17.2

12.1

1.3

4.3

10.7

15.5
Qsamied

(\%)

80.5

6.8

9.0

2.2

1.5

0.0

0.0

- Mylar-to-G10 adhesive also adds small amount of mass

- Consider using mylar/copper material on precise cathodes only

* Harre van der geana materiak, Ref. Gen TN-93-268

Normelized Chember Dentection - a Function of

Myler Cethode Subetrate Thickneas and Cu Certhode Thickness

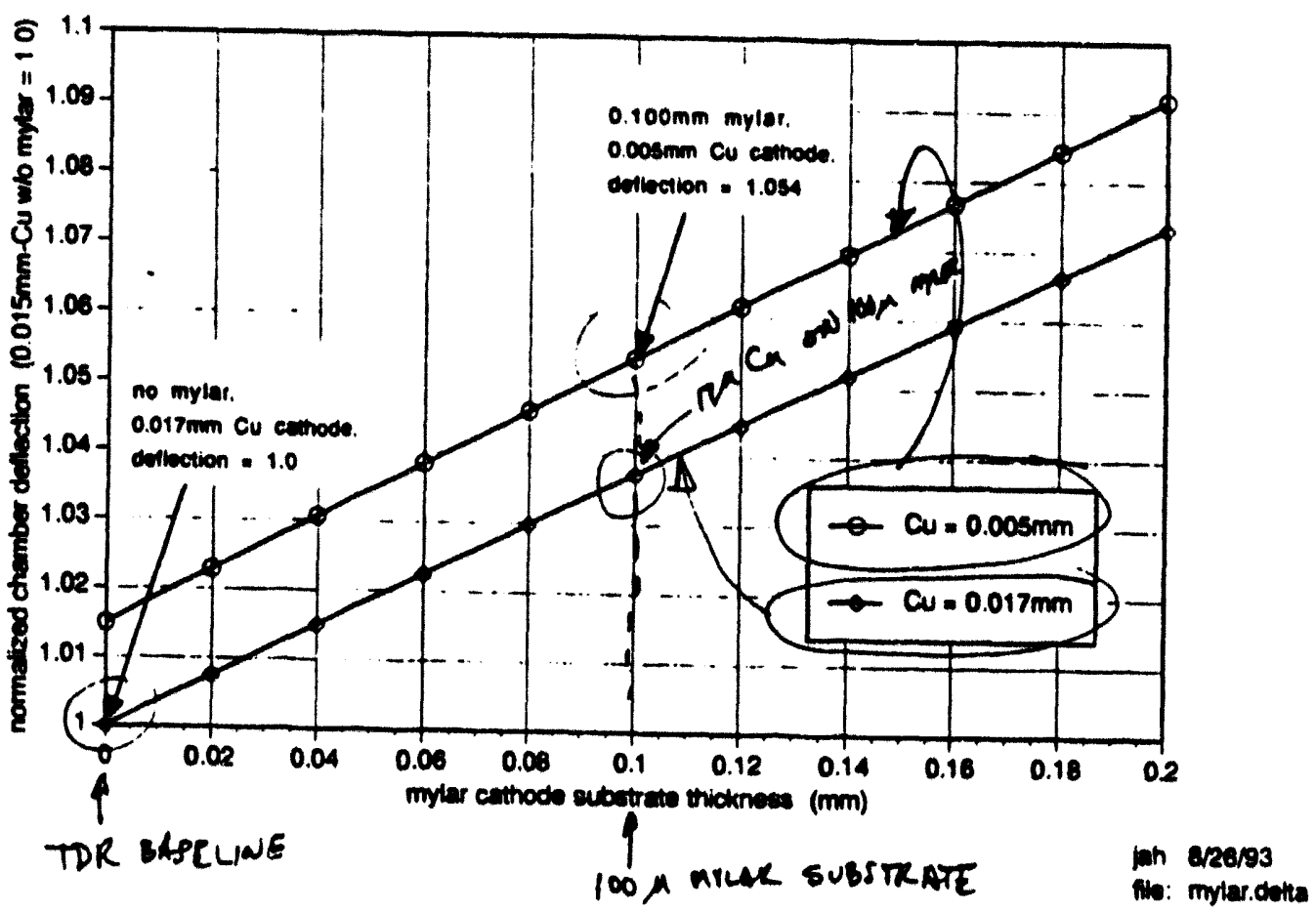




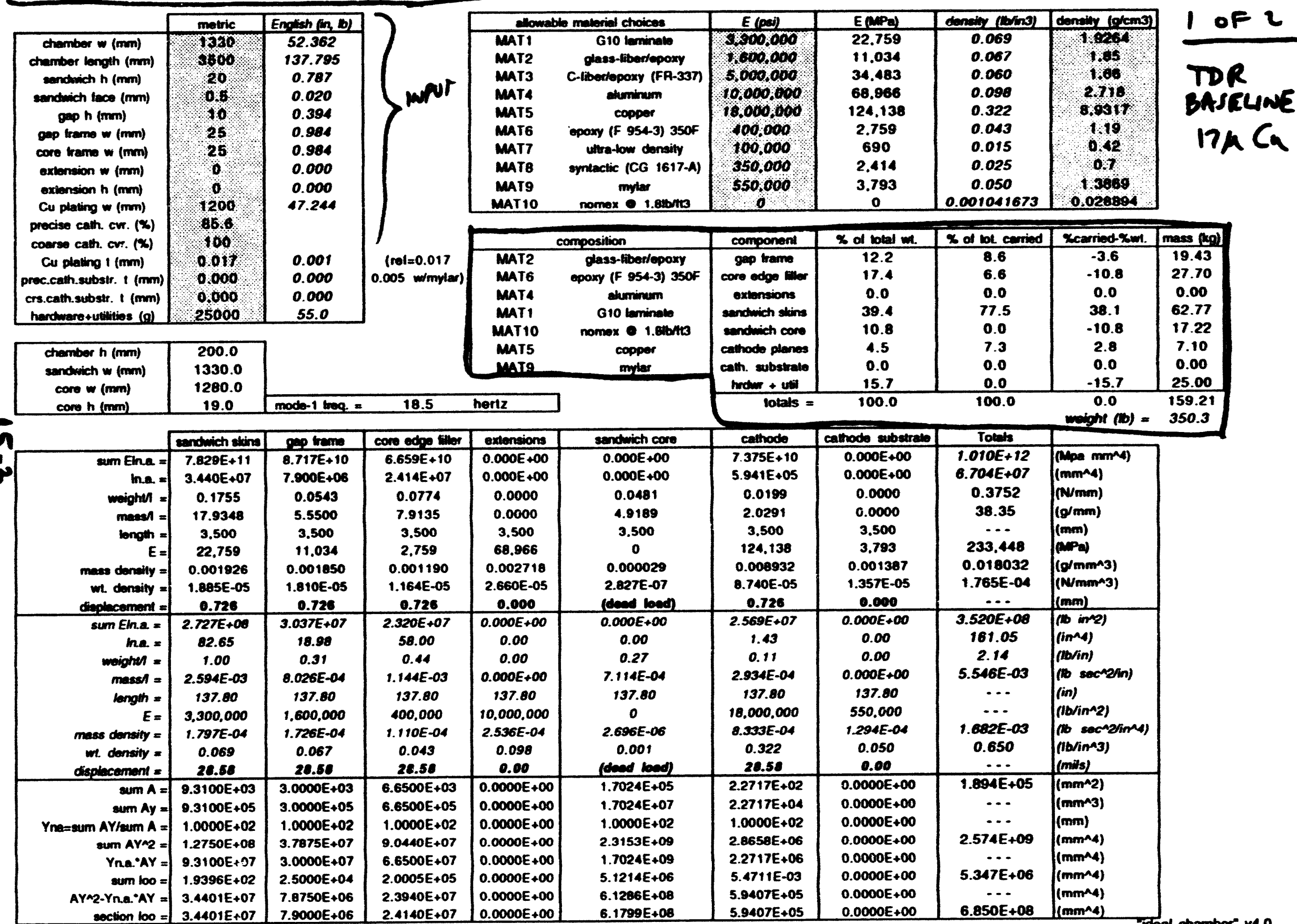




\begin{tabular}{|c|c|c|c|c|c|c|c|c|c|c|}
\hline & metric & English (in, (1) & & \multicolumn{2}{|c|}{ allowable malerial choices } & $E(p s i)$ & E(MPa) & density (binin) & dendity (O/cmin) & \\
\hline $\begin{array}{l}\text { Chember w }(\mathrm{mm}) \\
\text { chamber length }(\mathrm{mm}) \\
\text { sandwich } h(\mathrm{~mm}) \\
\text { sandwich lace }(\mathrm{mm}) \\
\text { gap } h(\mathrm{~mm}) \\
\text { gap trame w }(\mathrm{mm}) \\
\text { core trame } w(\mathrm{~mm}) \\
\text { extension w }(\mathrm{mm}) \\
\text { exlension } h(\mathrm{~mm}) \\
\text { Cu plating } w(\mathrm{~mm})\end{array}$ & $\begin{array}{l}1330 \\
6000 \\
20 \\
0.5 \\
10 \\
25 \\
25 \\
0 \\
0 \\
1200\end{array}$ & $\begin{array}{c}52.362 \\
137.795 \\
0.787 \\
0.020 \\
0.394 \\
0.984 \\
0.984 \\
0.000 \\
0.000 \\
47.244\end{array}$ & Iupor & $\begin{array}{l}\text { MAT1 } \\
\text { MAT2 } \\
\text { MAT3 } \\
\text { MAT4 } \\
\text { MAT5 } \\
\text { MAT6 } \\
\text { MAT7 } \\
\text { MAT8 } \\
\text { MAT9 } \\
\text { MAT10 } \\
\end{array}$ & $\begin{array}{c}\text { G10 laminale } \\
\text { glass-liberfopoxy } \\
\text { C-liber/opoxy (FA-337) } \\
\text { aluminum } \\
\text { copper } \\
\text { epoxy (F 954-3) 350F } \\
\text { ulra-low donsily } \\
\text { syntactic (CG 1617-A) } \\
\text { mylar } \\
\text { nomex e 1.81bna } \\
\end{array}$ & $\begin{array}{l}8,500,000 \\
5,000,000,000 \\
10.000 .000 \\
10.000,000 \\
100,000 \\
100,000 \\
350,000 \\
550,000 \\
0\end{array}$ & $\begin{array}{c}22.759 \\
11.034 \\
34.483 \\
68.966 \\
124.138 \\
2.759 \\
690 \\
2.414 \\
3.793 \\
0 \\
\end{array}$ & $\begin{array}{l}0.069 \\
0.067 \\
0.060 \\
0.098 \\
0.322 \\
0.043 \\
0.015 \\
0.025 \\
0.050 \\
0.001041673 \\
\end{array}$ & 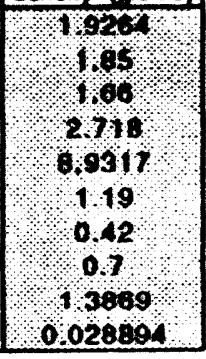 & \\
\hline & & & & & composition & componem & $x$ of total $\mathrm{w}$. & $x$ of lot carried & xcarriod-xm. & $\operatorname{mass}(\mathrm{kg})$ \\
\hline $\begin{array}{c}\text { Cu plating I }(\mathrm{mm}) \\
\text { prec.cath.substr. I (mm) } \\
\text { cr.cath.substr. I (mm) } \\
\text { haroware+utilitios }(\mathrm{g})\end{array}$ & $\begin{array}{r}0005 \\
0,100 \\
0,100 \\
25000 \\
\end{array}$ & $\begin{array}{c}0.000 \\
0.004 \\
0.004 \\
55.0 \\
\end{array}$ & $\begin{array}{c}\text { (rel }=0.017 \\
0.005 \text { w/mylar) }\end{array}$ & $\begin{array}{l}\text { MAT2 } \\
\text { MAT6 } \\
\text { MAT4 } \\
\text { MAT1 }\end{array}$ & $\begin{array}{c}\text { glass-liber/epoxy } \\
\text { opoxy (F 954-3) 350F } \\
\text { aluminum } \\
\text { G10 laminate }\end{array}$ & $\begin{array}{l}\text { gap lrame } \\
\text { core edge tiller } \\
\text { extensions } \\
\text { sendwich skins }\end{array}$ & $\begin{array}{c}12.1 \\
17.2 \\
0.0 \\
38.9\end{array}$ & $\begin{array}{c}9.0 \\
6.8 \\
0.0 \\
80.5\end{array}$ & $\begin{array}{c}-3.1 \\
-10.3 \\
0.0 \\
41.5\end{array}$ & \begin{tabular}{|c|}
19.43 \\
27.70 \\
0.00 \\
62.77 \\
17.29
\end{tabular} \\
\hline $\begin{array}{l}\text { chamber h }(\mathrm{mm}) \\
\text { sandwich w }(\mathrm{mm}) \\
\text { core w }(\mathrm{mm})\end{array}$ & $\begin{array}{l}200.0 \\
1330.0 \\
1280.0\end{array}$ & & & $\begin{array}{l}\text { MAT10 } \\
\text { MAT5 } \\
\text { MAT9 }\end{array}$ & $\begin{array}{c}\text { nomex } 1.816 \text { nt } \\
\text { coppor } \\
\text { mvlar } \\
\end{array}$ & $\begin{array}{l}\text { sandwich core } \\
\text { cathode planes } \\
\text { calh. substrate } \\
\text { hrowr + util }\end{array}$ & $\begin{array}{c}10.7 \\
1.3 \\
4.3 \\
15.5 \\
\end{array}$ & $\begin{array}{l}0.0 \\
2.2 \\
1.5 \\
0.0 \\
\end{array}$ & $\begin{array}{c}-10.7 \\
0.9 \\
-2.8 \\
-15.5 \\
\end{array}$ & $\begin{array}{c}17.22 \\
2.09 \\
6.99 \\
25.00 \\
\end{array}$ \\
\hline core $h(\mathrm{~mm})$ & 19.0 & mode-1 linog. $=$ & 18.0 & hertz & & folals $=$ & 100.0 & 100.0 & $\begin{array}{c}0.0 \\
\operatorname{aight}(b)=\end{array}$ & $\begin{array}{l}161.19 \\
354.6\end{array}$ \\
\hline & sendwich skins & gep trams & core edge lillor & exdensions & sandwich core & calhode & cathode substrato & Totals & & \\
\hline $\begin{array}{r}\text { sum Eln.a. }= \\
\text { In.a. }= \\
\text { weighth }= \\
\text { mass }= \\
\text { longth }= \\
E= \\
\text { mase density }= \\
\text { w. density }= \\
\text { diaplacement }=\end{array}$ & \begin{tabular}{|c|}
$7.829 E+11$ \\
$3.440 E+07$ \\
0.1755 \\
17.9348 \\
3.500 \\
22.759 \\
0.001926 \\
$1.885 E-05$ \\
0.785 \\
\end{tabular} & $\begin{array}{c}8.717 E+10 \\
7.900 E+06 \\
0.0543 \\
5.5500 \\
3.500 \\
11.034 \\
0.001850 \\
1.810 E-05 \\
0.705 \\
\end{array}$ & $\begin{array}{c}6.659 E+10 \\
2.414 E+07 \\
0.0774 \\
7.9135 \\
3.500 \\
2.759 \\
0.001190 \\
1.164 E-05 \\
0.765 \\
\end{array}$ & $\begin{array}{c}0.000 E+00 \\
0.000 E+00 \\
0.0000 \\
0.0000 \\
3.500 \\
68.966 \\
0.002718 \\
2.660 E-05 \\
0.000 \\
\end{array}$ & $\begin{array}{c}0.000 E+00 \\
0.000 E+00 \\
0.0481 \\
4.9189 \\
3.500 \\
0 \\
0.000029 \\
2.827 E-07 \\
\text { doad loed) } \\
\end{array}$ & $\begin{array}{c}2.169 E+10 \\
1.747 E+05 \\
0.0058 \\
0.5968 \\
3.500 \\
124.138 \\
0.008932 \\
0.740 E-05 \\
0.765 \\
\end{array}$ & $\begin{array}{c}1.447 E+10 \\
3.015 E+06 \\
0.0195 \\
1.997 ! \\
3.500 \\
3.793 \\
0.001387 \\
1.357 E-05 \\
0.785 \\
\end{array}$ & $\begin{array}{c}9.728 E+11 \\
7.043 E+07 \\
0.3808 \\
38.91 \\
\ldots . \\
233.448 \\
0.018032 \\
1.765 E-04 \\
\ldots \\
\end{array}$ & 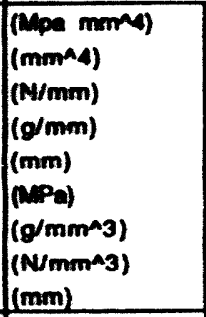 & \\
\hline $\begin{array}{r}\text { sum Eln.a. }= \\
\text { In.a. }= \\
\text { weight }= \\
\text { mass }= \\
\text { length }= \\
E= \\
\text { mass density }= \\
\text { wh. density }= \\
\text { displacement }=\end{array}$ & $\begin{array}{c}2.727 E+08 \\
82.65 \\
1.00 \\
2.594 E-03 \\
137.80 \\
3,300,000 \\
1.797 E-04 \\
0.069 \\
30.12\end{array}$ & $\begin{array}{c}3.037 E+07 \\
18.98 \\
0.31 \\
8.026 E-04 \\
137.80 \\
1.600 .000 \\
1.726 E-04 \\
0.067 \\
30.12\end{array}$ & $\begin{array}{c}2.320 E+07 \\
58.00 \\
0.44 \\
1.144 E-03 \\
137.80 \\
400,000 \\
1.110 E-04 \\
0.043 \\
30.12 \\
\end{array}$ & $\begin{array}{c}0.000 E+00 \\
0.00 \\
0.00 \\
0.000 E+00 \\
137.80 \\
10,000,000 \\
2.536 E-04 \\
0.098 \\
0.00 \\
\end{array}$ & $\begin{array}{c}0.000 E+00 \\
0.00 \\
0.27 \\
7.114 E-04 \\
137.80 \\
0 \\
2.696 E-06 \\
0.001 \\
\text { (dead lood) }\end{array}$ & $\begin{array}{c}7.555 E+06 \\
0.42 \\
0.03 \\
8.630 E-05 \\
137.80 \\
18.000 .000 \\
8.333 E-04 \\
0.322 \\
30.12 \\
\end{array}$ & $\begin{array}{c}5.041 E+06 \\
9.17 \\
0.11 \\
2.888 E-04 \\
137.80 \\
550.000 \\
1.294 E-04 \\
0.050 \\
30.12 \\
\end{array}$ & $\begin{array}{c}3.389 E+08 \\
169.21 \\
2.17 \\
5.627 E-03 \\
\ldots \\
\ldots \\
1.682 E-03 \\
0.650 \\
\ldots \\
\end{array}$ & 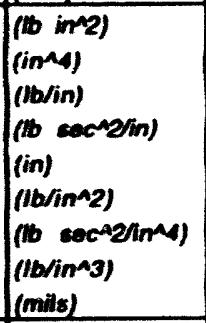 & \\
\hline $\begin{array}{r}\operatorname{sum} A= \\
\operatorname{sum} A y= \\
\text { Ynas=sum AYraum } A= \\
\operatorname{sum} A Y{ }^{A}= \\
\text { Yn.a. } A Y= \\
\operatorname{sum} 100= \\
\text { AYA2-Yn.a.:AY }= \\
\operatorname{section} 100=\end{array}$ & $\begin{array}{l}9.3100 E+03 \\
9.3100 E+05 \\
1.0000 E+02 \\
1.2750 E+08 \\
9.3100 E+07 \\
1.9396 E+02 \\
3.4401 E+07 \\
3.4401 E+07\end{array}$ & $\begin{array}{l}3.0000 E+03 \\
3.0000 E+05 \\
1.0000 E+02 \\
3.7875 E+07 \\
3.0000 E+07 \\
2.5000 E+04 \\
7.8750 E+06 \\
7.9000 E+06 \\
\end{array}$ & $\begin{array}{l}6.6500 E+03 \\
6.6500 E+05 \\
1.0000 E+02 \\
9.0440 E+07 \\
6.6500 E+07 \\
2.0005 E+05 \\
2.3940 E+07 \\
2.4140 E+07 \\
\end{array}$ & $\begin{array}{l}0.0000 E+00 \\
0.0000 E+00 \\
0.0000 E+00 \\
0.0000 E+00 \\
0.0000 E+00 \\
0.0000 E+00 \\
0.0000 E+00 \\
0.0000 E+00\end{array}$ & $\begin{array}{l}1.7024 E+05 \\
1.7024 E+07 \\
1.0000 E+02 \\
2.3153 E+09 \\
1.7024 E+09 \\
5.1214 E+06 \\
6.1286 E+08 \\
6.1799 E+08 \\
\end{array}$ & $\begin{array}{l}6.6816 E+01 \\
6.6816 E+03 \\
1.0000 E+02 \\
8.4287 E+05 \\
6.6816 E+05 \\
1.3920 E-04 \\
1.7471 E+05 \\
1.7471 E+05 \\
\end{array}$ & $\begin{array}{l}1.4400 E+03 \\
1.4400 E+05 \\
1.0000 E+02 \\
1.8215 E+07 \\
1.4400 E+07 \\
1.2000 E+00 \\
3.8153 E+06 \\
3.8153 E+06 \\
\end{array}$ & $\begin{array}{c}1.907 E+05 \\
\cdots \\
\cdots \\
2.590 E+09 \\
\cdots \\
5.347 E+06 \\
\cdots \\
6.884 E+08 \\
\end{array}$ & $\begin{array}{l}\left(m m^{n} 2\right) \\
\left(m m^{n} 3\right) \\
(m m) \\
\left(m m^{n} 4\right) \\
\left(m m^{n} 4\right) \\
\left(m m^{\wedge} 4\right) \\
\left(m m^{n} 4\right) \\
\left(m m^{n} 4\right)\end{array}$ & \\
\hline
\end{tabular}


GEM TN-93-494

\section{Miscellaneous 4-Gap CSC Finite Element Analyses}

\section{Contents:}

No frame on long edges, frame on ends only (2 pages)

No sandwich core material, frames on all edges ( 2 pages)

Support along ends and along one long edge ( 2 pages)

Massless solid "post" added to center of chamber ( 3 pages)

$12.5 \mathrm{~mm}$ wide G-10 frame, skin thickness $=0.5 \mathrm{~mm}$ ( 2 pages)

$25.0 \mathrm{~mm}$ wide G-10 frame, skin thickness $=0.5 \mathrm{~mm}$ ( 2 pages)

$25.0 \mathrm{~mm}$ wide G-10 frame, skin thickness $=1.0 \mathrm{~mm}$ ( 2 pages)

Baseline 4-gap CSC analysis using non-linear NIKE3D analysis code (2 pages)

Baseline 4-gap CSC analysis using linear GEMINI analysis code (2 pages)

Summary:

Various extreme conditions are explored in order to develop an understanding of the relative importance of components or support conditions.

Non-linear analysis using NIKE3D allows the prediction of membrane sag of $0.5 \mathrm{~mm} \mathrm{G}-10$ skins without sandwich cores, providing an upper limit to the effect of skin-to-core bond failure. Supporting along one edge gives an upper limit to the effect of chamber "pairing" in phi. Varying parameters such as frame width and skin thickness provide insight into the sensitivity of gravity sag to these values. 


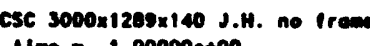
$11 \mathrm{mo}=1.00000+00$

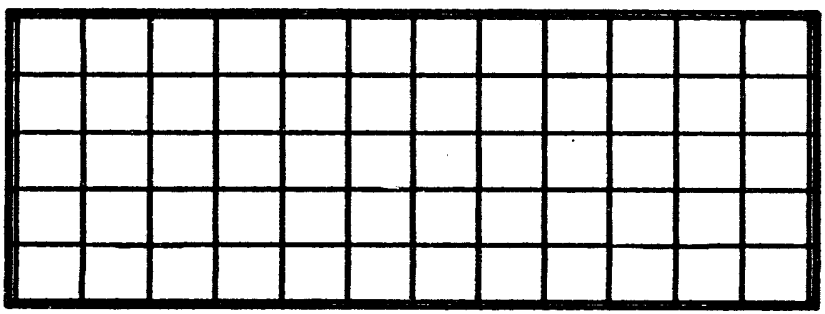

5

$$
\begin{aligned}
& \csc 3000 \times 1200 \times 140 \text { J.H. no } 11000 \\
& 1100=1.000000+00 \\
& \text { NO FRAME ON WONG EDCES } \\
& \text { FRAME ON ENSS ONCY }
\end{aligned}
$$

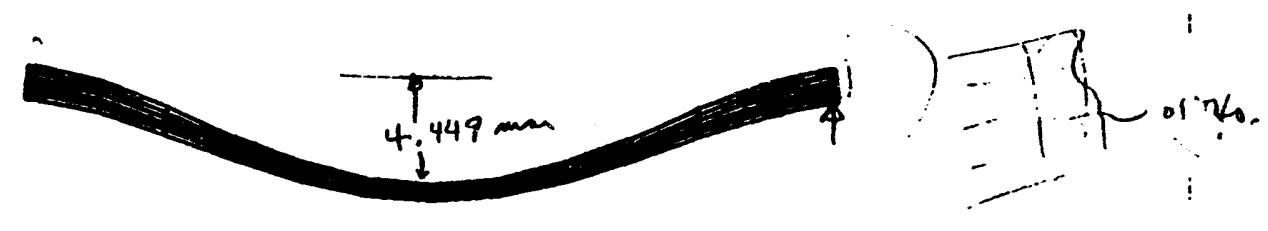

$\lim _{\rightarrow \infty}^{x}$

diop. seele foeter $=1.0000+02$

CSC 3000, 1289:1 40 J.H. no from

$11 \mathrm{mon}-1.000000+00$

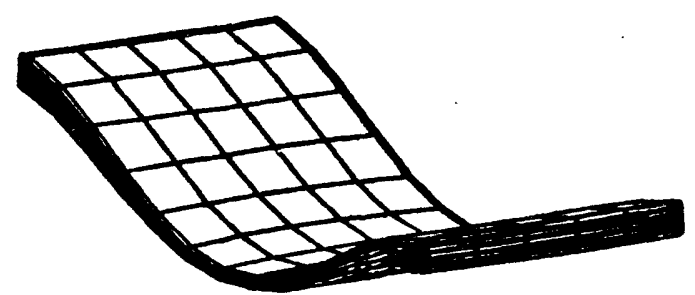

$\infty^{2}$ 
1 file:

2 readine

3

4 directory:

j. .11762:csc: noedge [all.]

6

7 objective:

8 Test effect of quasi-kinematic mount on overall deflections.

9 Remove side frames and observe change in deflection pattern.

10 Compare with $25 \mathrm{~mm}$ and $12.5 \mathrm{~mm}$ wide frames to study shear coupling. 11

12 Quasi-kinematic mount (4 points in z)

13 node 1: x y z displacement restrained (code 7)

14 node 15: x $z$ displacement restrained (code 6)

15 node 113: $\quad z$ displacement restrained (code 3)

16 node 120: $\quad z$ displacement restrained (code 3)

17 skin thickness $=0.5 \mathrm{~mm}$

$183500 \mathrm{~mm} \times 1289 \mathrm{~mm} \times 140 \mathrm{~mm}$

194 gaps e $10 \mathrm{~mm}, 5$ panels e $20 \mathrm{~mm}$

20

21 observations:

22 max. deflection $=4.449 \mathrm{~mm}$

23 deflection at edges $=4.449 \mathrm{~mm}$

24 deflection at center $=4.263 \mathrm{~mm}$

25 Curvature due to shear-free edges is apparent.

26 Deflection is only four times greater than the $1.161 \mathrm{~mm}$ value for $25 \mathrm{~mm}$ frames.

27 Panel separation varies severely along length. (Most apparent from side.)

28 Top three gas gaps close at center of span (analysis shows overiap).

.9 panel deflection $=0.053 \mathrm{~mm}$ ( 4.68 of total)

30

31 (Solution time $=604 \mathrm{sec}$. or $\$ 25.17$ )

32 (Total run time $60.5 \mathrm{sec}$. )

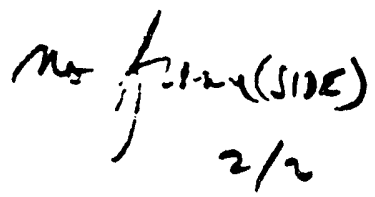

$t=0.5$ 
CSC 3000x1209n140 J.Horvalh 2/1/93
IIme $=1.000000400$

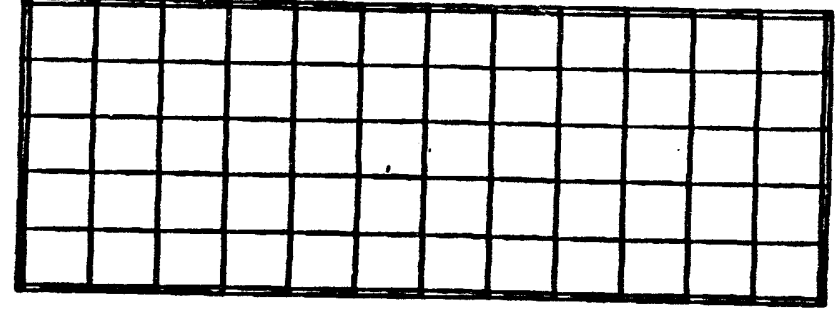

$\ddot{\ddagger}$

L.

disp. seele footer $=1.000$ tos

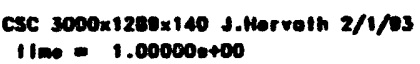

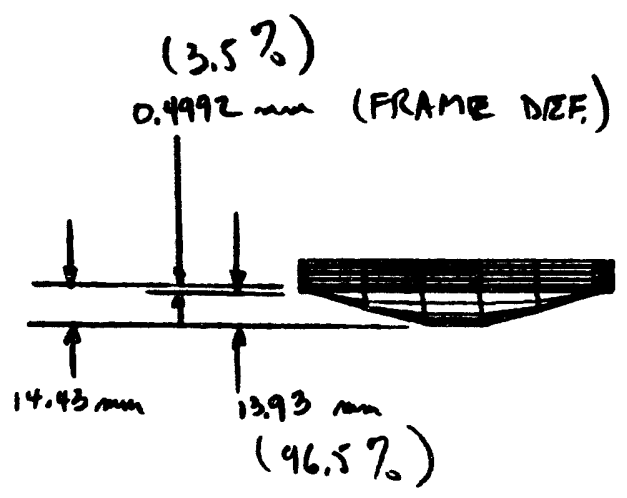

t.
CSC 3000x1289x140 J.Horvalh 2/1/8s

$11 \mathrm{mo}=1.000000400$

4-GAP CSC

no corre matirial Disp. $\times 10$.

QUASI-KINEMATIC (4 supports in $z$ )

$t_{\text {SKIN }}=0.5 \mathrm{~mm}$

WITHOUT HoweYCONB CORE
L.

disp. secte tecter $=1.0000 t 01$

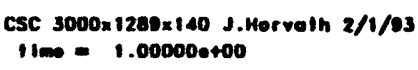

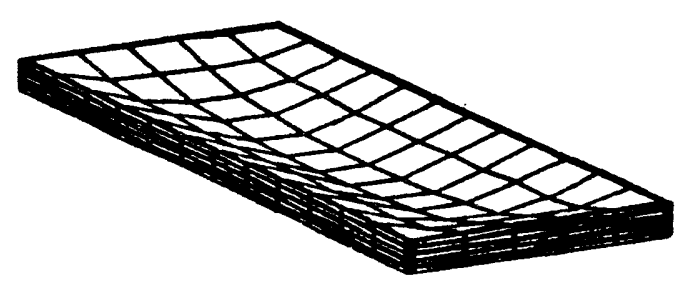

$\mathbb{1}^{2}$

disp. ecele lacter $-1.0000 t 01$

diep. ecele lacter -1.0090401

离 


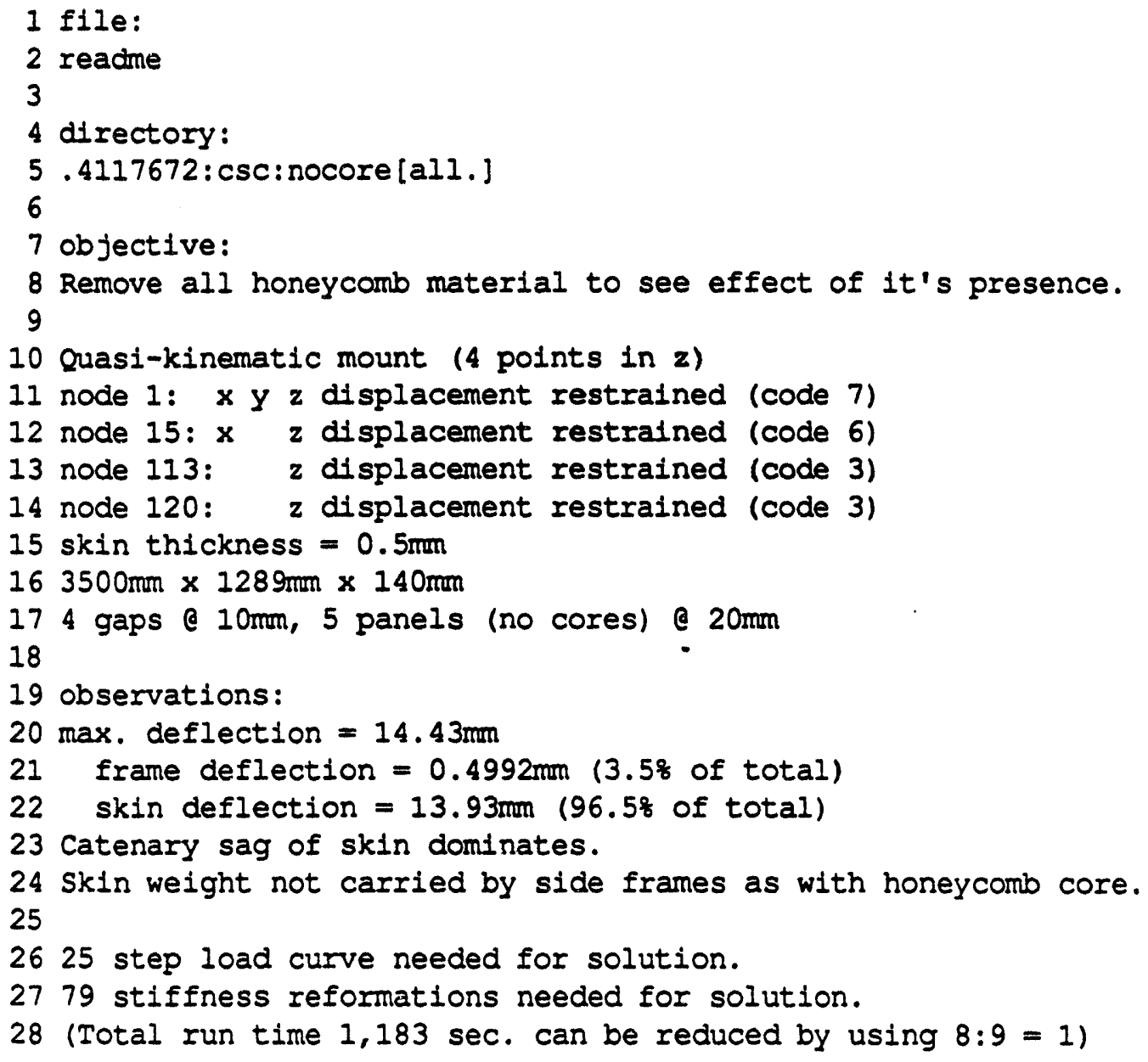


.02100 .1 csc $3000 \times 1200 \times 140 \mathrm{Jan}$ $1100=1.000000+00$
.02100 .1 CSC 3000n:208x140 sam

$1 \mathrm{lmos}=1.000000000$

SUPPORT ALONG

3-EDCES

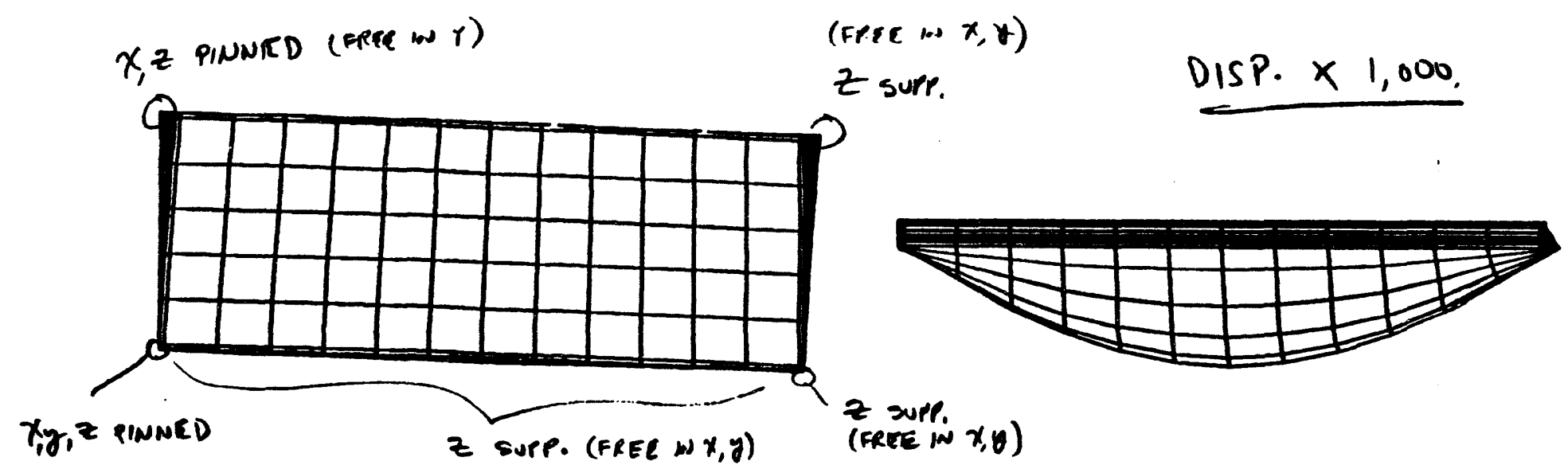

$\frac{1}{6}$

$\mathfrak{t}_{\longrightarrow}$

d1ep. 00010 feotor $=1.0000+03$

$\mathfrak{L x}_{x \rightarrow \infty}^{2}$

disp. seale toeter $=1.0000003$

$002100.1 \csc 3000 \times 1230 \times 140 \mathrm{JaH}$

$1100=1.000000+00$

$202100.1 \csc 3000 \times 1260 \times 140$ saH

$1100-1.000000+00$

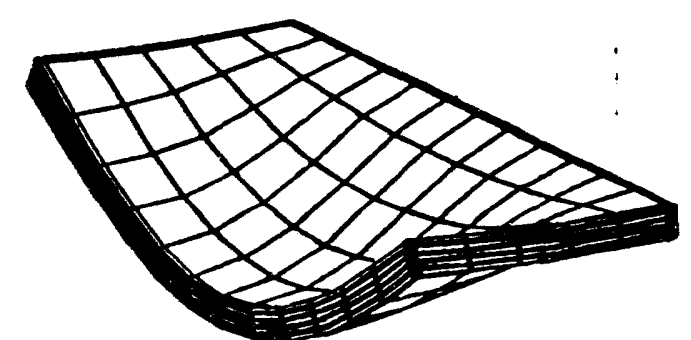

\rfloor$^{2}$

Slop. ecele lacter -1.0000 tos 
7 objective:

8 Observe effect of supporting one long edge in vertical direction.

9 This represents a bounding condition for linked panels (the improvement

10 achieved if the paired panel edges are infinitely stiff.)

11

12 Quasi-kinematic mount (4 points in $z$ )

13 node 1: $x$ y $z$ displacement restrained (code 7 )

14 node 15: $x \quad z$ displacement restrained (code 6 )

15 node 113: 2 displacement restrained (code 3)

16 node 120: 2 displacement restrained (code 3)

17 Also nodes $17,19,21,23,25,27,29,31,33,35,37, \& 39$ (code 3)

18 skin thickness $=0.5 \mathrm{~mm}$

$193500 \mathrm{~mm} \times 1289 \mathrm{~mm} \times 140 \mathrm{~mm}$

204 gaps \& $10 \mathrm{~mm}, 5$ panels (no cores) \& $20 \mathrm{~mm}$

21

22 observations:

23 max. deflection $=0.661 \mathrm{~mm}$

24 compared to max. deflection of $1.161 \mathrm{~mm} w / 0$ edge support.

25

26 (Total run time $60 \mathrm{sec}$. can be reduced by using $8: 9=1$ ) 
RIGID MASSLESS "POST" THROULA CRNTER OF CSC

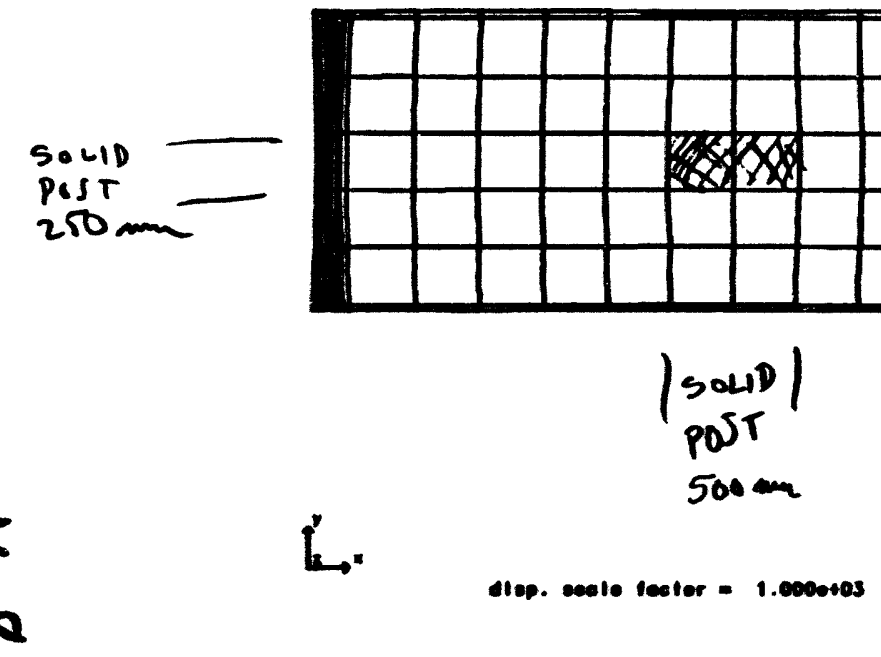

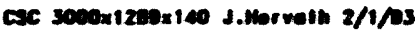
1100 - $1.000000+00$
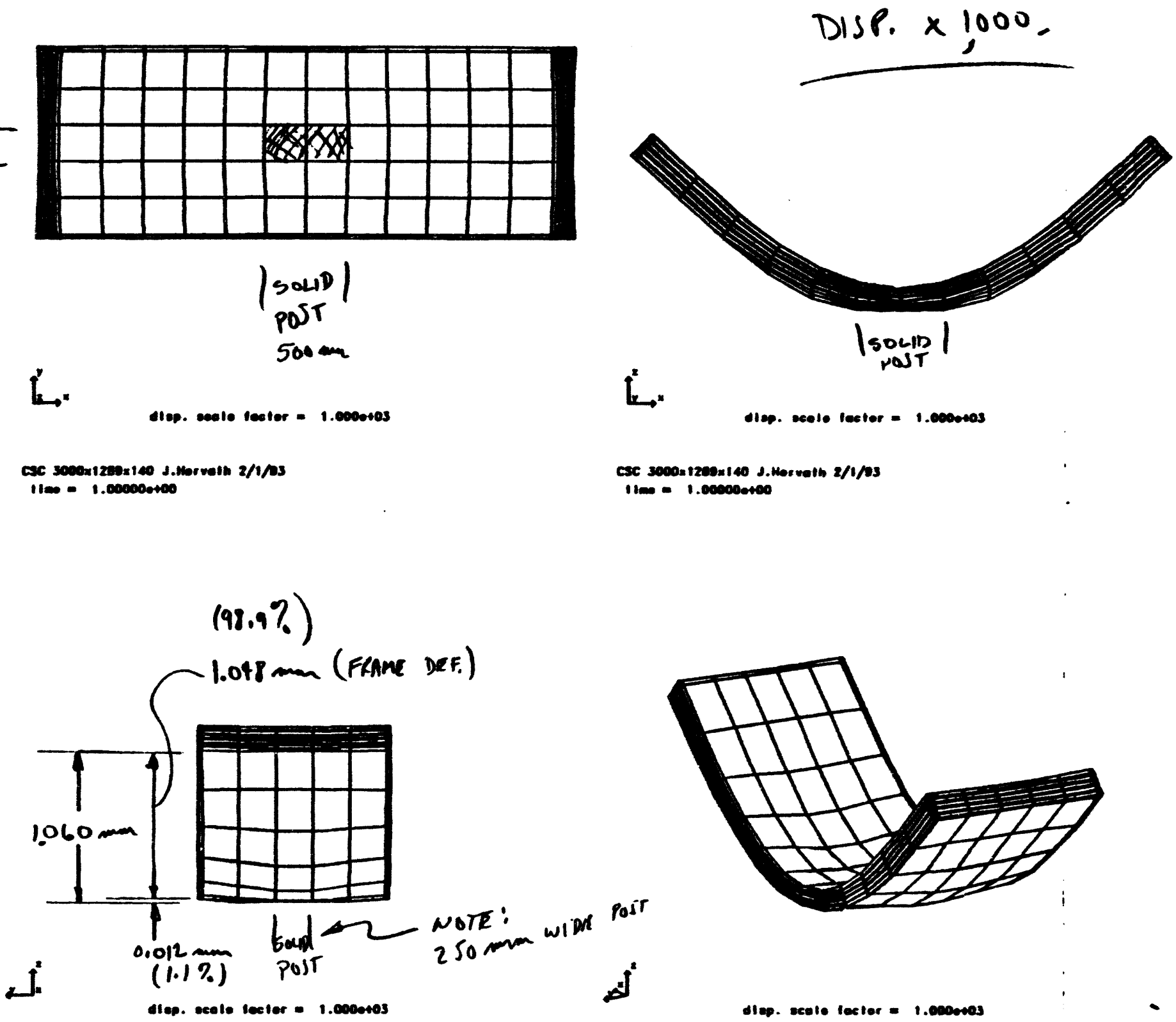

dlep. scule focter $=1.0000003$ 

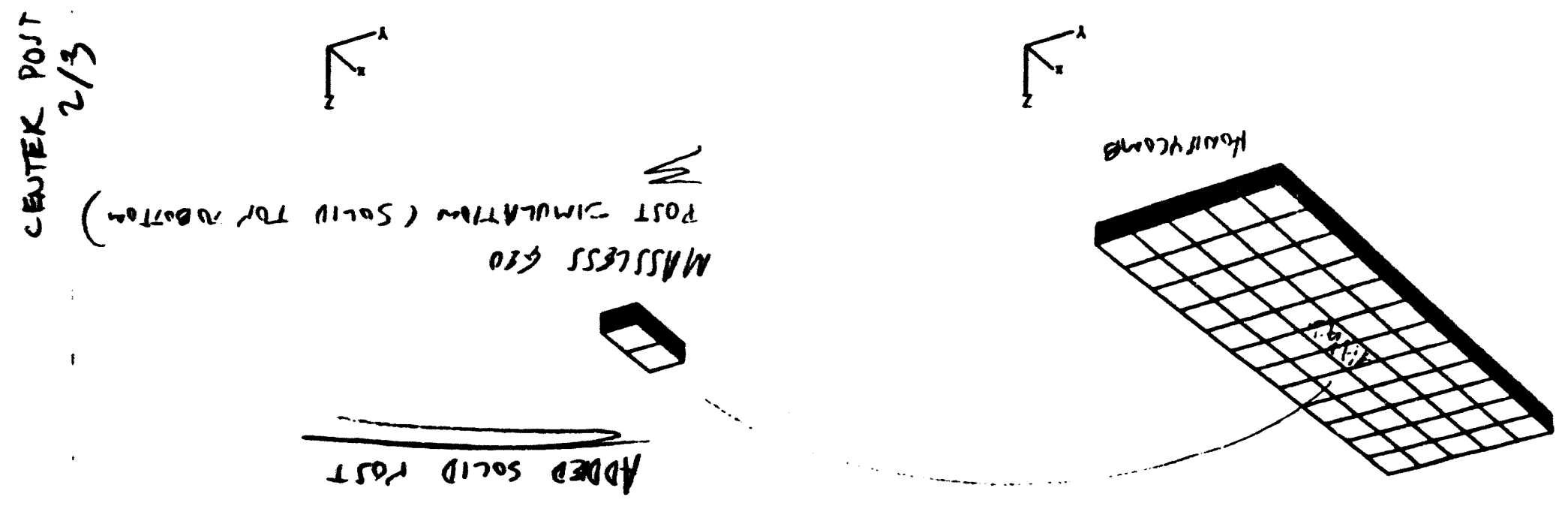

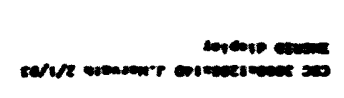

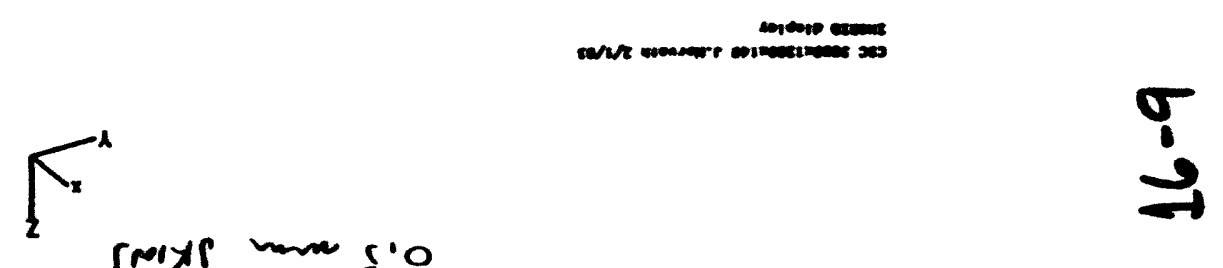

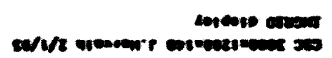

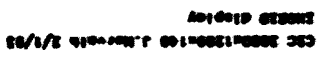


Identify effect of center post on deflections by adding a

$248 \mathrm{~mm} \times 575 \mathrm{~mm}$ post through the center of the CSC.

10 The post has the mechanlcal properties of G10 but 18 massless.

11 This represents an extreme bounding condition on the beneficial

12 effects (if any) of the gas gap spacers on overall deflections.

13

14 Quasi-kinemat1c mount (4 points in 2)

15 node 1: $x$ y $z$ displacement restrained (code 7)

16 node 15: $x \quad z$ displacement restralned (code 6 )

17 node 113: 2 displacement restrained (code 3 )

18 node 120: $\quad 2$ displacement restrained (code 3 )

19 skin thickness $=0.5 \mathrm{~mm}$

$203500 \mathrm{~mm} \times 1289 \mathrm{~mm} \times 140 \mathrm{~mm}$

214 gaps 0 10m, 5 panels (no cores) e 20mm

22 Sol1d massless $G 10$ post $(247.8 \mathrm{~mm} \times 575.0 \mathrm{~mm})$ at center of CSC.

23

24 observations:

$25 \mathrm{max}$. frame deflection $=1.048 \mathrm{~mm}$

26 compared to frame def. of 1.108 without large post.

27 Reduction in panel sag from $0.053 \mathrm{~mm}$ to $0.012 \mathrm{~mm}$ due to unrealist lc

$28250 \mathrm{~mm}$ post width in model.

30 (Solution time 77 sec.) 
$\csc 30000120001100$ (12.3m irem)

11000 - 1.000000000

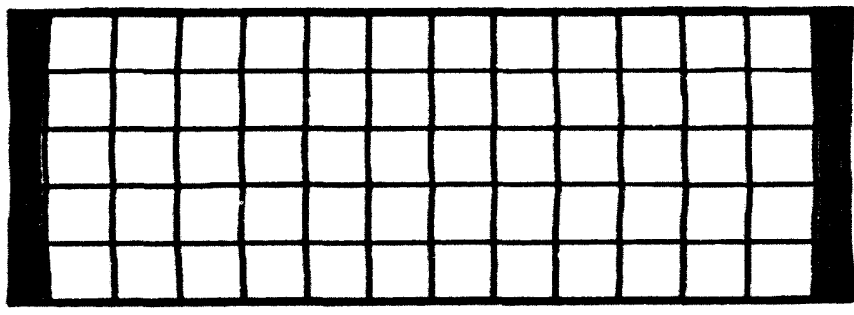

$\stackrel{5}{*}$

11se.

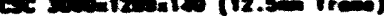

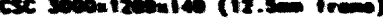

inn - I.emenower

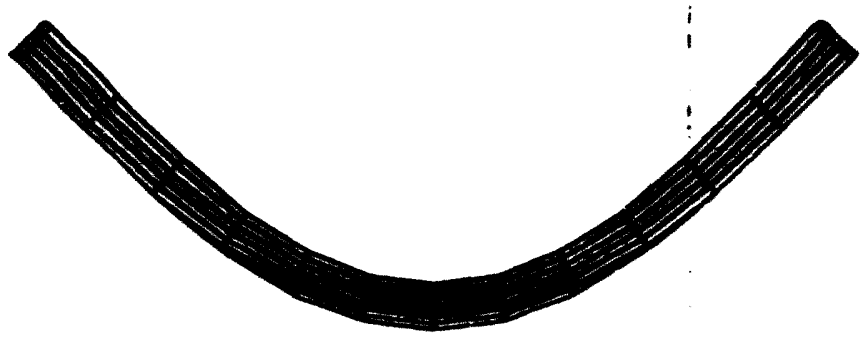

E.

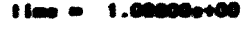

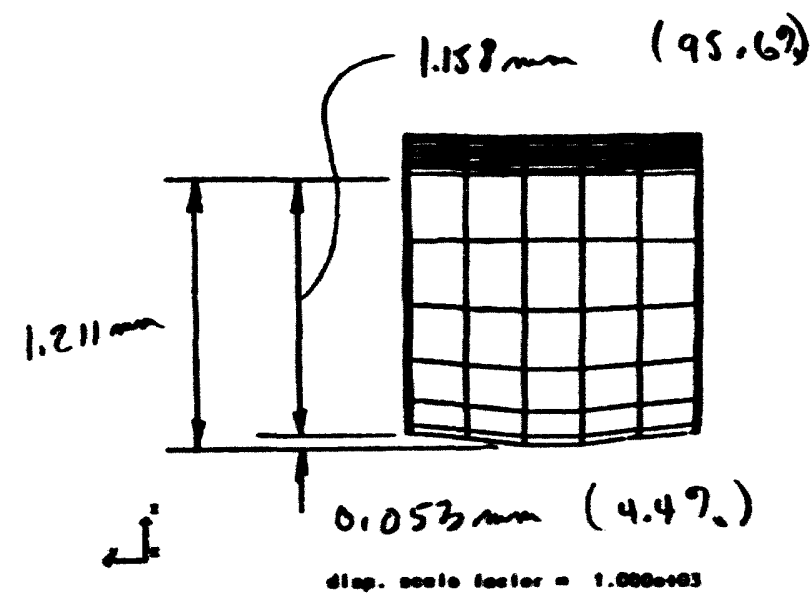

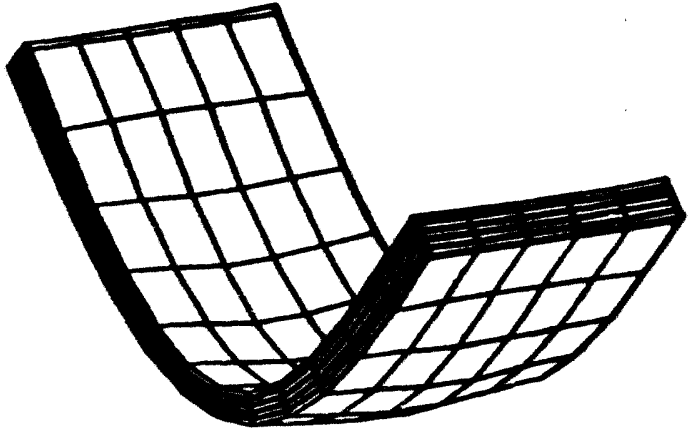

s

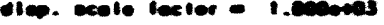

$\frac{1}{0}$

$\sim \underbrace{y}_{j} \sum_{j}^{\infty}$ 
GoO
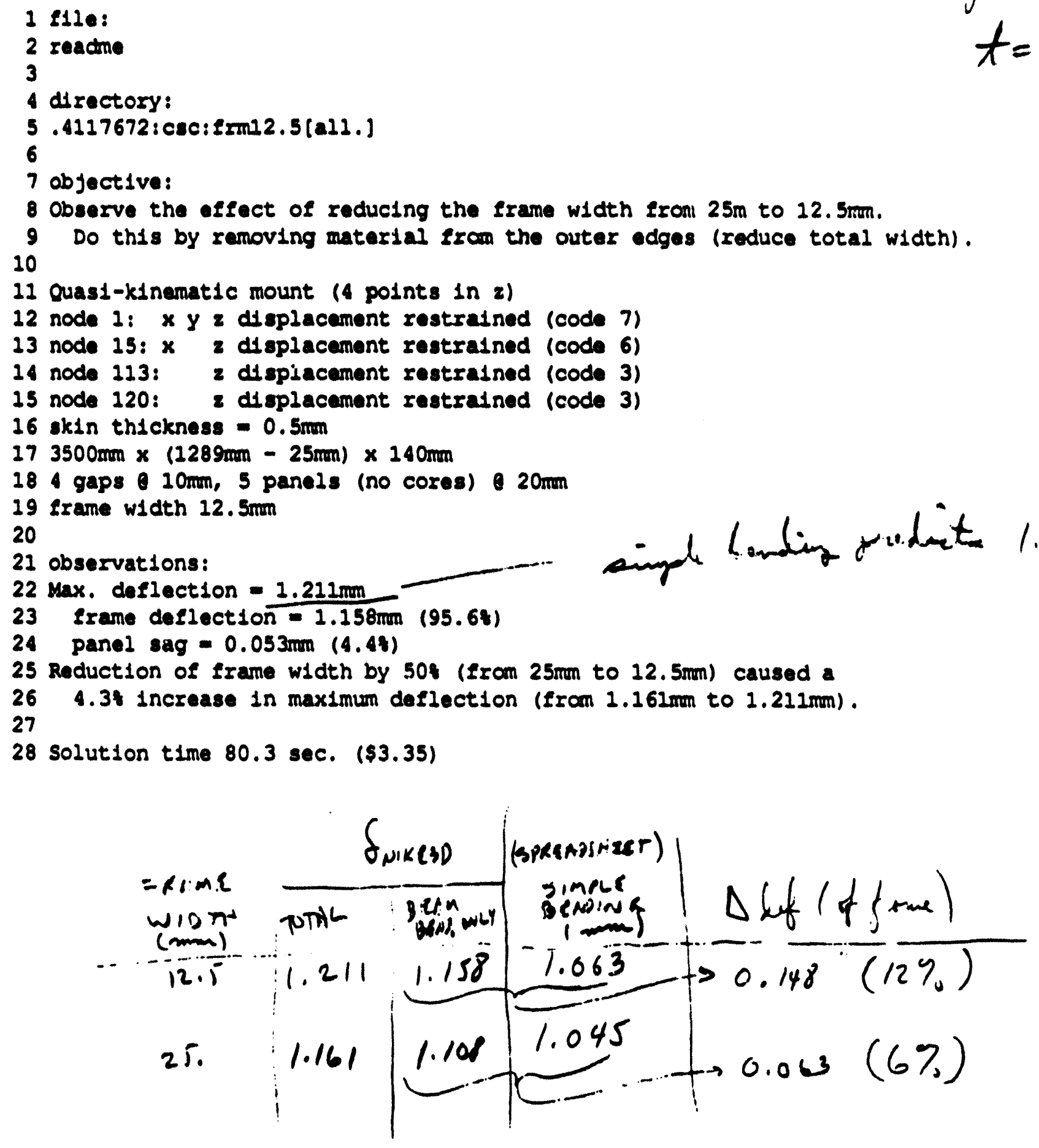

$16-12$ 


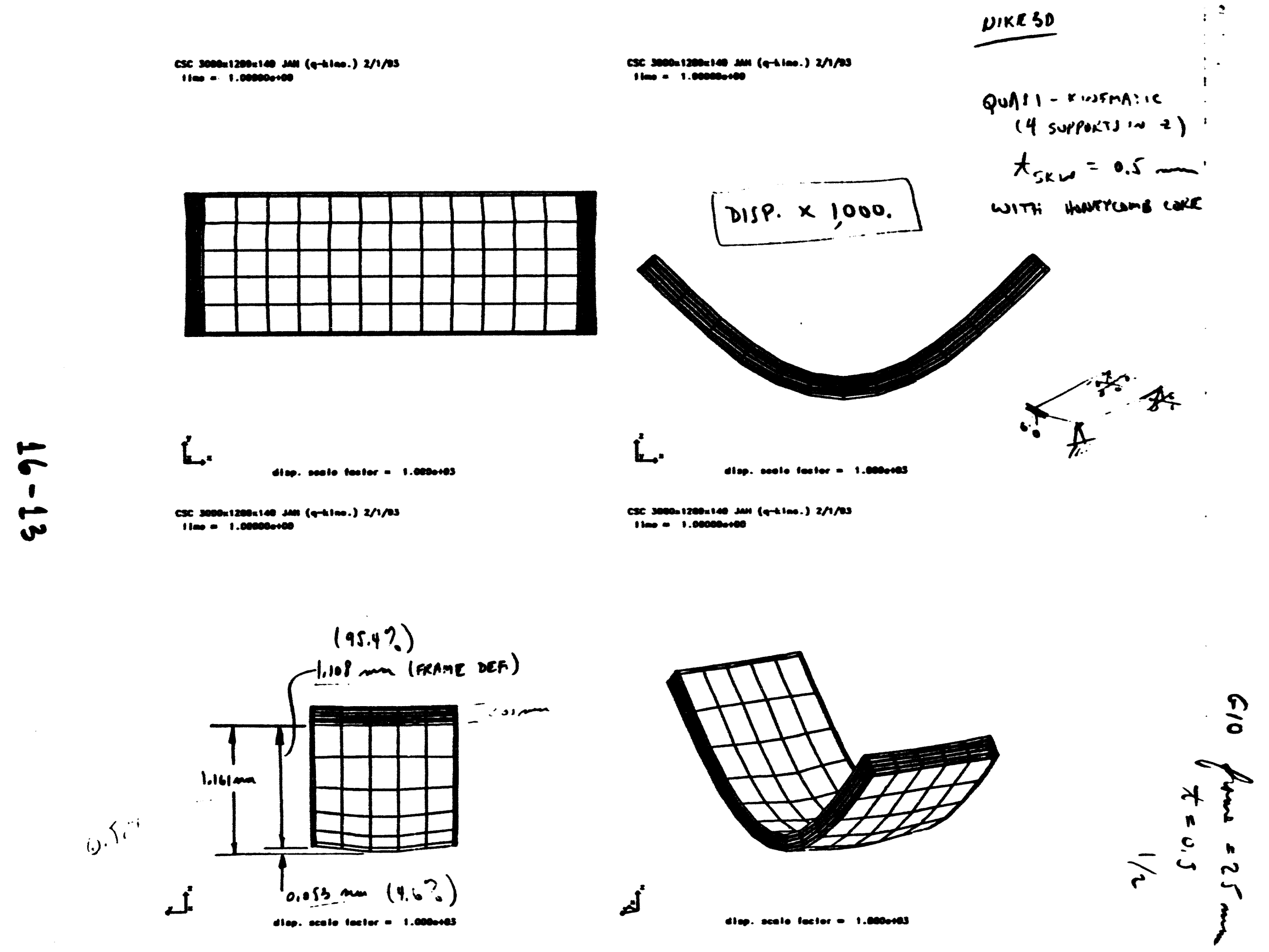




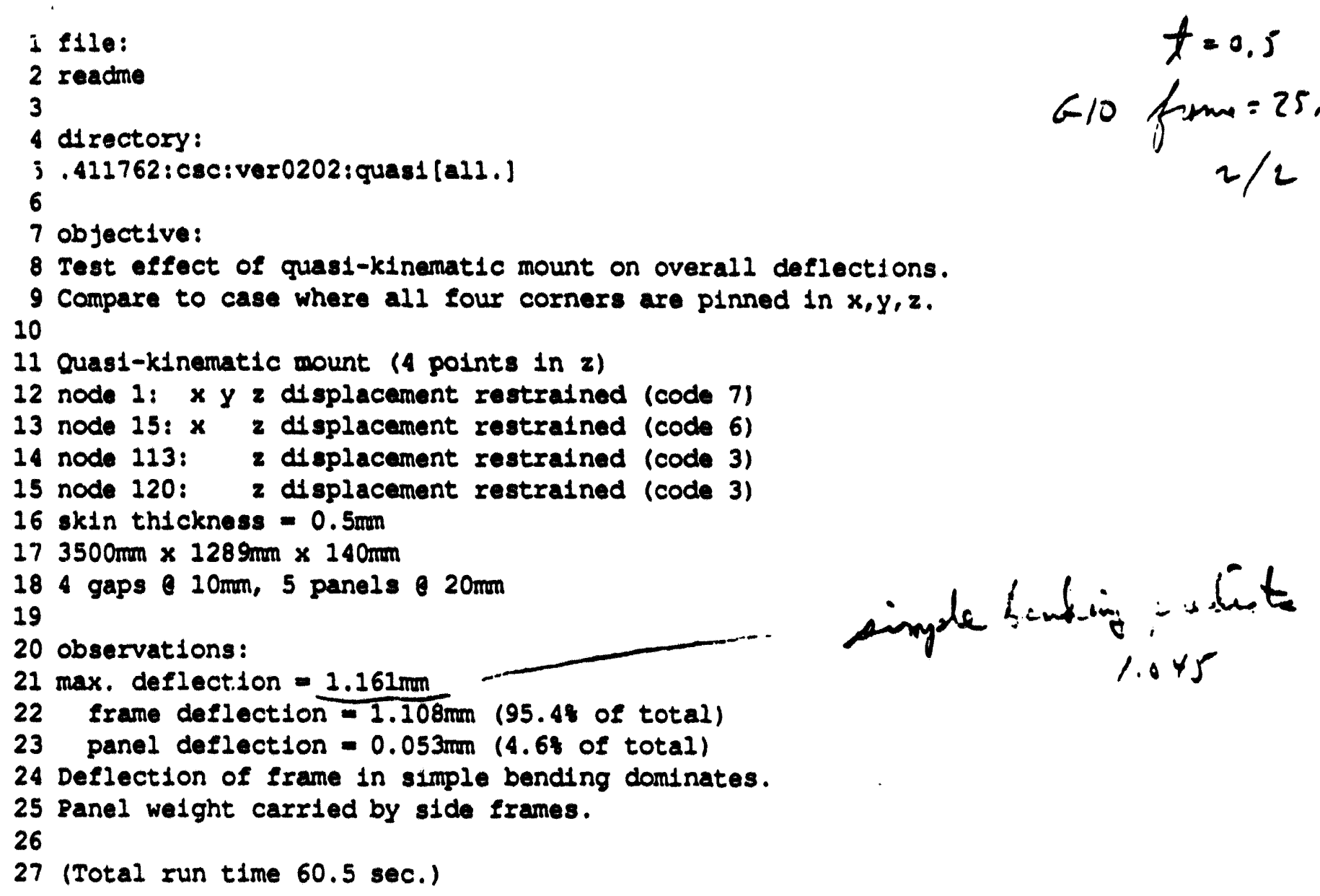

610

$$
t=0.5
$$

$f_{\mathrm{f} m \mathrm{~m}}=25$ 


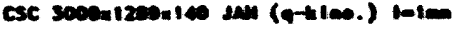

$1100=1.000000+00$

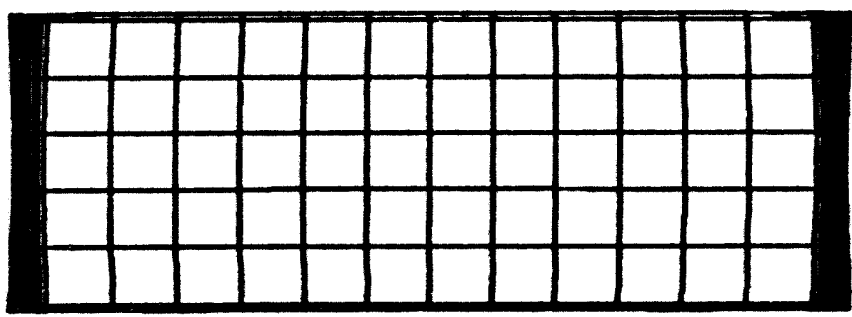

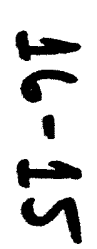

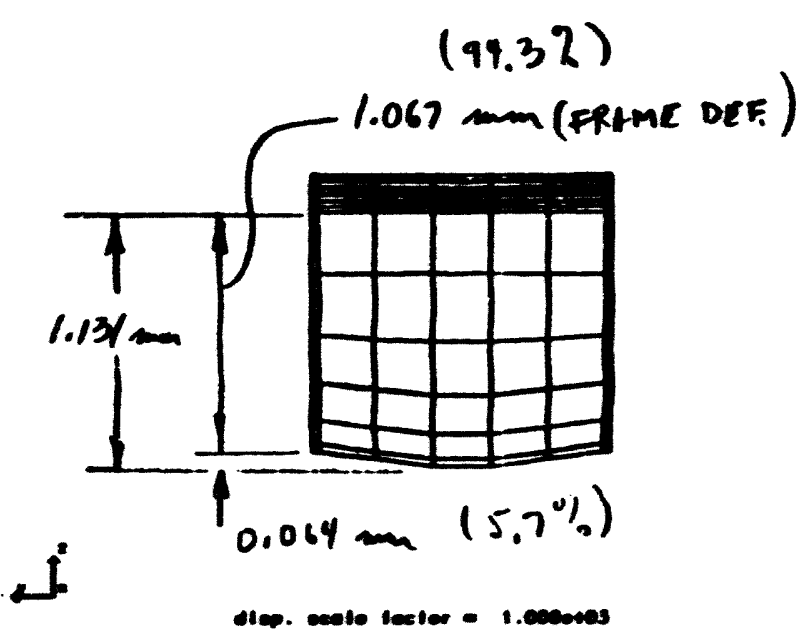

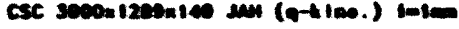

$1 \mathrm{kmol}=1.000000+00$

NIKE 30

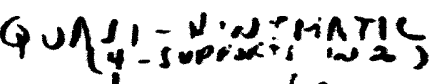

$\lambda_{\text {Srin }}=1.0 \mathrm{~mm}$
$[D$ isP. $\times 1,000]$

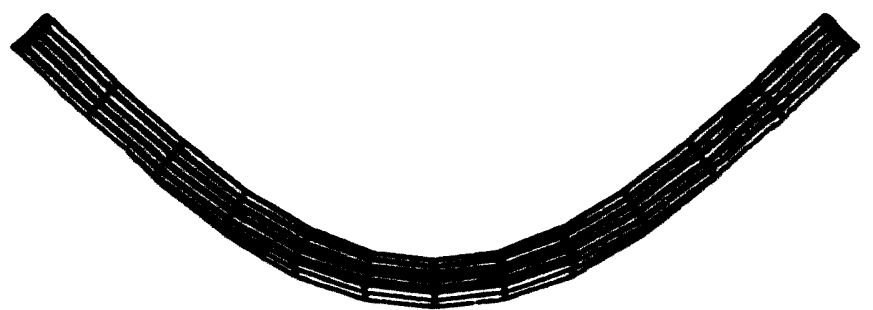

$t_{1}$

Alis. seole ceetor = 1.000000

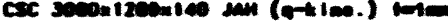

1100 - 1.000000000

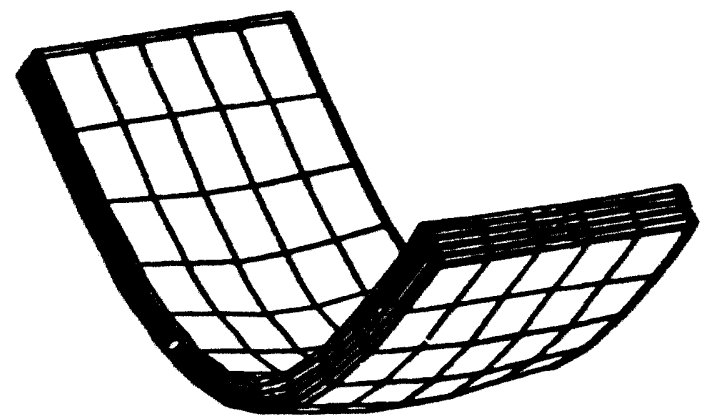

$d^{2}$

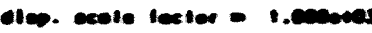

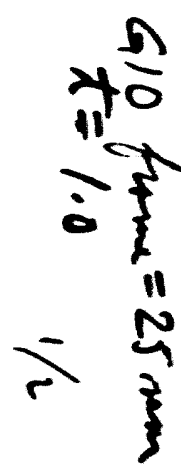


เ.

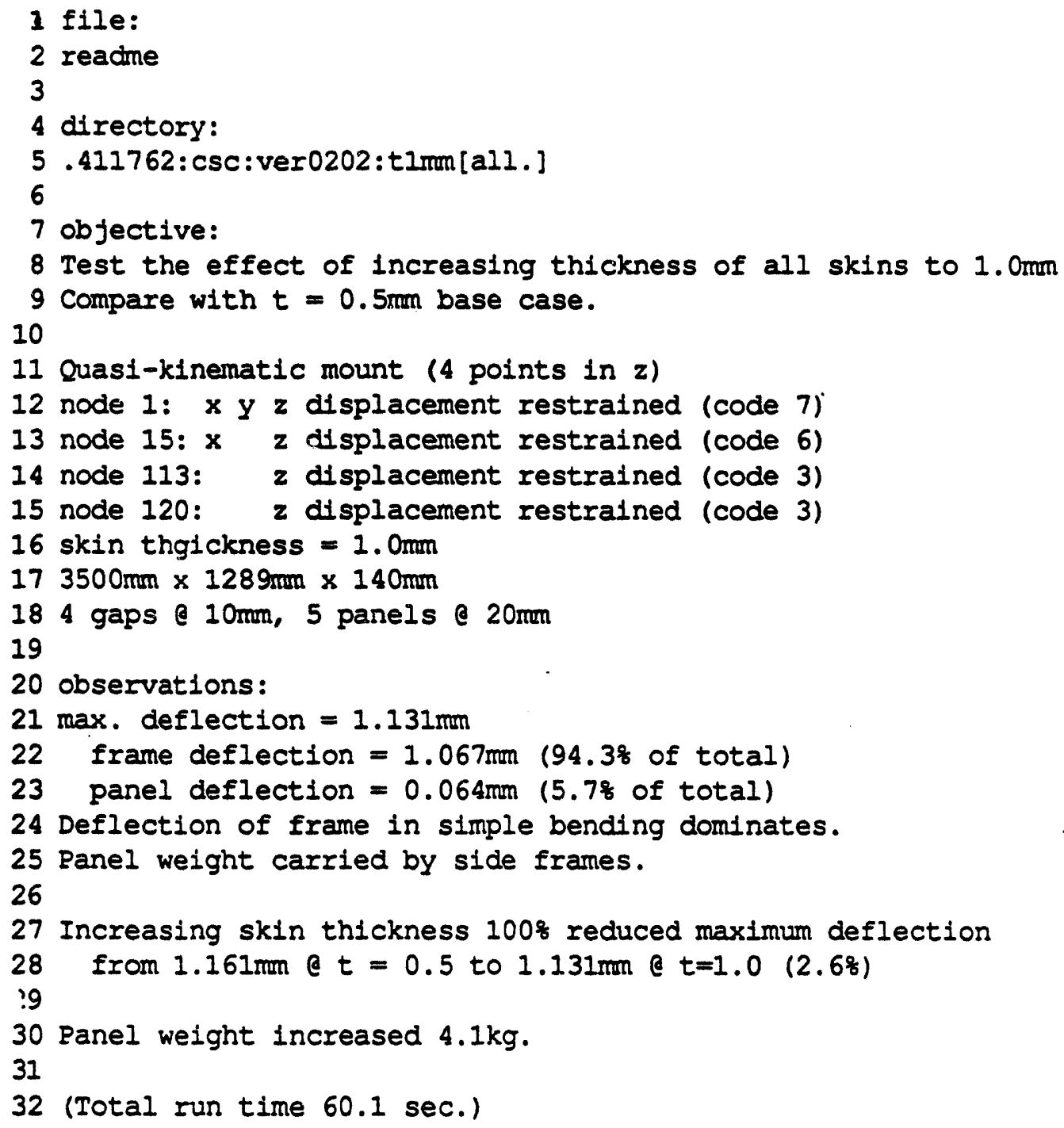

G10 Eth F/L LR

$$
t=1.0 \quad 2 / 2
$$

frame $25 \mathrm{~mm}$

$16-16$ 
CsC s000n1289u140 J.Morvelh 2/1/19s

$1100=1.000000+00$
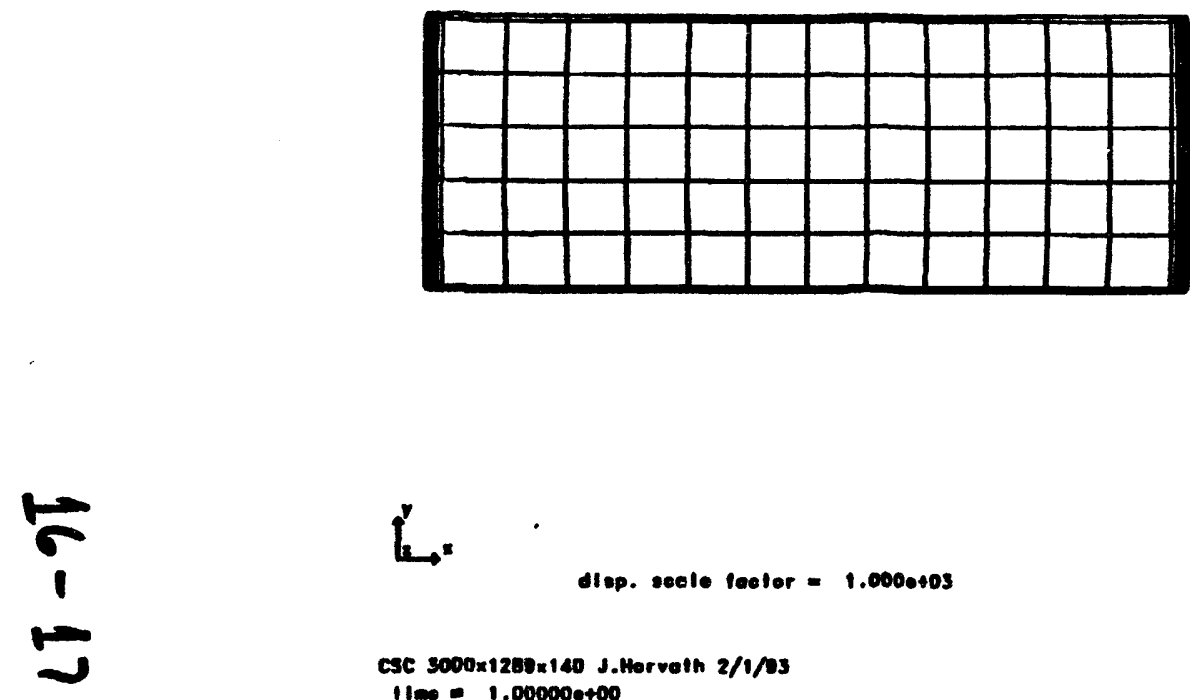

$\mathfrak{l}_{\rightarrow}^{y}$

dlep. seele teetor $=1.0000+03$

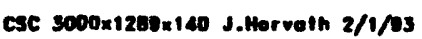

$1100=1.000000+00$

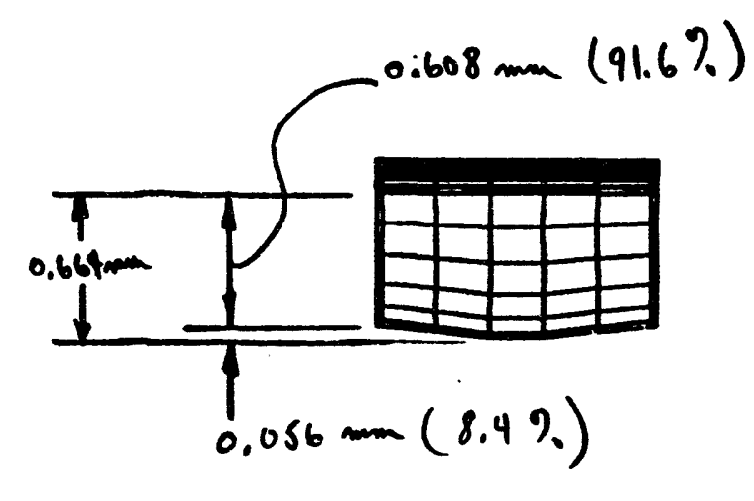

$\sqrt{3}$
CsC 3000x1209x140 J. Horvalh 2/1/s3

$1 \mathrm{imo}=1.000000+00$
(No ORTHOROPKC PROYS.)

DISP. $\times 1,000$.

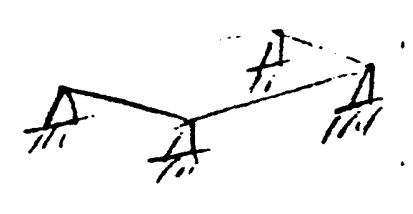

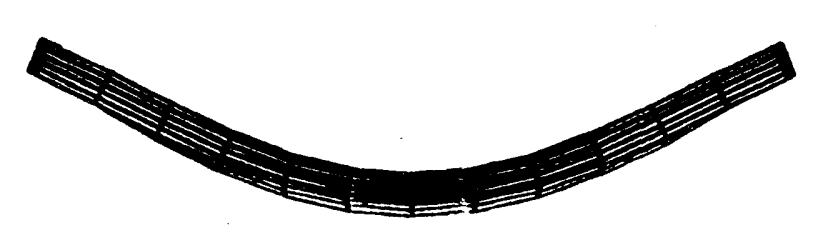

$t_{x \rightarrow x}^{2}$

disp. soole foctor $=1.0000+03$

CSC $3000 \times 1200 \times 140$ J.Horvalh $2 / 1 / 93$

$1 \mathrm{im}=1.000000+00$

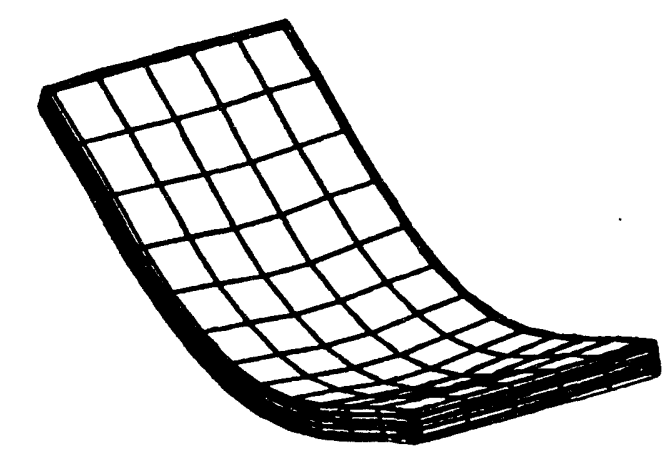

$4^{2}$

dlep. ecole loctor - 1.0000t03 


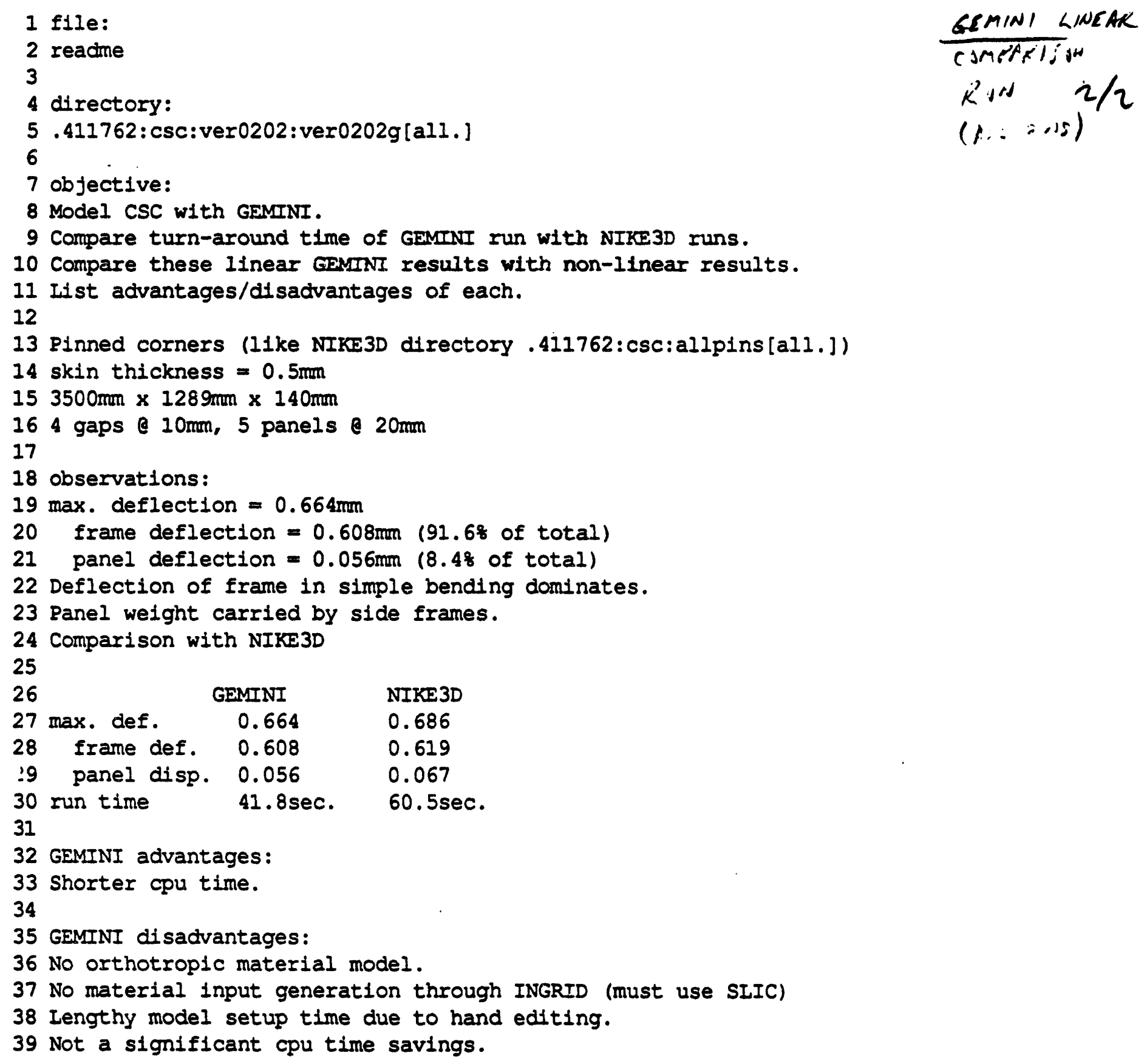




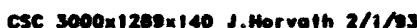
$1100=1.000000+00$

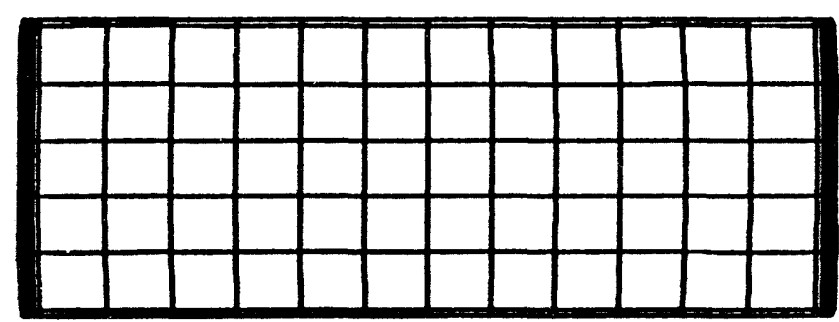

客<smiles>CCCC</smiles>

d1ep. Eeale teetor $=1.0000+03$

$\csc 3000 \times 1200 \times 140$ J.Horvath 2/1/03

1100 - $1.000000+00$

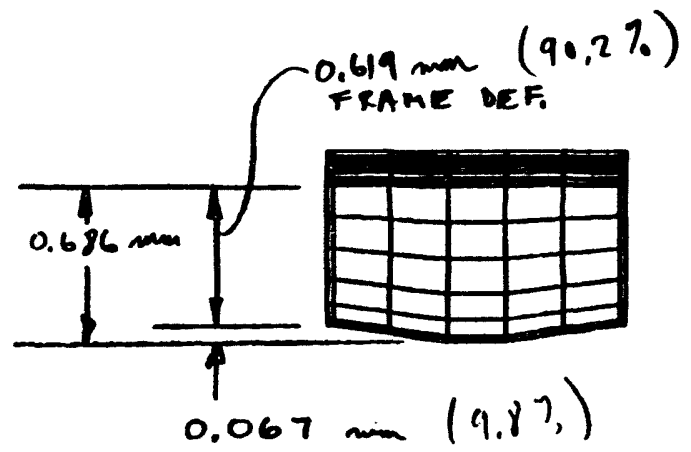

$\sqrt{3}$

diep. ecele coeter = 1.0000003
CSC 3000 1285:140 J.Hervath 2/1/8s

$11 \mathrm{mo}=1.000000400$

NIKESD

4 suppis in $Y, y,+$ yose.

$t_{\text {SKIN }}=0.5 \mathrm{~mm}$

DISP. $\times 1,000$.
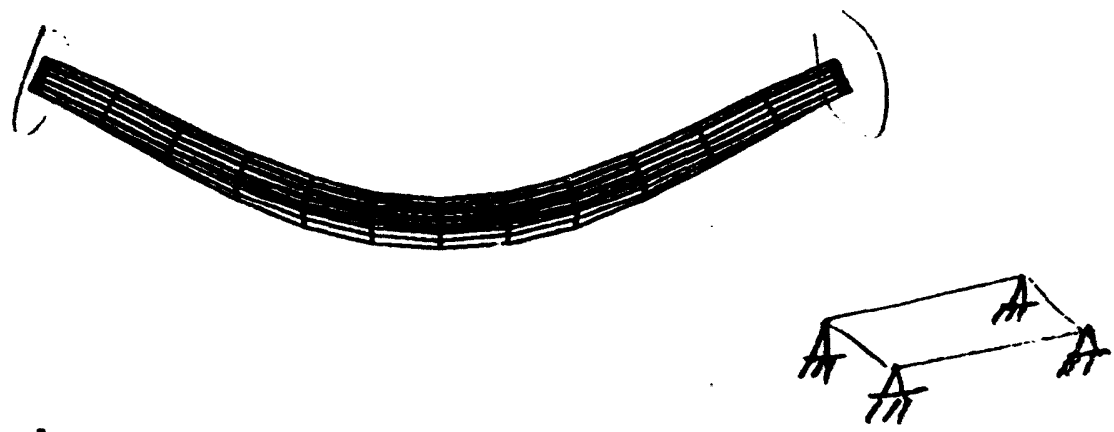

$\stackrel{x}{2}$

Alsp. scele factor $=1.0000+03$

CSC 3000 $1250 \times 140$ J. Hoerveth 2/1/103

$1100=1.000000+00$

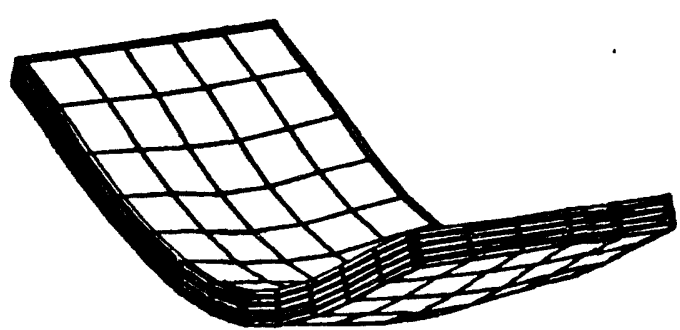

$\omega^{2}$
2
0
$-\quad 2$
1
$\frac{r}{5}$
$\frac{\pi}{\pi}$ 


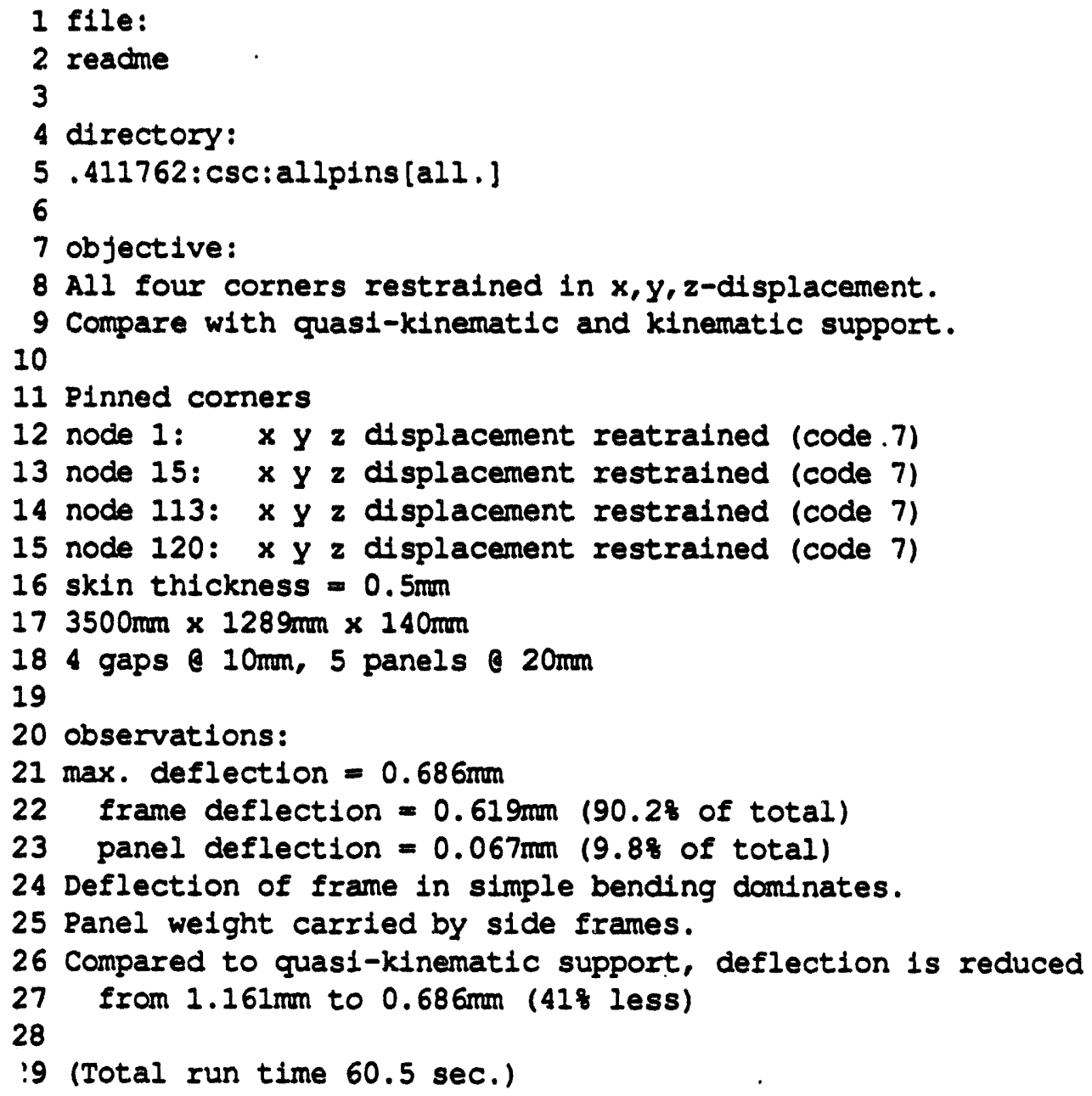

NI 2530

comporis on Rum

(the Dial) DON-LINRAR

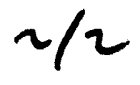


GEM TN-93-494

\section{Creep}

\section{Contents:}

Adhesive bond Line summary viewgraph (1 page)

Sandwich panel material viewgraph (1 page)

\section{Summary:}

Bond-line shear between sandwich panel skins are prone to creep. Proper selection of adhesives and low stresses will reduce susceptibility to creep over life of the structure.

The abstract for GEM TN-93-508, Estimating Creep Deformations of Large Precision Cathode Strip Chamber Panels, hy S.J. Wineman reads as follows:

"Existing work on the creep behavior of honeycomb panels and glass-reinforced epoxy panel skins was reviewed. Creep data for glass-reinforced epoxy is used to obtain a lower bound for creep deformation of the panels. An upper bound for creep deformation would depend on the properties of the adhesive and the fabrication process. Therefore, creep tests of prototype panels are needed for a better estimate of creep deformation." 


\section{Adhesive Bond Line Shear Stresses Are Low}

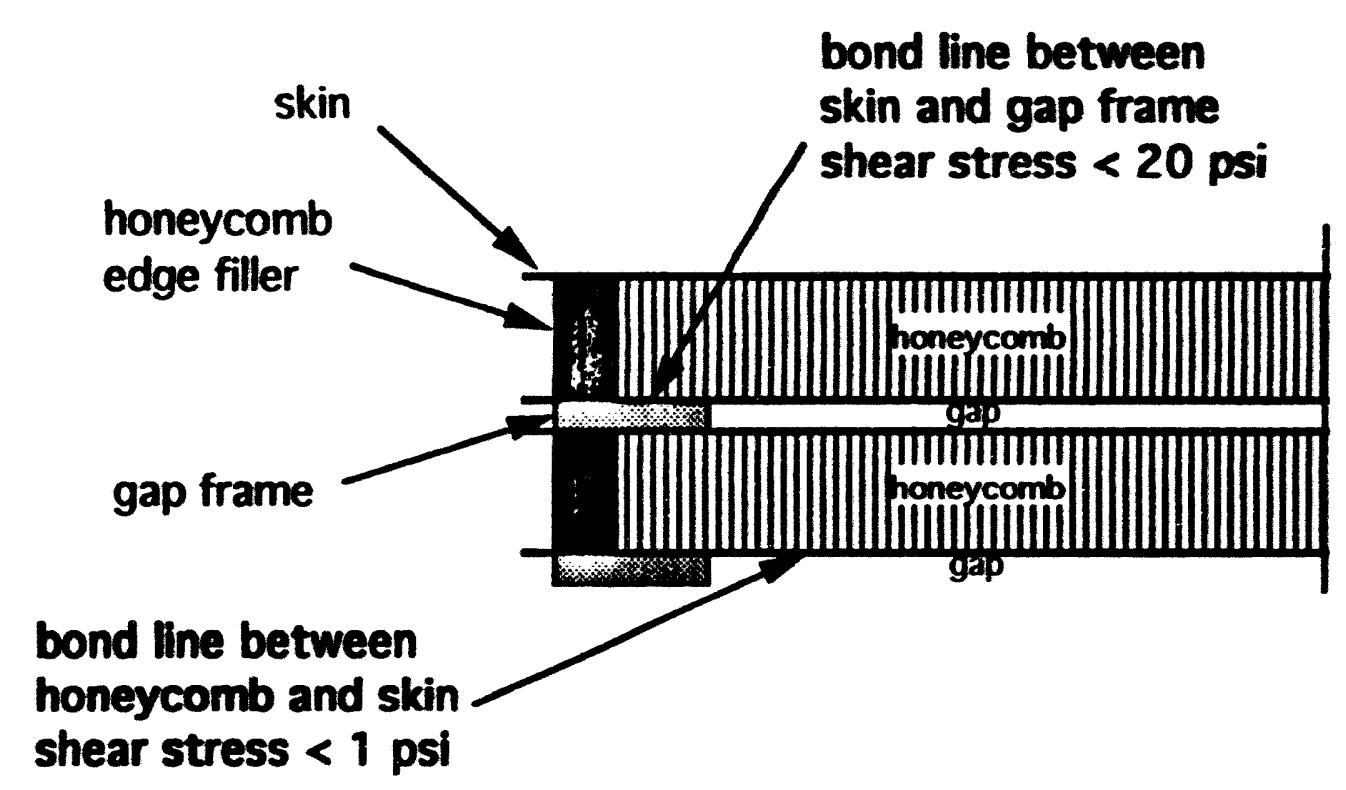

- Thermoset adhesive bonds resist creep (oven cured)

- Room temperature adhesive bonds are stable if the bond line shear stress is less than 700 psi which is $10 \%$ of ultimate

- Stress in region of external supports is controlled by design of the connection 


\section{Sandwich Panel Materials Influence Long Term Stability}

- In general, high temperature bonds are stable and room temperature bonds are not.

- Bond lines under shear are most likely to creep if stress is above $10 \%$ of ultimate or the operating temperature is high.

- The critical bond line between the honeycomb and the face sheets is only $0.005^{\prime \prime}$ thick. Precise control of adhesive viscosity that is needed to form adhesive fillets is difficult for room temperature bonding systems.

- Bonding is best performed at the same humidity the part will experience during operation. Water can take years to equilibrate by diffusion.

- Glass fibers are "dirt cheap", but Kevlar fibers are more water resistant.

- Standard edge seal materials with $50 \%$ fiber content can transmit loads and are well suited for honeycomb edge bolt regions.

- "Nomex" is a generic term covering a variety of performance specifications.

- Employing a plastics specialist to review vendor processes is essential. 
GEM TN -93-494

18. Single Sandwich Panel Gravity Sag

Contents:

Two independent finite element analyses of single TDR panel gravity sag (2 pages)

Hand calculation of single panel gravity sag ( 2 pages)

Summary:

A single TDR SL-3 sandwich panel simply supported at the ends sags about $20 \mathrm{~mm}$ under its own weight.

$$
18-1
$$




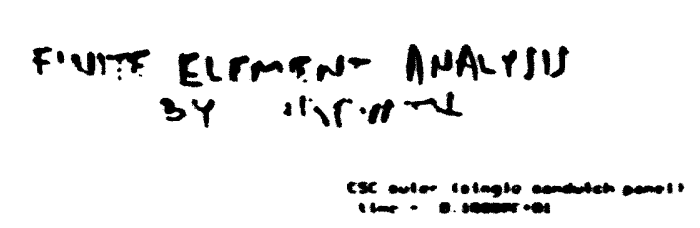

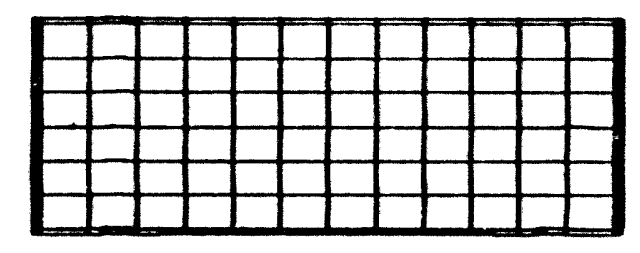

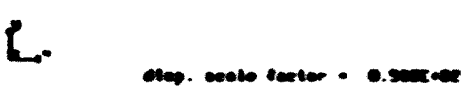

110

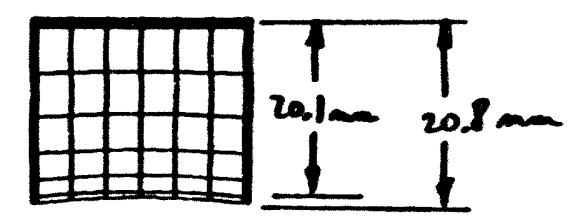

j

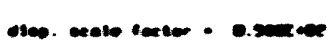

UHFCTIF: . $411762 / C S C B A S E 3 /$ SAF ONE 1

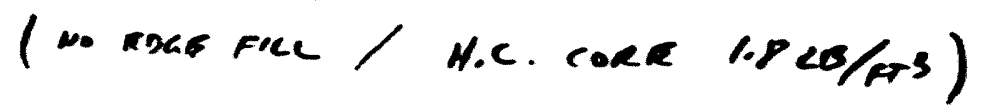

1

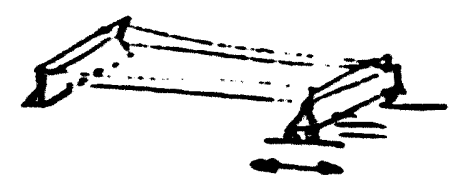

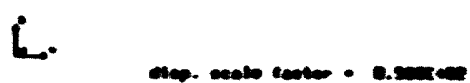

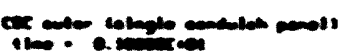

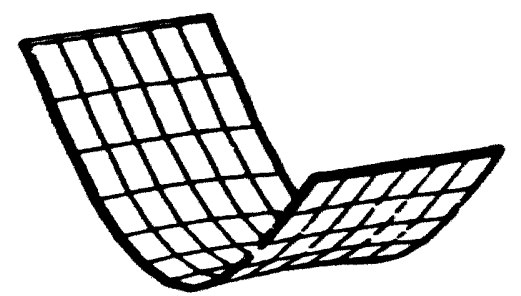

蛋京

j

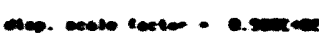


SINGLE

Single Honey comb Sandwich (No Gap Frame)

PANEL $4 / 4$

OVerall width: $1250 \mathrm{~mm}$

overall length: $3402 \mathrm{~mm}$

ends simply supported across width (button skin)

Super Collider, Detector Panels

time $=0.10000 E+01$

$$
\begin{aligned}
& G_{a b}=1.034 c+05 \frac{g}{m \cdot \sec ^{2}} \\
& G_{b c}=2.620 c+07 \\
& G_{c a}=1.034 c+05
\end{aligned}
$$

(FINITE REGENT ANALYSIS DY MEMICHERLS)

\begin{tabular}{l|c|c|c|c} 
& Analytical & NOD $-S_{0}-L$ & $N_{30}-S_{L}-L$ & $N 30-S_{h} H-L$ \\
\hline center deflection & 18.2 & 19.00 & 20.06 & 18.32 \\
\hline edge deflection & - & 19.72 & 20.82 & 19.02
\end{tabular}

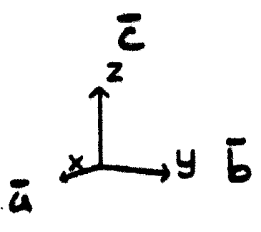

diss. scale factor $=0.100 E+02$

Analytical: Hexcel based hand calks, $0.5 \mathrm{~mm}$ skins, $19 \mathrm{~mm}$ cire $\Rightarrow 20 \mathrm{~mm}$ sit N3D-So-L : Nike jd analysis, solid elements for skins $\Rightarrow 20 \mathrm{~mm}$ stack height Highest shear modulus oriented along length

N3D-ShL-L: Nike Bd analysis, shell elements for skins, 19 mm core $\Rightarrow 19 \mathrm{~mm}$ stack 1 Highest share modulus oriented along length

NBD-ShH - L : Nike sd analysis shell elements for Skins, $20 \mathrm{~mm}$ cire $\Rightarrow 20$ mom stack $i$ Highest shear modulus oriented along length $18-3$ 

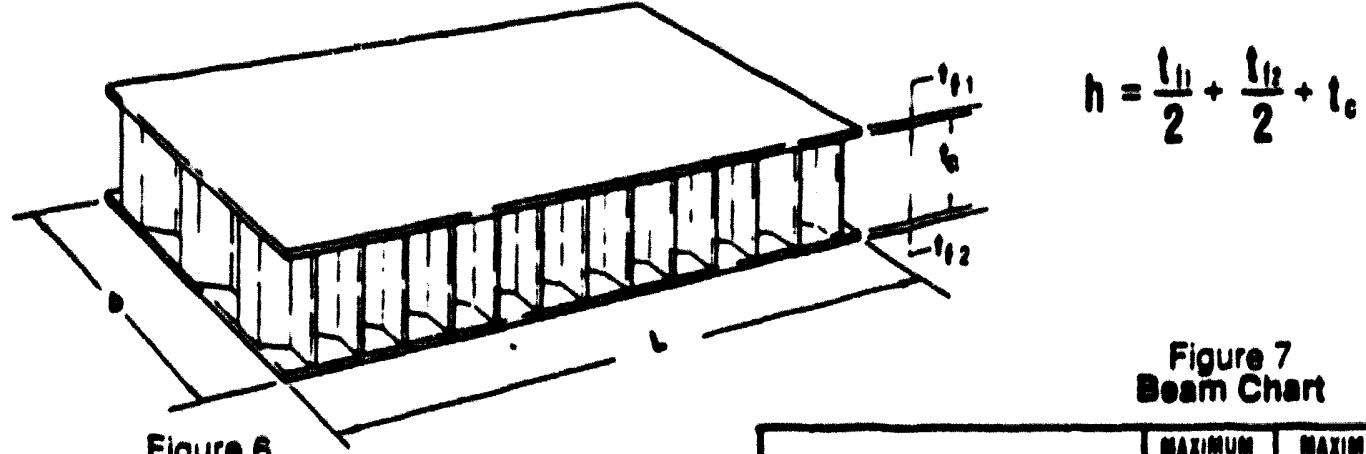

Figure 6

\section{Donding Stress in Faeings}

$\sigma_{11}=\frac{M}{t_{i n} b} \quad$ where $M$ is determined by

\section{Core Shear Siress}

$T_{c}=\frac{V}{n_{b}} V$ is from figure $?$

Doflection $K_{b}$ and $K_{8}$ from Figure 7

$\Delta=\frac{2 K_{b} P L^{3} \lambda}{E_{1} l_{f} h^{2} b}+\frac{K_{a} P L}{h G_{C b}} \quad \begin{aligned} & \text { (for same skin } \\ & \text { materials) }\end{aligned}$

or

$\Delta=\frac{K_{b} P L^{2}}{D}+\frac{K_{s} P L}{h G_{c} b} \quad$ (see $D$ below)

fFor most long beams. the second term is relatively small. but should be checked if deflection is critical.)

Face Dimpling

$$
\sigma_{c n}=\frac{2 E_{1}}{\lambda}\left[\frac{l_{1}}{s}\right]^{2}
$$

Face Wrinkling

$$
\sigma_{c n}=0.82 E_{1}\left[\frac{E_{c} t_{1}}{E_{1} l_{c}}\right]^{1 / 2}
$$

$$
0=\frac{E_{1} t_{1} E_{2} t_{2} h^{2} b}{E_{1} t_{1} \lambda_{2}+E_{2} t_{2} \lambda_{1}} \text { or } \frac{E t_{1} t_{2} h^{2} b}{\left(t_{1}+t_{2}\right) \lambda} \text { or } \frac{E t h^{2} b}{2 \lambda}
$$

Figure 7

Boam Chart

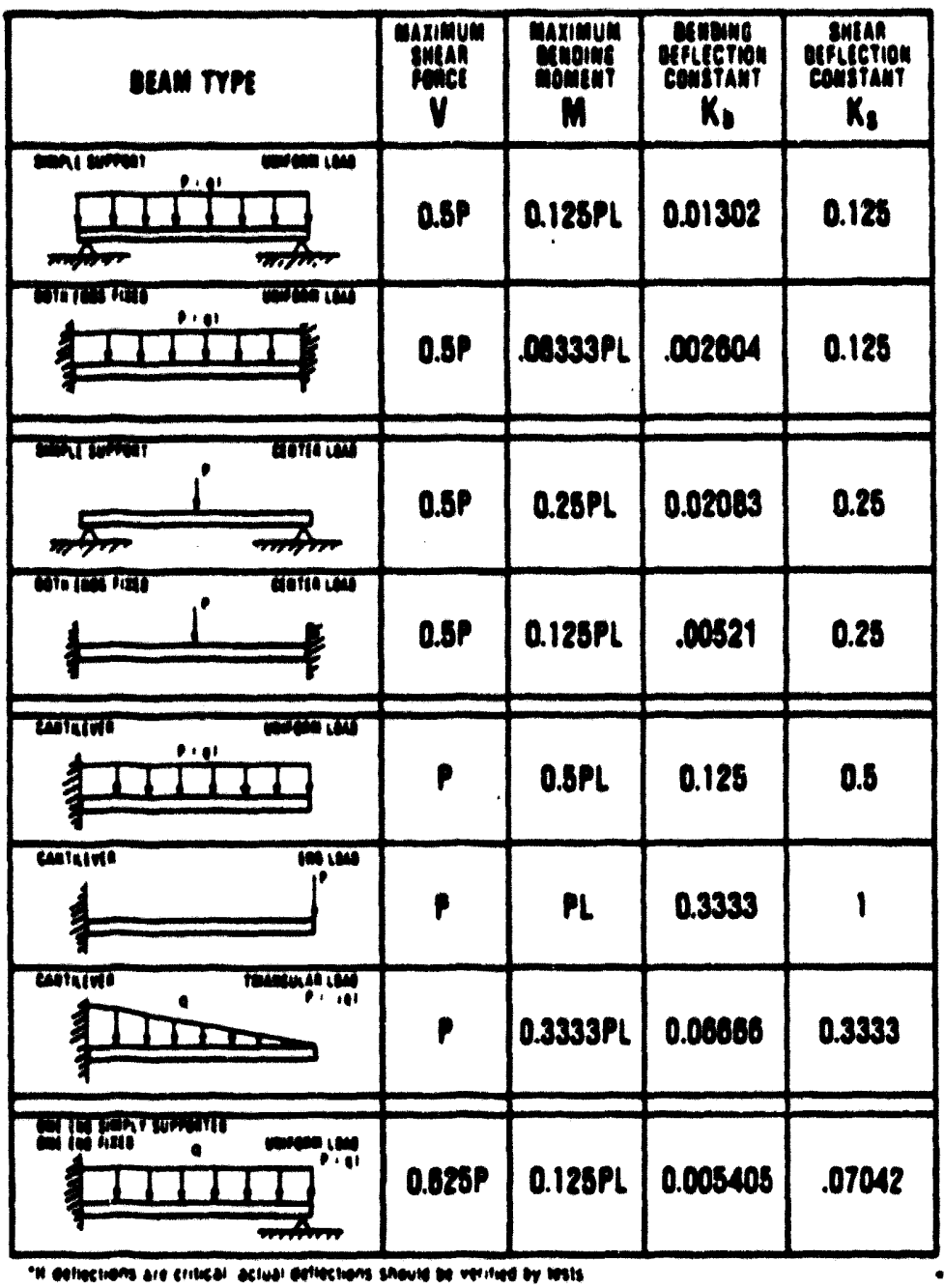

\section{Llat of Torme}

$\begin{aligned} P & =\text { Tolal Load } \\ l & =\text { Span } \\ \sigma_{1} & =\text { Facing Stress } \\ t_{1} & =\text { Skin Tnickness } \\ n & =\text { Centroid Distance } \\ T_{c} & =\text { Core Shear Stress }\end{aligned}$

$\Delta=$ Deflection

$E_{1}=$ Faeing Modulus

$G_{c}=$ Core Shear Mooulus

$b=$ Widin

$\sigma_{c a}=$ Critical Facing Stress

$D=$ Panel Stitiness

$\lambda=1 \cdot \mu^{3}$

$\mu=$ Facing Poisson's Ratio

$S=$ Cell Size

$E_{e}=$ Core Compression Modulus

$I_{c}=$ Core Thickness

1 s Moment of Inertia 


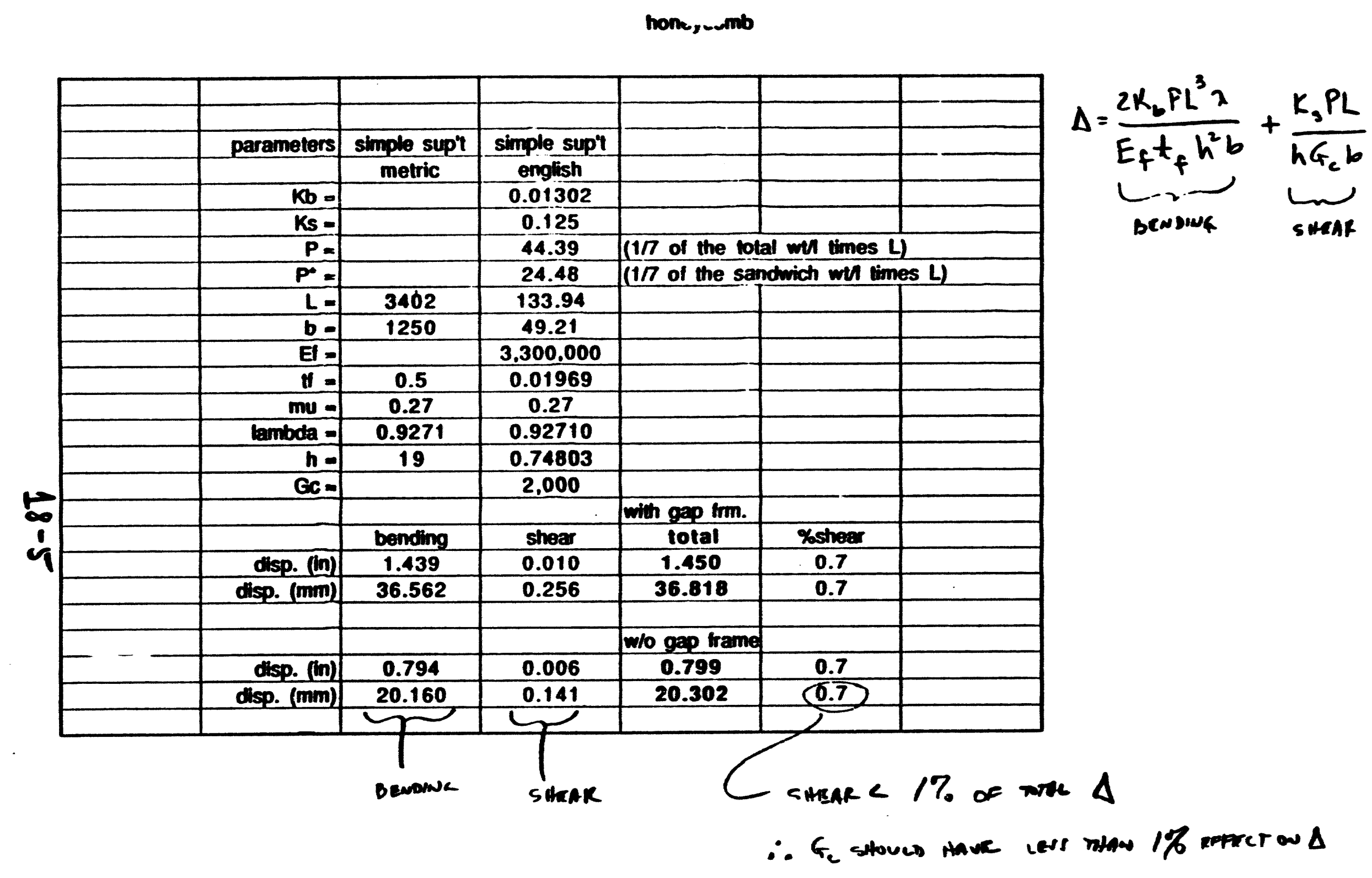

SIMGLE SANDWICA PANEL SAG

REF. HEXCEL TSB-RY (r.14) 


\section{Superpanels}

Contents:

Superpanel layout, SL-2 panels at $5.0 \mathrm{~m} \times 1.9 \mathrm{~m}$ ( 3 pages)

Superpanel gravity sag calculation (1 page)

\section{Summary:}

Maximum gravity sag of $4 \mathrm{~mm}$ is now dominated by center w/t edge panel sag. This could be reduced without adding much mass by using stiffer sandwich panels (i.e. sandwiches with thicker core to separate skins more).

\section{$19-1$}




$$
\begin{aligned}
& 1 \text { OP } 3 \\
\text { SL-2 SUPBRPAHELS } & (25.0 \mathrm{~m} \times 1.9 \mathrm{~m})
\end{aligned}
$$

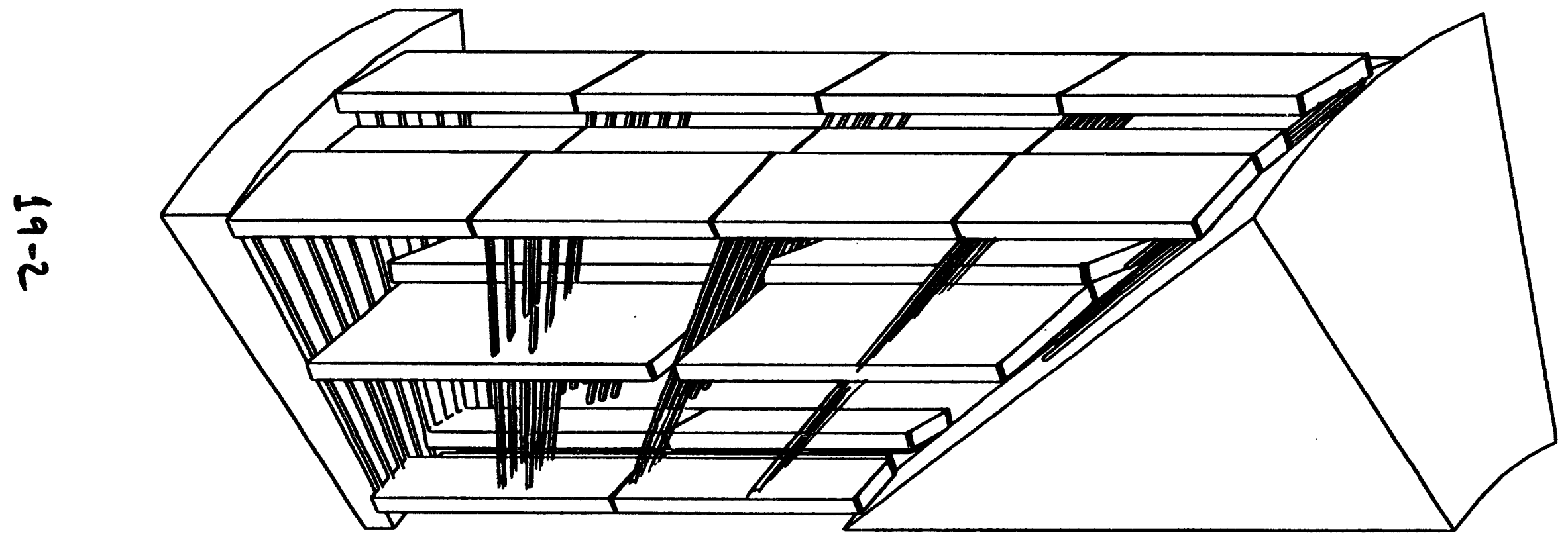




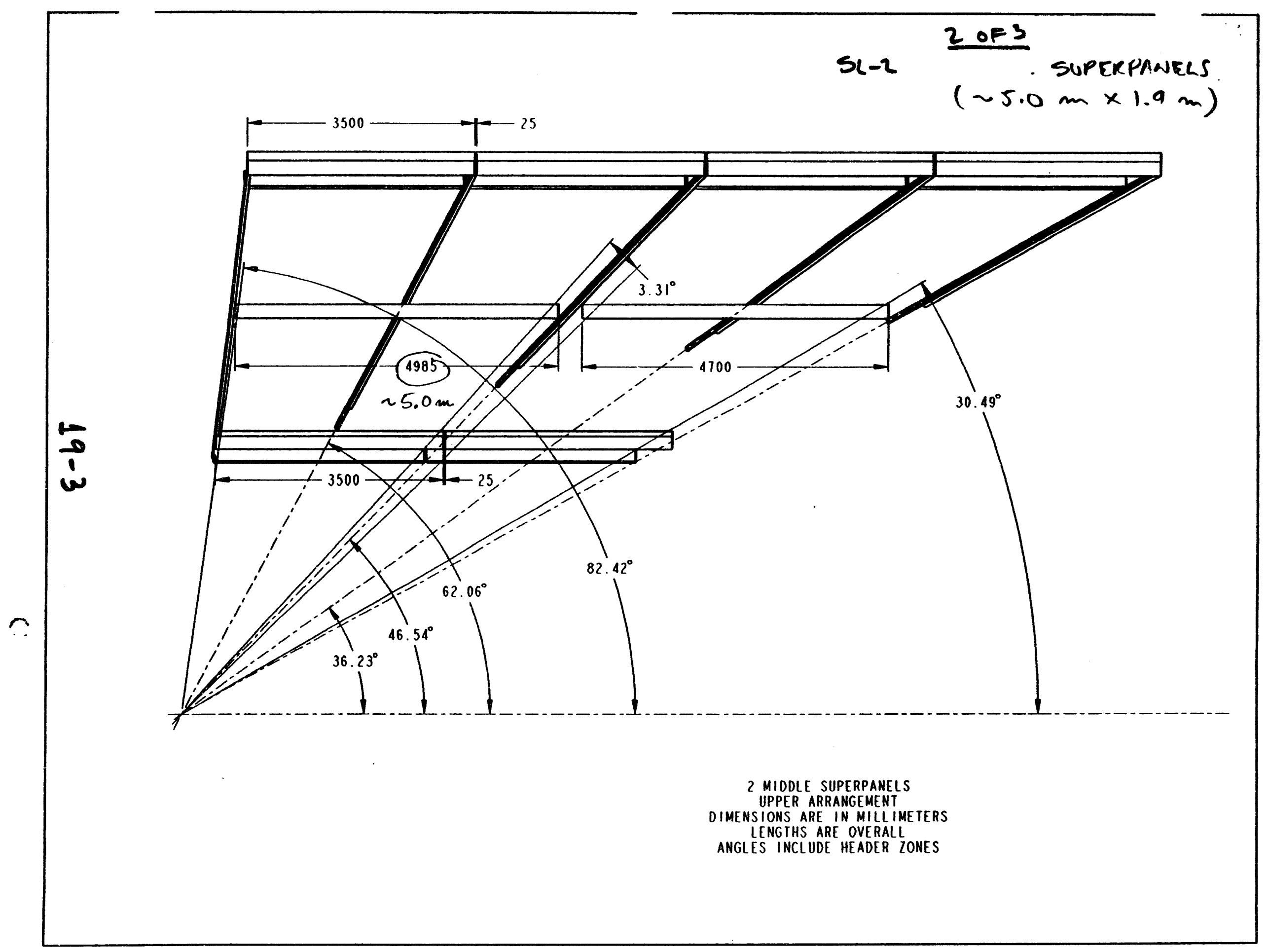




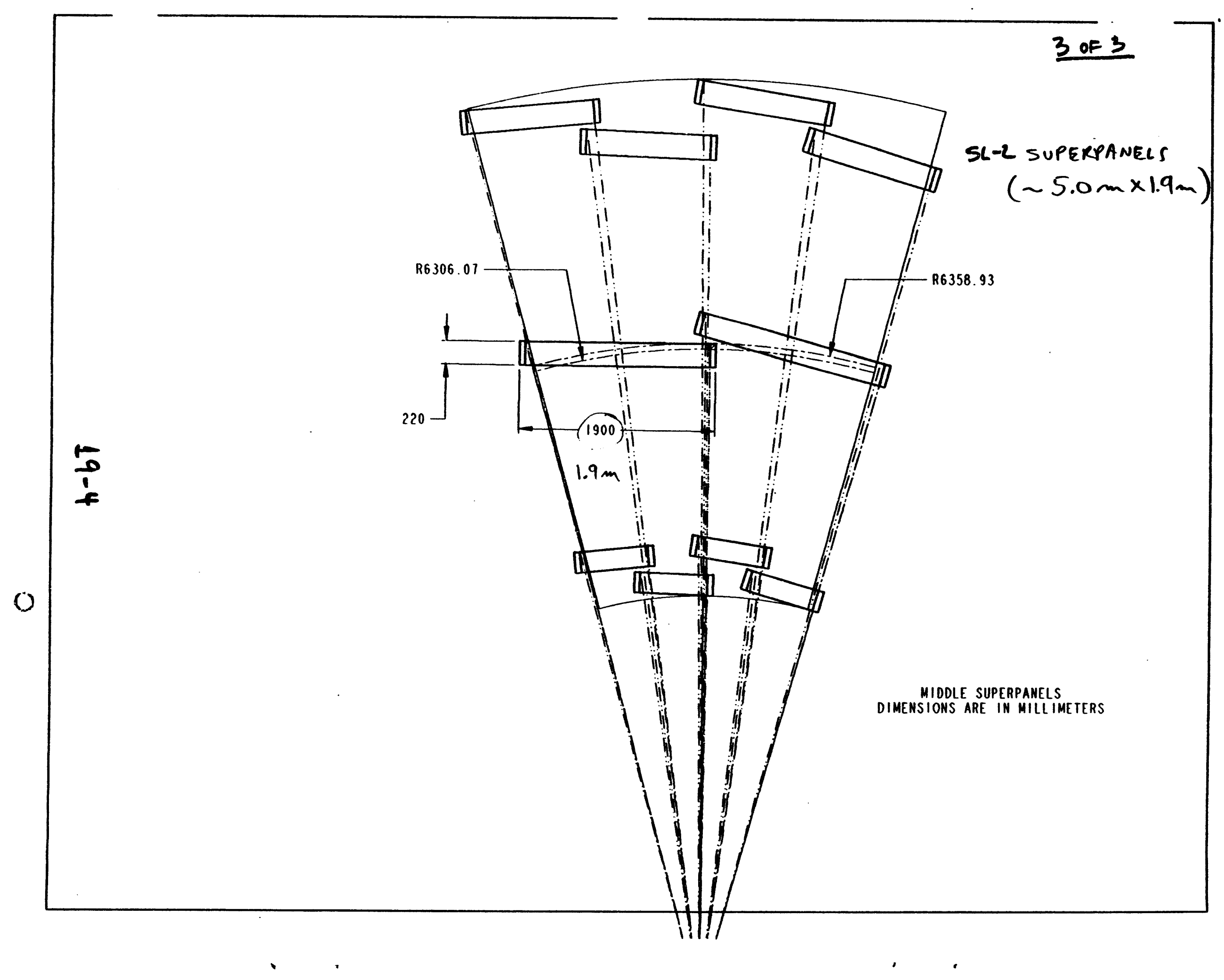




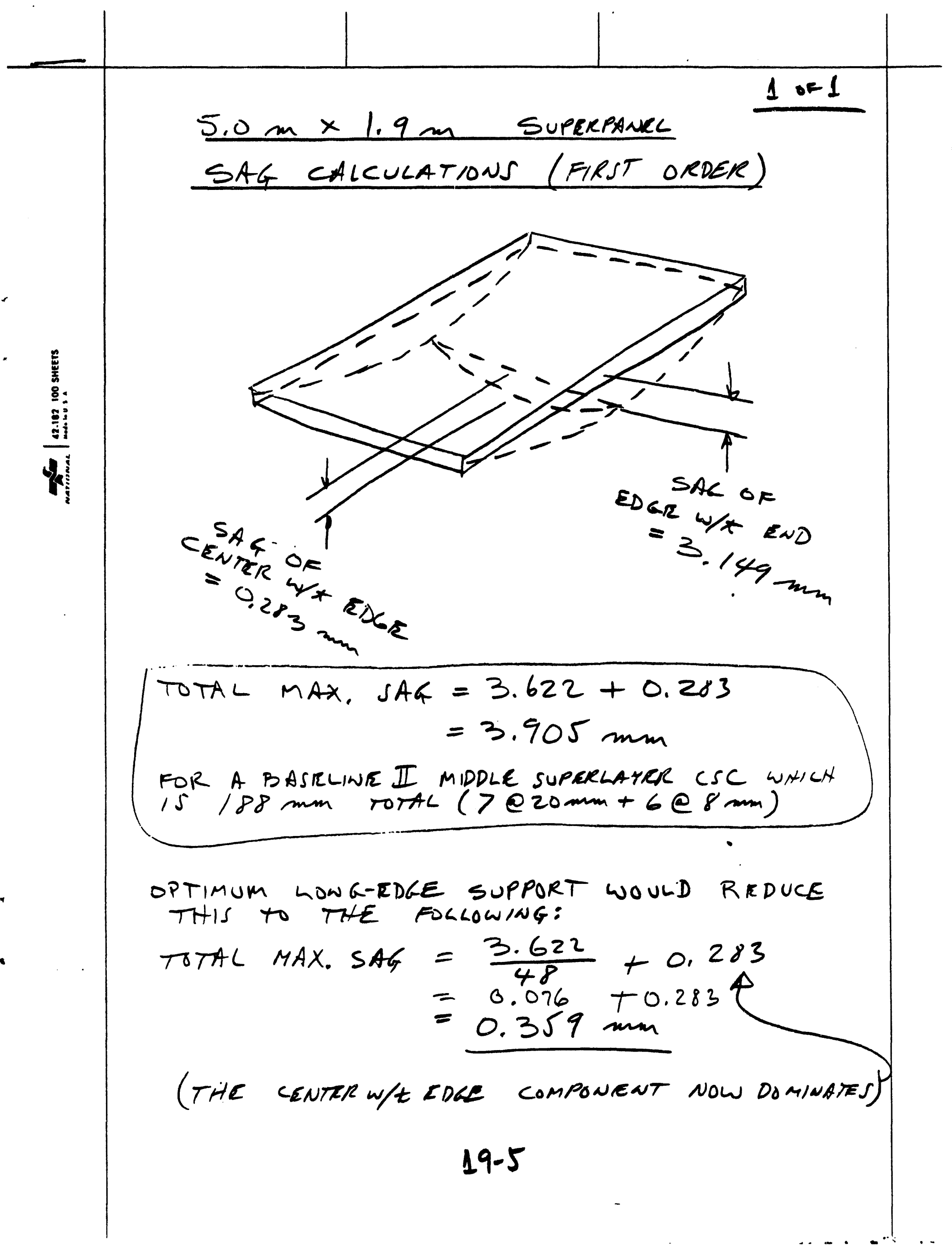


GEM TN-93-494

\section{Finite Element Model Error Analyses}

\section{Contents:}

Element mesh density error analysis (7 pages)

Sandwich skin shell element error analysis (5 pages)

\section{Summary:}

The required mesh density of Hughes-Liu shell elements for adequate representation of sandwich panel skins is determined by performing a series of analyses with different mesh densities. The maximum deflection is plotted against the number of degrees-of-freedom and an asymptotic limit is established. Excessive mesh density slows down convergence while inadequate mesh density underestimates deflection and overestimates stress.

The use of shell elements rather than solid elements for sandwich skins introduces a slight error due to the geometric definition of the element. For a sandwich skin thickness of $0.5 \mathrm{~mm}$ the shell approximation error is about 4 percent. 
Finite Element Model Error Analysis
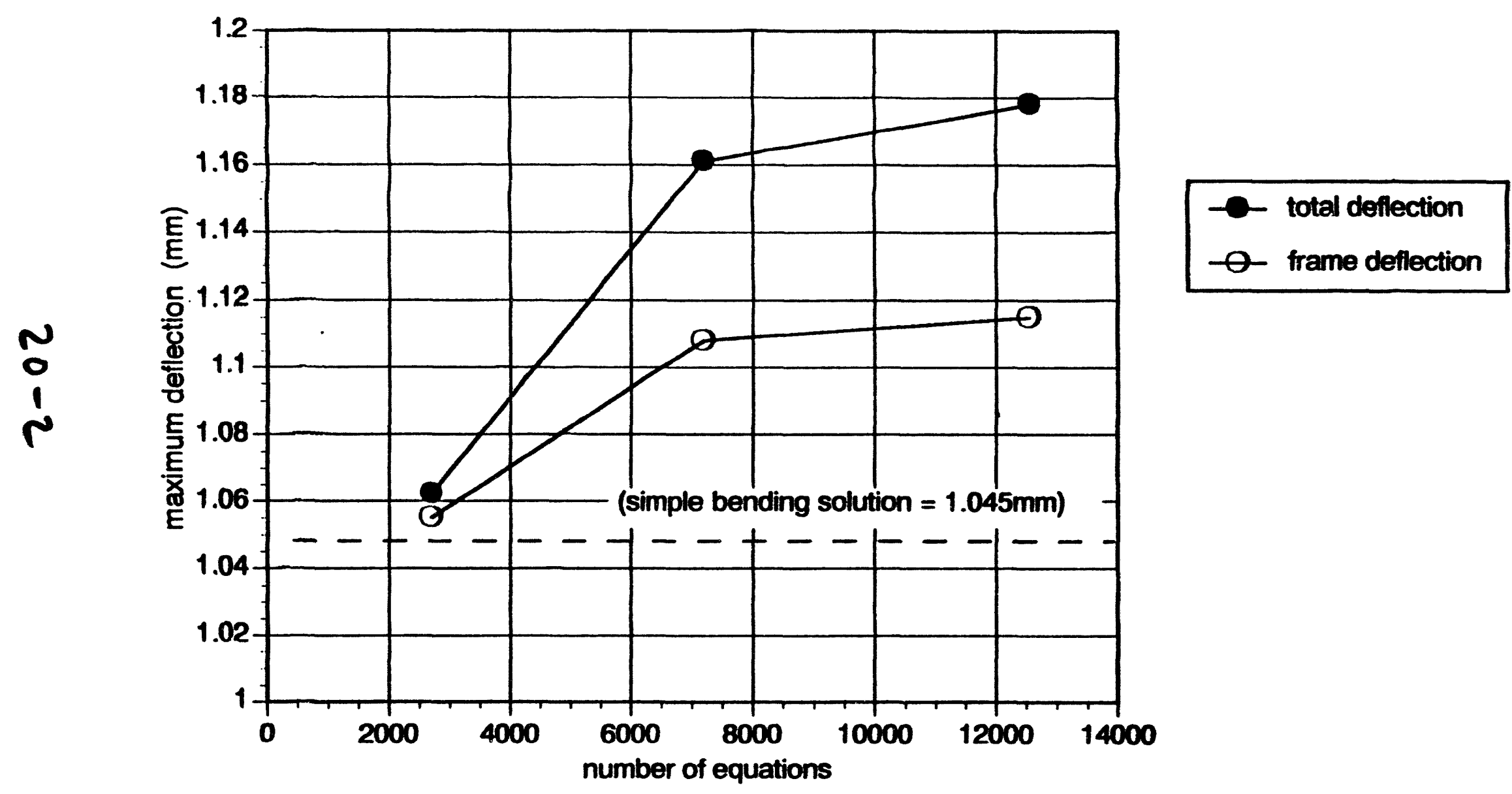


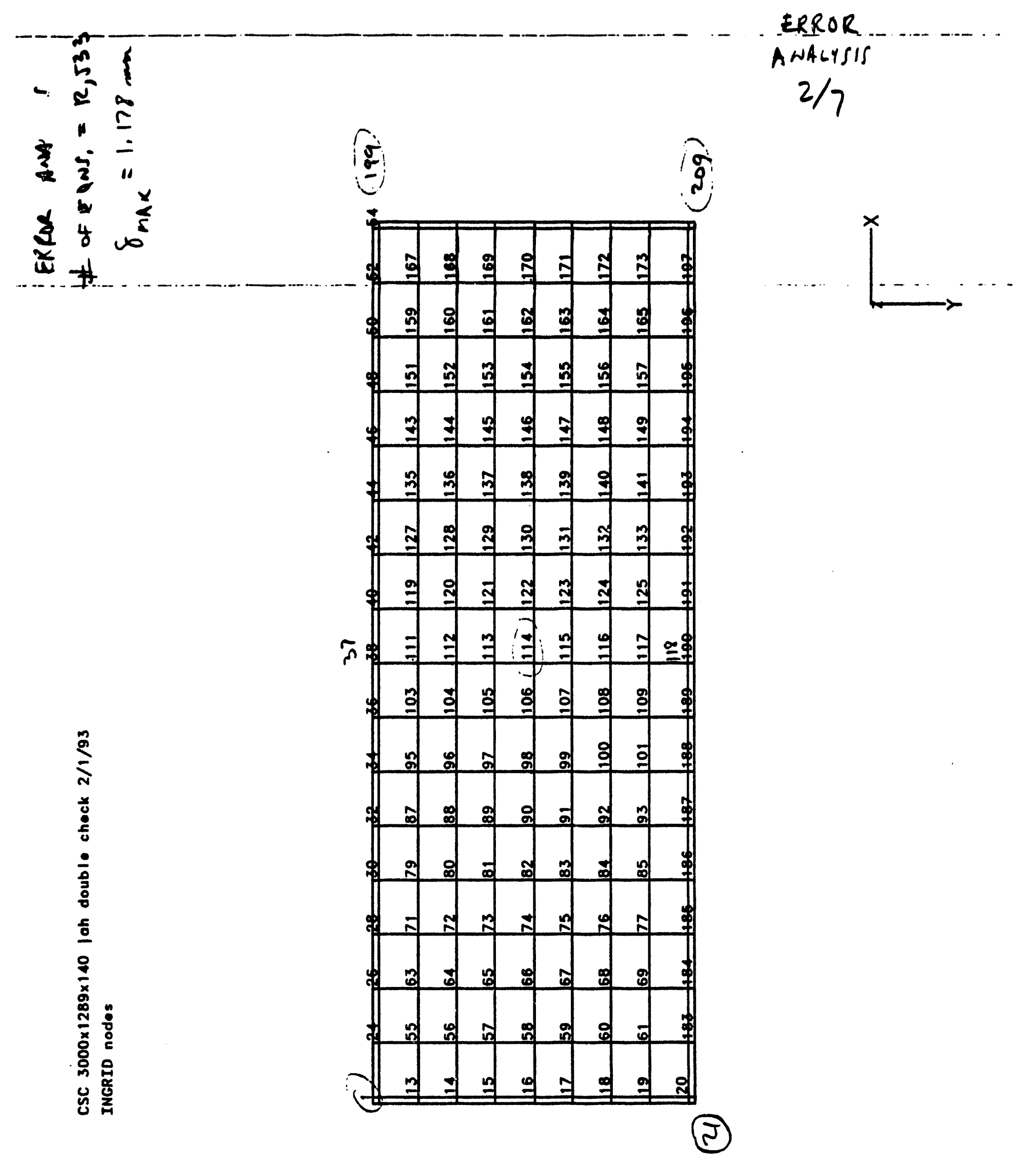




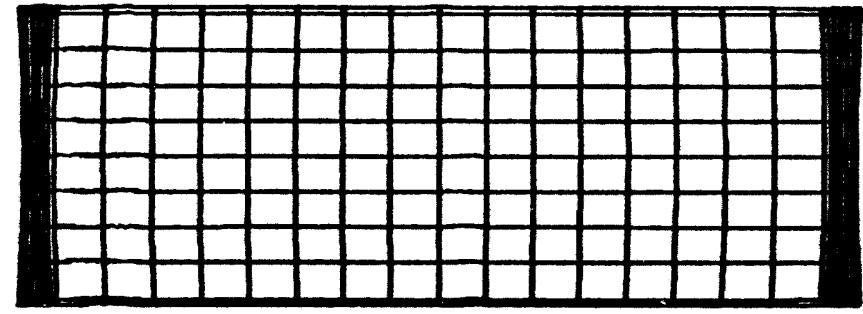

1
0
1

$t_{i=1}$

dise. 20010 toetor $=1.0000+03$

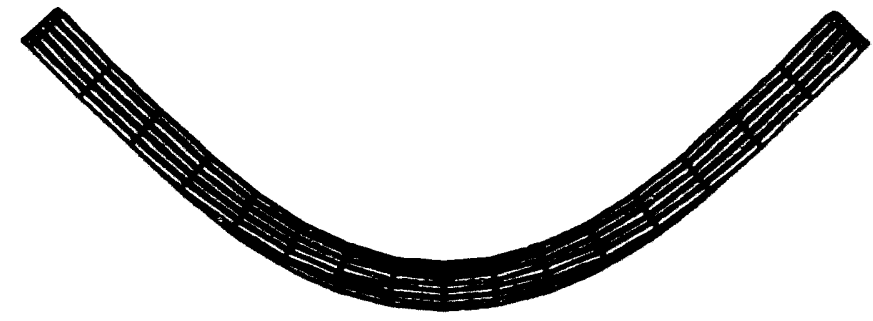

6

Alop. seete teoter $=1.0000003$

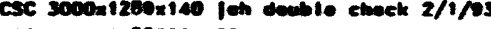

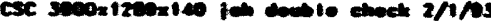

$1100-1.000000000$
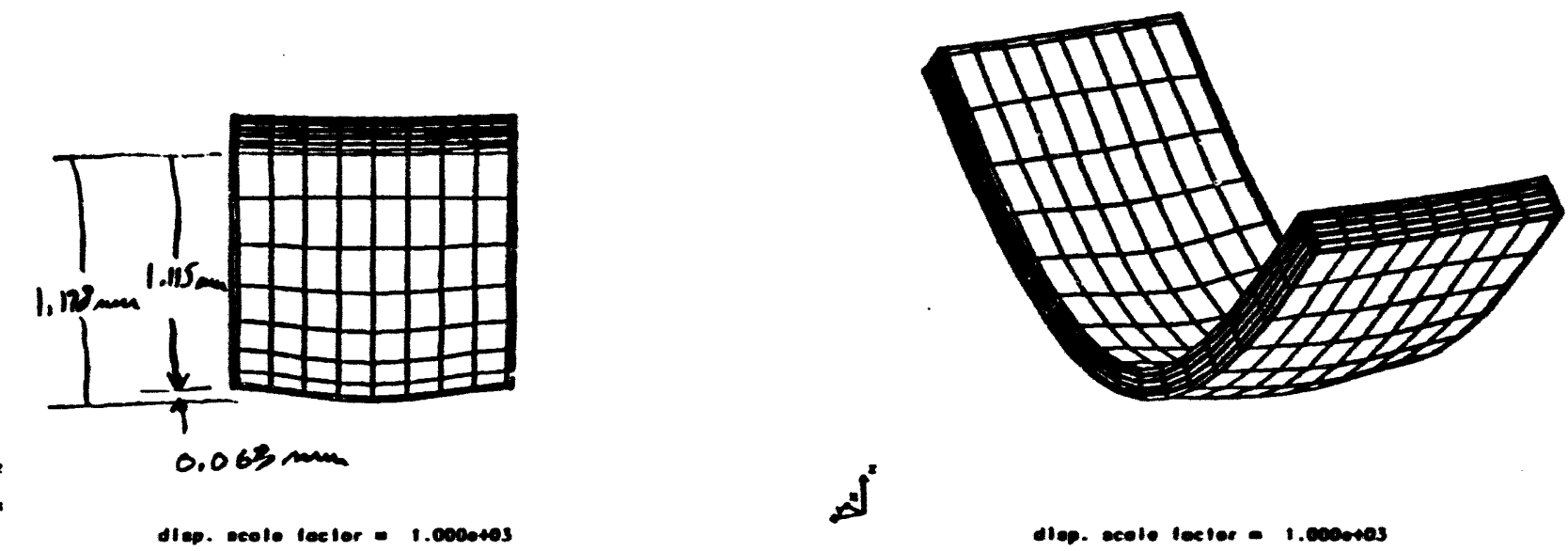

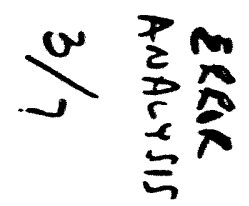

.

Slap. seole loctor - 1.0000+03

s

dlep. ecele toeter - 1.000000s 
ERror A. IIs

\# of EQurs $=7193$ $\delta_{\max }=1.161 \mathrm{~mm}$

1
0
1
9

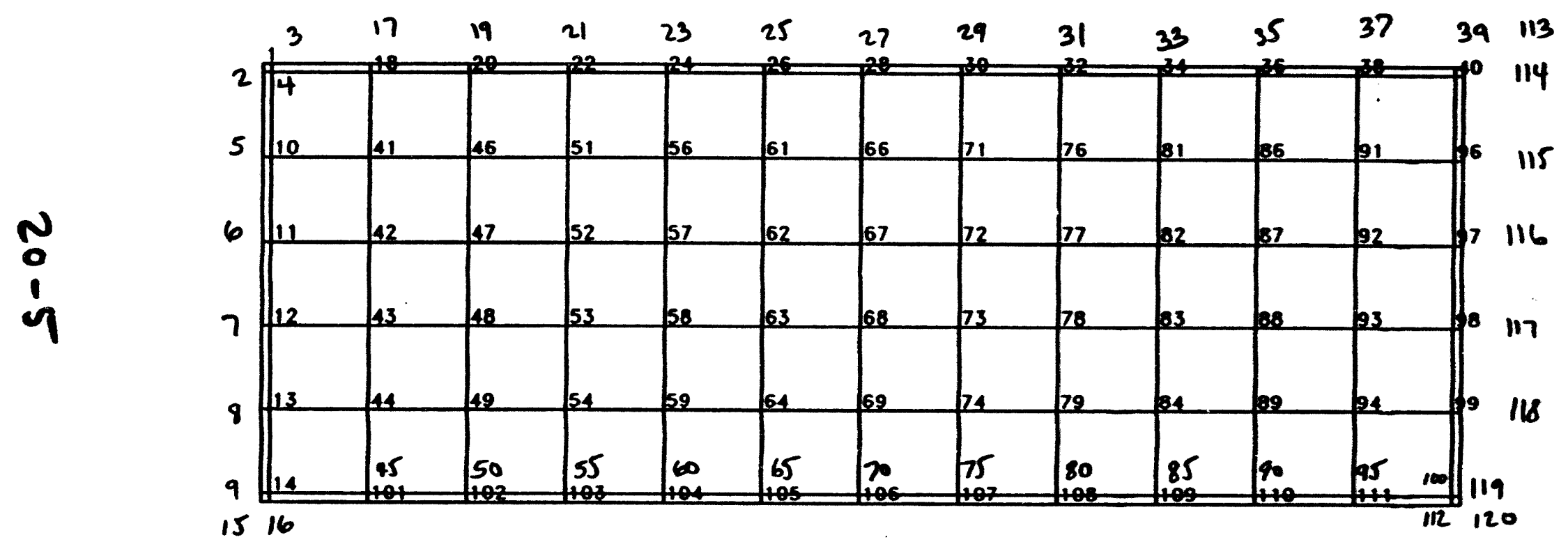

1516

CSC $3000 \times 1289 \times 140$ J.Horvath $2 / 1 / 93$

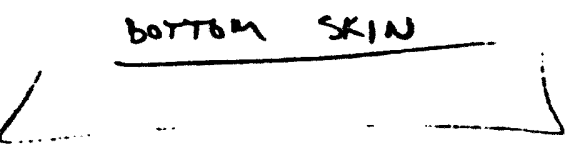

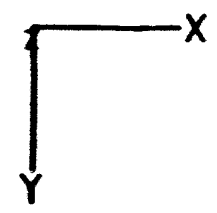

喜器 


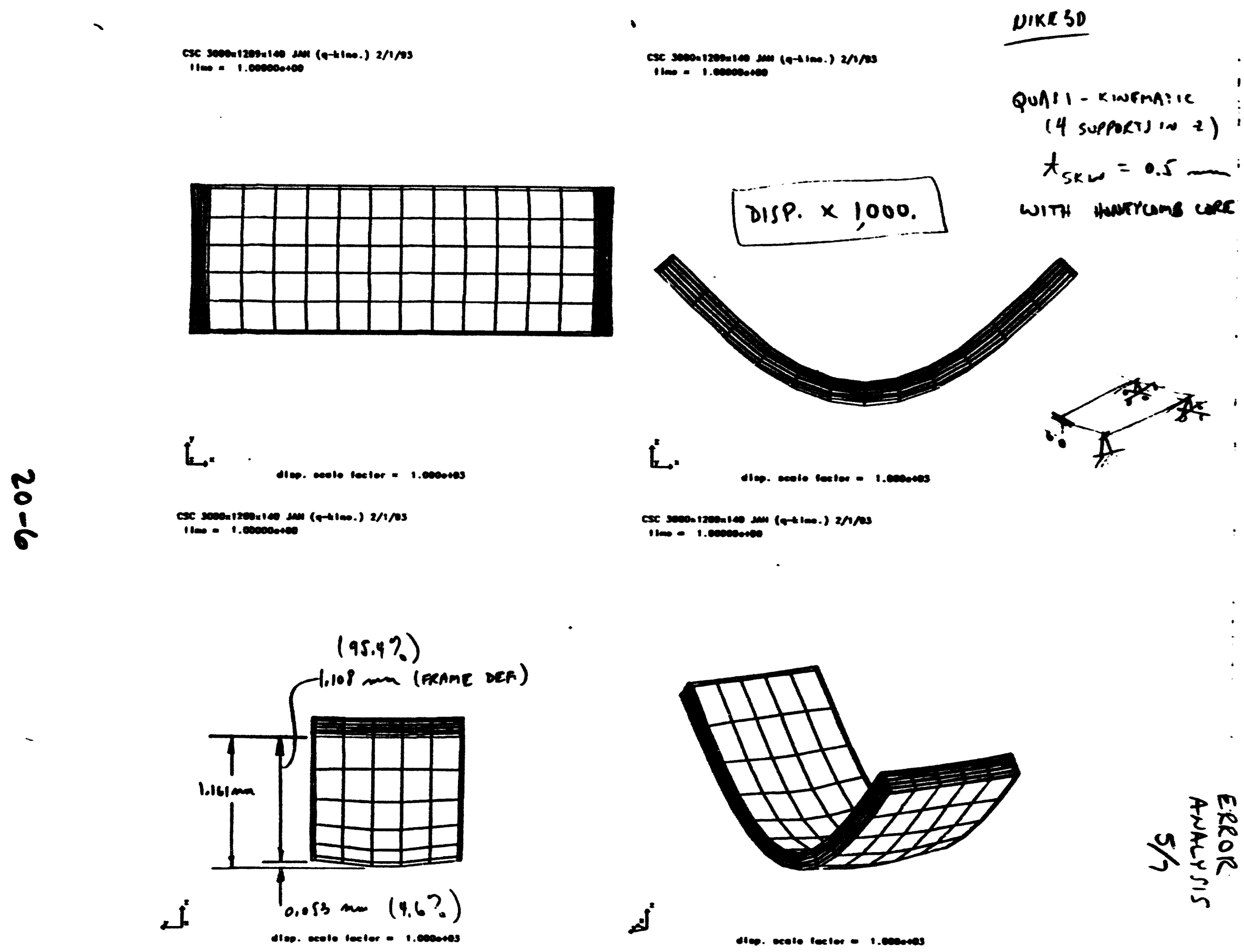


CSC $3000 \times 1289 \times 140$ loh error check $2 / 1 / 93$ INGRID nodes

ERcise AnALYCis

\# of egors = 2693 :

$\delta_{\text {MAX }}=1.062 \mathrm{~mm}$

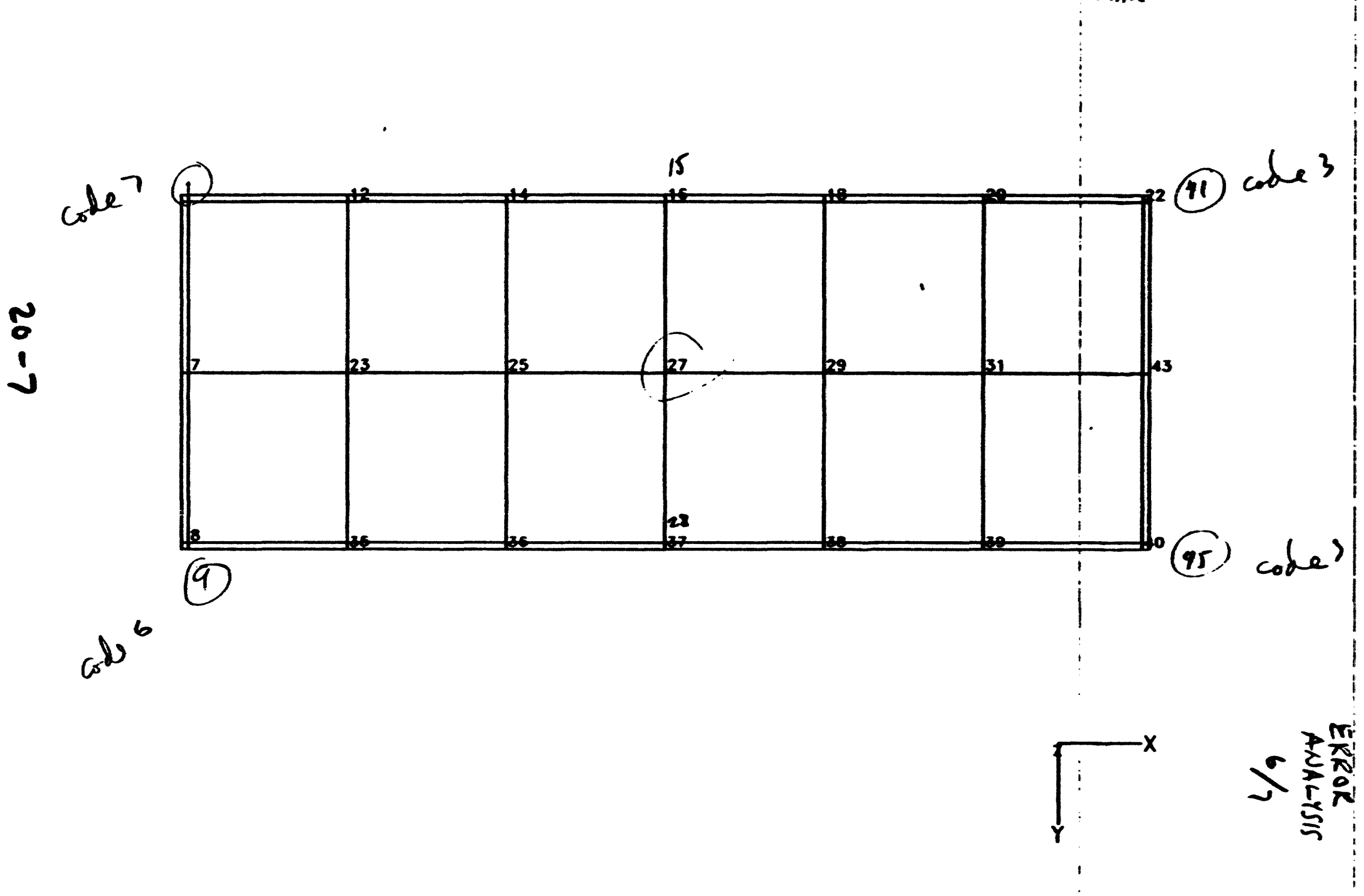




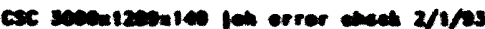
1 loo - 1.

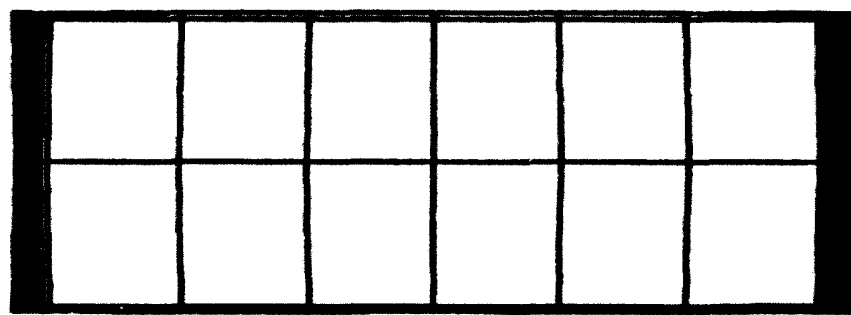

\& L.

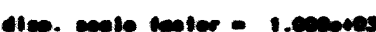

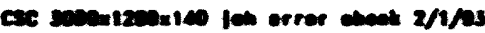
$1100-1.00000000$

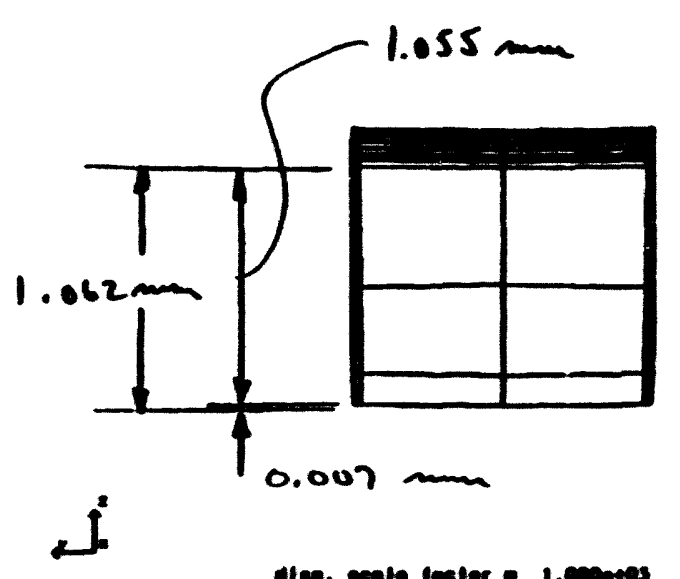

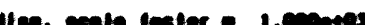

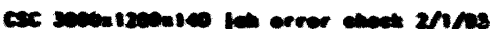

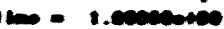

Elror Anacrsis

NDOFP 2693 dom 1.962

$n$

7193

. 1.161

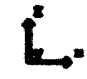

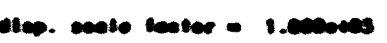

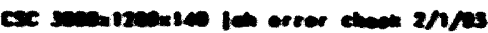
ino - 1.0000000

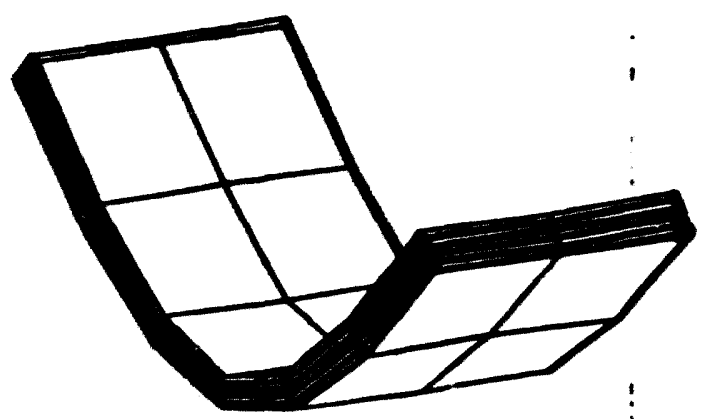

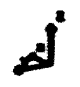

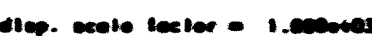

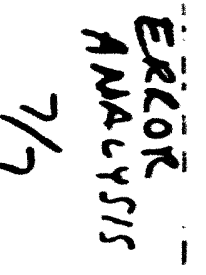


Chart3

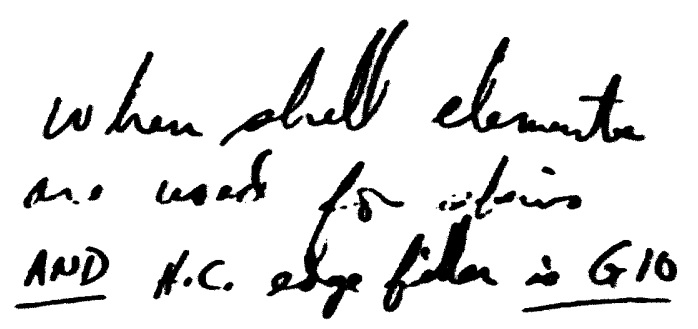

Percent Error in Frame Stiffness vs. Skin Thickness

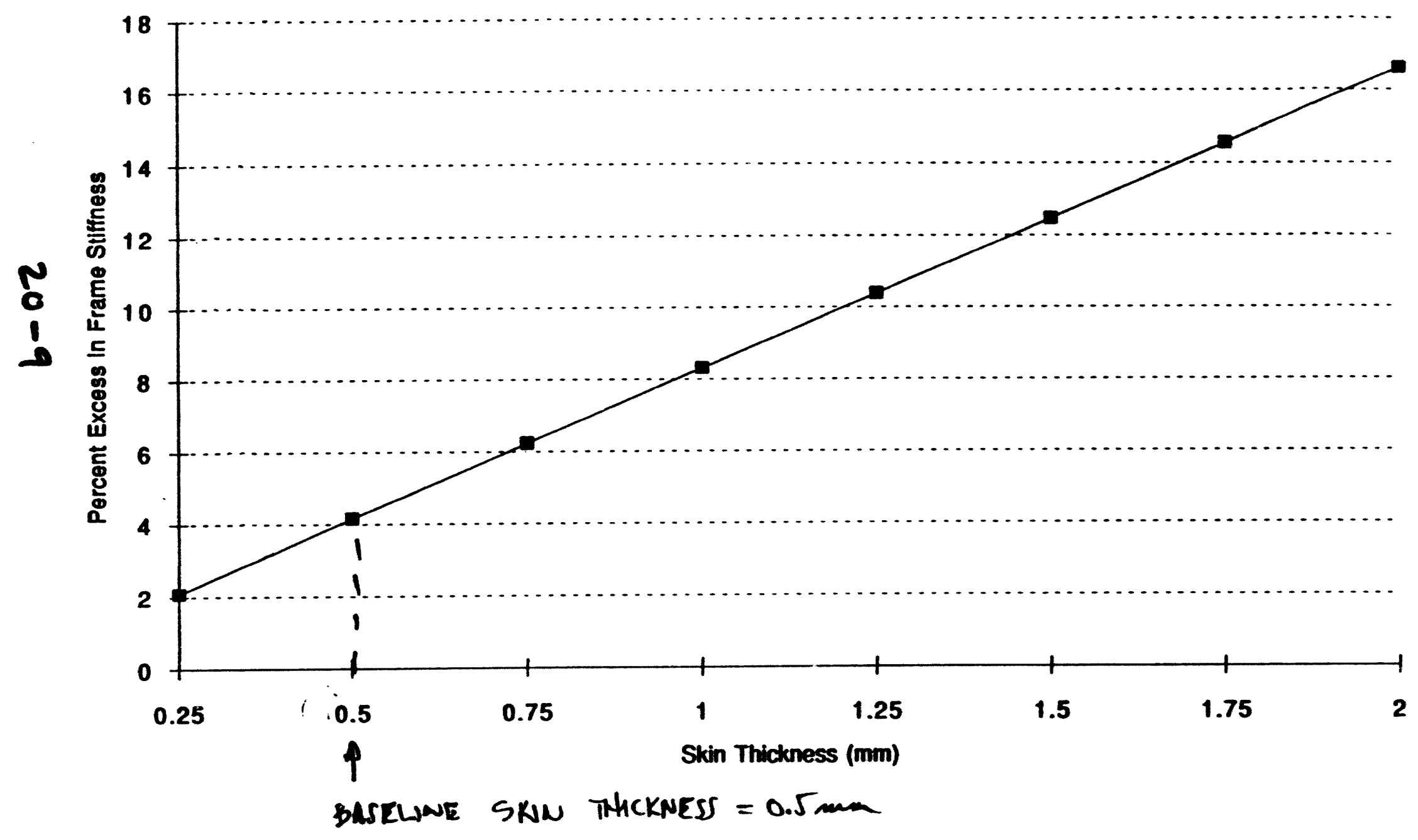




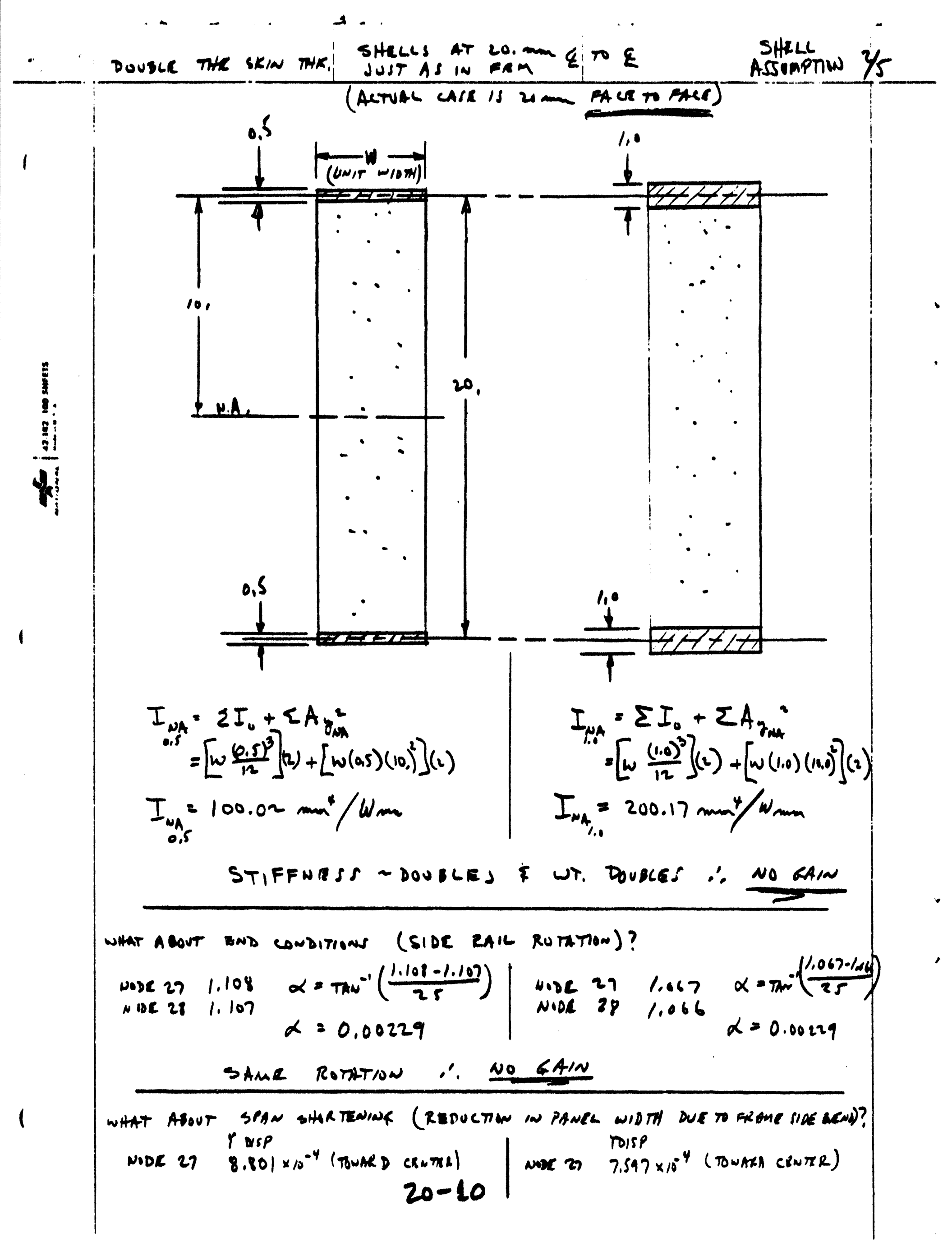




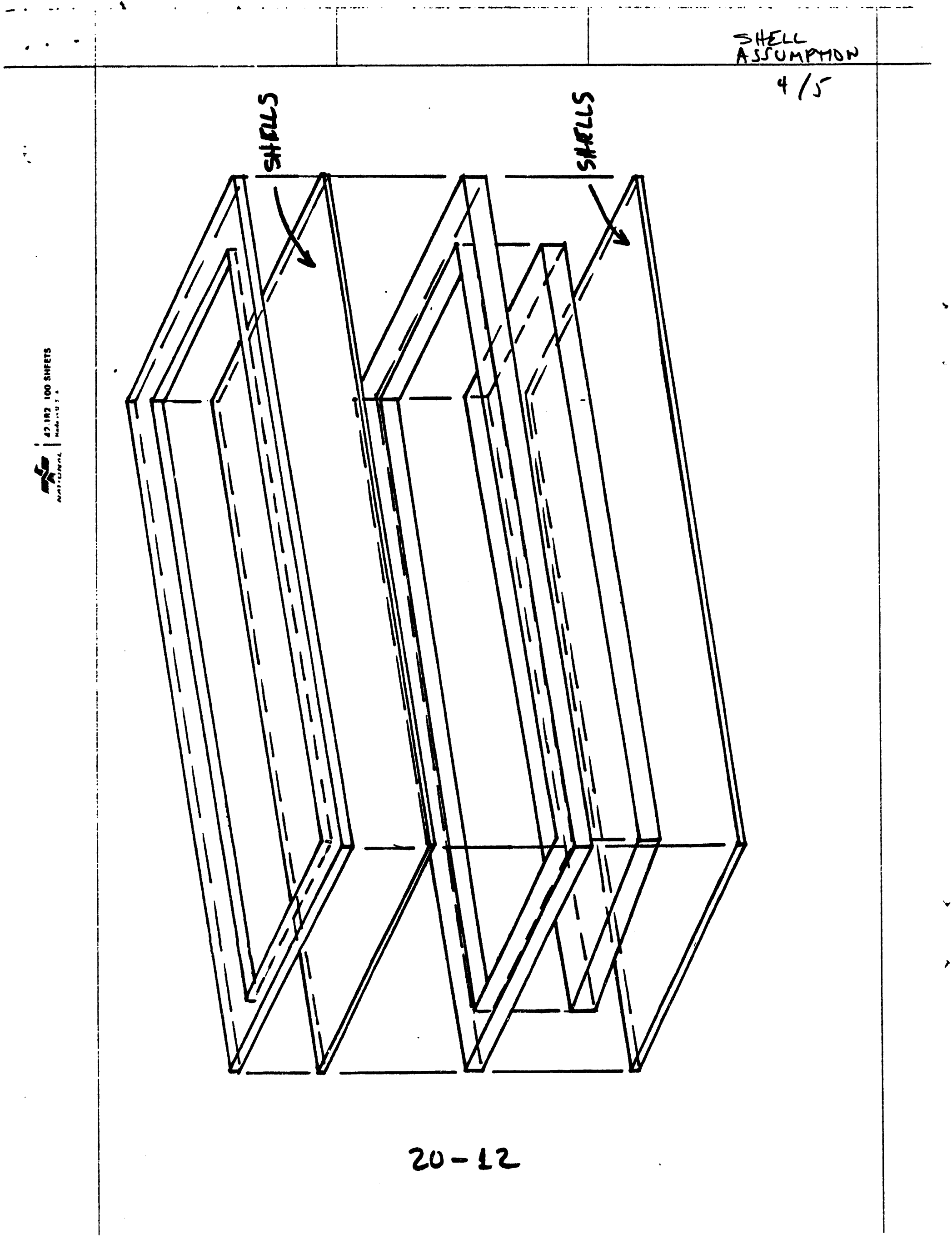


CSC 3000x1209n140 s.thorvath 2/1/93

11 mo - 0.

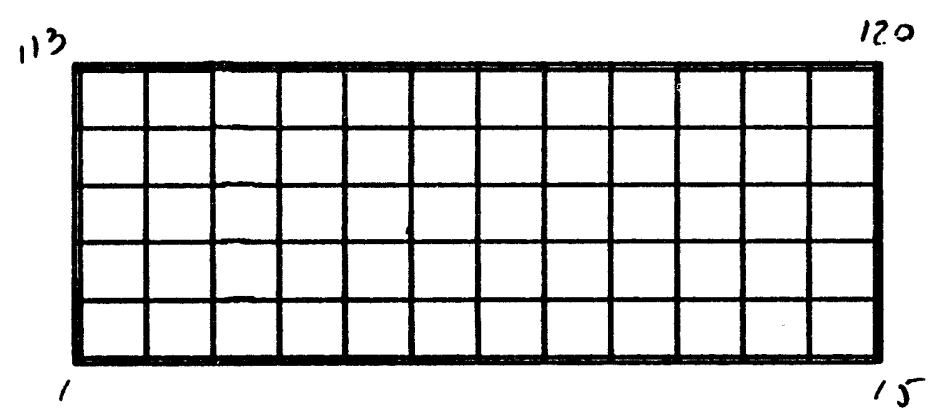

$\stackrel{x}{x}$

elep. seele leetor $=1.0000+00$ (deloull)

CsC 3000n1200*140 J.Horveth 2/1/03

11 ino $=0$.

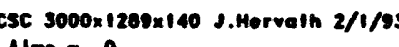

$11000=0$.

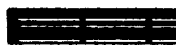

$\mathfrak{l i m}_{i \rightarrow \infty}^{2}$

dlep. seale foctor $=1.0000+00$ (dofoull)

CSC 3000:1289x140 J.Horvalh 2/1/93

$11 \mathrm{mon}=0$.

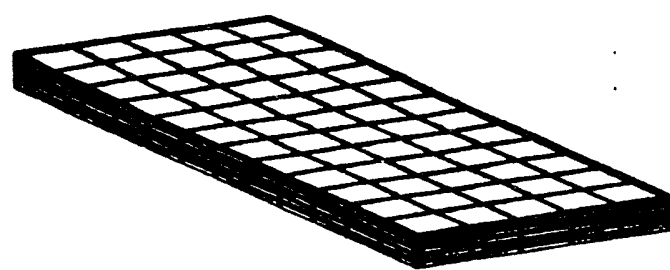

$\underbrace{2}$ 
GEM TN-93-494

\section{References}

1. GEM TN-92-76 REV C, GEM Baseline I, July 9, 1992.

2. GEM TN-92-199, The GEM Muon System Based on Cathode Strip Chambers, September 28, 1992.

3. GEM TN-93-268, Measured Characteristics of NIKHEF "Honeycomb" Strip Material, January 14, 1993.

4. GEM TN-93-262, Technical Design Report, April 30, 1993.

5. GEM TN-93-412, Muon Chamber Design Meeting - SSCL, May 18, 1993.

6. GEM TN-93-350, Gravity Sag of Sandwich Panel Assemblies as Applied to Precision Cathode Strip Chamber Structural Design, July 12, 1993.

7. GEM TN-93-440, GEM Muon Group Meeting - SSCL, July 12-13,1993.

8. GEM TN-93-460, Comparison of Gap Frame Designs and Materials for Precision Cathode Strip Chambers, September 9, 1993.

9. GEM TN-93-508, Estimating Creep Deformations of Large Precision Cathode Strip Chamber Panels, November 15, 1993. 

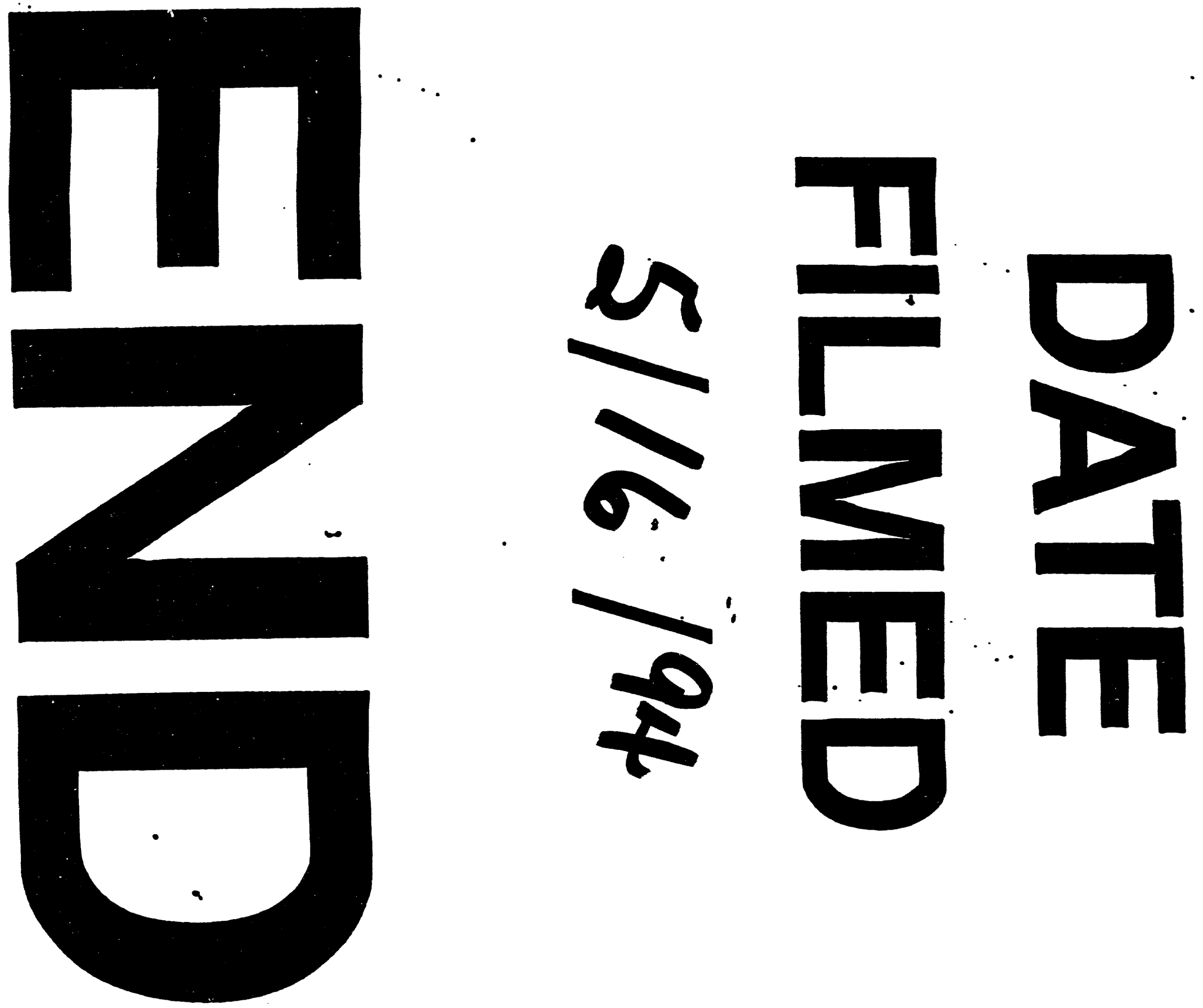
